Architecture:

\title{
The Third Teacher
}

By:

Paola Vega

\begin{abstract}
A thesis submitted to the Faculty of Graduate and Postdoctoral Affairs in partial fulfillment of the requirements for the degree of
\end{abstract}

Master of Architecture

Carleton University

Ottawa, Ontario

() 2019

Paola Vega 

Dedicated to the children and staff of

Kaban Montessori School

Hillfield Strathallan School

Clanmore Montessori School

Montessori Jewish Day School 


\section{Abstract}

"If salvation and help are to come, it is from the child, for the child is the constructor of man, and so of society."

From the earliest stages of life, according to Linda M. Zane in

Pedagogy and Space, we build "our beliefs and knowledge through an active engagement with the world around [us]." ${ }^{1}$ If we accept that the environment plays a fundamental role within the development of a human being, then the design of early learning environments should be a leading concern not just to educators, but architects and society as a whole. This thesis will begin by researching how a child's development is affected by the built environment in the early years up to the age of nine. Focusing on the conditions and opportunities at Kaban Montessori School in Mississauga, Ontario - primarily Montessori principles used to develop 'learning materials' and 'prepared environments' - the thesis considers and critically reviews current progressive learning spaces and guidelines.

Can the Montessori method be seen as a tool, and scale its thinking to construct more meaningful architectural learning environments? In re-thinking these progressive spaces, strategies for enhancing learning environments will be explored and proposed. These will attempt to encourage development, actualize pedagogy and improve cultural connections at

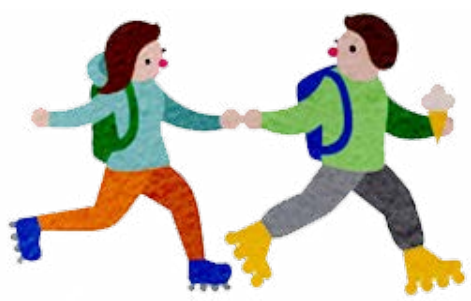
this early age. An emerging project questions how learning environments could be designed to holistically reflect the progressive condition; thereby better providing for the natural developmental needs of the child, while responding to the potentials and new phenomenon prevalent in our current time. 


\section{Acknowledgments}

I owe a great deal of thanks to many people,

but most of all to:

Yvan Cazabon and Roger Connah, for serving as my

advisors, for creating a positive environment, and for

your feedback and patience;

The staff and children of Kaban, For continuously

welcoming me into your community and contributing

beautiful ideas and insights to the thesis;

Melanie Li, Matthew Lerch and Dad, for the advice

and conversations that helped shape the start of my

project;

Mom, for your wealth of knowledge and resources

that guided my thesis research;

Olivier Larocque, for carefully reviewing the text, your constant encouragement and reminding me to enjoy the process. 


\section{Glossary}

Absorbent Mind is a time, from birth to 6 years, when the child has a great capacity to learn through absorbing and synthesizing the stimuli from their environment. ${ }^{2}$

Autodidactic is a term used by Montessori to describe learning materials which enable children to teach themselves. ${ }^{3}$

Casa is the Montessori term for 'children's house', and is the equivalent of a primary or preschool classroom for children ages $2.5-6$ years. ${ }^{4}$

Control of Error is a device integrated into certain learning materials to aid a child in perceiving their own mistakes without the assistance of adults. ${ }^{5}$

Early Childhood Education describes the learning environments for children $6 \mathrm{mo}-9$ years.

Erkinder (German) "child of the earth". This concept is a part of the Montessori philosophy and drives the school's sustainability and ecology program, activities and material. ${ }^{6}$

Learning Environment is composed of the learner, other students, the teacher and the physical environment. It is inclusive of both physical and psychological components.

Learning Materials include any physical elements that are designed or intended to 'teach'. These elements can either be open or closed material. Open learning material describes material that has no right answers and provide many ways of engagement and construction (ie. Sand). Closed learning material is strategically designed to have either a single or very few correct completions (ie. puzzle). ${ }^{7}$

Learning Space is composed of only the physical components and spatial qualities of a learning environment.

Lower Elementary is a classroom for children ages 6 - 9 .

Nido is a Montessori term used for an infants classroom, for children $6 \mathrm{mo}-15 \mathrm{mo} .^{8}$

Play in the context of Montessori schools, is often interchangeably used with the word 'work', and vise versa.
All forms of 'play' contribute, in one way or another, to a child's development. It is defined by any activity which is spontaneously and freely chosen by the children, which absorbs their whole being. ${ }^{9}$

Pedagogy is the art and science of teaching. ${ }^{10}$

Planes of Development are stages of growth identified by specific developmental characteristics that contribute to the development of the next plane. Each plane also corresponds to specific age groups. ${ }^{11}$

Practical Life activities and learning materials help children learn how to take care of their surrounding environment. This includes learning about hygiene, empathy and working independently or in groups to navigate real-life situations. ${ }^{12}$

Prepared Environment is a term used in Montessori to describe learning spaces strategically prepared for the child's optimal developmental needs. ${ }^{13}$

Progressive of, relating to, or constituting an educational theory marked by emphasis on the individual child's needs and capacities, flexibility in learning procedures, and encouragement of self-expression. ${ }^{14}$

Third Teacher is concept brought into awareness through the schools of Reggio Emilia. It refers to the mindful design of the settings in which children learn in relation to the environment as an active participant in the learning process. In this concept, the parent is considered the first teacher and the teacher is considered the second. ${ }^{15}$

Toddlers is a Montessori Classroom for children $15 \mathrm{mo}-2.5$ years.

Self Construction is a Montessori term used to describe the child's ability to create and drive their own learning and identity. ${ }^{16}$

Sensitivities are periods when children are particularly absorbed with mastering certain life skills. All sensitive periods overlap and manifest in a non-linear fashion. "Those which are most evident in the first three years of life are sensitivity to movement, language, acquisition of 
skills for organization, order, and attention to small detail, whilst skills for refinement of the senses or developing social aspects of life are prominent from about three years onwards. When these special traits appear it is essential that they are nurtured...because once the sensitivity passes, the acquisition of these skills will no longer come as naturally to the child." ${ }^{17}$

Micro is the localized scale attributed to the classrooms and specialized rooms within a school.

Mezo refers to the scale of the whole school.

Macro refers to the scale beyond the school. 


\section{Content}

$\begin{array}{ll}\text { iii } & \text { Dedication } \\ \text { iv } & \text { Abstract } \\ v & \text { Acknowledgments } \\ \text { viii } & \text { Content } \\ x & \text { Prologue } \\ \text { xii } & \text { Preface: Positioning the Thesis } \\ \text { xiii } & \text { Glossary }\end{array}$

001 Part 01 Introduction

1.0 Introduction

1.1 Transactional Relationship

1.2 A Brief History of Education: A Timeline

1.3 The Progressive Condition

1.4 The Montessori Method

$$
\begin{aligned}
& \text { A Scientific Method } \\
& \text { Stages of Development } \\
& \text { Planes of Sensitivity } \\
& \text { The Prepared Environment }
\end{aligned}
$$

1.5 The Scientific Form

\section{Part 02 _ Guidelines \& Design Patterns}

2.0 Learning Spaces

Intro to Guidelines and Design Patterns

The Problem with the Classroom

Comparative Index: Elements of School Design

2.1 Participatory Design

Introduction; Continuing the Research

Research Ambitions + Methodology + Workshop

Interpretation and Analysis + Concluding Thoughts 
$2.2 \quad$ Freedom

Encouraging Independence + Competence

Risk vs. Safety

2.3 Community \& Culture

Pedagogy of Place

Variation of Social Structure

$2.4 \quad$ Order

Secure + Personal Landmarks

Scale, Simplicity + Spatial Definition

2.5 Interactive

Variation in Sensory Stimulation

2.6 Integrated + Innovative

Integrated Spaces

Buildings That Teach

2.7 Erkinder

Wild Spaces

Natural Materials

Sustainable Systems

$2.8 \quad$ Postscript 
004 Part 04 _ Citations

4.0 Endnotes

4.1 List of Illustrations

4.2 Bibliography

4.3 Historical Timeline Endnotes

4.4 Historical Timeline Image Index

4.5 Historical Timeline Bibliography

\section{Part 05 _ Appendices}

A Workshop/ Ethics Clearance

B Workshop/ Children's Photographs

C Workshop/ Children's Drawings

D Workshop/ Teacher Interviews

E Process Drawings 


\section{Prologue}

A Memory

I woke up to the sound of my mother's voice, she was on the phone. Vaguely listening, eyes still closed "alright sounds good, l'll see you tomorrow then", curious, I open my eyes...

- No! My windows are frosted and beyond them, big snowflakes falling from the sky. Now out of bed and peering through my window, I see it - It's everywhere! Worry kicks in. I run past my mom to the TV, "snow day!" she cheers, I'm not having it, I switch on the news reading the school cancellation notices running along the bottom of the screen...reading...reading...nothing, no mention of my school! I look over at my mom, now smiling, "my schools not on here, It's not closed, let's go!" I say running back to my room to get ready. She follows me, a loving but incredulous look now on her face, "we are not driving in that" she exclaims. All hope leaves me and an overwhelming feeling of, what I now know as "FOMO" (fear of missing out) fills me instead. Desperate, I resort to begging...a lot...but no give. My mom consoles me and tells me that whatever I was working on at school, I can continue the next day, I know she's right, but I'm still upset at the snow for making me miss school - even if just for a day. 
At age eleven, I had one year left at my Montessori Elementary school before I graduated, and I loved every second of it. So much so that, for that last year, even though my family and I had moved an hour away, my parents agreed to let me finish my Montessori journey before enrolling me in the public middle school closer to our new house.

Throughout my entire life, I have had a personal relationship with this progressive approach to education. As a young child living in Mexico, I attended my mother's own Montessori school, which she ran from our home in the city. After moving to Canada at six years old, I was enrolled at a Montessori school (the one from my story), which I attended for six years. Moving from Mexico to Canada was difficult at first, but being in a school that reminded me so much of home, made my transition a happy one. Around halfway through my elementary schooling, my mother decided to open her own Montessori school here in Canada for children eighteen months to six years of age. Although I was too old to enroll as a student, I became a part of another school community, one that I could help grow and contribute ideas from my own experiences.
Looking back, I know that these schools, their environments, pedagogies, and communities shaped who I am today. I remember my childhood fondly because of my memories from school, and for that, I cherish and explore all opportunities where I can perhaps help make another child's learning experience equally memorable.

Now, as an architecture student and Montessori alumni, I approach the topic of progressive learning spaces from both my childhood and adult life experiences. As a child, who enjoyed her Montessori education tremendously, but also as an aspiring architect who is beginning to understand the effects of physical environments on human development, and who feels that perhaps the spaces from my own childhood could have done even more to inspire the curious child that I was. 


\section{Preface}

\section{Positioning The Thesis}

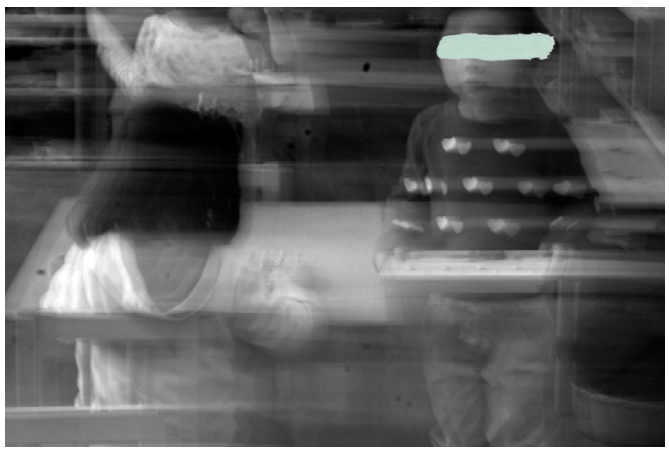

Fig. 1

Children in the classroom
This thesis represents part of a continuing effort towards designing learning environments that better meet the needs of children. Building upon the years of environmental design research articulated in the theoretical framework of progressive pedagogies, this thesis focuses on the planning and design of physical environments where children spend most of their day - at school. In the past several decades, numerous environmental design researchers, psychologists, philosophers, anthropologists, and educators have observed, recognized, studied, analyzed, quantified, developed, and expounded upon the need for learning environments to nurture the natural development of the child. Out of these efforts, a vision of how these environments might look, feel and affect behaviour is emerging with increasing clarity.

This thesis intends to further explore this vision and to build on the practices brought forward by progressive pedagogies. 
As such, this thesis holds the following

foundations:

- The physical environment plays an essential role in human life, beginning in the early origins of childhood. Thus, a sensitive and thoughtful design approach towards children's spaces can enhance the quality of life for all humanity. Through first accepting this notion, it stands to reason that the needs of children are a priority and supporting their development, both as individuals and as a collective, will lead to a happier and more fulfilled society.

- $\quad$ Architecture should act as a third teacher; It's design, a manifestation of the teaching approach living through the space. Thus, the key variable is not space on its own, but the equal relationship between teacher and parent, space and pedagogy. Nonetheless, any learning space can be misused if the pedagogical ideas and practices are not reflected within it, in other words, "A progressive teaching approach cannot thrive in conventionally designed spaces, just how a progressive environment design would be wasted if not used to its full potential." 18
Although the typical progressive space already seeks to reflect the principles of progressive pedagogies, they too, due to spatial, economic, social, and environmental constraints, are not able to fully embody their own pedagogy as much as they should. This thesis considers how these ideas might be fully realized as architectural manifestations and suggests design responses that reflect them through identifying, exploring and interpreting the principles, guidelines, learning materials and prepared environments that prevail among progressive learning schools and their corresponding approach to education, primarily Montessori.

Thus, the motivating question for the thesis can be summarized as:

How can we design learning environments that wholly reflect their progressive pedagogies and better provide for the natural developmental needs of the child, while responding to the shortcomings and new phenomenon present in our time? 


\section{Part 01}

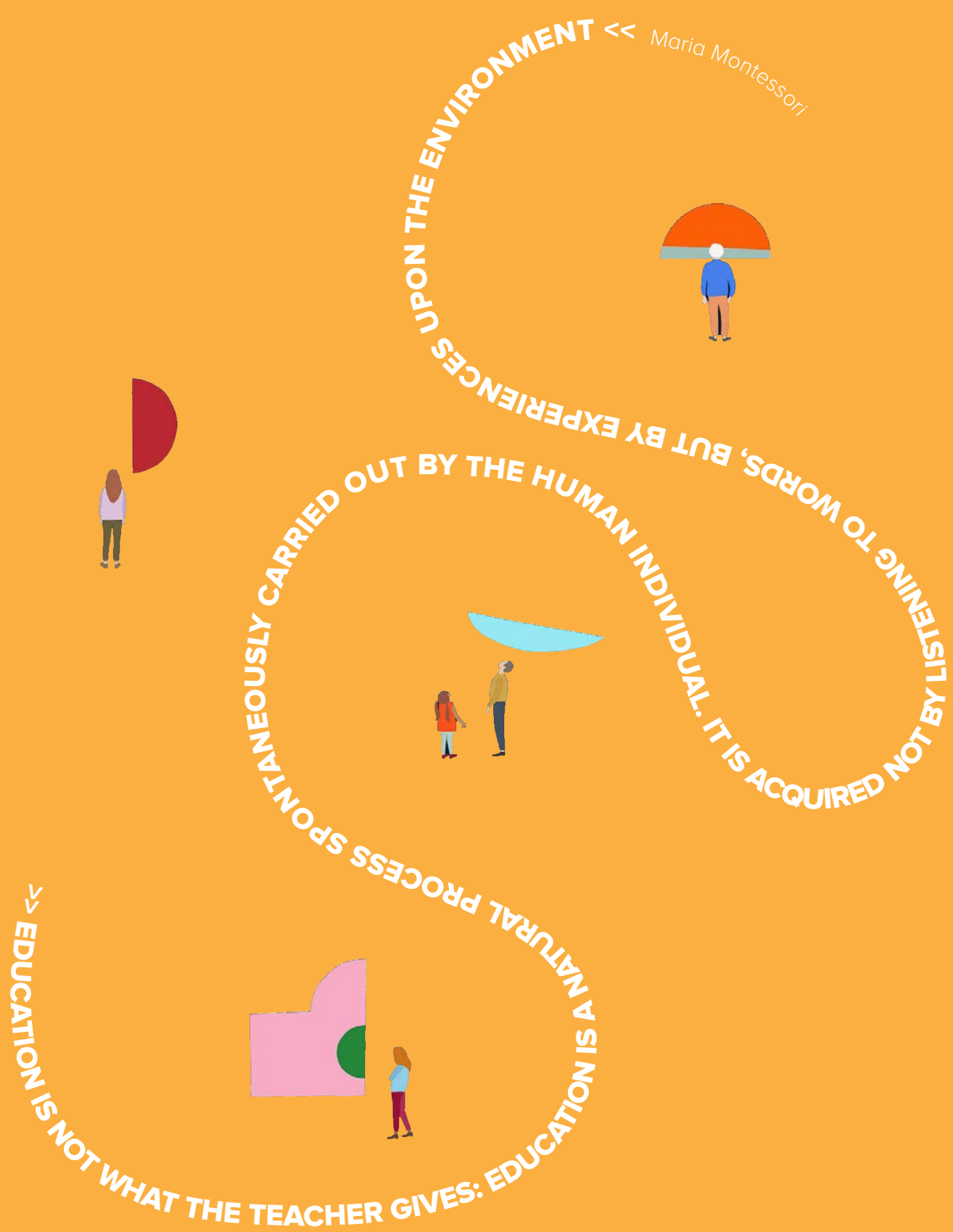

Fig. 2 


\section{0 _ Introduction}

\section{A Brief Narrative of the Intro Content}

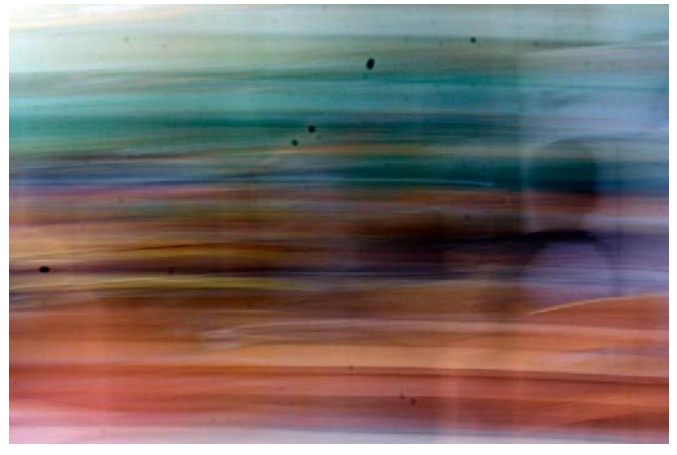

Fig. 3

Conceptual Photograph - Taken at Kaban

Montessori School
We begin by situating education within an environment-behaviour framework, as well as its historical context as a starting point in order to better understand the roots and developments of progressive learning spaces.

Further exploring the nature of progressive pedagogy and space, our research will define and identify the characteristics of the progressive condition, especially the critical developmental principles of a learning environment delivered by the Montessori pedagogy. This thesis also aims to interpret the direction in which progressive education is moving, or rather, returning and expand on how certain shortcomings and new phenomena in our current times are affecting its development.

Through these studies, we may better recognize the progressive condition and thus be equipped to design architectural tools that adapt its patterns to learning spaces. 


\section{1 _ Transactional Relationship}

\section{Regarding physical environment and human behavior}

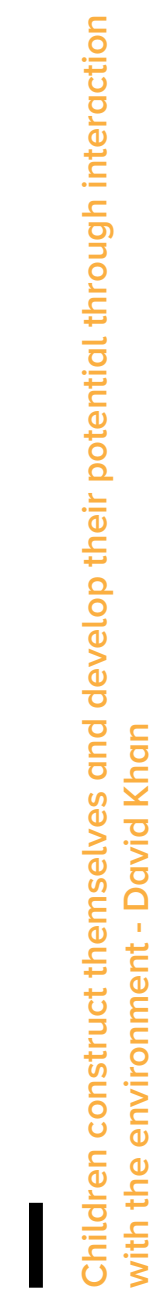

"the environment shapes the learner, and the learners influence their environment; the learners and the learning environment actively shape each other."

- Peter Lippmann

Moreover, the last several decades have supported new fields of research concerned with environment-behaviour interactions. The professionals, whose work provides the foundation for this thesis, are currently asking more complex sets of research questions in regards to identifying the specific aspects of design-behaviour relationships, such as age and 
individual dispositions towards an environment.

In addition, they are encouraging early childhood practitioners and designers to acquaint

themselves with the empirical research being formulated so that they may continue to develop, design and build environments that achieve developmental goals and employ architecture as a tool for education. ${ }^{21}$

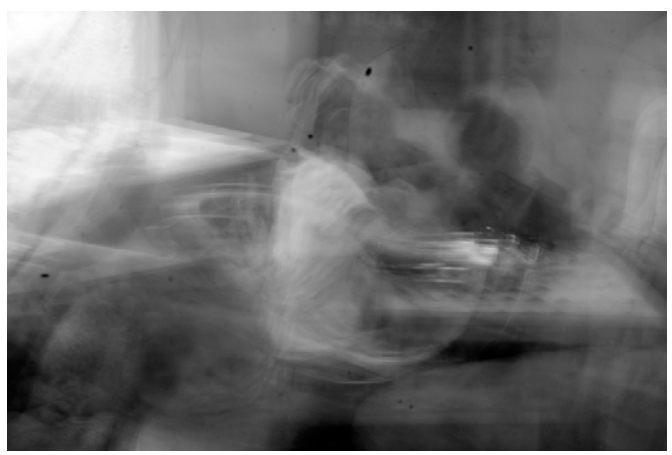

\section{Fig. 4}

Conceptual Photograph - taken at Kaban Montessori School

This is not to say that such ideal environments for learning do not already exist in one form or another. Thoughtful environments designed to meet the needs of the child are achievable, the challenge is in continuing to design a variety of ways that makes such spaces accessible and the norm for society. 


\section{2 _ A Brief Timeline}

\section{A Brief History of Education}

Education should evolve to reflect the social, political and economic forces that surround it. Throughout history, there have been many shifts in the paradigms that construct the educational ideologies of the time; from Ancient Greece's theoretical forums, industrialized mass-education, to the progressive movement and global knowledge network we see today. These changes not only transform how society conceives child development, but they also manifest as physical changes in the architecture of the school.

A brief timeline of notable influences on early childhood education, architecture and progressive pedagogies that have developed globally and locally (Canada) through the ages.

Using the timeline to explore the events and ideas

from early records of education, the colonial

period, the gradual dissemination of knowledge

to all social classes, to the effect of compulsory

public education, this study begins to understand

the roots of today's progressive movement and the influences history has had on curriculum, teacher-student relationships, and the learning environment. 


\section{HISTORY}

程

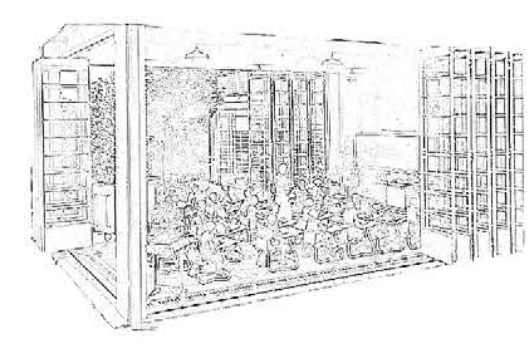

300 100- $1500 \quad 1600 \quad 1700 \quad 1800 \quad 1850 \quad 1900 \quad 1915-1930-$ 1960-

$1990-$

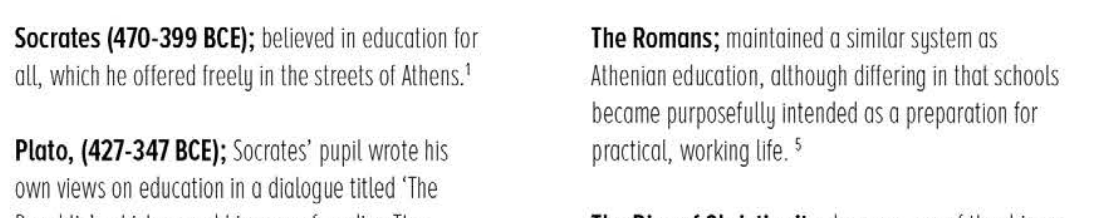

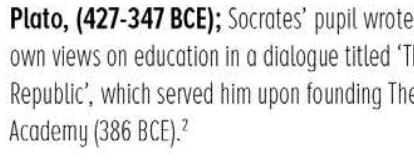

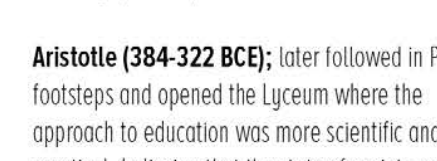

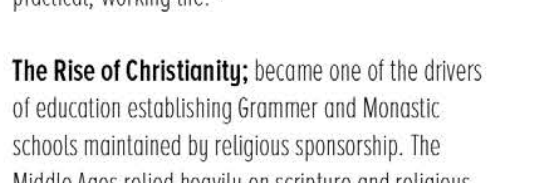

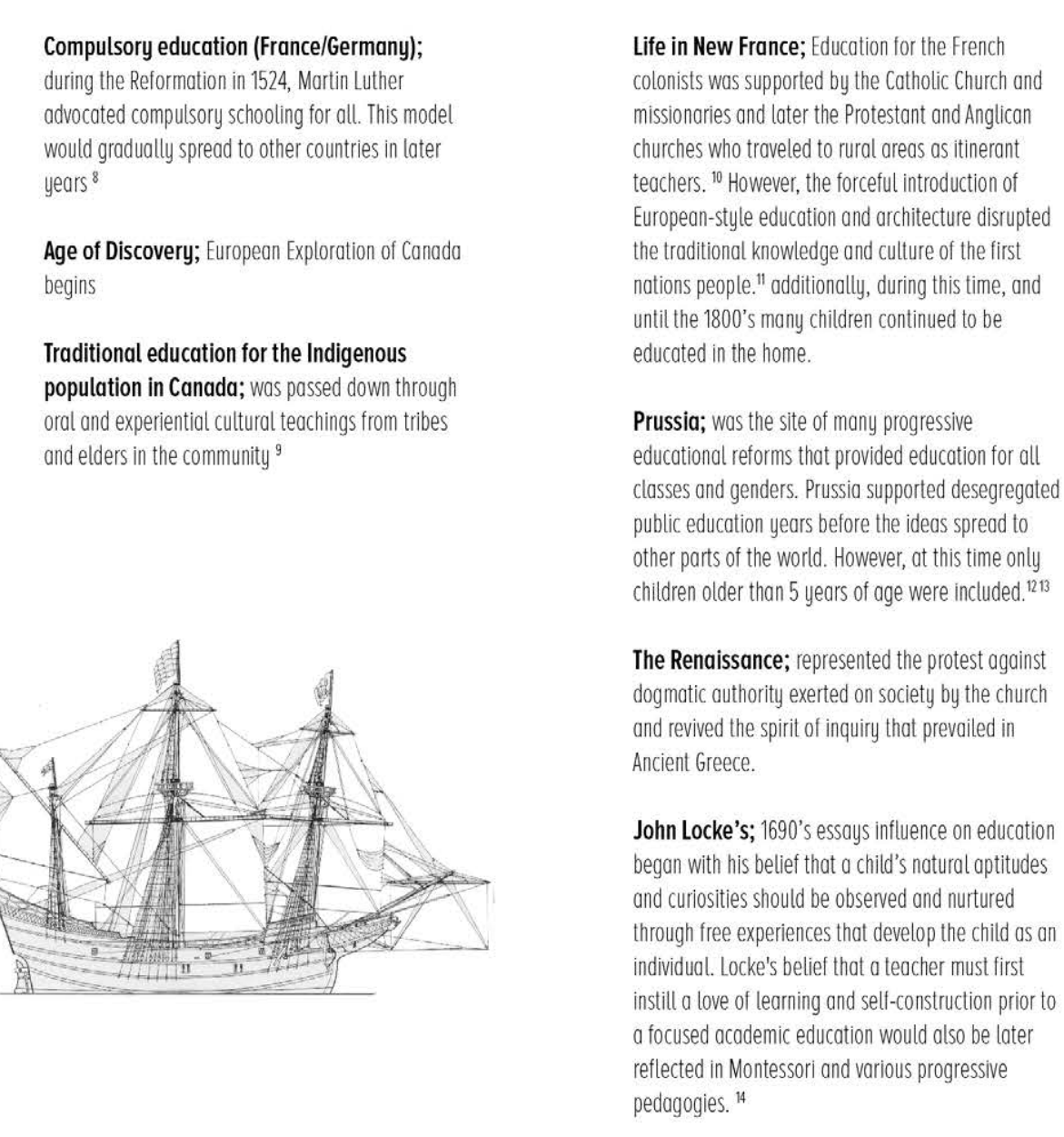
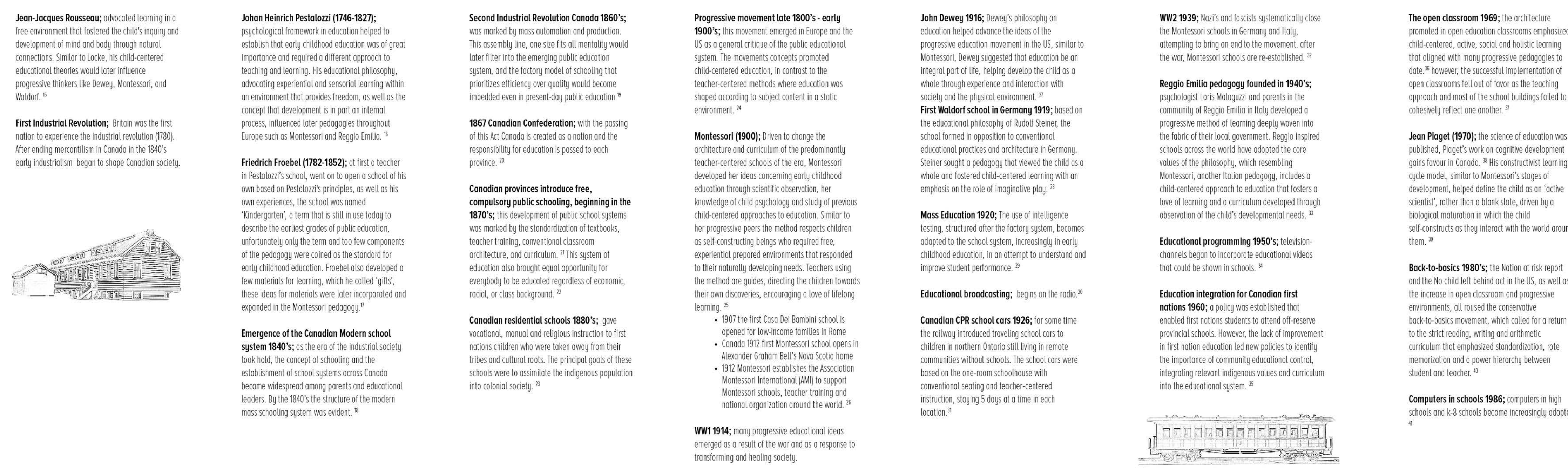

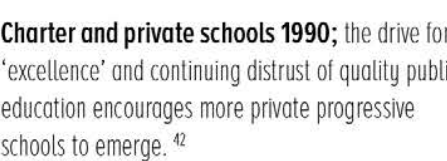

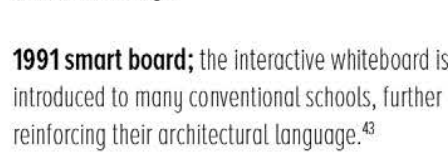

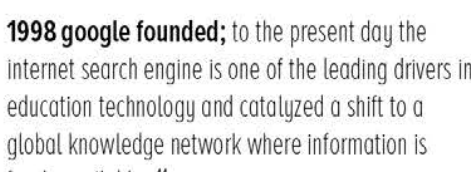

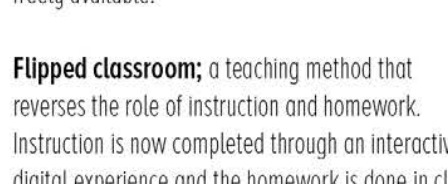

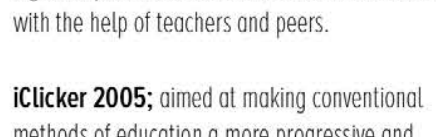

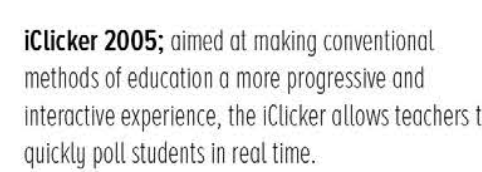

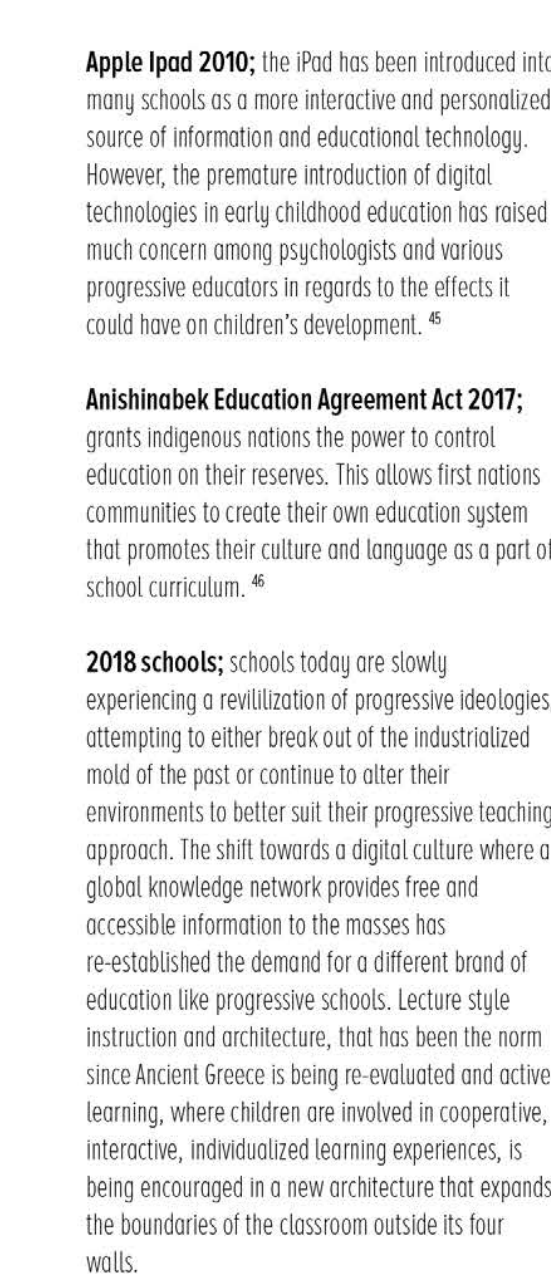




\section{3 _ The Progressive Condition}

A Pedagogy

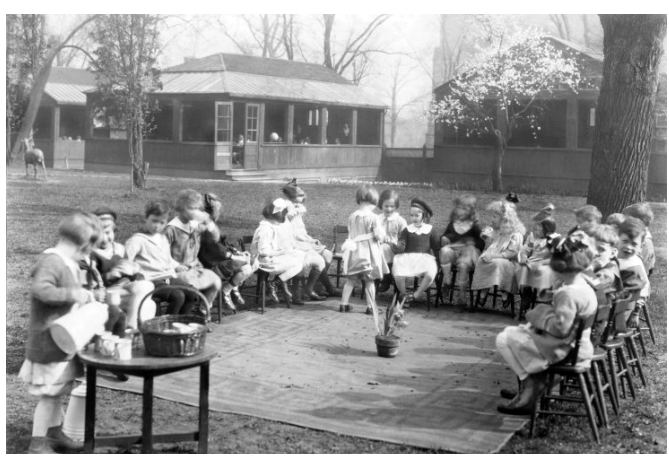

Fig. 5

Children engaged in child led community activity and discussion at the Park School of Buffalo (1912)
"The function of education is to teach one to think intensively and to think critically. Intelligence plus character - that is the goal of true education - Dr. Martin Luther King Jr.

Progressive education does not necessarily have a single fixed definition, in that no two pedagogies that align themselves within the progressive tradition strictly follow the same model or process. Most progressive pedagogies, although fundamentally similar, have diverse interpretations of the progressive condition, specifically the weight and hierarchy allocated to its leading characteristics. ${ }^{22}$ Despite such variations, leading characteristics do exist. These shared principles have formed the common core of progressive education and emerge as a continuum, where schools, progressive or traditional, are not merely one or the other, but rather exists somewhere on this spectrum. Thus, authentic progressive learning environments are "characterized according to how closely they reflect a commitment [to the following values]." 23

The Whole Child: Within the progressive condition, the view of the child is based on the concept that education is not merely meant to prepare the child 


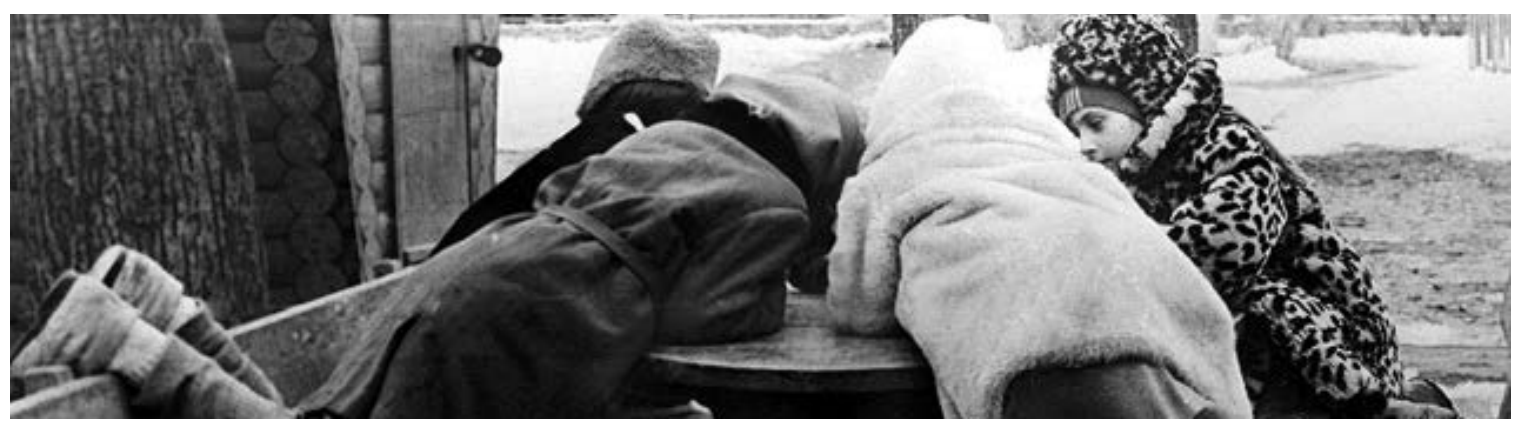

Fig. 6

Children absorbed in the process of discovery

for life as an "educated citizen...or employee in training...participating in the economic system," 24 rather it must also cultivate and inspire a love of learning, creativity, compassion, self-knowledge, skepticism, sense of responsibility, independence, social skills, and emotional and physical health.

The goal of holistic education aims to create experiences and environments that are optimal for the development of the whole human being. This approach recognizes that in order for children to be able to reach their unique and full potential, they must be guided and encouraged to develop not just their intellectual skills, but also their "physical, psychological, emotional, interpersonal, moral and spiritual potentials." 25

\section{Community and Collaboration: The progressive} condition recognizes that learning does not just happen alone or within the school. Children learn from one another, their teachers and the community at large. Throughout all aspects, this approach emphasizes collaborative problemsolving, and active participation within the community. These pedagogies encourage diversity and provide opportunities for children to become caring citizens involved in their cultural and ecological communities. ${ }^{26}$

\section{Active learning: A progressive condition} requires children to play an active role in the construction of their knowledge, curriculum, and environment. It encourages experiential learning where there is more discussion, questioning, experimentation and an active engagement with the physical world. ${ }^{27}$ In an active learning environment, children's contributions and ideas are taken seriously. Education is not a mere transmission of information from one person to another, but an intricate, non-hierarchical relationship of knowledge between people and their environment. ${ }^{28}$ Due to this, project-based interdisciplinary learning occurs naturally within 
authentic progressive learning environments.

Individualized learning: The progressive condition perceives each child as an individual with unique interests, requirements, and momentum. For this reason, progressive education "takes [its] cues from [each child]," in order to provide the optimal environment and curriculum for their development. ${ }^{29}$

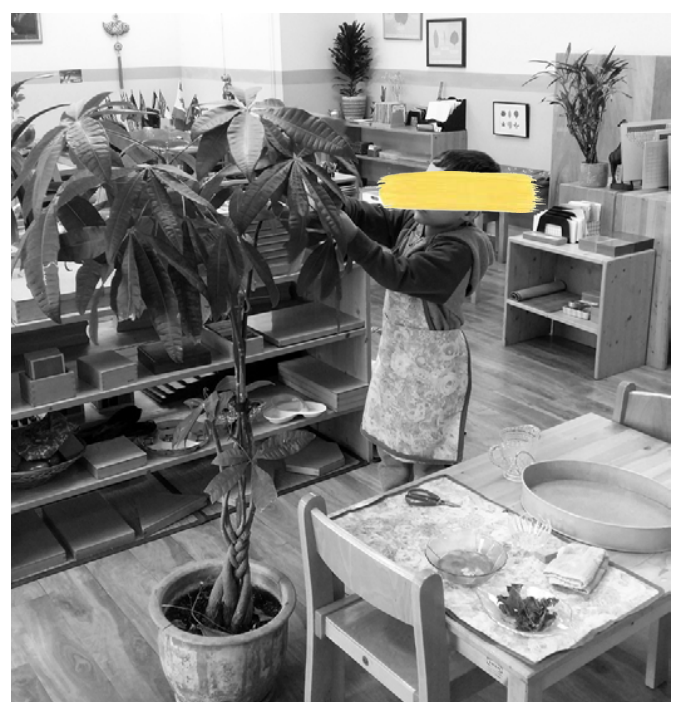

Fig. 7

A child engaged with self chosen activity (caring for the classroom plant) - Kaban Montessori School
As we come to better understand the progressive condition it becomes clear that the stemming pedagogies focus on learning rather than teaching, the child rather than the standard or system. While it may be currently more complicated to live on the progressive end of the spectrum, the more we are influenced by the insights of the progressive condition, the more we must rethink the intention of education and thus the design of learning environments. Fortunately, education today is experiencing a rediscovery of the progressive condition as more and more research in support of progressive methods of education emerge, confirming the benefits these values have on young children. ${ }^{30}$ As society becomes more familiar with educational alternatives, the demand for progressive learning spaces and pedagogy increases. ${ }^{31}$ We now begin to see a shift in even conventional schools as they slowly integrate more of its values into their curriculum and architecture. ${ }^{32}$ Likewise, progressive schools now gaining a wider following should take the publics current interest, as well as the emerging child development data as incentives to improve their own learning spaces. Through developing more accurate architectural reflections of their values, these schools will be able to truly thrive and become leaders in the progressive education movement. 
Matrix 01

Mosaic

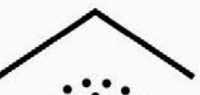

$\therefore \because \because$

$\because \because \because \because$

$\because \because \because$

order
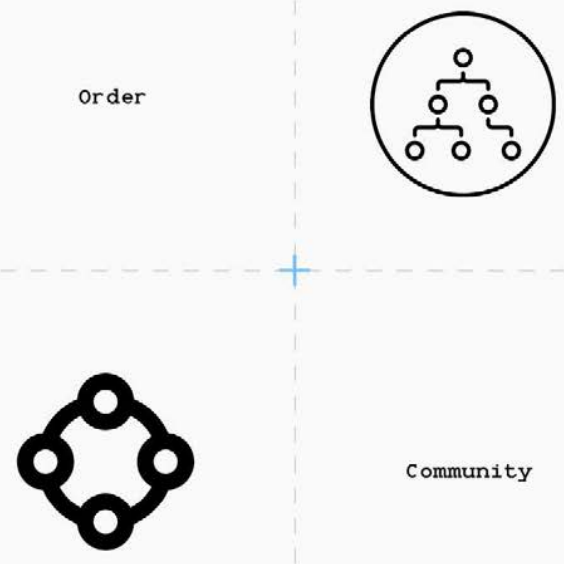

Community

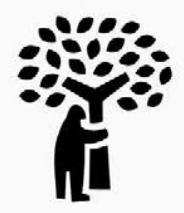

Erkinder

Simplicity

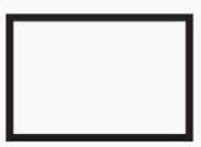

Interactive

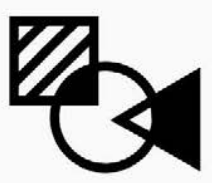

80

Material

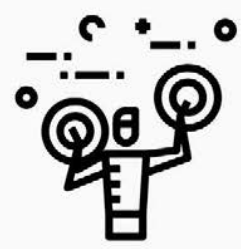

Freedom

The Progressive Condition 


\subsection{The Montessori Method}

\section{A Progressive Pedagogy}

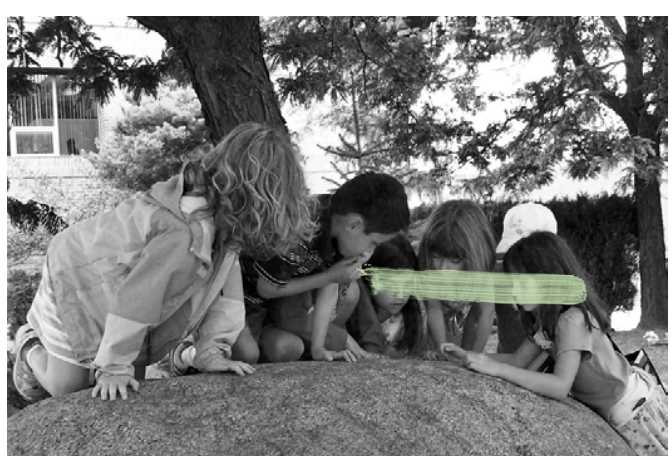

Fig. 9

Children captivated by the small insects

traversing a boulder - Kaban Montessori School
"In the spirit of our science, we must remain open to the possibility of new discoveries that go beyond Montessori's original experiments." - Ginni Sackett

As a key contributor to the ideas and practices of the progressive educational movement, Italian physician Dr. Maria Montessori, developed a scientific method of education based upon her observations of children. ${ }^{33}$ In the simplest form, the method calls one to merely study the child, to take what they have given and expressed and use it to create an environment where they can succeed naturally. ${ }^{34}$

The Montessori Method, which was shortened from its original title, 'Il Metodo della Pedagogia Scientifica applicata all educazione infantile nelle Casa dei Bambiini', is based on the "scientific foundation [of]: observation, experimentation, recognition of new phenomena, and the reproduction and utilization of the new phenomena." ${ }^{35}$ As a result, the pedagogy remains an open-minded system meant to evaluate and adapt to new discoveries, in accordance with the individual needs and interests of the child. ${ }^{36}$

Following the methods of a scientist, Dr. Montessori was able to quickly systematize 
and share her finding from the first Montessori schools through the philosophy developed. ${ }^{37}$ Akin to progressive pedagogy, Montessori schools view learning and development as intrinsically connected. The Method places the child at the center of the educational process, following their innate developmental interests and needs while incorporating them into all aspects of the curriculum. ${ }^{38}$ The environment is then guided by a deep respect for the child as an individual whose complete development - cognitive, social, emotional and physical - is at the root of the philosophy. ${ }^{39}$ Thus, the Method emphasizes the careful preparation of the environment both physically and psychologically. ${ }^{40}$ Rather than being modeled on the factory of the industrial revolution, the Montessori school takes after a university style studio where the children are free to explore and pursue their own projects and learning. ${ }^{41}$

Following this view of the active child as intrinsically motivated, the learning environment must become more than a place where the transmission of knowledge occurs and facts are relayed. It was evident to Dr. Montessori that children are endowed with a great capacity to absorb and learn from their environments without any need for direct instruction; that children are driven by a desire to be capable, independent human beings, competently contributing to their world. ${ }^{42} 43$ And when placed in an environment specifically designed for their appropriate developmental needs, children become "producers of culture...knowledge makers", capable of self-construction. ${ }^{44}$

Montessori concluded that the child has an integral relationship with their surroundings and it is the teacher's duty to support and inspire the child in their self-construction. Thus, a teacher's goals include observation of the child in relation to their designed setting, so as to continuously innovate their surroundings, providing for their needs and removing any obstacles to their growth, inspiring a child's love of learning, and serving as a resource, who can help guide their discoveries. 4546

With such a philosophy in place, the curriculum unfolds from the natural laws and principles of human development, ultimately emerging by way of the environment and the materials within. ${ }^{47}$ Accordingly, similar to the role of the teacher, architects then play a vital role in the development of the child. How and to what degree this role is reinforced will be explored further in this thesis. 
Before continuing to examine the principles which underpin the philosophy and design of Montessori learning environments, it is important to understand how these learning environments are methodized in terms of a child's development and predispositions to certain qualities of space and action. ${ }^{48}$ Dr. Montessori observed that a child's biological development can be reasonably defined by age and that it occurs in three sixyear phases: birth to six, six to twelve and twelve to eighteen. These are further subdivided into classrooms with three-year, mixed age groups (for social and developmental reasons). ${ }^{49}$ This thesis, however, will be focusing on the first 9 years of life, as they are considered, by most progressive pedagogies, the most important period in a human's development. ${ }^{50}$ Within these planes of development, Montessori recognized certain sensitive periods, where the child is absorbed by distinct environmental and social characteristics, thus following particular learning patterns. Within the first plane, children become fascinated with developing their independence, coordination, concentration, and sense of order. ${ }^{51}$ During the second plane, a child's predominant dispositions include imagination, socialization, and a sense of moral justice, although they continue to refine their previously learned skills. ${ }^{52}$ Architects should then be very aware of these periods of sensitivity,

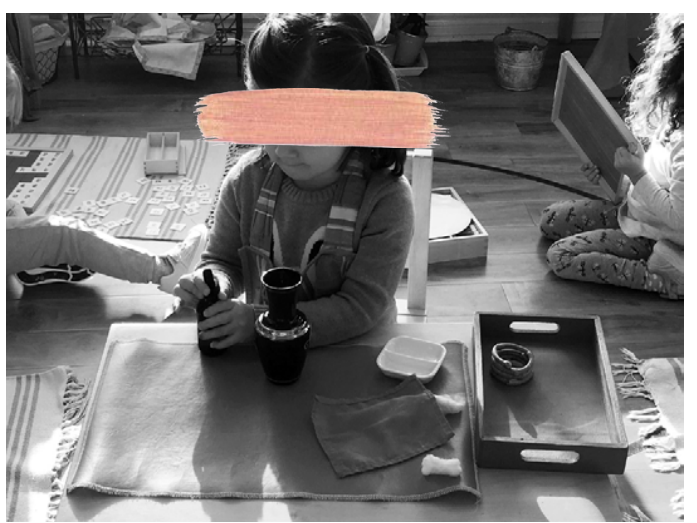

Fig. 10

Children of different ages working in parallel. All are exposed to a variety of materials for different developmental stages.

in order to be able to appropriately incorporate them within the design of specific learning spaces and help children develop to their full potential.

These essential developmental principles articulated throughout the Method and translated into all aspects of play, curriculum and school environment include the concepts of "freedom, structure and order, reality and nature, beauty and atmosphere, the Montessori materials, and the development of community life." 53

Montessori saw freedom as an essential component of the child's self-construction, it is the mechanism through which a child must experience learning, as well as through which we can come to better understand them. ${ }^{54}$ As such, it is entwined within all of the principles which follow. 
It is important to distinguish however, the freedom referred to in Montessori and within this thesis from the versions of liberty exercised among other progressive pedagogies. Unlike the boundless liberty that sprang as a reaction to the oppressive authority of more conventional systems of education, freedom in Montessori is a freedom within limits. ${ }^{55}$ This freedom is synonymous with independence and self-discipline, hence, this freedom is developed and aided through the learning environment as it provides opportunities for the child to flourish. The limits to their freedom depend only on the collective interest and wellbeing of the community and environment.

Further, when speaking of freedom, consider freedom of choice and movement (free to move about from indoor to outdoor environments, choose their own learning activities, and work independently or with others) as the fundamental drivers of this principle. ${ }^{56}$ "As discovered through many psychological studies, movement and cognition are closely entwined." ${ }^{57}$ Children learn by doing, "[their] mind is handmade," such that actively and spontaneously exploring, examining, touching, and manipulating their environment, help "build up a storehouse of impressions and thoughts about the physical world around them." 58 Based on this, typical progressive learning spaces must develop to include a great deal of object manipulation and opportunities for interaction.

The second critical element of a Montessori environment, and one that supports free choice, is structure and order. These elements aid learning and development by establishing a mental order within the child. ${ }^{59}$ In other words, the spatial and conceptual order that is prepared and designed within a successful Montessori learning environment is internalized by the child, helping them to build an intelligence, understanding, and trust of the space around them. ${ }^{60}$ Correspondingly, "studies of human memory [show that children's learning improves] when information is presented in a [physically or conceptually] organized way." 61

Within the school, order is manifested at many levels. Although the children do not experience a strict structure when it comes to their daily schedules, Montessori environments are very ordered at the micro level. ${ }^{62}$ This means that certain material features, movements, layouts, elements, colours, and patterns (some of which will be expanded upon further in the study) within a learning environment can facilitate the manifestation of the child's sense of order. 


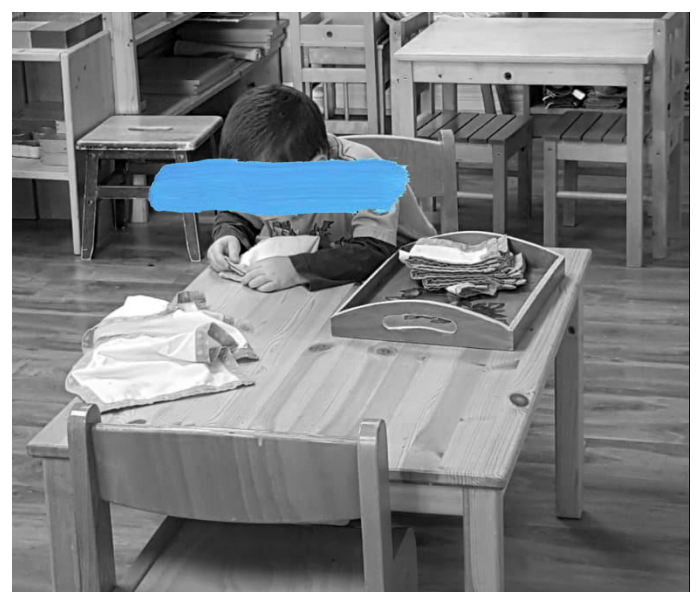

Fig. 11

A child choosing to refold all the classroom place mats is compelled to line up all their edges, until he is satisfied that they are all in order - Kaban Montessori School

For example, "a Montessori classroom is filled with vast arrays of sequenced learning activities, known as the Montessori materials," through which children progress at their own individual pace. ${ }^{63}$ In order to provide structure for the child, the materials are arranged in logical sequence from simple to complex, concrete to abstract and are spatially organized within the classroom into subject areas. ${ }^{64}$ Due to the level of freedom within the Method, an ordered environment supports a child's independence, empowering them to navigate and easily find what they are looking for without adult assistance. ${ }^{65}$

Moreover, learning materials provide a tactile and interactive experience through which to learn, helping the child to physically conceive abstract concepts. They are also viewed as a part of a learning continuum, interrelating all areas of study, even though they are physically categorized. ${ }^{66}$ In other words, through the learning material, the curriculum's subjects, which include: practical life (care of self and environment, control of body and adaptation to social context), sensorial (development of senses), geometry and mathematics, language, sciences, social studies, and the arts, are integrated to expose the connection among all areas of life. ${ }^{67}$

Another important aspect of learning materials is their multi-faceted quality and control of error. Certain autodidactic materials must be able to "offer multiple levels of challenge and be used repeatedly [during different planes of development], as well as provide immediate feedback to the child, helping them discover their own mistakes. ${ }^{68}$ Likewise, one might question how the concepts valued in learning materials can be scaled and thoroughly translated into architectural tools for learning.

The third principle of a Montessori environment is its emphasis on reality. However, to first understand what is meant by 'reality', the role of pretend play in the traditional Montessori Method must be made clear. Dr. Montessori 
observed that when given the chance, children preferred to participate in the real adult world, using real tools and creating real things, over a fantasy world where the environment and tools are representational. ${ }^{69}$ Although there are some divergent, open-ended learning materials and spaces within Montessori schools, such as clay, drawing, the sandbox, etc., that support creativity and imagination, playing pretend with certain didactic learning materials is discouraged in an attempt to reduce the confusion that might occur between a child and a material's intended lesson. Similarly, children under the age of three and a half must first understand the reality of space and object, prior to being able to conceptualize and alter reality. ${ }^{70}$ Generally, however, Montessori learning environments "have less opportunity to symbolically manipulate objects [and spaces] in pretense [than other progressives pedagogies]." ${ }^{71}$ It is also important to note that while pretend play involves a transformation of reality, in a similar manner as creative expressions, not all pretend play is creative. When objects and spaces meant for pretend play are already predetermined and pre-imagined by adults, the level of creativity required by the child is dampened.

Additionally, among other factors, the increase of working parents in the 21st century has translated to a significant number of children spending larger amounts of time in early childcare. ${ }^{72}$ Consequently, this has also resulted in a reduction of a child's daily territory, their freedom within it and the amount of time they have for free (pretend) play at home. ${ }^{73}$ Due to the shifts in society and the increase in interest devoted to the developmental benefits of imaginative, creative play, it seems pertinent to reconsider the value of pretend play in Montessori learning environments. Perhaps the Montessori pedagogy and the reflected architecture must evolve to accommodate the 21 st-century child and provide equal opportunity for authentic contact with the real world as well as for materials and spaces specifically allocated for creative, imaginative play to occur.

The third and fourth principles emphasized in the Montessori method introduce nature and community life as an essential part of progressive learning spaces. Dr. Montessori was aware that with the spread of urban life, children's direct exposure to nature and cultural/social diversity would be essential for their holistic development. ${ }^{74}$ Apart from the intrinsic health and developmental benefits experienced through time spent in natural environments (which will be further explored later in this thesis) the more opportunities children are given to expand their awareness and 


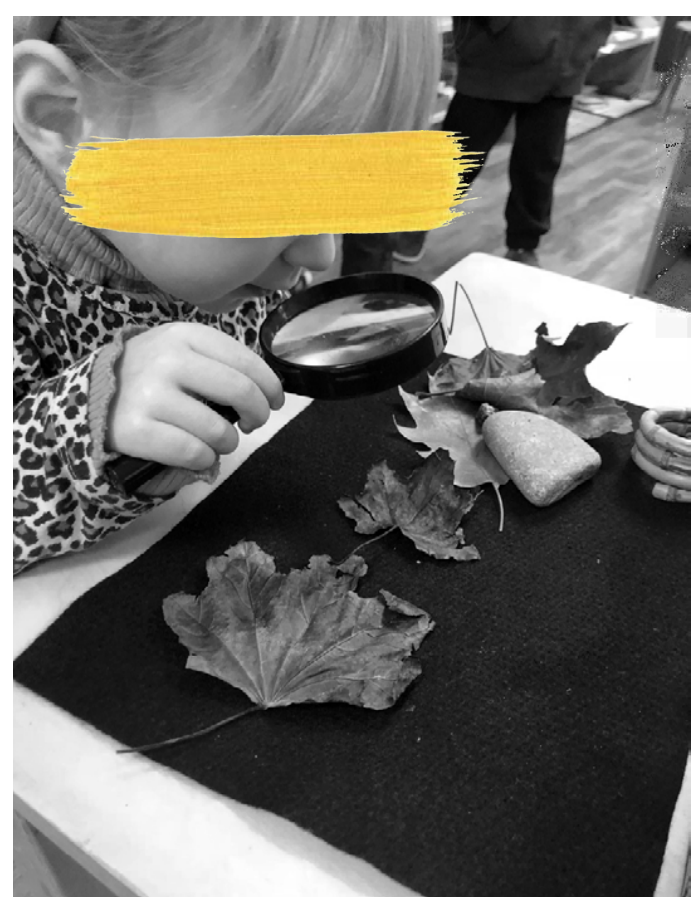

Fig. 12

Discovering natures fine details. Able to freely move from outside to inside, the child collects artifacts to explore - Kaban Montessori School

make real connections to the environmental and cultural conditions within their world, the more likely they will become, understanding, accepting, appreciative and caring citizens. ${ }^{75}$ Altogether, the principles described aim to develop a potential in the child for "creativity, initiative, independence, inner discipline and self- confidence; this is the central focus of Montessori education and "the goal toward which all Montessori philosophy and Method are aimed." 7677

Through beginning to understand progressive pedagogies and the Montessori Method, we begin to question the learning spaces society expects children to inhabit. Questions of space - how does the architecture surrounding a child affect their development? Culture - how do you respect, preserve and encourage knowledge and diversity within a community? Freedom - How do you facilitate and build on a child's innate potential for self-construction? Individuality - how do you create an environment that satisfies the needs of both the group and the individual? 


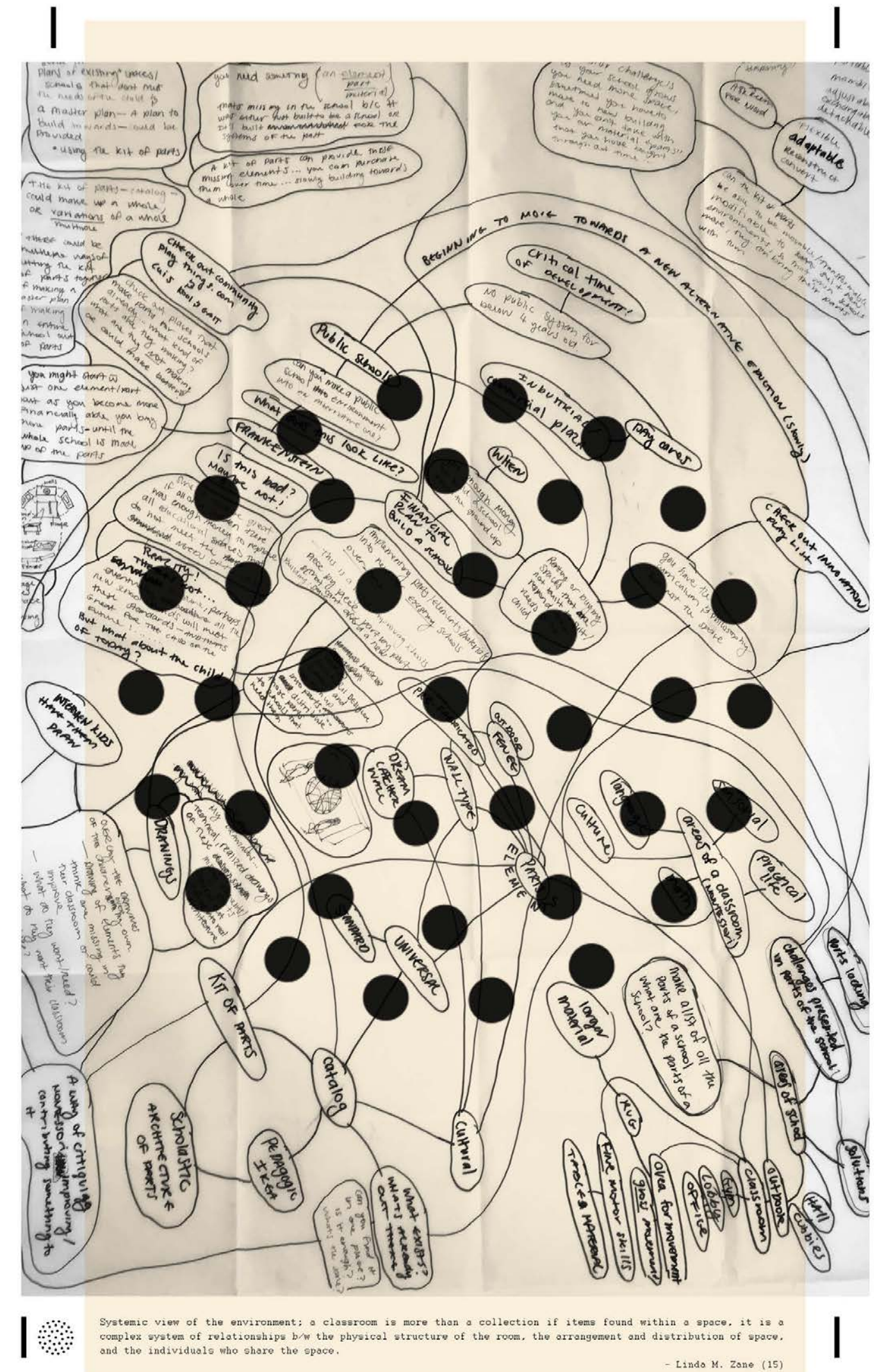




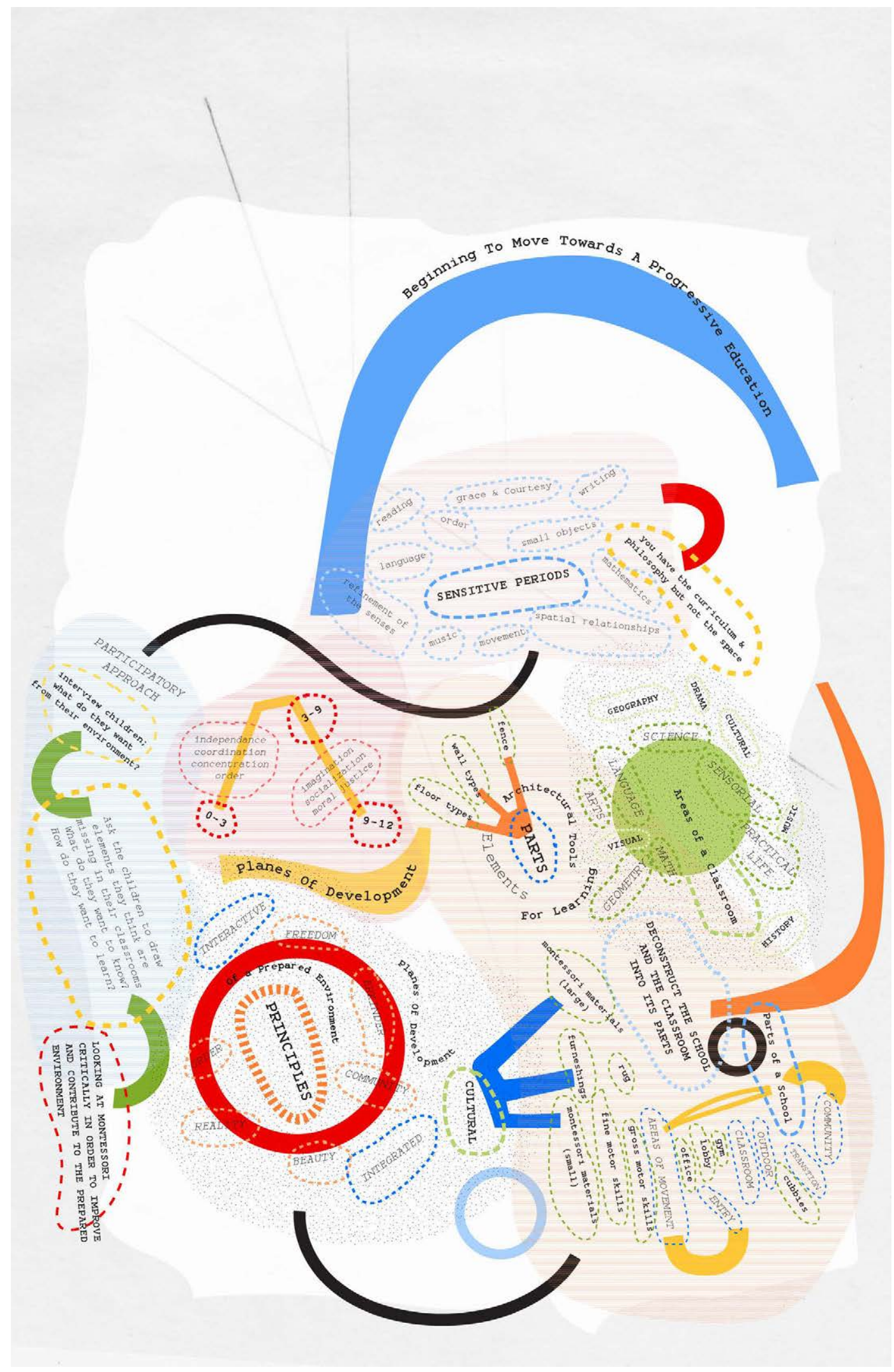




\section{5 _ The Scientific Form}

\section{A Spatial Interpretation of the Scientific Method}

"Children need the freedom to appreciate the infinite resources of their hands, their eyes and their ears, the resources of forms, materials, sounds and colours." - Loris Malaguzzi
Inspired by the values upheld in the progressive condition, as well as Dr. Montessori's scientific approach to education, this thesis now asks how the spirit of scientific observation, evaluation and experimentation, used in the creation of the Montessori pedagogy can be similarly applied to its learning spaces. Through further exploring the scientific method as it applies to all areas of scientific inquiry we identify that the model, illustrated in Fig. 15, revolves around the testing of ideas. ${ }^{78}$ This model is further divided into periods of exploration and discovery, community analysis and feedback, and benefits and application, all naturally recurring and informing one another in a feedback loop. ${ }^{79}$

A child's learning process often involves repeating the same learning stage many times to account for the new knowledge, ideas and questions gained along the way. This often means that children will move fluidly through the model, returning to the same period (learning material or question) multiple times, but at progressively deeper levels of understanding. ${ }^{80}$ Additionally, this aspect of the scientific model supports the multi-faceted 


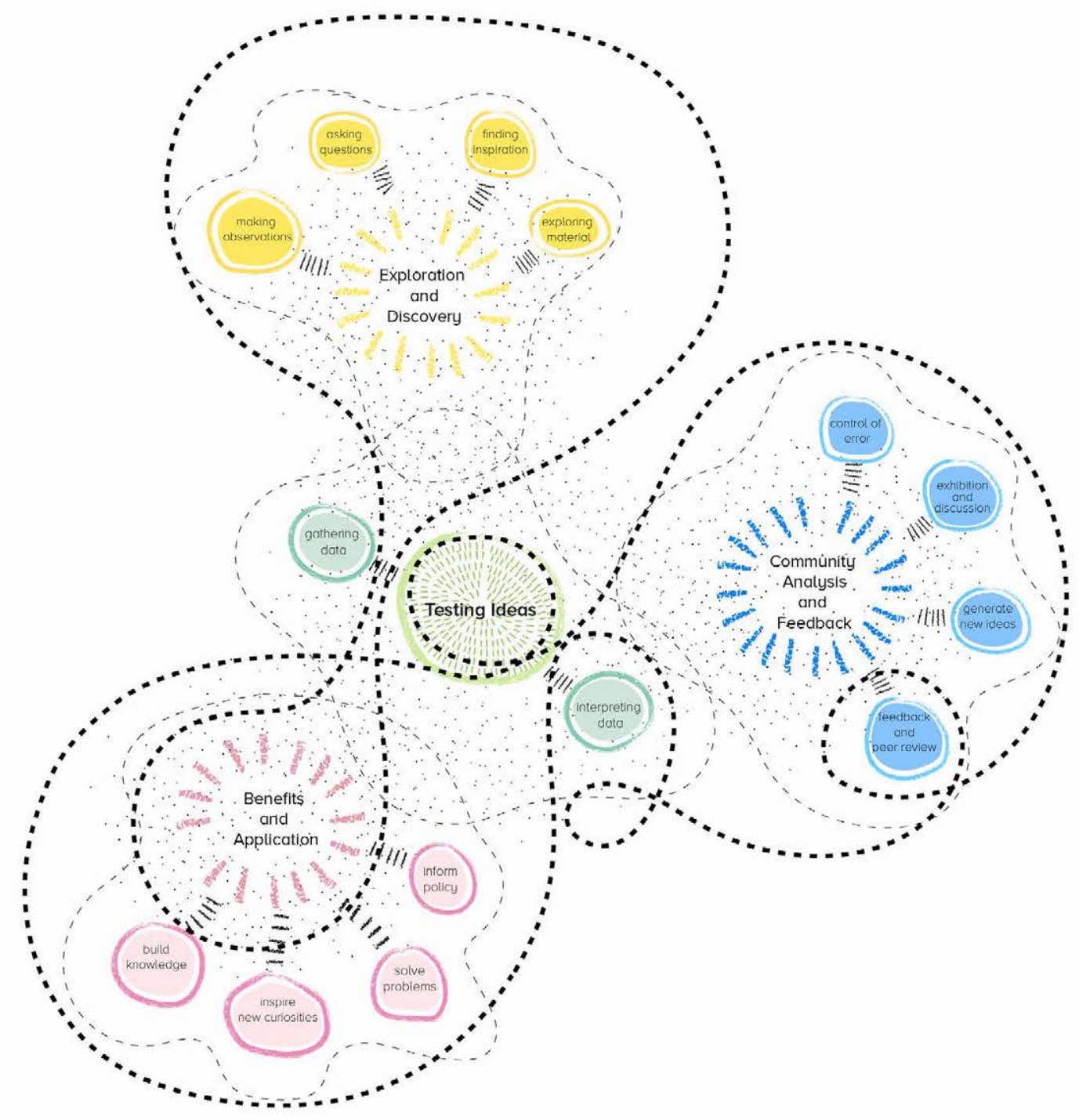

The Scientific Method A Blueprint for Scientific Investigation 
quality in Montessori learning material that encourages children to revisit them at different stages of development. Thus, if the scientific method was re-imagined in spatial form, the different periods within the model would need to be expressed through the buildings architectural elements, layout and programmatic relationships. In other words, in order to materialize the scientific method, all learning spaces, including interstitial areas, within the school, as well as the support spaces connecting the school to the greater community must allow the child to move fluidly through the different learning environments, just as they would through the scientific model.

Accordingly, the following mapping (Fig. 16) illustrates a variety of learning spaces in relation to the periods within the scientific model. The mapping also interprets a potential strata or spatial order that could exists between learning spaces, specifically between those that occur within the school to those whose proximity is among the greater community.

Note* most progressive curriculums integrate all subject areas in order to gain a holistic understanding of the world. 
explorotion and discovery
community anatysis and feedback
testing ideos
benefits and application

-

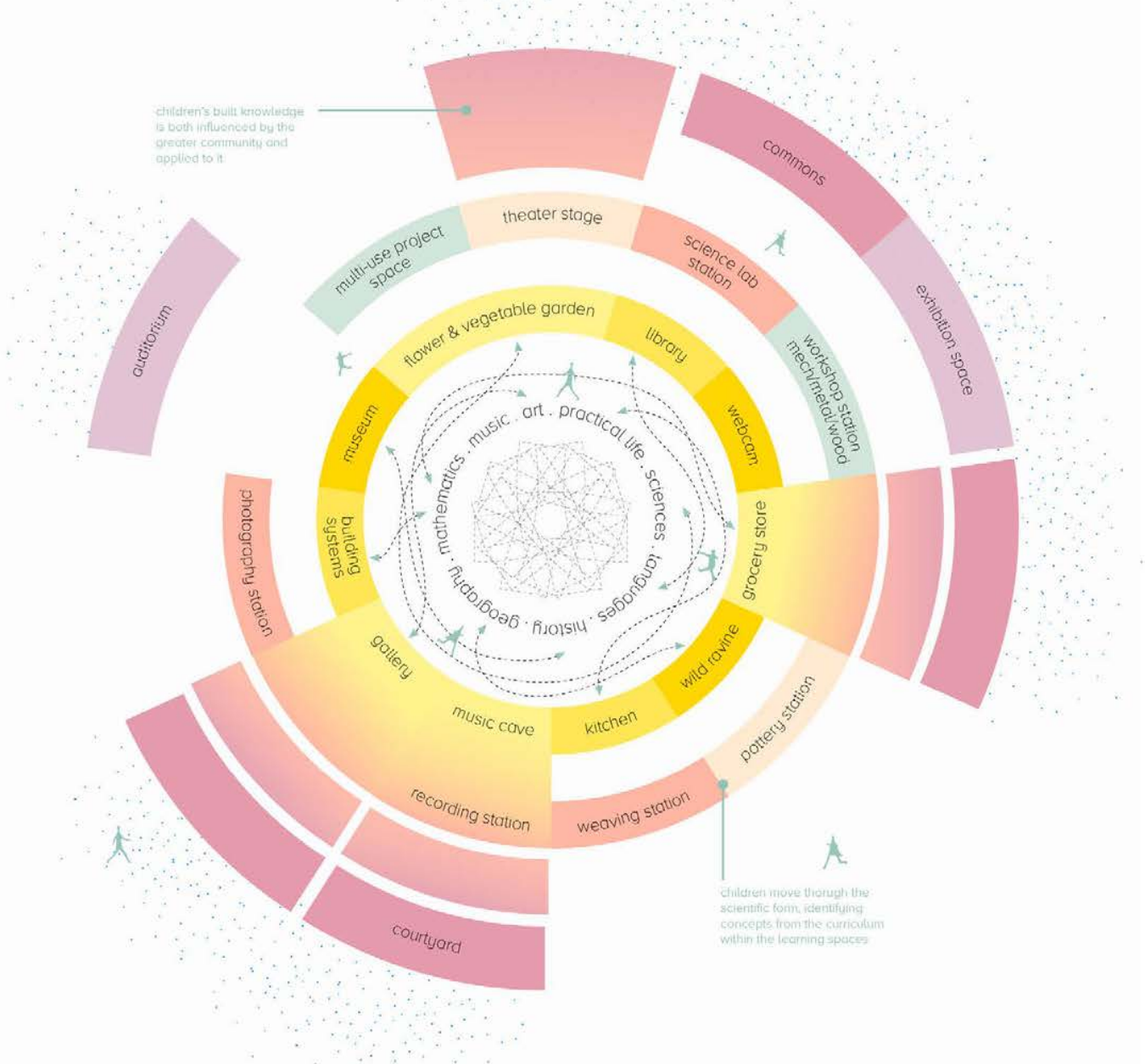

The Scientific Form

Between Method and Learning Space

Fig. 16 The Scientific Form 


\section{Part 02}

A 1<smiles>[Y]C1[C+]C=[C+]1</smiles>

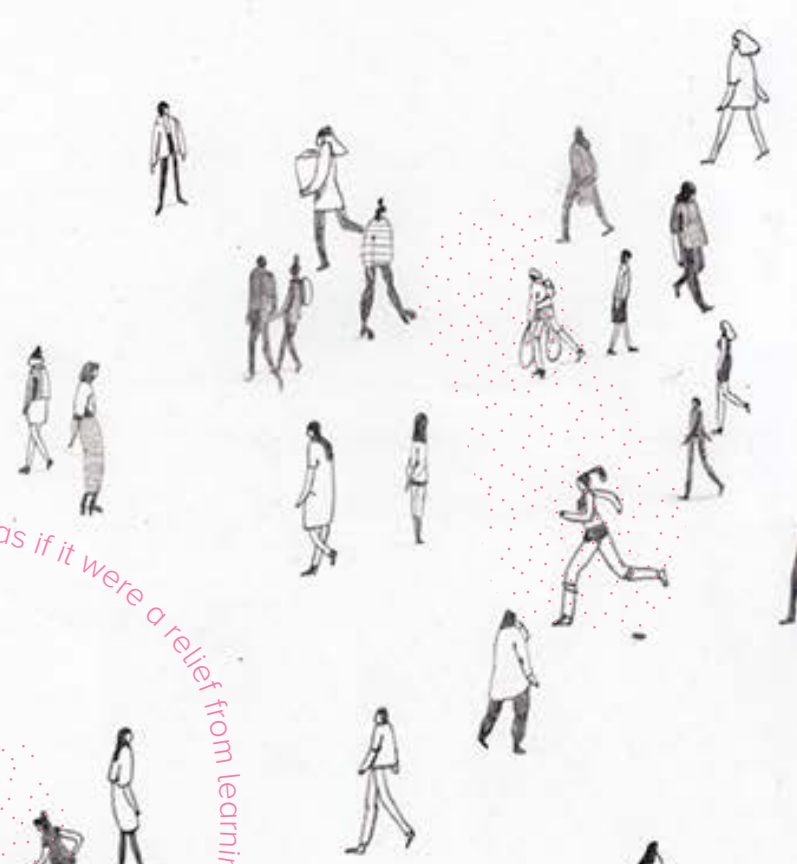

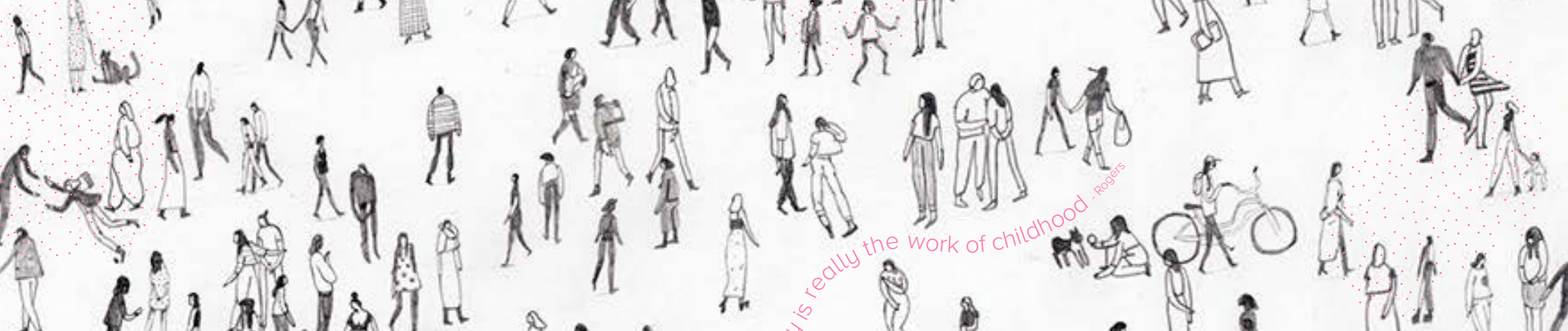

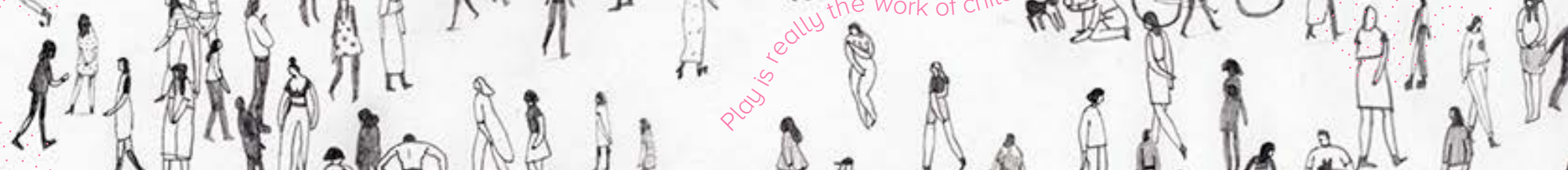

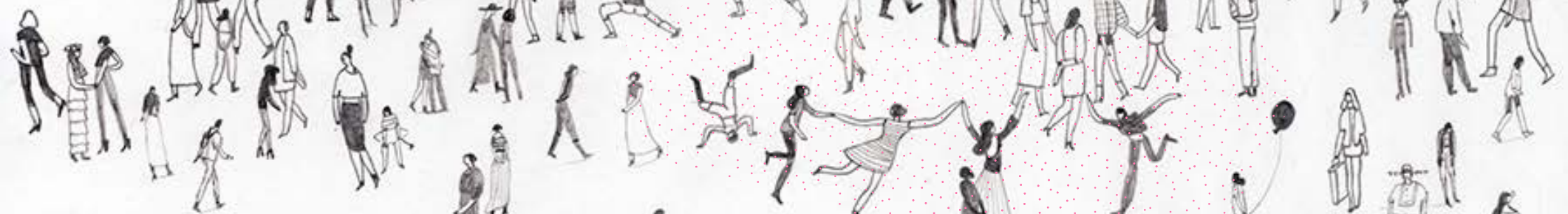
多

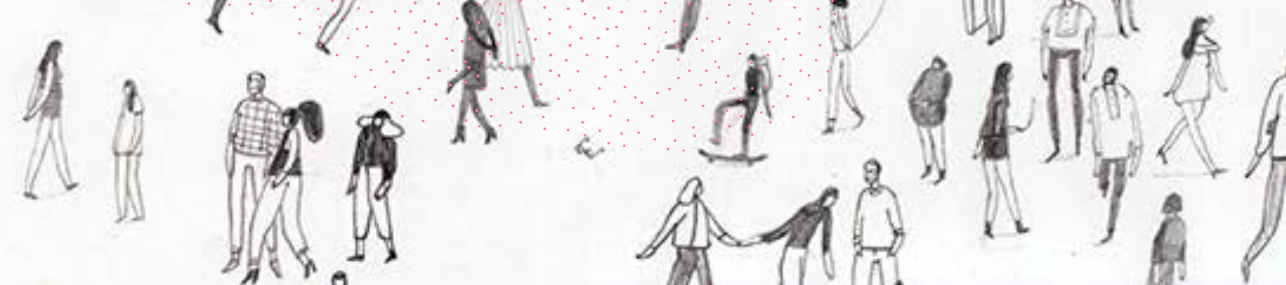




\section{0 _ Learning Spaces}

\section{Intro to Guidelines + Design Patterns}

Note* $^{*}$ wherever possible, the study refers to the available research in educational and developmental psychology to support the design strategies. In the absence of empirical data, however, we rely on the reasoning of early childhood practitioners and theoreticians, such as Dr. Montessori, as well as our own reflections and interpretations.
Having now contextualized and established the pedagogical foundations, rationale and fundamental values of progressive education, primarily those of the Montessori Method, the study has determined eight critical principles that all early childhood progressive learning spaces should embody and persistently design towards, in order for space to positively contribute to the holistic development of a child's intellect, body, and character.

These principles, which essentially form a framework by which this thesis can assess existing progressive environments and continue to develop a variety of spatial strategies that will inform new designs, include the concepts of:

Participatory Design

Freedom

Community and Culture

Order

Interactive

Integrated

Innovative

Erkinder 
In order to further discern these principles and analyze the elements that compose progressive learning spaces, an illustrative comparative index, seen in Fig. 7 catalogues the following six progressive schools: Fuji Kindergarten by Tezuka Architects (Fig. 1), Nursery in la Chapelle-les-sciers by Lacroix Chessex (Fig. 2), Farming Kindergarten by Vo Trong Nghia Architects (Fig. 3), HN Nursery by HIBINOSEKKEI, Youji no Shiro (Fig. 4), KM Kindergarten and Nursery by HIBINOSEKKEI, Youji no Shiro (Fig. 5), and Montpelier Community Nursery by AY Architects (Fig. 6).

The index deconstructs one space within each school into individual components and categorizes each spatial element into the respective principles. Through comparing the spatial qualities between the schools the study begins to recognize prominent patterns and design strategies used to respond to the needs of the child.

The following chapters will further illustrate and delineate the characteristics and socio-emotional, cognitive and physical goals of the eight principles of progressive learning spaces. The research will then consider their implications as they apply to the child's developmental needs and the physical setting and suggest design strategies through which the ideas and concepts presented can be interpreted through architectural forms, patterns, relationships, materials, organizations, and program.

Moreover, to further define and interpret the progressive principles previously listed, the proposed design strategies draw from the analysis of the program, architectural conditions, site and cultural context at Kaban Montessori School and its surrounding community (Fig. 1). Within this context, the thesis will explore architectural interventions at a variety of scales (micro, mezo, macro), which will aim to realize the latent potential of these learning environments and ways in which progressive school architecture can positively reinforce the learning experience as the third teacher.
Note* Kaban was one of the participating schools from the Vega Workshop held with children from four participating schools.

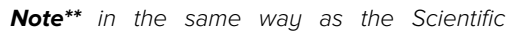
Method, all of the guiding principles are nested within one another. Their basis' and patterns all forming part of the progressive continuum. Thus the ideas in one support or often mirror those of another. 


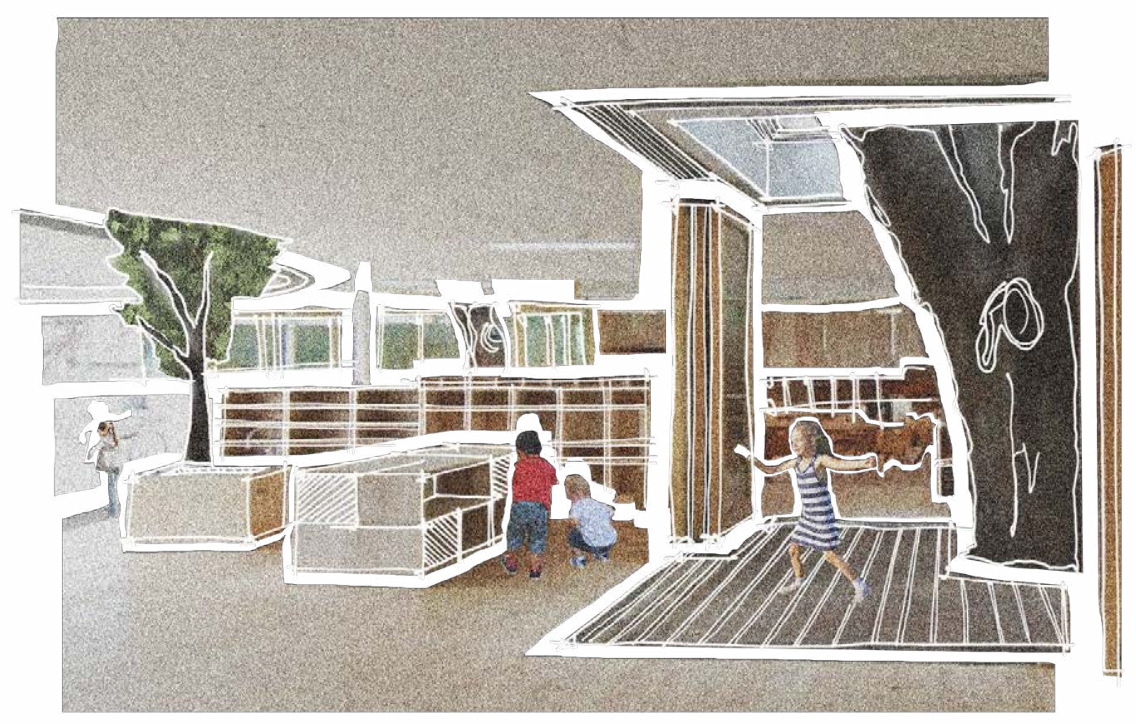

Fig. 1 Fuji Kindergarten

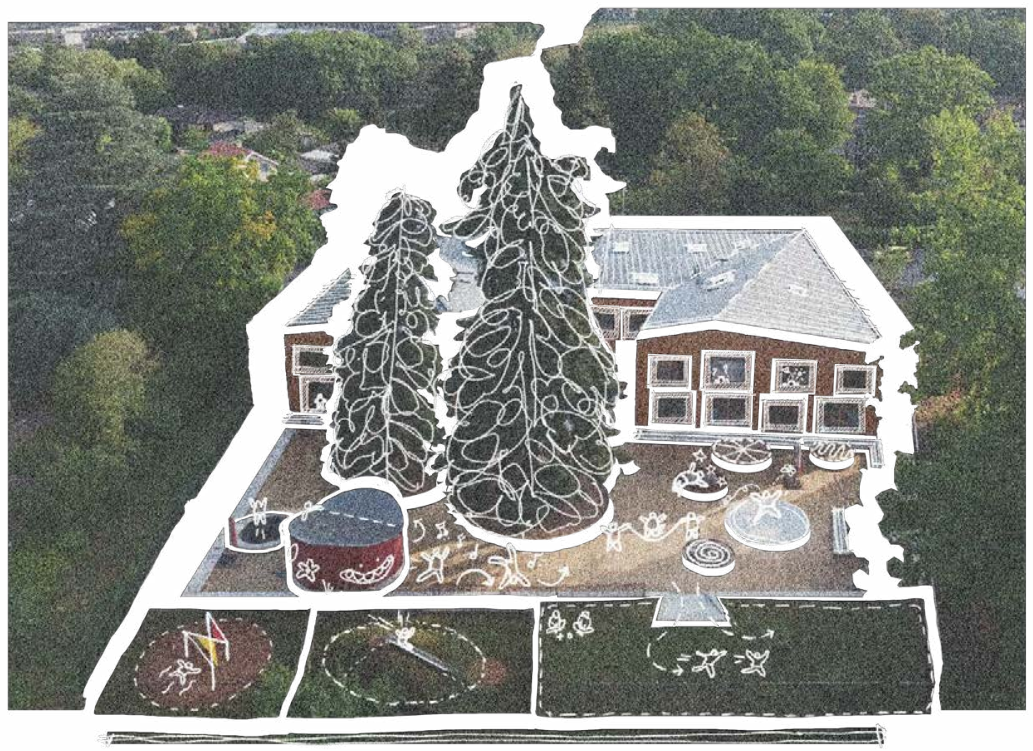

Fig. 2 Nursery in la CHapelle-les-Sciers 


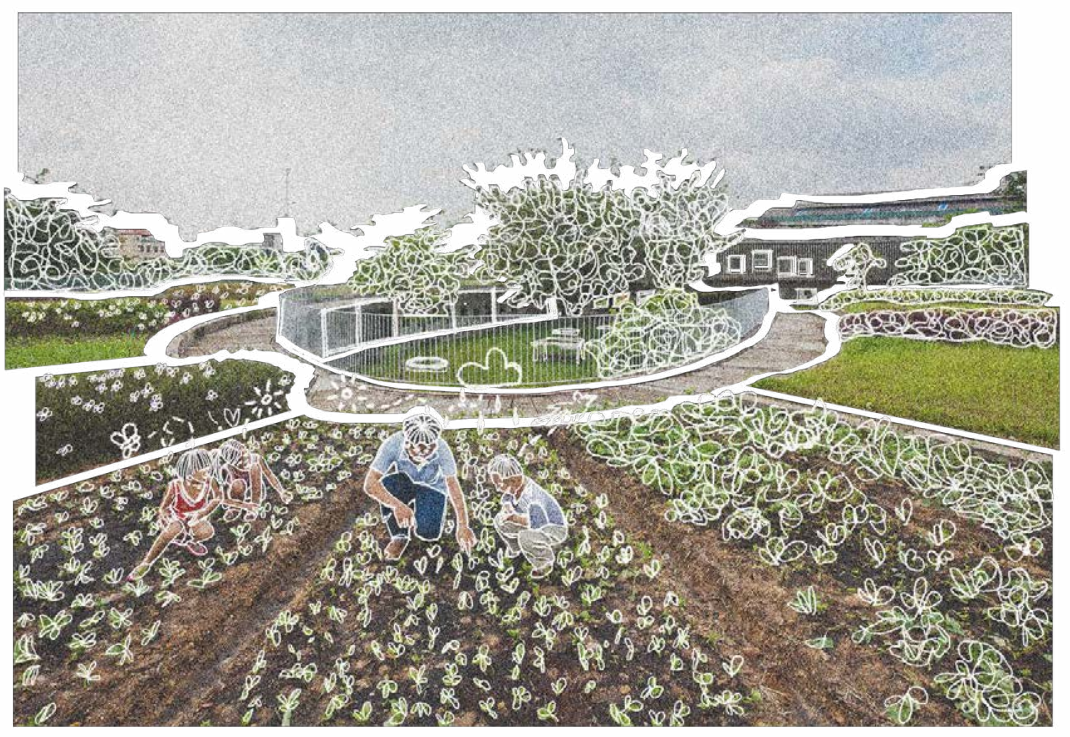

Fig. 3 Farming Kindergarten

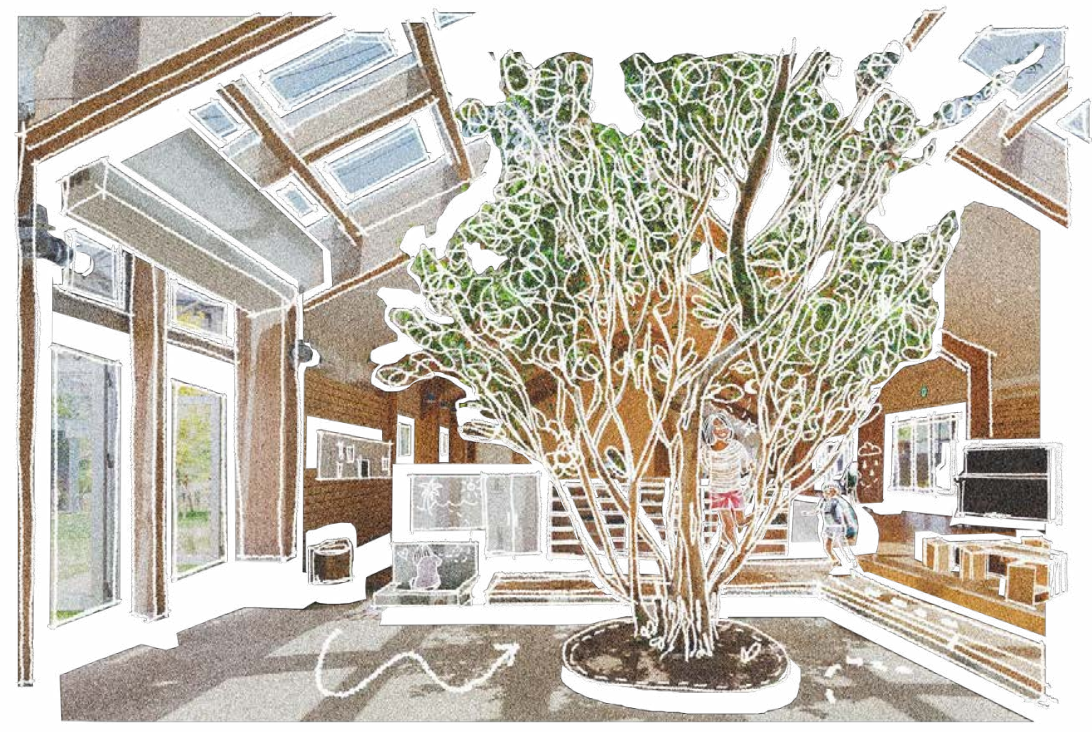

Fig. 4 HN Nursery 


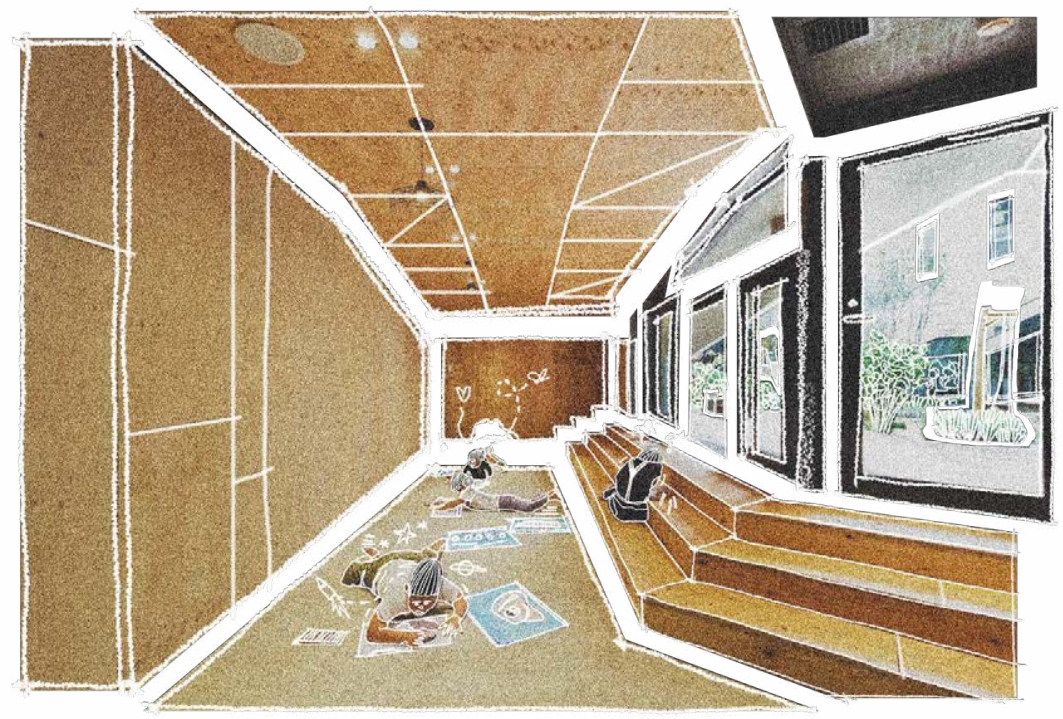

Fig. 5 KM Kindergarten and Nursery

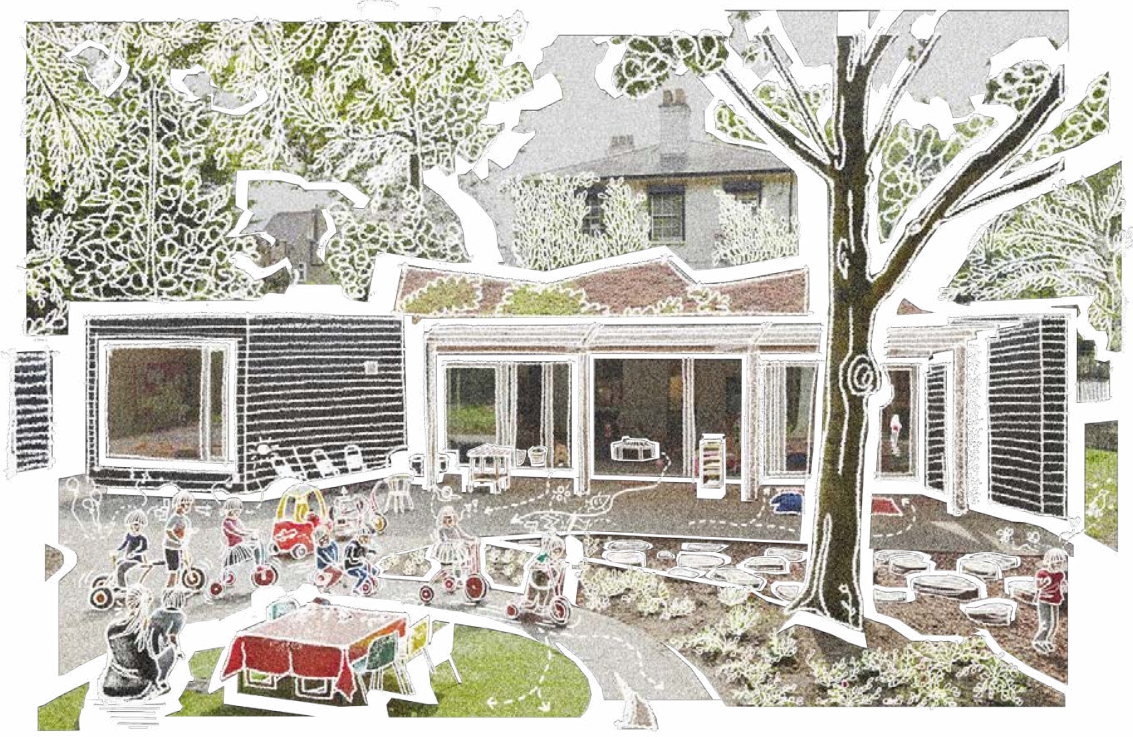

Fig. 6 Montpelier Community Nursery 


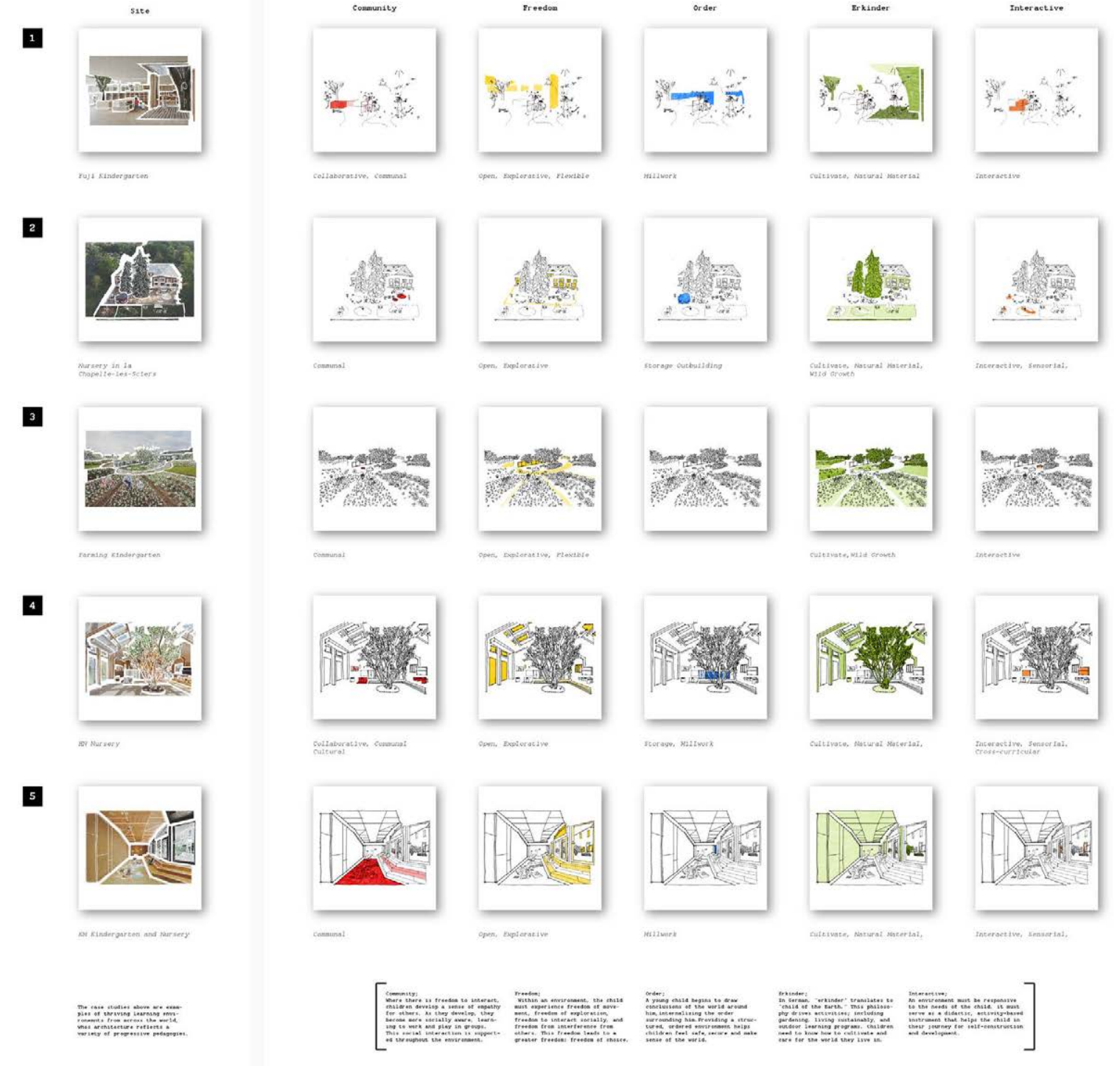

Fig. 7 Comparative Index 


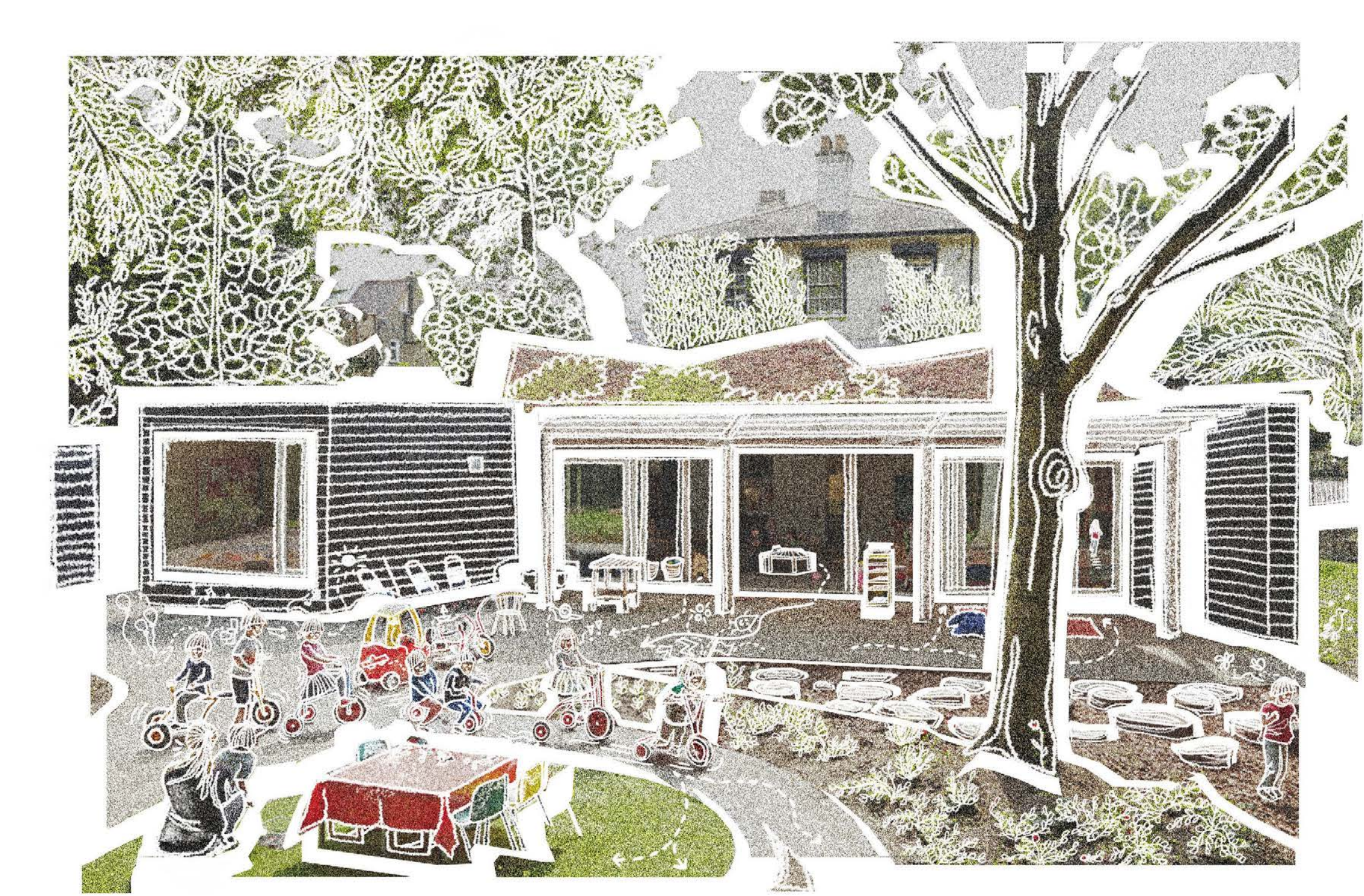

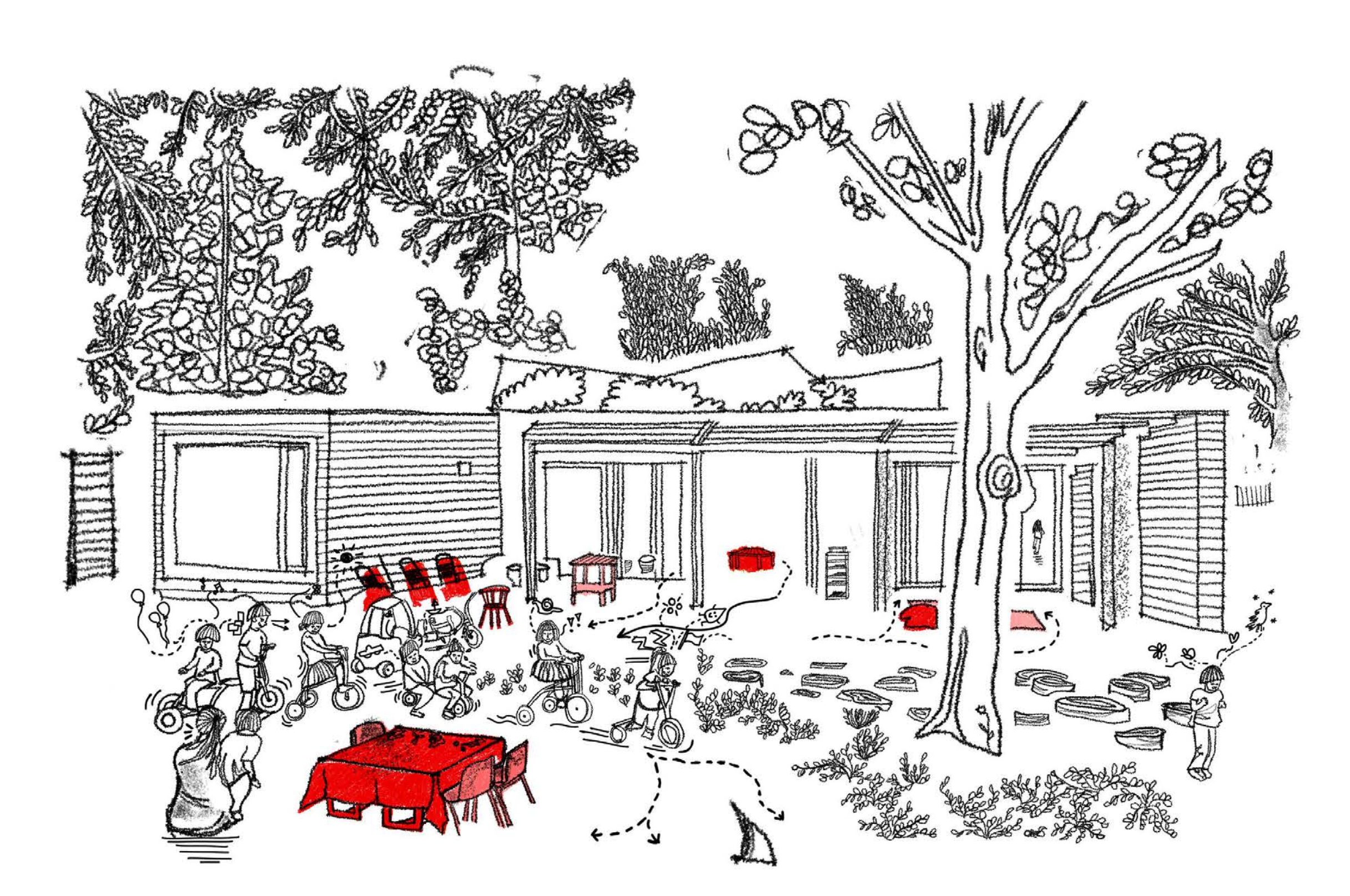

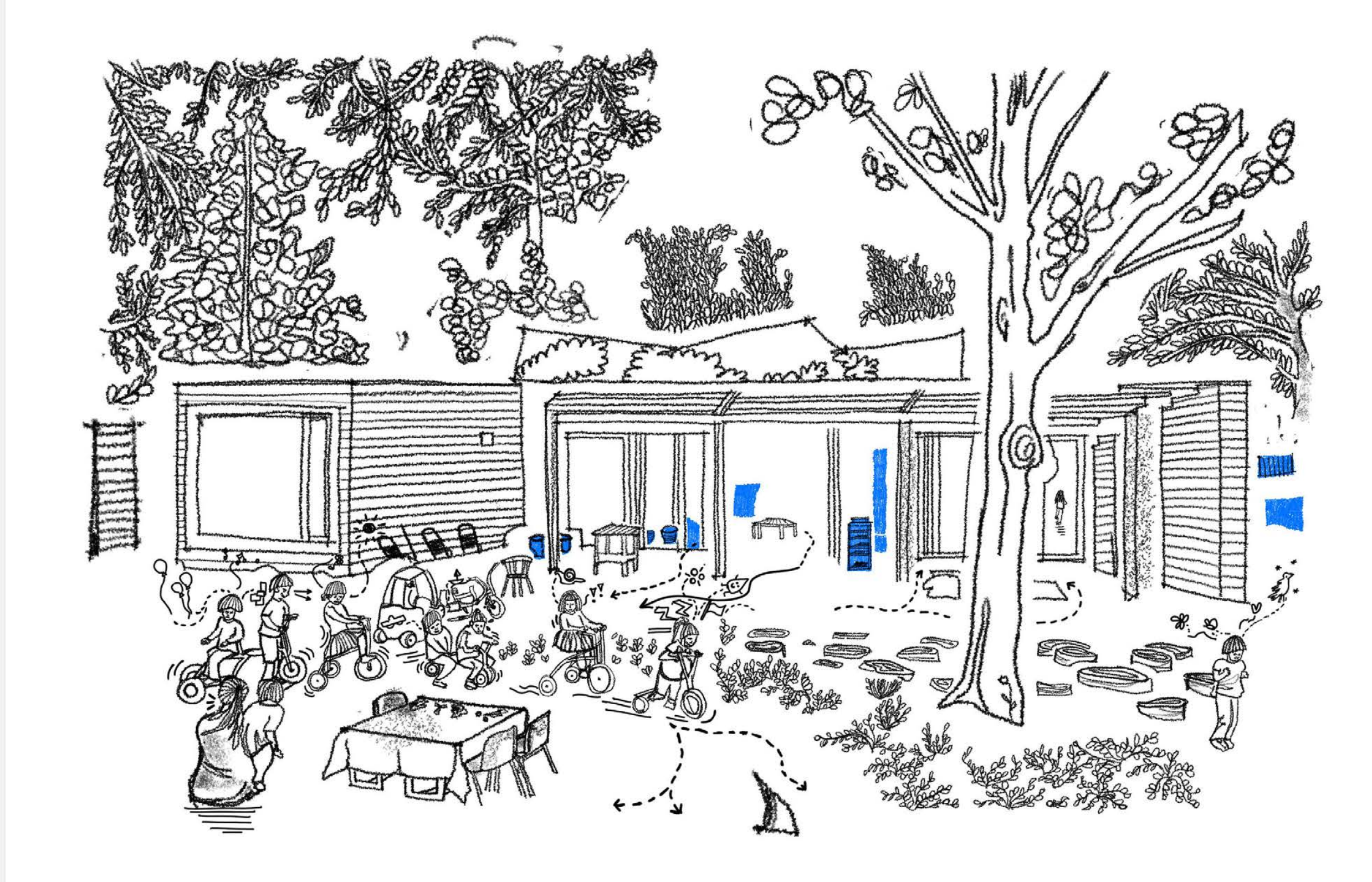

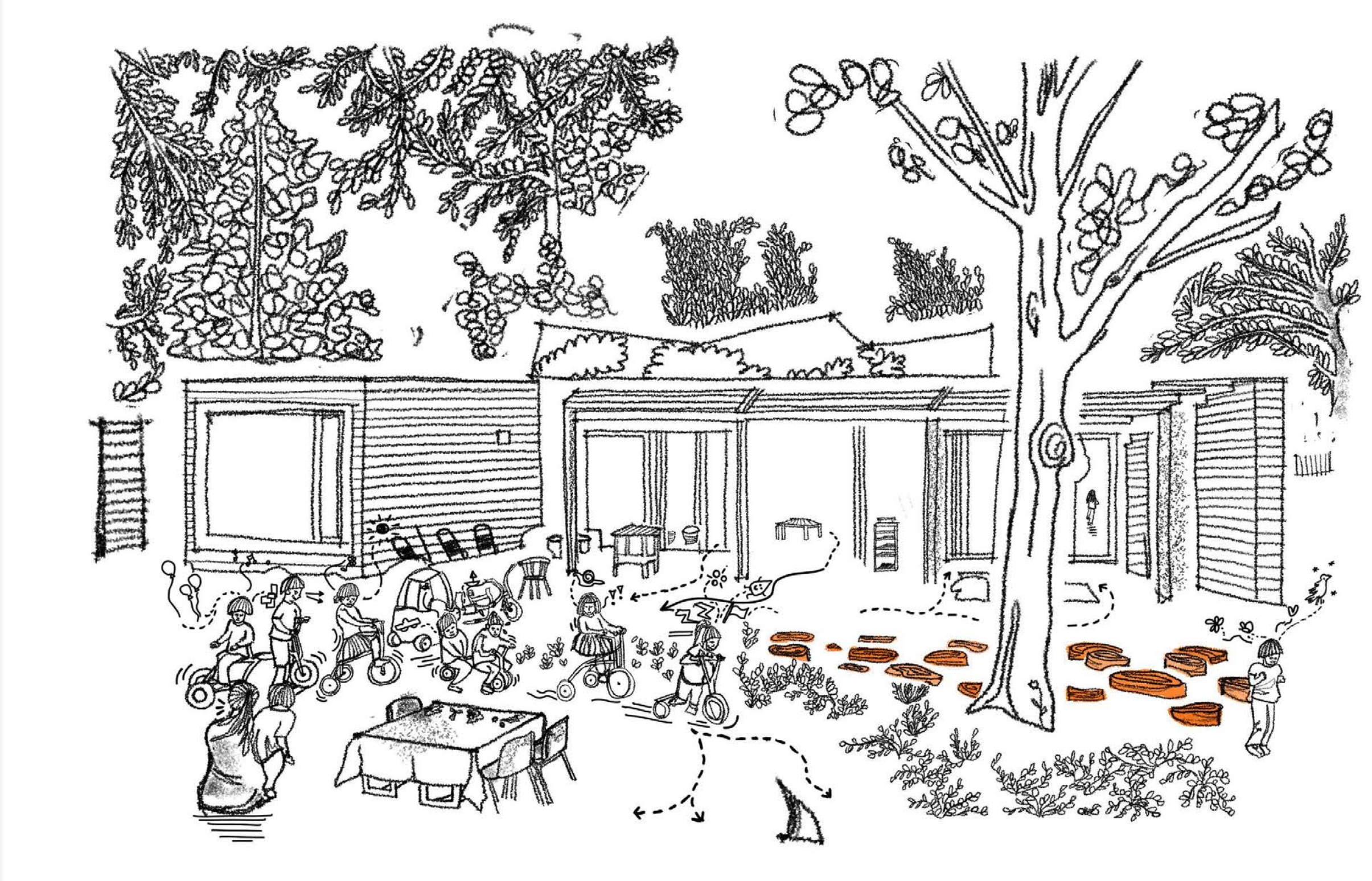




\section{0 _ Learning Spaces}

The Problem with the Classroom

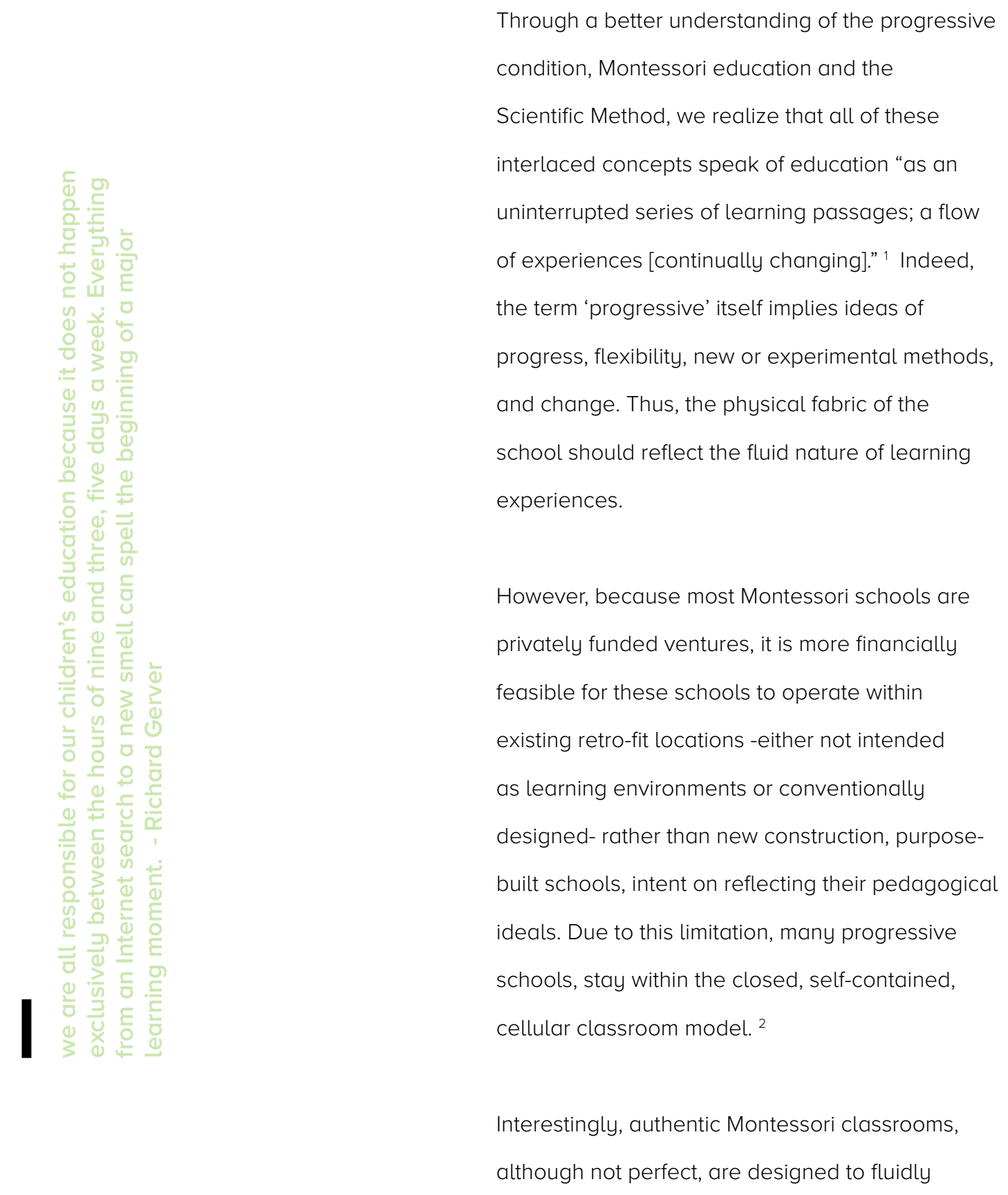


entwine the diverse learning experiences happening within. The key is viewing the classroom as "more than a collection of [materials] found within a space. It is a complex system of relationships between the physical structure of the room, the arrangement and distribution of spaces, and the individuals who share [it]." ${ }^{3}$ As mentioned in the 'Montessori Method' chapter, when preparing a Montessori classroom, the school orders the spaces into distinct learning areas, categorized by subject, see Fig. 9. However, although the areas are spatially defined, they remain interrelated. The transitions between them, are seen as fluid, transformable learning spaces, which children can adapt to their current needs and activities.

In this state, classrooms become the place where the majority of learning occurs, absorbing the function of many specialized learning spaces. Although children benefit from the spatial and learning diversity and freedom designed into each classroom, it is very common for this fluid design strategy to stay within its four walls. The result is a detachment of the classroom from the rest of the learning spaces in the school, more isolated experiences and the perpetuation of the classroom-centric design approach. 

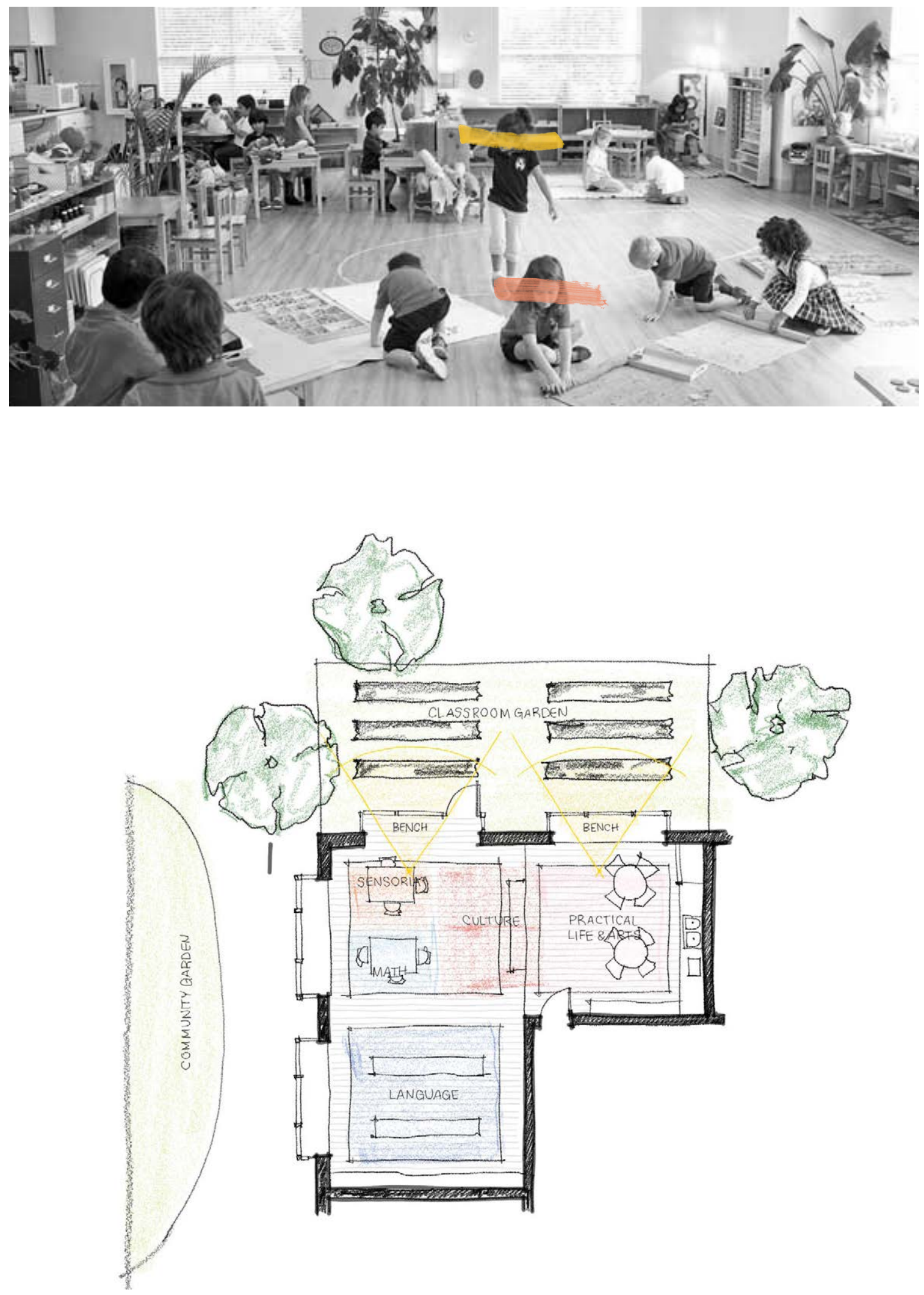
In terms of the scientific form, the classroom

could become a place that not only generates

its own learning experiences, but whose reach

into the greater learning environment (school

and community) allows children to return to the

classroom and draw from their experiences

abroad while testing, analyzing, reflecting and

sharing their discoveries with the rest of the class.

In this respect the classroom, school and greater

community are a micro - mezo - macro structure of

the scientific form (Fig. 10), all holding opportunities

for exploration, discovery, testing of ideas and

community feedback. Each can be considered

meeting places of experiences and the centers of

learning at progressively larger scales.

In the same way, the classroom - school dynamic parallels that of the house in the village, in that

all knowledge cannot be found solely within

the parameters of the house. Thus, the children

should be provided with opportunities for spatial

independence, learning not only in their home, but

the streets and the grocery store.
"A school of the future is not [solely] a building, it cannot start with a structural blueprint that, once built and inhabited, will define what happens within the space.

It is about creating flexible, almost liquid environments that can change and develop as quickly as the world around them. "

- Ginni Sackett

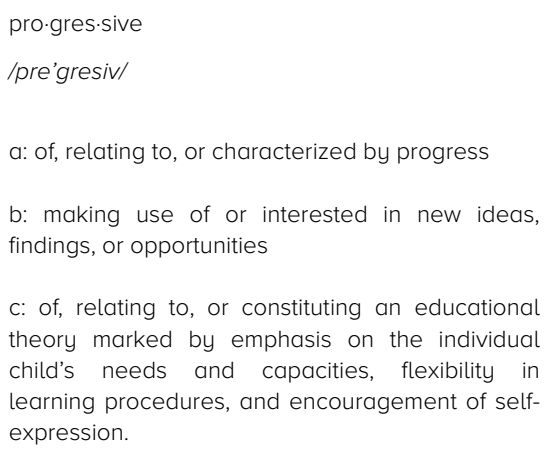
theory marked by emphasis on the individual child's needs and capacities, flexibility in learning procedures, and encouragement of selfexpression. 


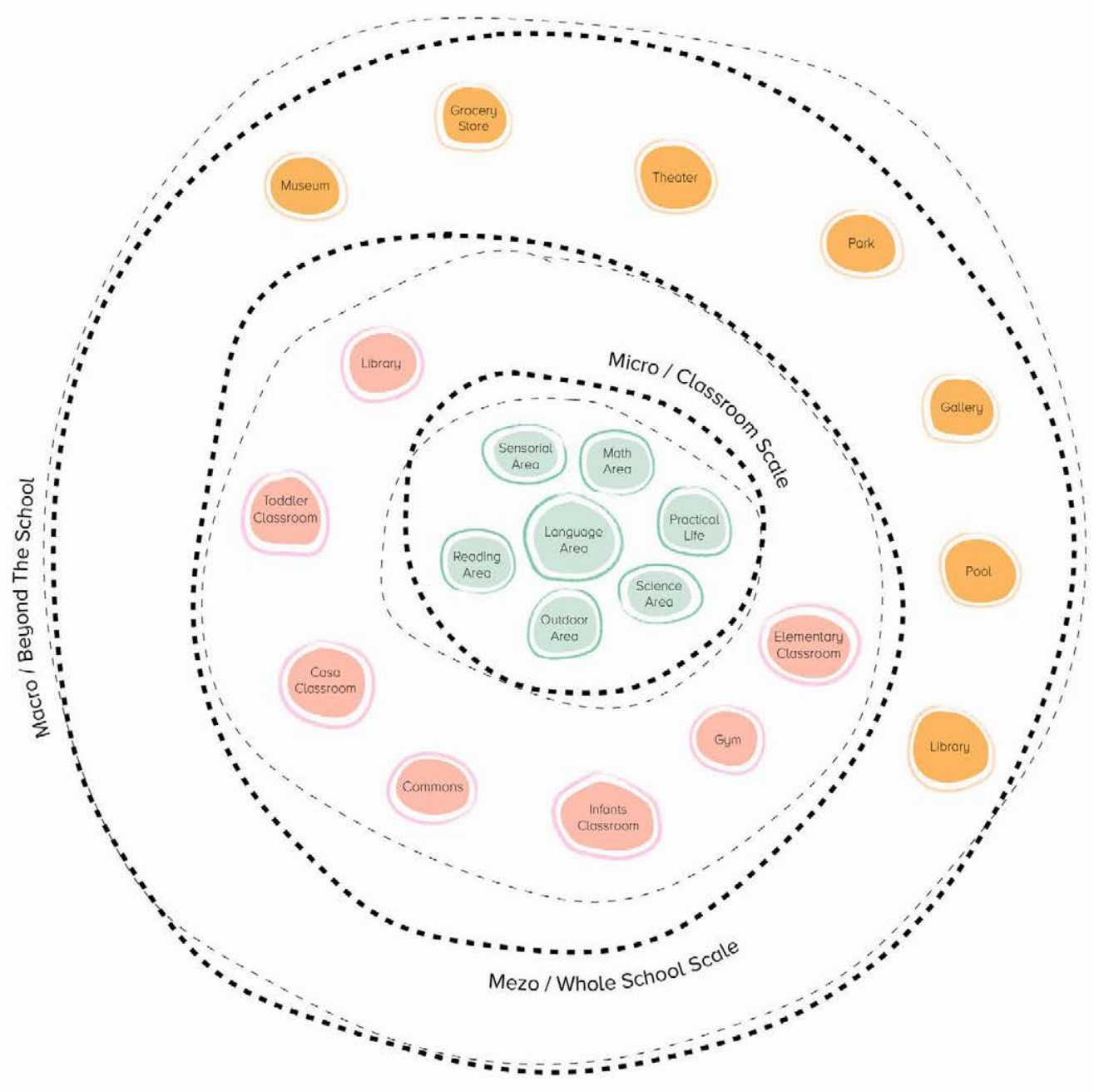

Scalar Mapping

of learning environments 



\title{
2.1 _ Participatory Design
}

\section{A Progressive Approach to Design}

\begin{abstract}
A participatory approach to design is a key principle within the progressive condition that allows the voices of children to be heard within the planning process. Thus, the following study examines the child's potential as an active participants in the architectural process of designing learning spaces. This aims to provide a framework through which we can come to better understand and interpret "children's knowledge, values, experiences, and use of place." 5
\end{abstract}

Progressive pedagogies such as Reggio Emilia and the Montessori Method, speak of an integrated approach to design where learning is seen as a collaborative process between adults and children, all searching for meaning together and co-creating their learning environments. ${ }^{6}$ “In her seminal research on children's cognitive development, Dr. Montessori acknowledged both the need to develop new ways for adults to work with children in educational settings and the importance of the environment on children's learning." 7 Additionally, the two-year ethnographic study conducted by Roger Hart, which discusses children's experience of place, 
analyzed children's feelings, knowledge, use and value of the environments most prominent in their lives. The study revealed that children's preferences for certain spaces relied heavily on the unique traces and landmarks they or others left on that place. "These personal details...of the children's own lives and work appeared to have great significance in developing place [and self] identity; [a landmark and history of who they are in that space]." 8 The 'Mosaic Approach', a methodological framework designed by Allison Clark and Peter Moss, also plays a valuable role within our study and will be examined further in the chapter, as this framework served as the primary guide for the fieldwork process.

In terms of child development and children's rights, a participatory approach is an important condition of the progressive design process. Since the ratification of Article 12 of the United Nations, 'Convention on the Rights of the Child', children's participation in the democratic process has been a core principle. ${ }^{9}$ The article states that all children, capable of forming their own views, have the right to freely express their opinions in all matters affecting their interests. Thus, the design of all environments in which a child lives must provide them with the opportunity to be heard. Implementing children's rights into the design process not only helps them discern their own needs, but it leads to more appropriate and useful learning spaces that children have defined for themselves. This approach also has a direct effect on a child's sense of empowerment and self-esteem. ${ }^{10}$ Through participatory activities in the design process, children "develop a sense of meaningful involvement and responsibility in society," learning that it is the people within a community, like themselves, who make decisions and are in control of their environment, and that the decisions they make affect the quality of the environment and people's lives. ${ }^{11}$

However, it is important to understand exactly what the term 'participation' entails because frequently the process is misguided and the approach is not reflective of the pedagogical values described. It is not enough for children to simply take part or be present. According to the Mosaic Approach, in order for the design process to benefit the child - and qualify as a participatory approach - the child must be involved from the earliest phase of the planning initiative, "as well as understand what the project or process is about, what it is for and their role within it." 12 Moreover when designing with children, it is very important to conclude the process by sharing the outcomes of the decisions made between the adult and 
the child, indicating where or how their input was used. In these ways, the values integrated within the research and progressive pedagogies mentioned above have strongly influenced the process, methodology, and framework of the fieldwork conducted.

In developing the methodologies for the study, the Mosaic Approach was consulted as the authors explored different methods for children to be active, competent participants in the design process, surveying and recording their views and experiences of place and architecture. ${ }^{13}$ The 'mosaic pieces' within the approach include child observation, child conferencing, tours of the school directed and recorded by the children, mapping and informal interviews with staff and parents, in order to build a more detailed understanding of children's experience. ${ }^{14}$ These methods asked the children to consider important things or places to them and what they enjoy or dislike doing.

Similarly to Hart, Clark and Moss, the Vega Workshop focused on engaging children's strengths rather than weaknesses, such as children's local knowledge, attention to detail, and their visual skills. ${ }^{15}$ This meant that the formal interview methods would only be directed towards the school staff, and the connection to children would be established through more informal verbal and non-verbal means of communication. The workshop, intended to build on similar studies done in the past, allowed for more flexibility within the activities, taking into account the unique context of Canadian culture and each child's individual particularities. The first part of the Vega Workshop, held at Kaban Montessori School, Clanmore Montessori School, Hillfield Strathallan Montessori School, and Montessori Jewish Day School, consisted of child-led tours, in order for children to be able to show and accurately describe why they enjoy or dislike the places they chose. Once at their location, the children were provided with a camera and asked to take a picture of what was important to them in this place. This was a crucial aspect of the Vega Workshop - giving the child full control of the tool and expedition.

The second part of the Vega Workshop included a mapping and drawing exercise where children were asked to draw similar questions already answered in the child-led tour, however now they were given indirect, as well as direct opportunities to express their positive and negative feelings regarding their learning spaces. 
Inspired by the Mosaic approach, the Vega Workshop acknowledged that children have different abilities and interests. Thus, it was important to include a range of methods from which all children would be able to express their views on their environment and take part in the exercises. ${ }^{16}$ Likewise, the variety of exercises allowed for the data to be compared and contrasted across the different methodologies.

The hope for the Vega Workshop was that its insights would allow for themes and patterns to emerge, revealing the child's view on learning spaces and providing the fieldwork and designer a new child-centric dimension through which to understand what constitutes a 'place'.

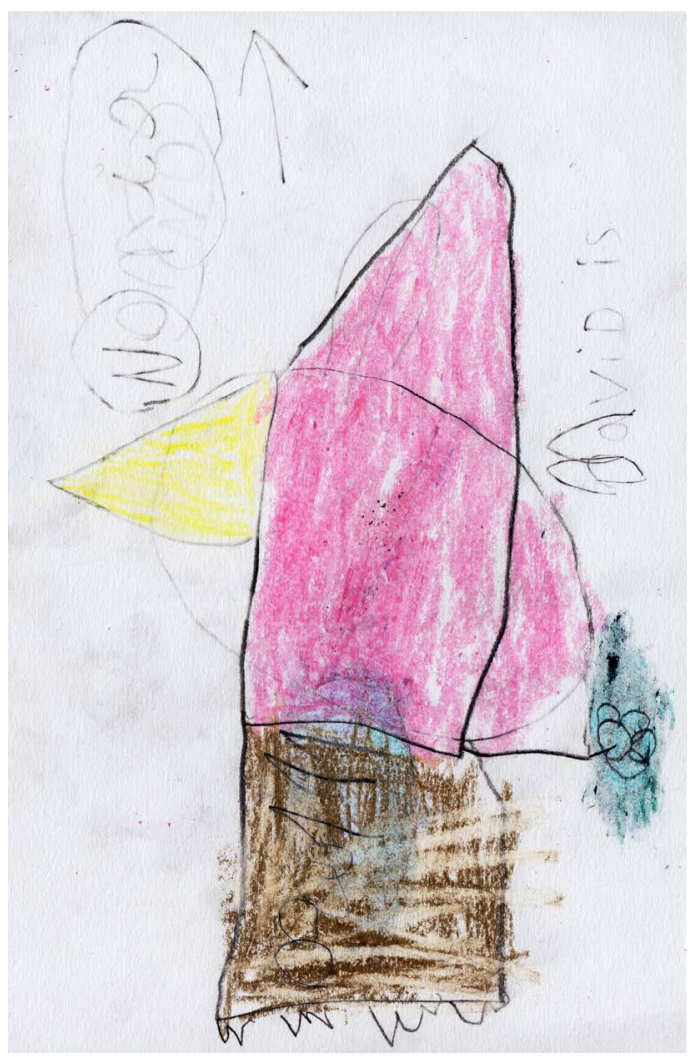

Fig. 11

Children's drawing from Catalogue 02

Note* refer to Appendices for the detailed breakdown of the workshop script and activities and the entire collection of data. 
After the data was collected the fieldnotes,

interviews, photographs, and drawings were

analyzed and organized into the catalogues that

follow. (pg. 42-43)

Fig 12-13, maps the location of each of the spaces visited on the child-led tour. The original plans of each school were used as the base plan, a yellow colour overlay indicating the child's favourite spaces. In contrast, the pink colour overlay indicates the child's least favourite space (in the order selected by the children). Below the plans, the photographs taken by the children throughout the child-led tour correspond to the highlighted locations above. From these photographs, key images have been selected in order to further analyze important findings from the tours. 
Catalogue 01

Child Led Tour Favourte Places

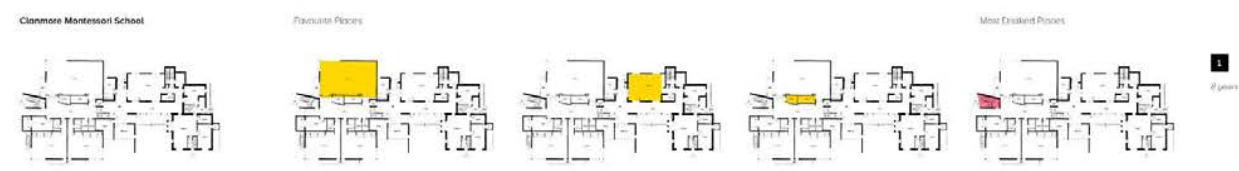

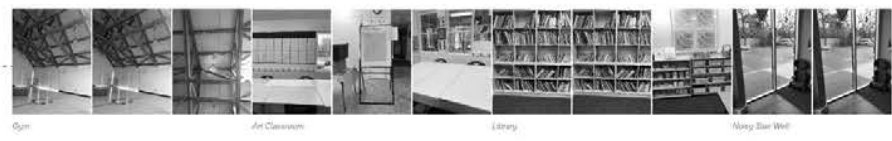

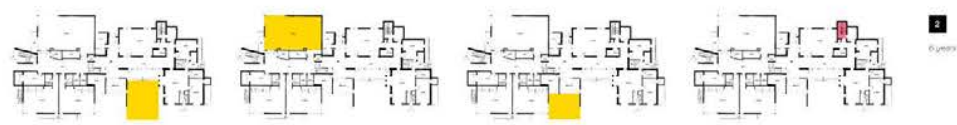

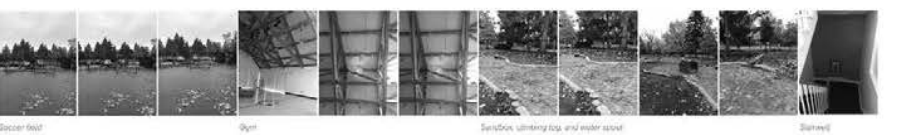

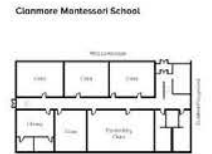
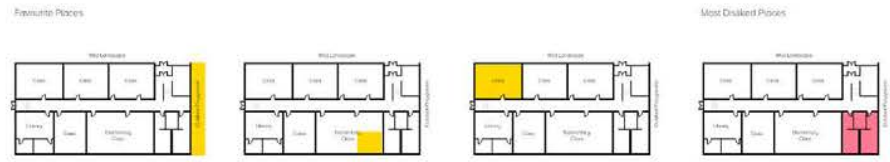

1
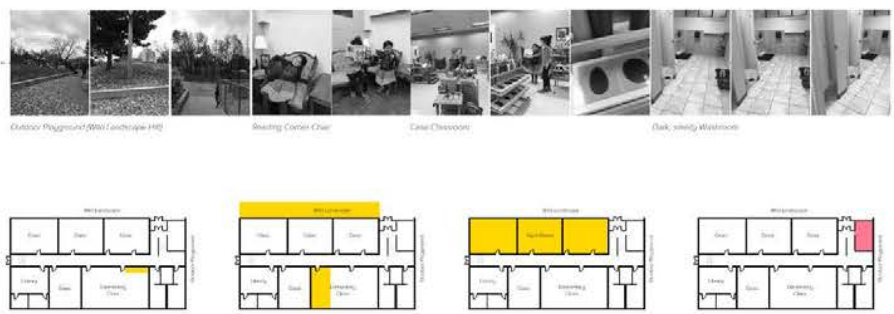

a

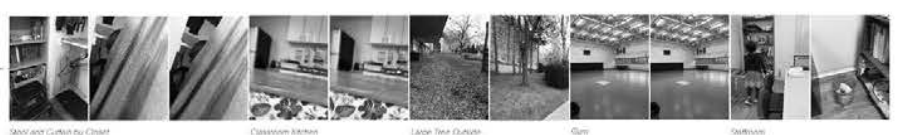

Fig. 12 Catalogue 01 - Child-led Tour /1 


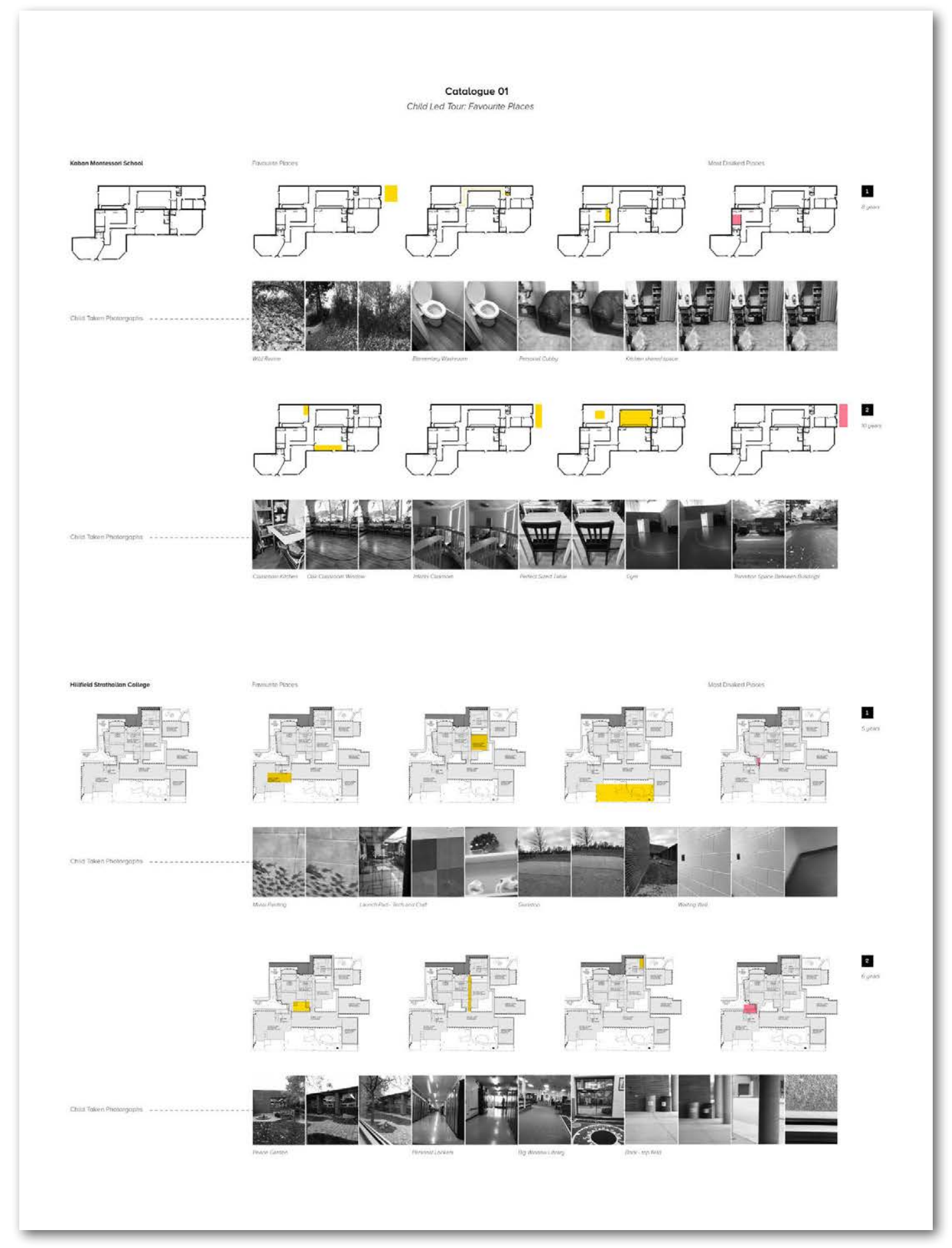

Fig. 13 Catalogue 01 - Child-led Tour /2 


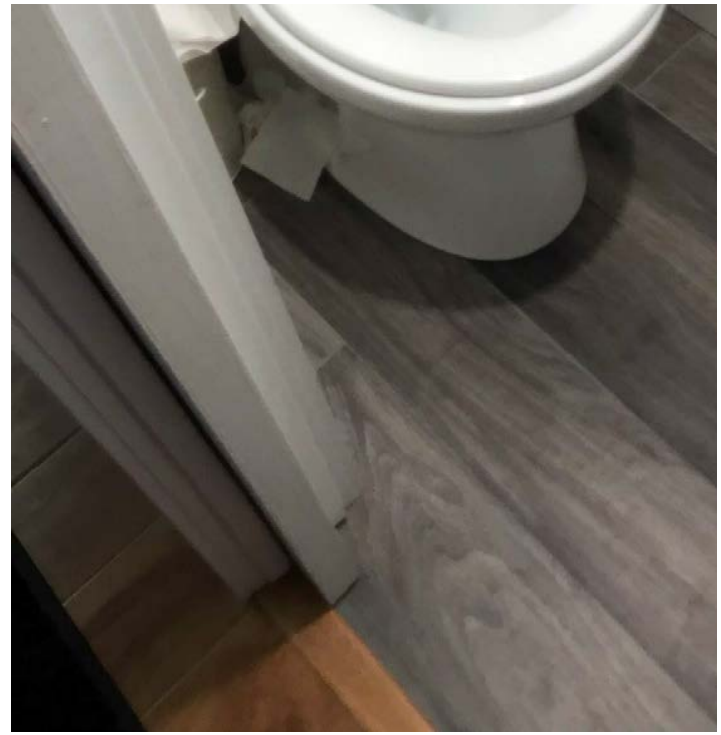

Fig. 14

Elementary Washroom - Child-led Tour

Fig. 14, marks an eight year-old's second favourite place in the school, the elementary washroom.

On further questioning, the child revealed that the washroom was his favourite because he was allowed to travel to the bathroom (located in the opposite end of the building) without any adult supervision. The classroom has a washroom pass system in place that gives the children the freedom to leave the classroom without asking for permission from the teacher. This freedom and independence was what the child enjoyed the most. Thus, the design of more learning spaces that allow for this quality of freedom and independence throughout progressive schools would not only meet the child's needs but provide more architectural responses to the principle of freedom valued within the progressive pedagogy. 


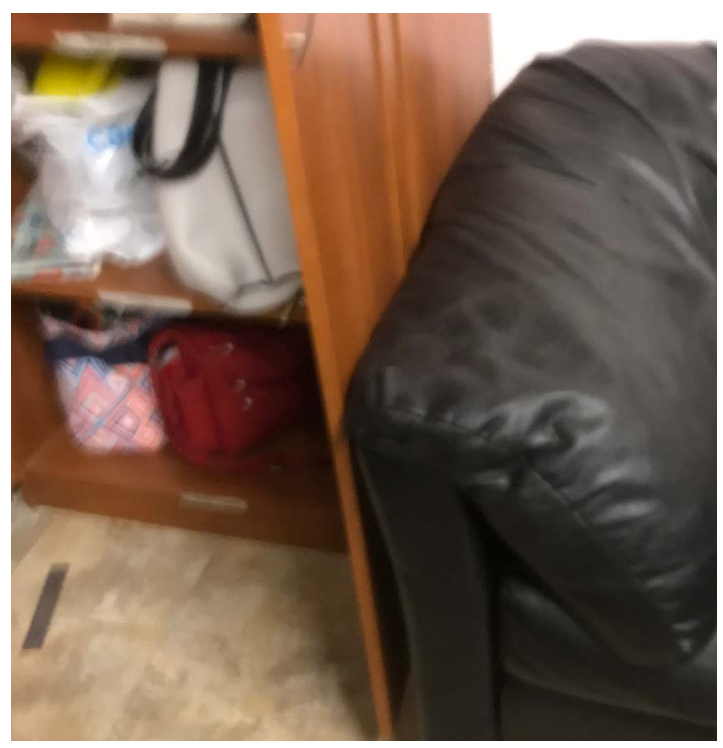

Fig. 15

Temporary Cubby - Child-led Tour

Fig. 15, shows an 8-year-old's third favourite space as their personal cubby shelf in the staff room (due to a limited number of cubbies outside the children's classroom). The child revealed that this space was special to him because it was his own. As Helen Clark reminds us in her comprehensive survey of learning spaces, the importance of ownership should not be underestimated. Children develop self-identity through these spaces, "connecting their well being to their aspirations of space." ${ }^{17}$ Furthermore, the child admitted that he liked his cubby over the other children's because it was in a place he shared with the teachers. This key piece of information aligns with Allison Clark's observations that children express negative feelings towards places with different hierarchies between adults and children. ${ }^{18}$ 


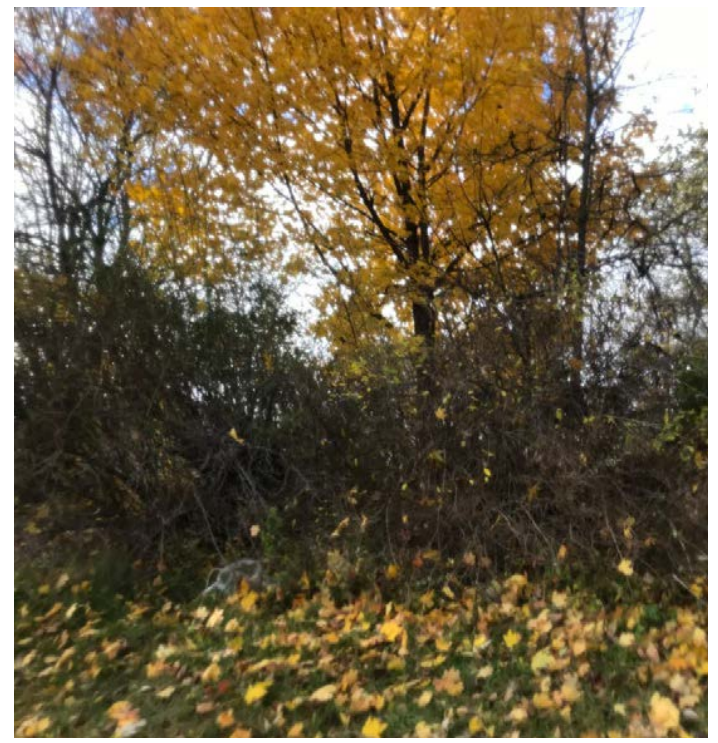

Fig. 16

Wild Ravine - Child-led Tour

Fig. 16 and 17, shows a ten and five year-old's favourite place as the 'wild' ravine between the school and the residential neighborhood. When brought there by the teachers, children are allowed to build forts and play inside the canopies of the small trees. Most children talked about how much they loved this place and told stories about how the unkempt nature of the space was perfect for their games and "building stuff". Interestingly,

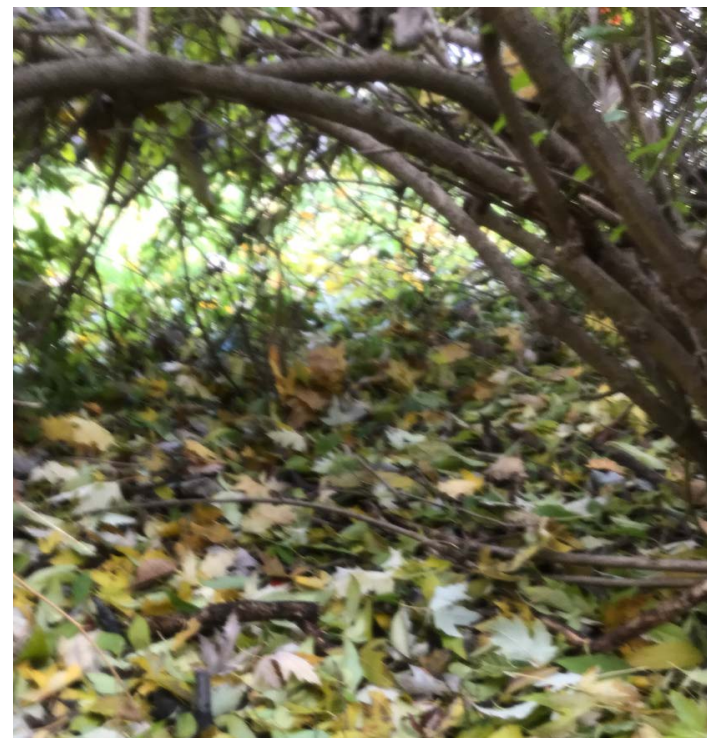

Fig. 17

Wild Ravine - Child-led Tour

it was much harder for the children to convey why they loved the 'wild place' so much. Instead, they resorted to energetic movements to describe the space, as well as guiding the researcher and teacher through it. The children's movements (Fig. 18), however, evoked a sense of freedom and imagination. 


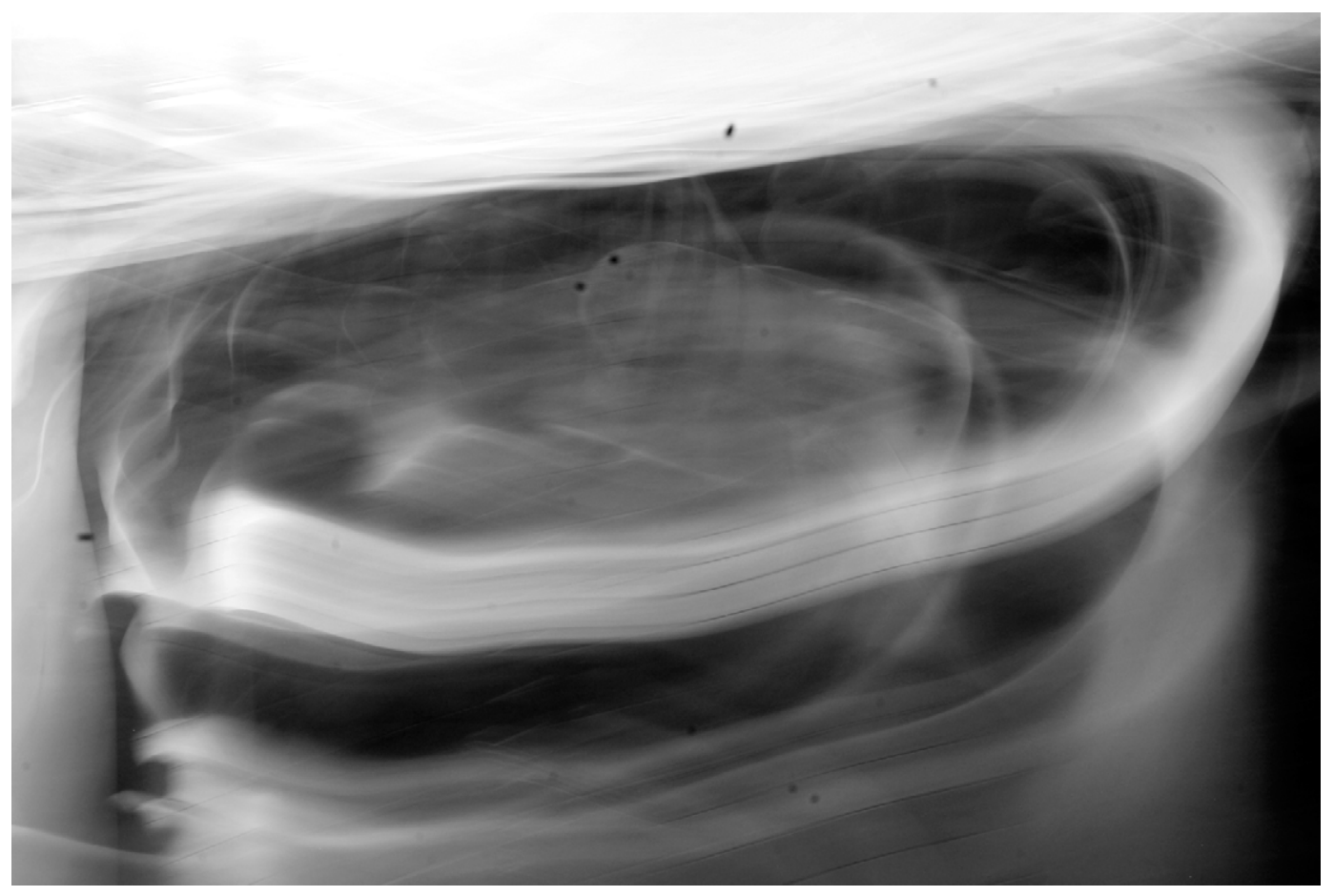

Fig. 18 Imaginative Movements /Conceptual Photograph 


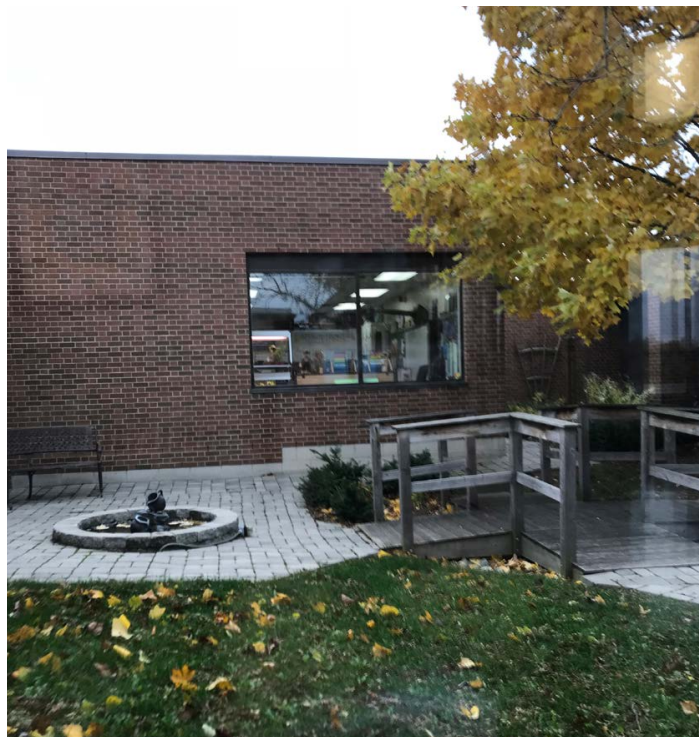

Fig. 19

Peace Garden - Child-led Tou

Fig. 19, shows a 'peace garden' located in an interior courtyard of the school. This space was among the most popular places in the school, and was chosen as a five year-old's favourite space. The child revealed how much they loved the 'fountain' and 'different stones you could sit on to listen to the birds', saying that they'd like to come here more often and bring their puzzles or the yoga corner here instead. The same child chose

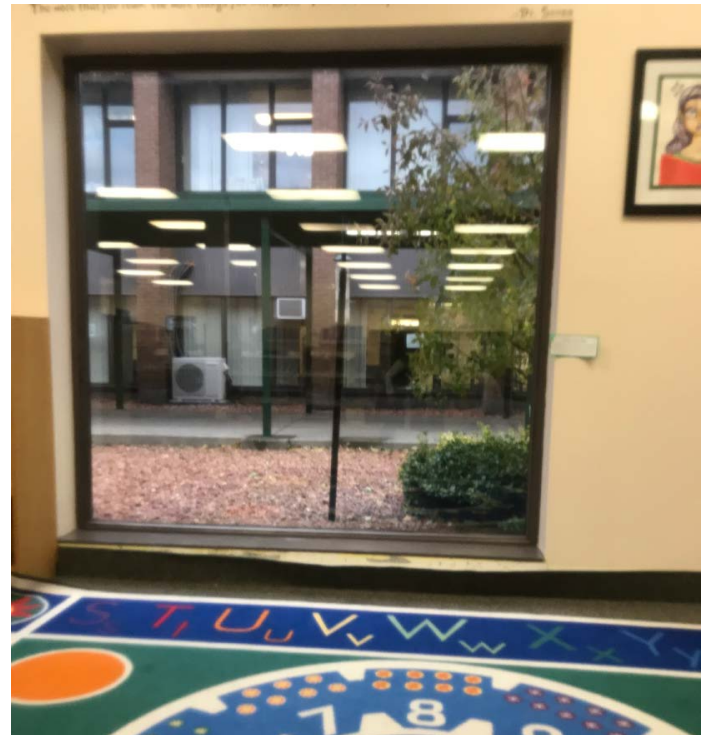

Fig. 20

Library Window - Child-led Tour

the big window in the library (Fig. 20) as their third favourite space in the school, again recalling how much they enjoy reading on the window sill and watching the birds and clouds out the window. 


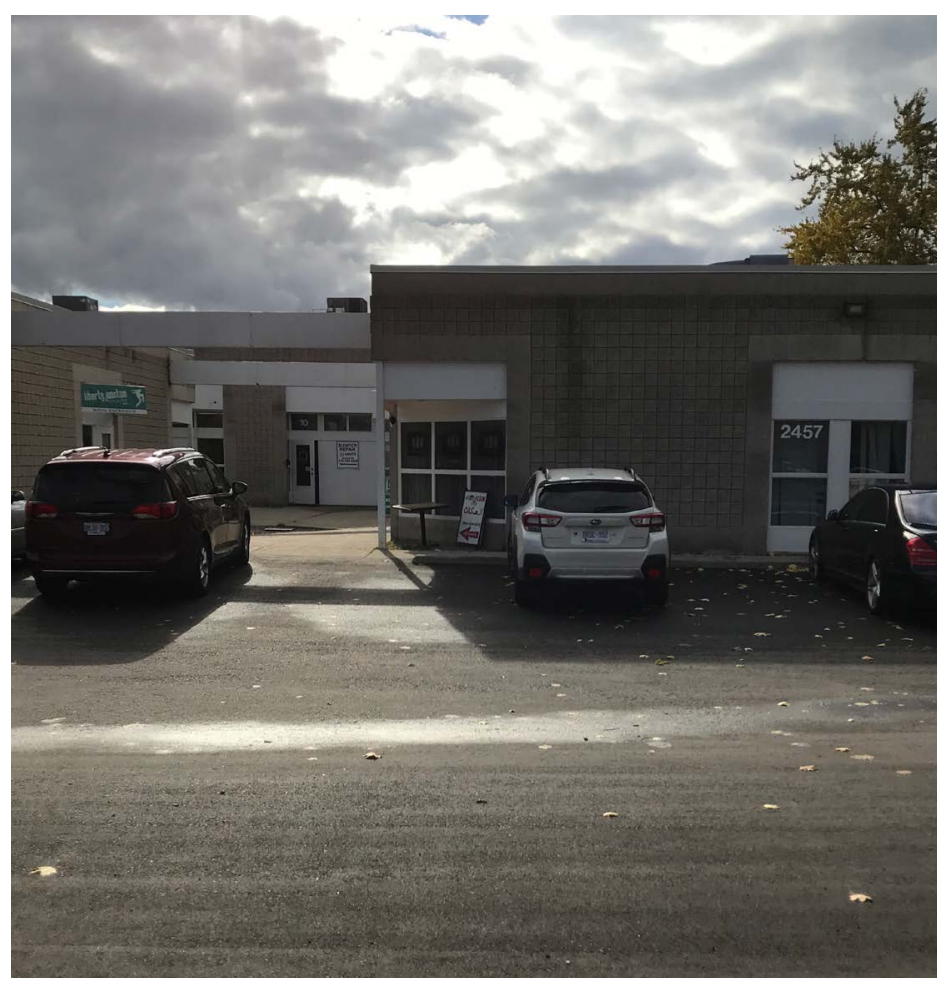

Fig. 21

Transition space between buildings - Child-led Tour

Fig. 21, shows the transition space between the 'toddler' building and 'casa' building at Kaban Montessori school. This space was a ten yearold's least favourite place. According to the child the courtyard and transition areas between the buildings are 'boring' and 'all grey', requesting that they should be more like their 'flower garden' ( $a$ term the children use to describe the wild ravine that is full of dandelions in the springtime). 


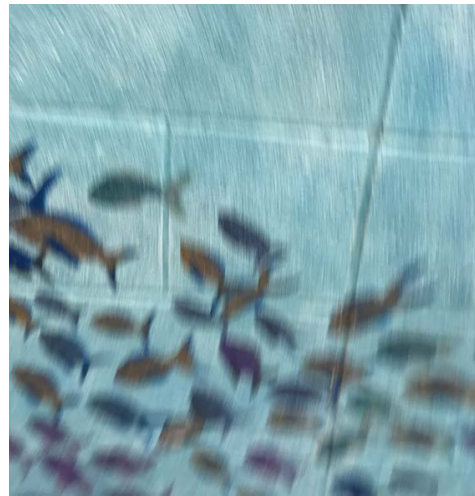

Fig. 22

Wall Mural - Child-led Tour

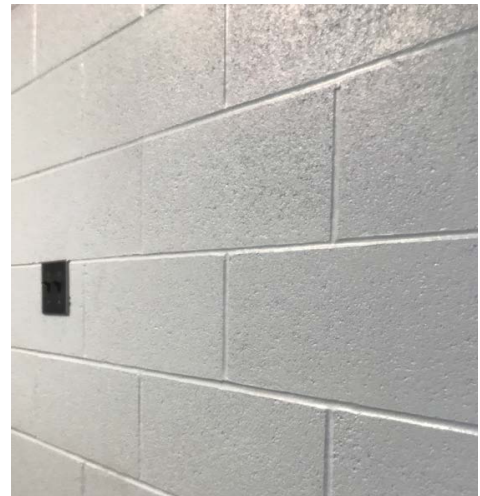

Fig. 23

Waiting Wall - Child-led Tour

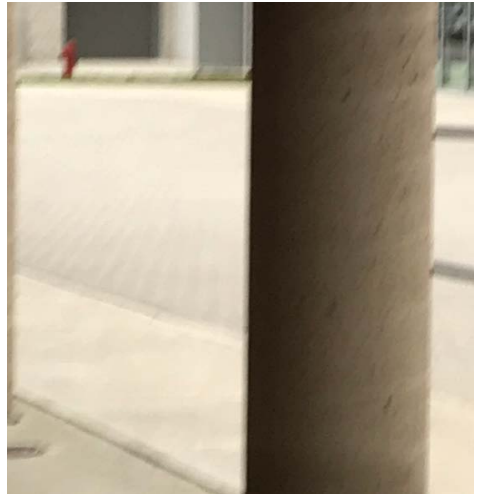

Fig. 24

Bricktop - Child-led Tour
Fig. 22, shows a five year-old's favourite wall in the school. The wall paints an underwater mural the child described as 'beautiful' and 'peaceful'; a place she said she stands by when she's feeling tired. The same child chose the 'waiting wall' (Fig. 23) as her least favourite place in the school. The waiting wall, located in a small hallway, was entirely whitewashed and looked out at a six year-old's least favourite place 'the bricktop' (Fig. 24). Both children described this area of the school as 'sooooooo boring' while covering both their eyes and wished there were things on the walls they could play with while they wait. The bricktop, where the children play when the field is wet, is located between the back of two buildings. The children's comments and photographs of this space focused on the invariable quality of the concrete and white brick material. Through comparing various children's least favourite spaces and photographs, the emerging pattern seemed to be an aversion to spaces with little interaction and sensory stimuli. However, many of the spaces with large amounts of visual and auditory stimuli, such as certain murals and stairwells were not among the children's favourites either, especially the youngest. The youngest children seemed to prefer more tranquil spaces, such as the peace garden, with soft rhythmic or recognizable changes in stimuli, a pattern also recognized by Weinstein and David. ${ }^{19}$ 


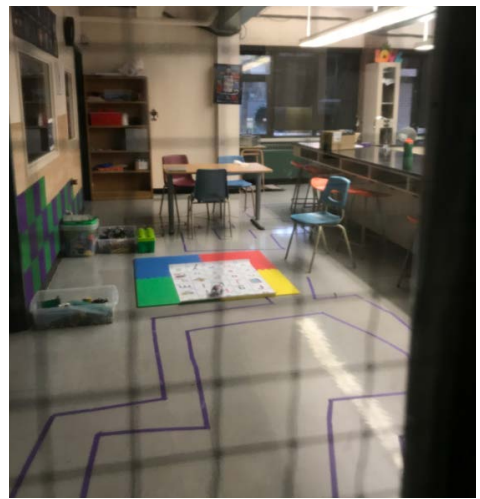

Fig. 25

Launch Pad - Child-led Tour

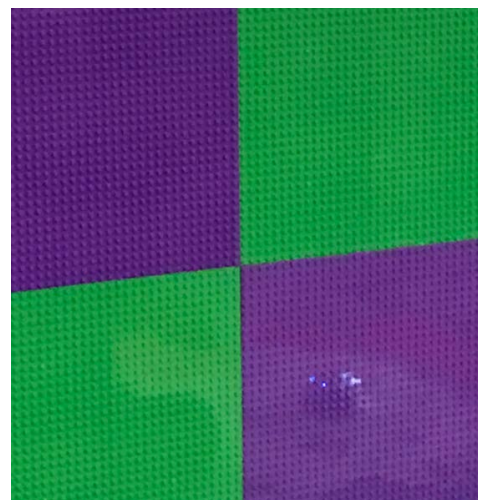

Fig. 26

Launch Pad Wall - Child-led Tour

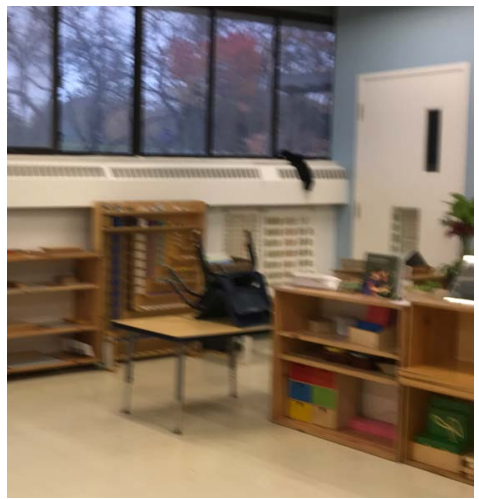

Fig. 27

Connecting Doors - Child-led Tour
Fig. 25, shows a very popular space in the school

- 'The Launch Pad'. This space is a five year-old's second favourite space in the school. Children can make an appointment with the 'Launch Pad' teacher and walk independently to this special classroom where the teacher helps them design, build or research a project of their choosing. The child was very excited to show off the robots they were building with the teacher and the wall they were redesigning with Lego pieces (Fig.26). Apart from the activities that occur in this space, the children were very excited to recount all of the times they have walked to this classroom on their own. Similarly, Fig. 27, depicts a ten yearold's third favourite space as the connecting door between two classrooms, which according to the child 'is great because you can move from room to room if you need to". Again, both of these spatial elements fit well within the pattern that children desire spaces where they can be and move independently. 


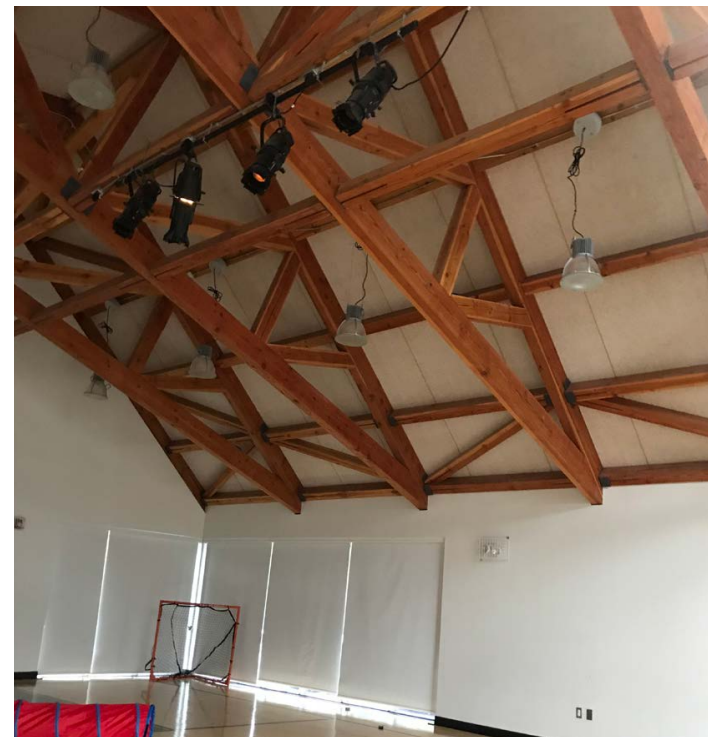

Fig. 28

Gym - Child-led Tour

Fig. 28 and 29, shows an 8-year-old's favourite space as the gym. Interestingly, the child's photos of the gym focused primarily on the roof's wood trusses, which he later drew as one of the biggest elements in his drawing of his favourite space. When asked why he was capturing this element in such detail, he said it was because he liked playing with the shadows they made on the floor and walls. Designing more spaces where shadow

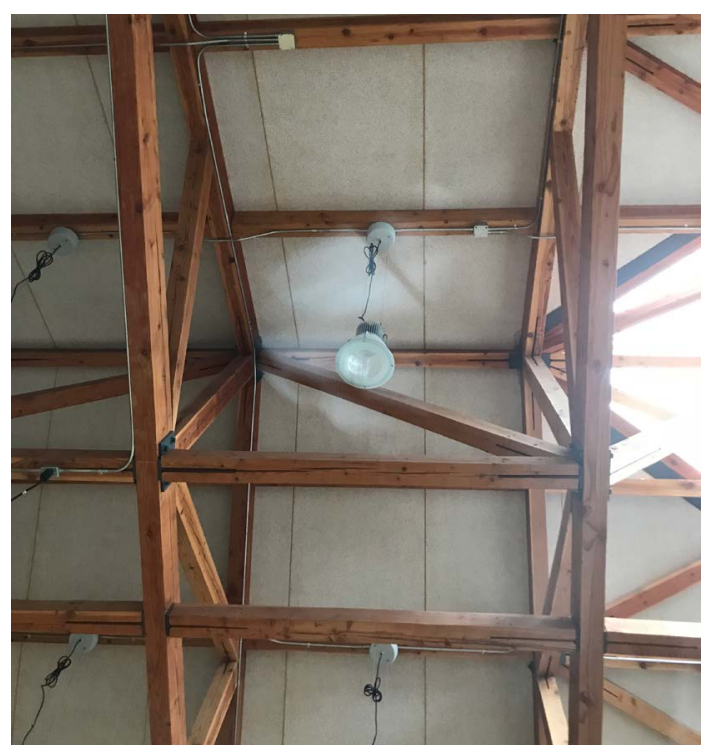

Fig. 29

Gym - Child-led Tour

play acts as an interactive element for young children could be a great way to introduce visual stimuli in a predictable and rhythmic pattern that is not too dramatic or disorienting, but is still dynamic and "occasionally diverse". 20 


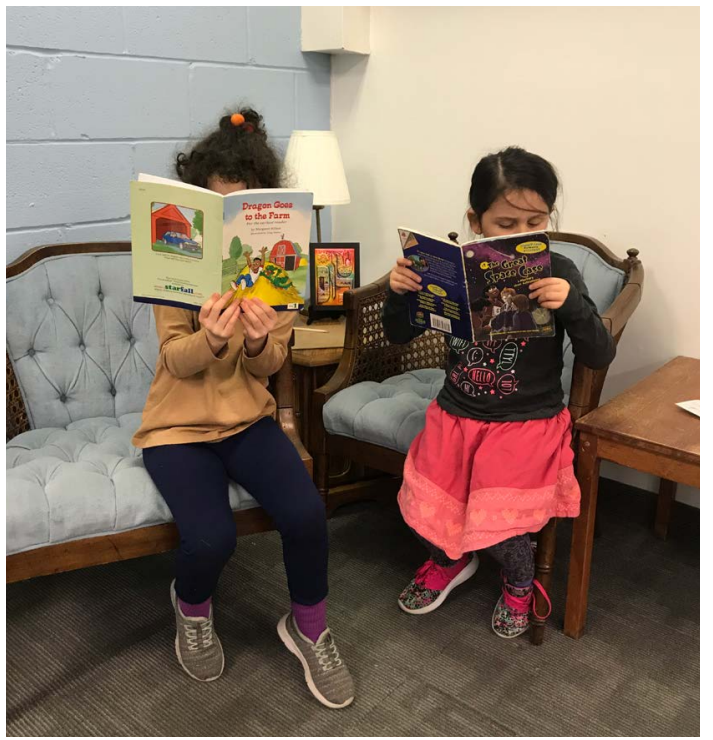

Fig. 30

Reading corner - Child-led Tour

Fig. 30 and 31, shows two children (five and ten years-old) whose second favourite places are unique and individual pieces of furniture. The first is an oversized blue reading chair and the second is a two person table and wood chair set that is, according to the child, 'the perfect size for their legs'. When comparing this pattern to those of the children whose favourite spaces were their personalized cubbies where they kept

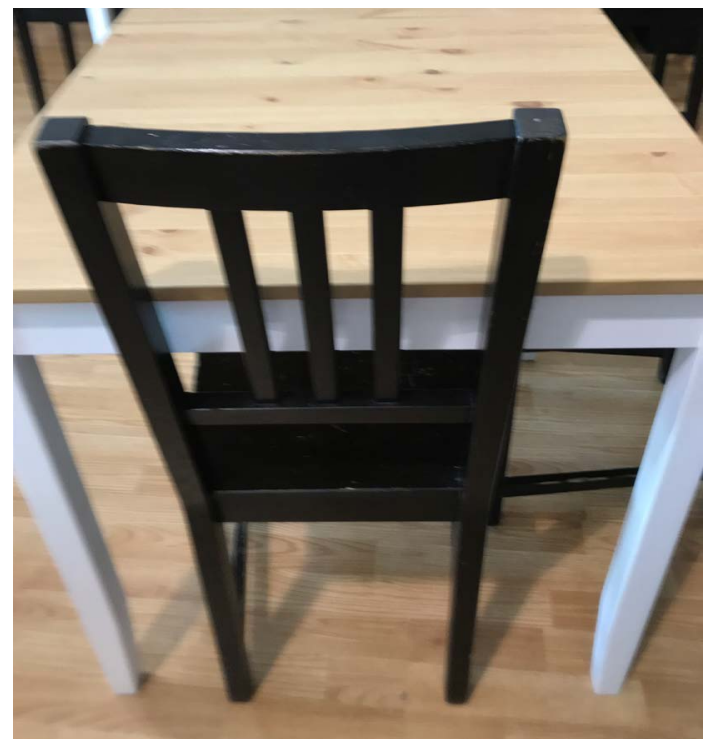

Fig. 31

Child sized table and chair set - Child-led Tour

their own work, the emergent theme continues to be one of ownership and personal connection. Similar to Hart's research, this study found that children seem to need at least one space they can personalize or identify with as a way to create personal landmarks allowing them to feel more comfortable in their environment. ${ }^{21}$ 


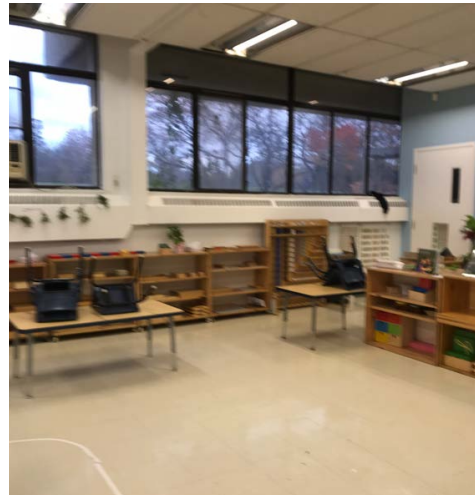

Fig. 32

Sister's Classroom - Child-led Tour

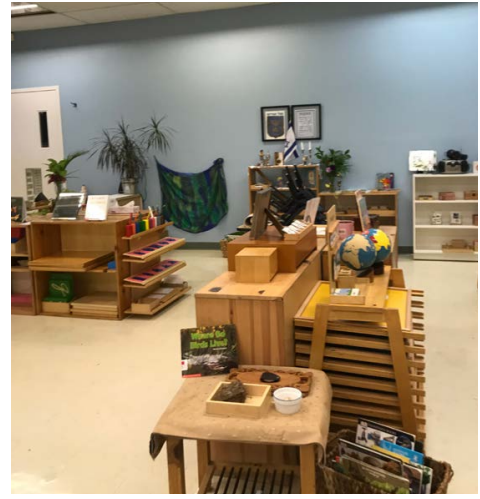

Fig. 33

Not Sister's Classroom - Child-led Tour

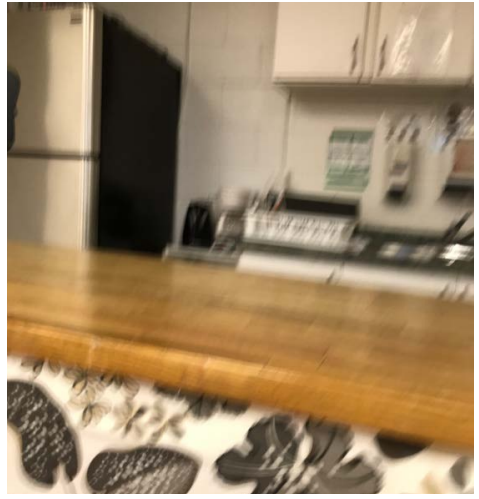

Fig. 34

Classroom Kitchen - Child-led Tour
Fig. 32 and 33, show a five year-old's favourite and least favourite place. The favourite being the sister's classroom and the least favourite the classroom where the sister (and the child) have never had a class. The pattern with some children, especially those with siblings at the school, again seemed to be one of personal connection, the sister's classroom in this case being the personal landmark. Beyond a personal connection, according to Ben Koralek, the role of memory also plays an important part within this design pattern. ${ }^{22}$ Fig. 34 depicts the kitchen in the sister's classroom as one of the child's favourite spaces and activities, as it not only reminds the child of time spent at home baking with their mom, but is an activity that the siblings can engage with together. This memory of space clearly contributes to a personal connection formed between the child, environment, security and identity. 


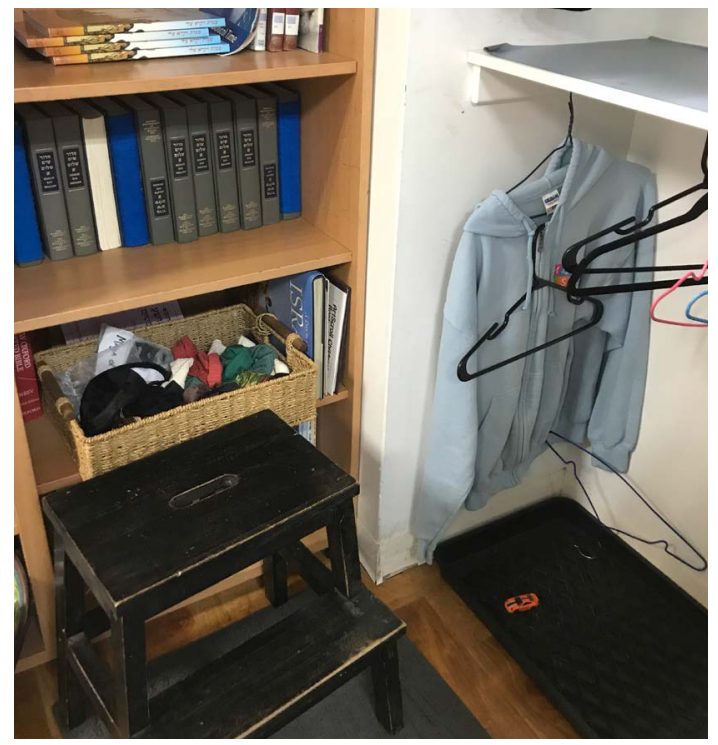

Fig. 35

Private reading stool - Child-led Tour

Fig. 35 and 36, show a six year-old's favourite space in the school as the stool and closet curtain in a corner of the classroom. When asked why these elements were their favourite, the child elaborated that often when reading, they wanted an intimate space quiet enough to be able to concentrate, and so they would take the stool and a good book inside the closet and close the curtain for privacy. This pattern,

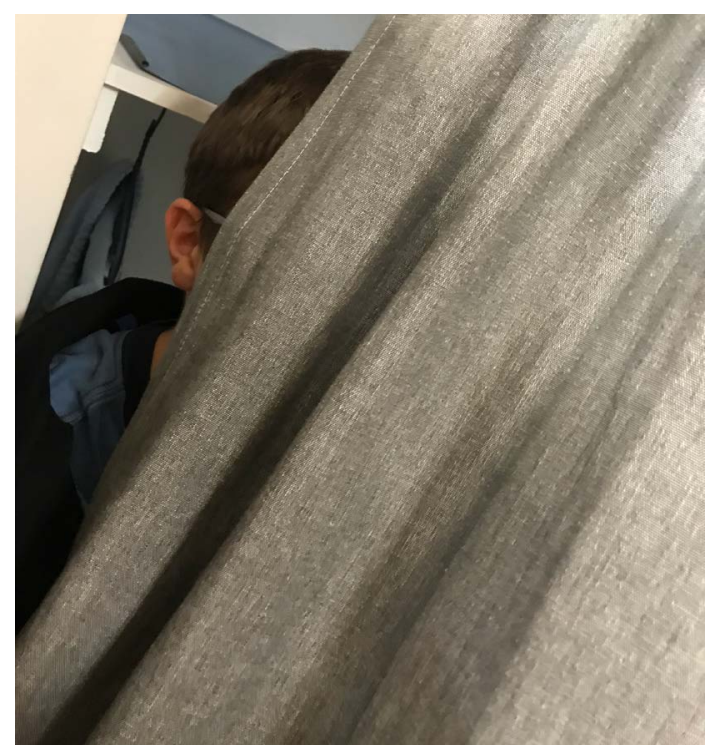

Fig. 36

Privacy curtain - Child-led Tour

although not always as particular as this instance, was apparent in a few other photographs and drawings where the children indicated a need for a variety of intimate and social spaces. 


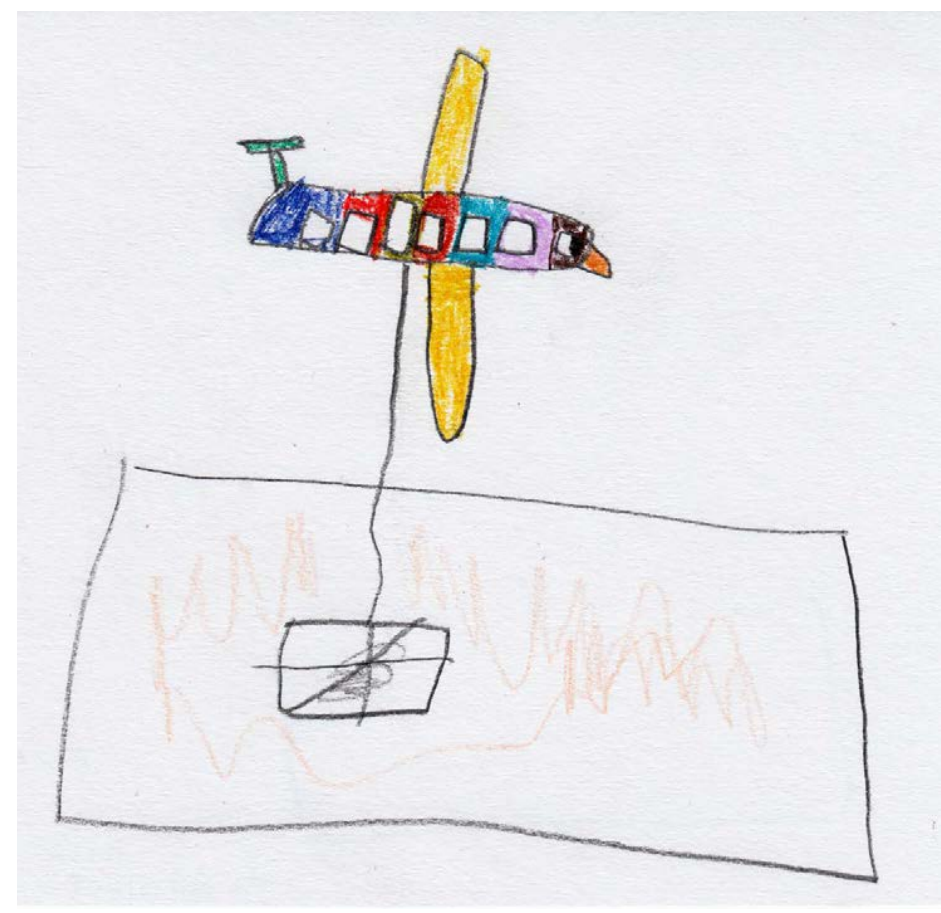

Fig. 37

School from above - Drawing Workshop

\section{The second portion of the Vega Workshop}

included the drawing exercises. Figs. 38 - 41, illustrate the entire collection of children's drawing, catalogued by question. The first question (Fig. 38) asked the children to draw their school from above. This was done in order to help the children begin to think about the spatial elements that make up their school. Interestingly, the plans (and in most cases elevations) comprised of only the elements that were either obviously a large spatial element of the school, or that had great significance to the children. For example Fig. 37, although illustrating the roof outline, focused on the drawing of the plane, as the child remembered the father telling them that he had once flown over the school. In this drawing, it is evident that even in plan, the relationship of memory and personal connection to space continues to be emphasized. 

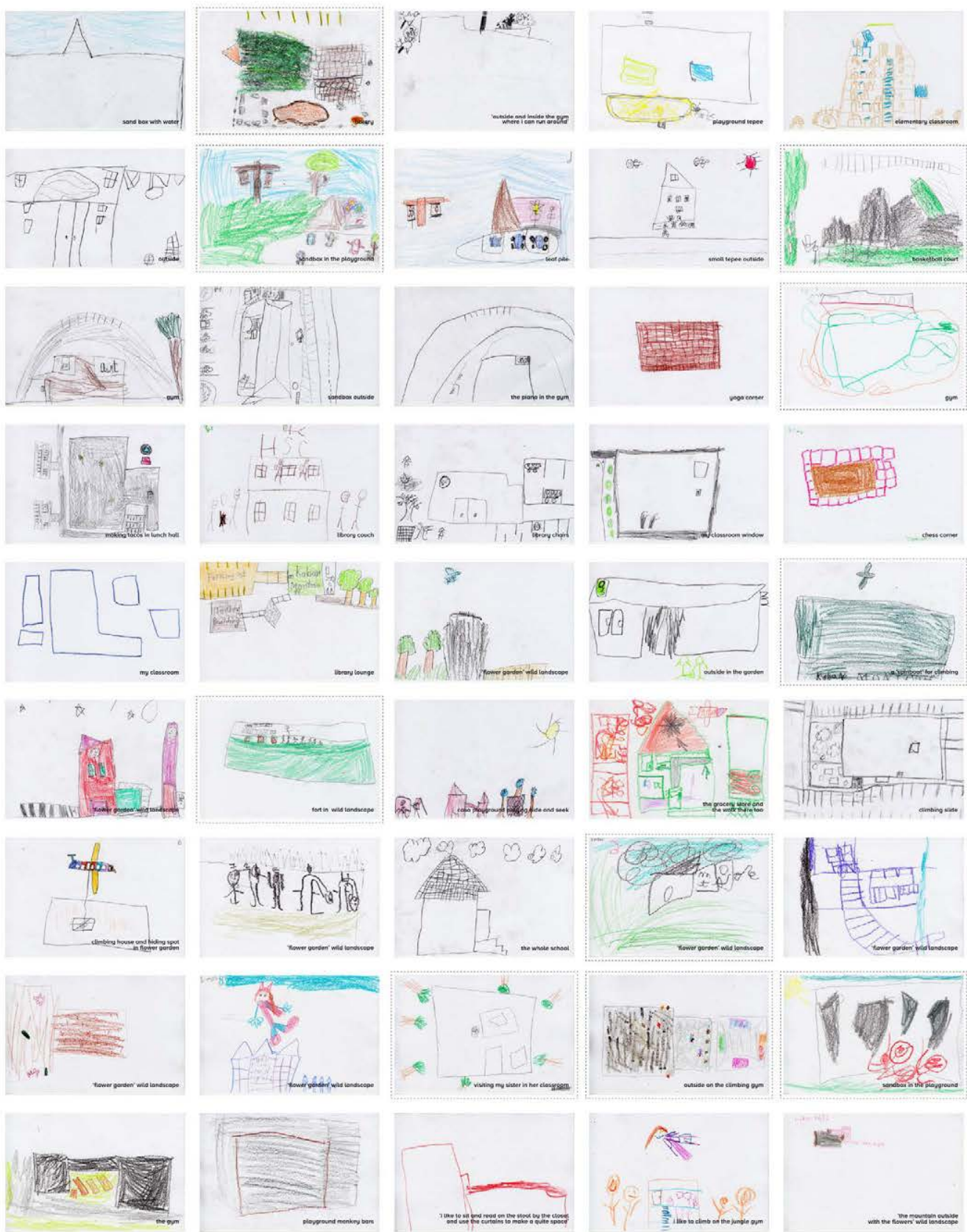

Chlldren's Drawing Workshop

Question 01 . What is the plen of fuour schoor? 


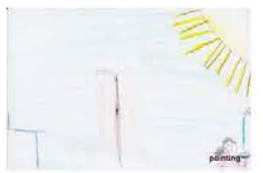

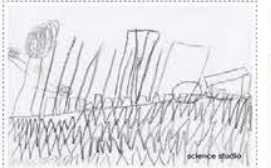
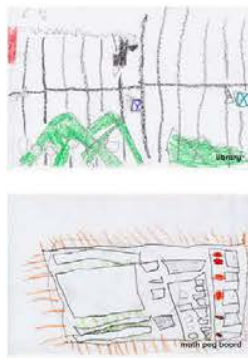

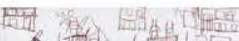

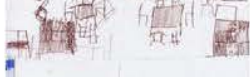

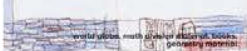
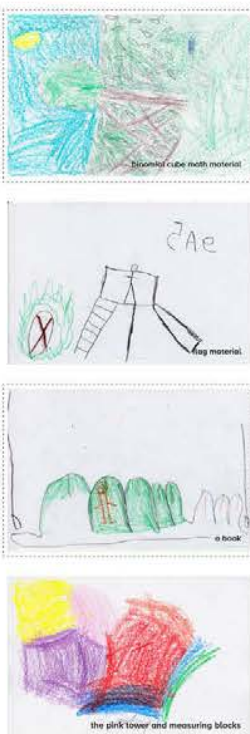
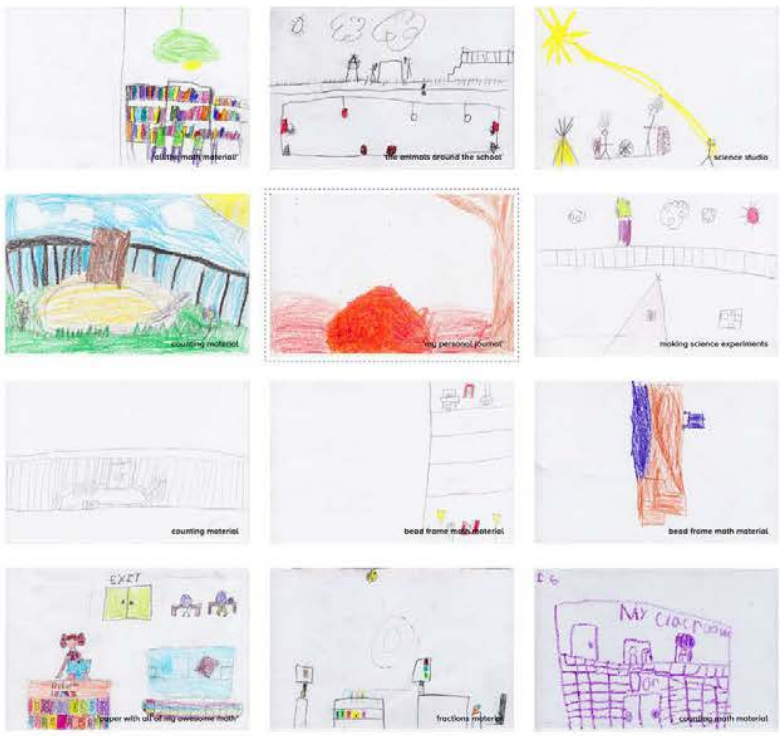

[xit 惯 1.
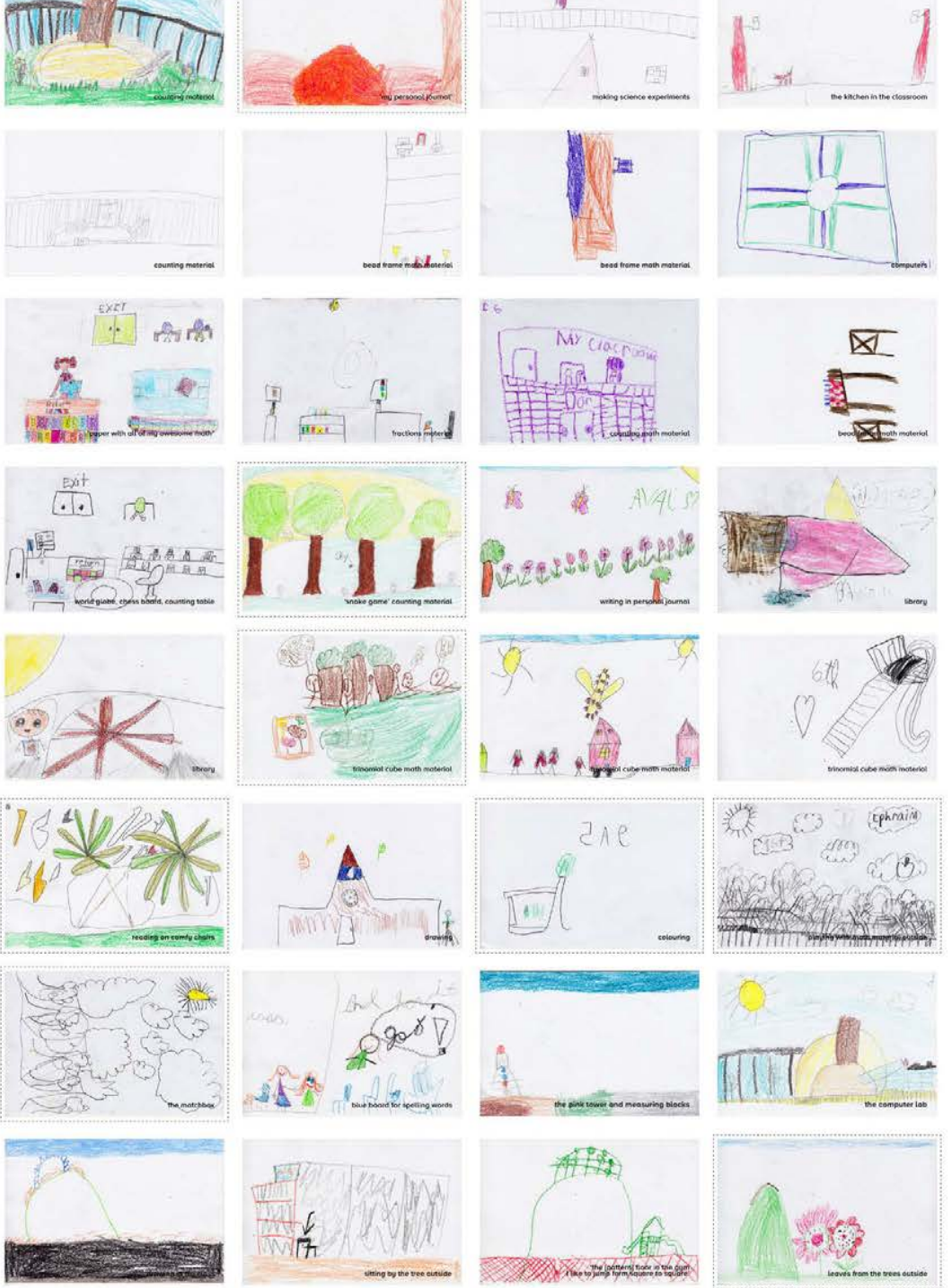

Children's Drawing Workshop 

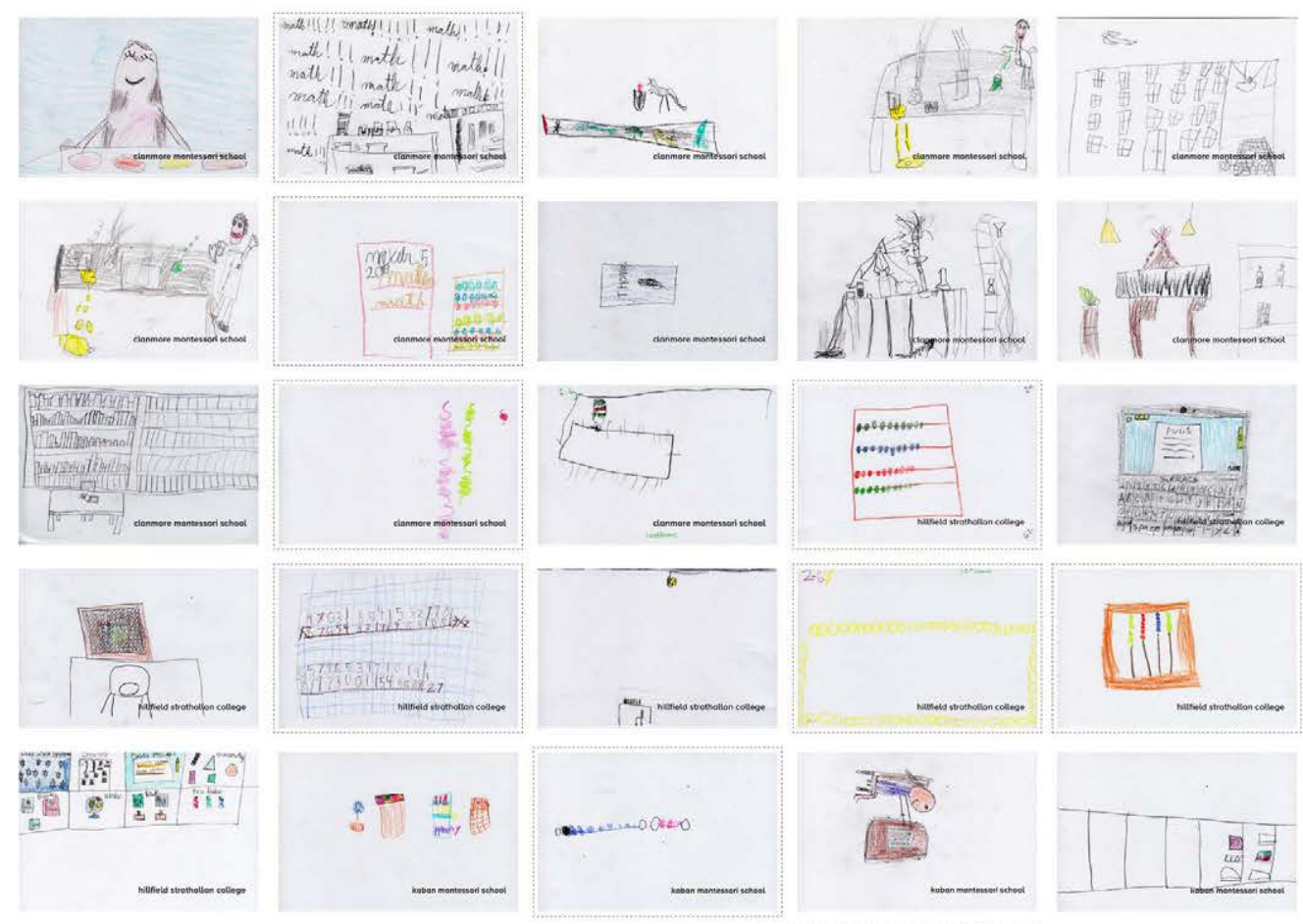

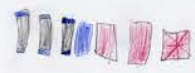

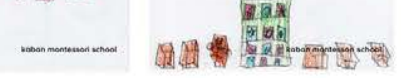
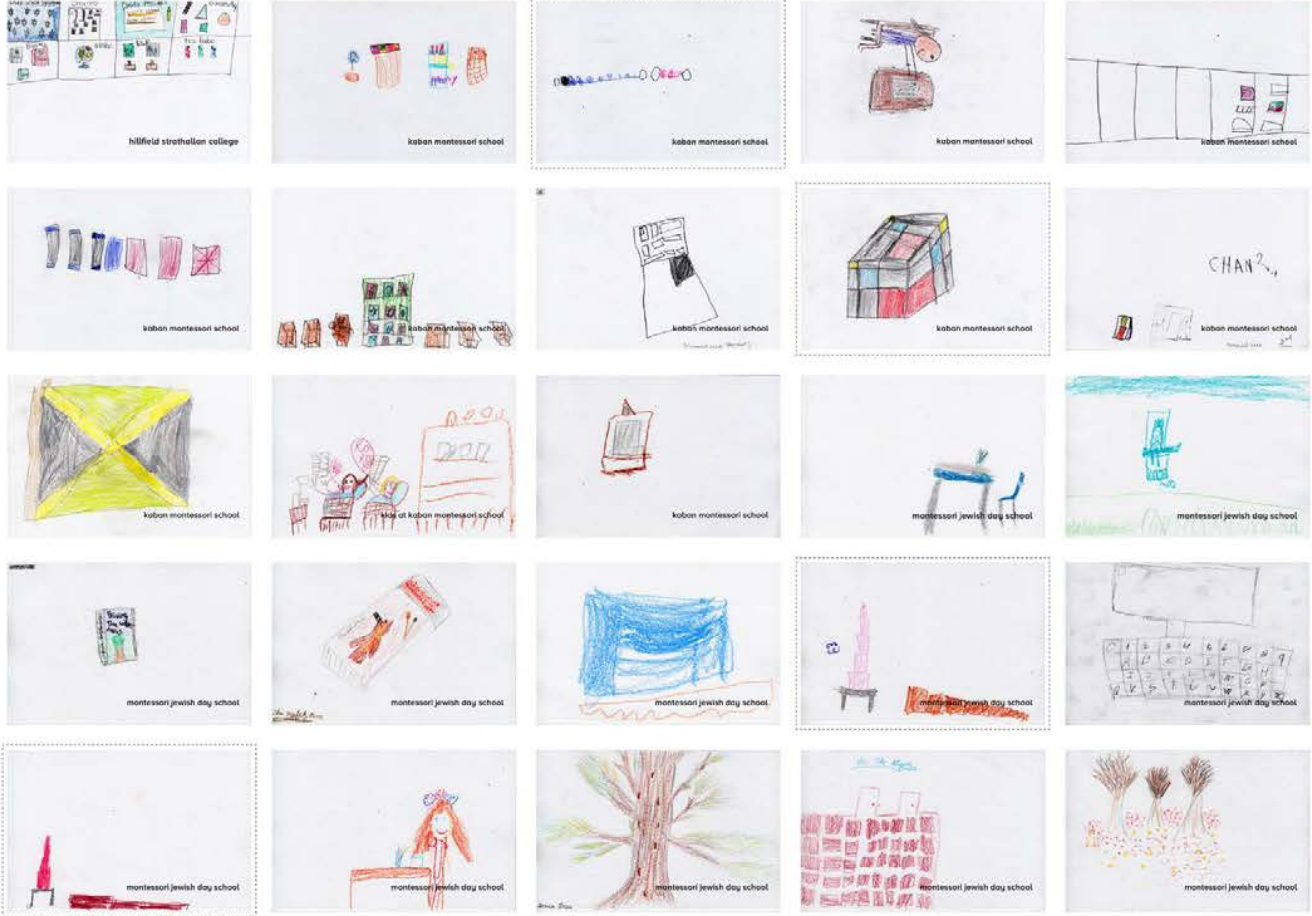

Children's Drawing Workshop

Question 03 . What is your fovourite Material? 

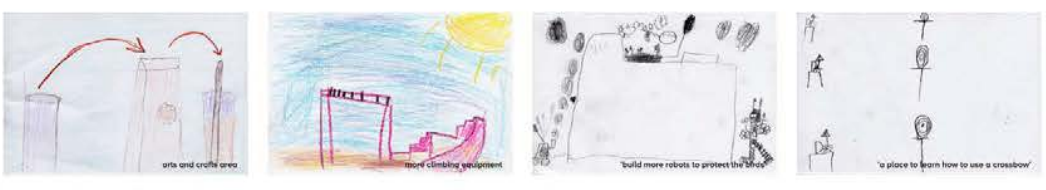

Nith and
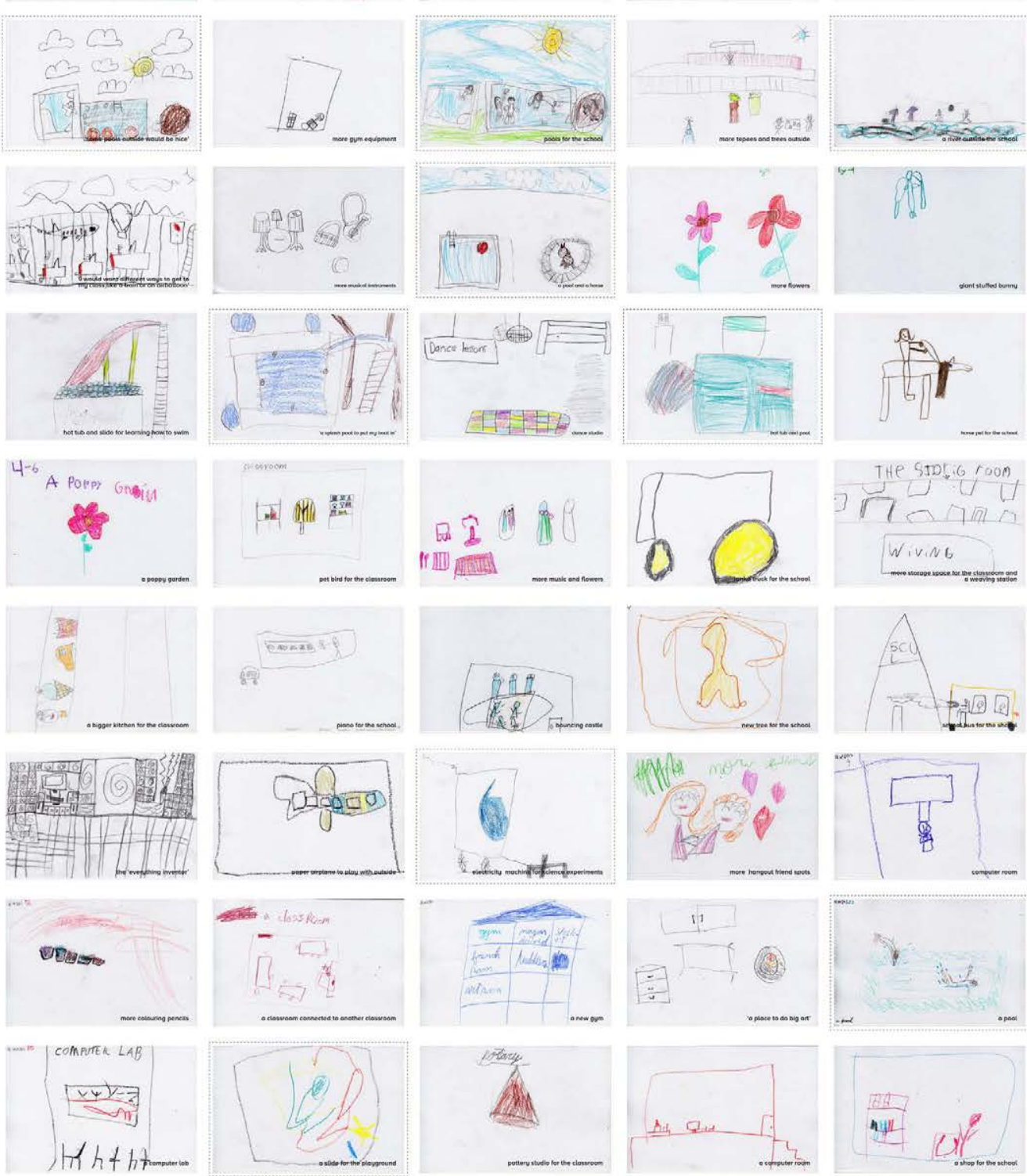

Children's Drawing Workshop

Question 04 - Something new you would add to your school? 


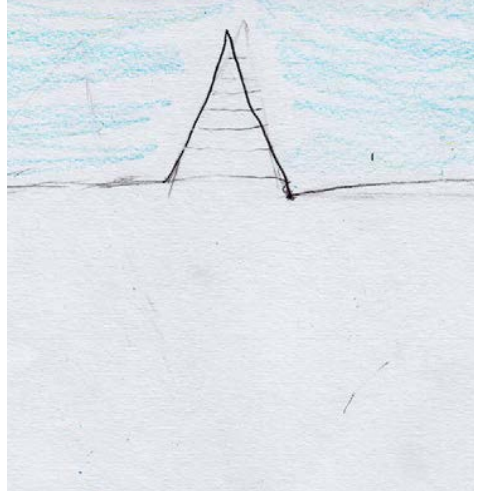

Fig. 42

Birds Beak - Drawing Workshop

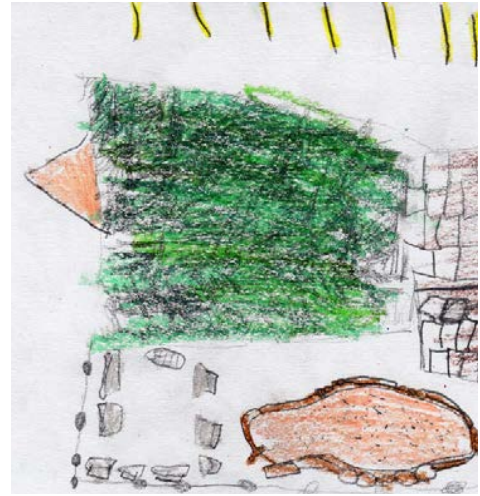

Fig. 43

Birds Beak - Drawing Workshop

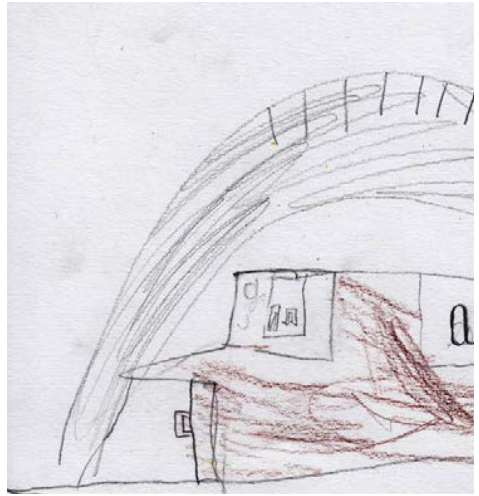

Fig. 44

Birds Beak - Drawing Workshop
Similarly, Figs. 42 - 44, depicts a prominent architectural element within the school referred to by the children as 'the birds beak'. Interestingly, this element was the first to be drawn for the children who included it in their drawings. It seems that the dynamic roof peak acts, for many children, as a landmark helping them orient and place other elements of the school in relation to it. Perhaps then distinct architectural element in schools are instrumental for children to be able to map their environment and navigate their learning spaces independently. 


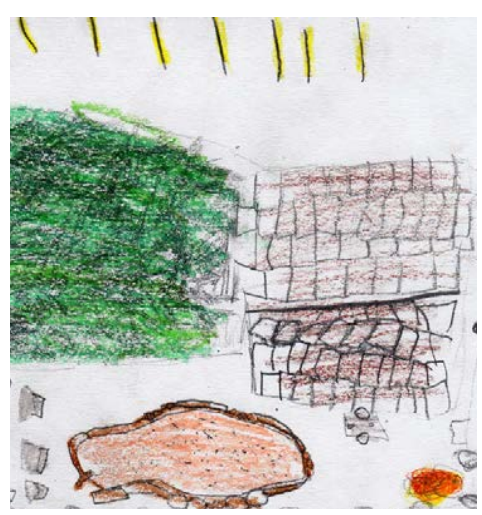

Fig. 45

Green Roof - Child-led Tour

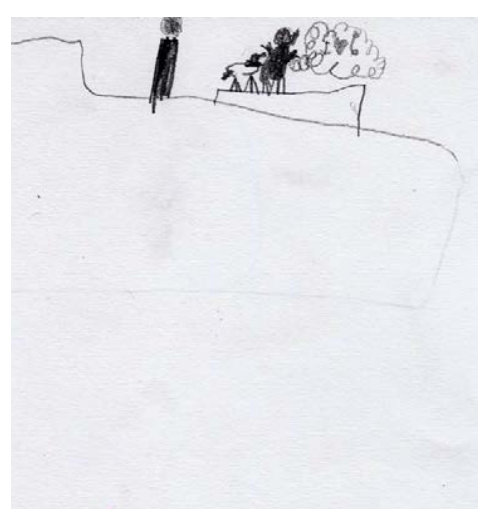

Fig. 46

Green Roof - Child-led Tour

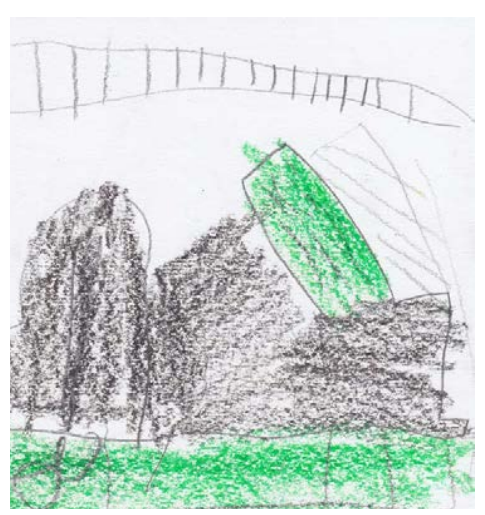

Fig. 47

Green Roof - Child-led Tour
Figs. 45 - 47, shows the green roof, another architectural element the children were surprisingly very aware of in their drawings. Although the children cannot see this element on a daily basis, the consistent inclusion of it in their drawings, was related to the children's fascination with the birds living above. When questioned about the green roof, the children were very interested in discussing how their roof worked. The teachers also revealed that the green roof was used as a way to approach different subjects and lessons in the curriculum relating to ecology; and that because the green roof was a part of their own environment, the children's interest and curiosity seemed to be heightened. Seeing that architectural elements have the potential to excite curiosity and further questions within the child, it seems valuable to expose more building systems and architectural elements to the children, as well as integrating them within the curriculum. 
Catalogue 02, 03 and 04 (Figs. 39 - 41), asks the children to draw their favourite space, their favourite material and something new they would add to either in or around their school, such as an activity, space or material. Within these drawings, similar patterns emerged comparable to those that appeared within the child-led tour and photographs. The patterns within these drawings were then analyzed and illustrated as themes for new speculative spaces, collaged from the children's drawings themselves.

\section{The first two speculative collage drawings (Fig}

$48,49)$ feature water as the emergent element illustrated by the children. It seems the children either have or want a deeper connection to water elements, whether it be pools of water, or flowing streams. In fact, many of the drawings that composed these collages were gathered from Catalogue 04 (something new you would add to your school), signaling that the children's need for water elements are not quite being met through the architectural landscape. According to Christopher Alexander, "People, [especially children], have a fundamental yearning for bodies of water...as it plays a [vital and profound] role in our psychology...[specifically as a therapeutic technique that aids and sets up growth experience]." ${ }^{23}$ Alexander suggests that we build details, such as run-off and water collection elements and water edge conditions to connect children to these sources. ${ }^{24}$

\section{The third and fourth speculative drawings}

(Figs. 50, 51) illustrate wild natural places and interactive adventure playgrounds as the second and third emergent themes. Just as with the photographs of the 'flower garden', ravines and playgrounds, the same types of spatial qualities can be found in the drawings that make up these collages, namely: intimate spaces of refuge, diversity of raw, scattered material (from which the children can freely build and develop their imagination), spaces that encourage children to use their bodies, take risks, test new skills, altogether places where the play is wilder. According to Stuart Brown, these types of learning spaces that allow for more rough and tumble play not only relieve tension, but give children the opportunity to regulate their emotions. ${ }^{25}$ Again, just as in the previous collage, this particular theme emerged from Catalogue 04 (something new you would add to your school), indicating that children require more wild learning spaces to explore.

The fifth speculative drawing (Fig. 52) Illustrates a communal workshop type space. The patterns 
from this collage emerged from Catalogue 02

and 03 (favourite space and material), indicating that the children value spaces in their school where they can explore a variety of subjects and test their ideas. Resembling the 'launch pad', a favourite learning space among many of the children throughout the child-led tours, as well as the themes in the two previous collages, this speculative drawing express the children's need for interactive spaces and materials through which to learn and test their imagination.

The last speculative drawing(Fig.53) also gathered material from Catalogue 02 (favourite spaces) and illustrates an interior learning space as described and drawn by the children. The drawings that compose this collage mirror the findings from the child-led tour and photographs that describe the patterns of personal connection, memory and ownership. Within this exercise children expressed their need for 'difference in sameness', a term used by Anita Rui Olds, to describe a child's desire for a variety of unique spatial and material qualities from which they can choose and with which they can identify. In other words, an opportunity for children that requires them to make decisions about where they fit in and feel comfortable in their environment, ultimately helping the child form an image of themselves. ${ }^{26}$ 


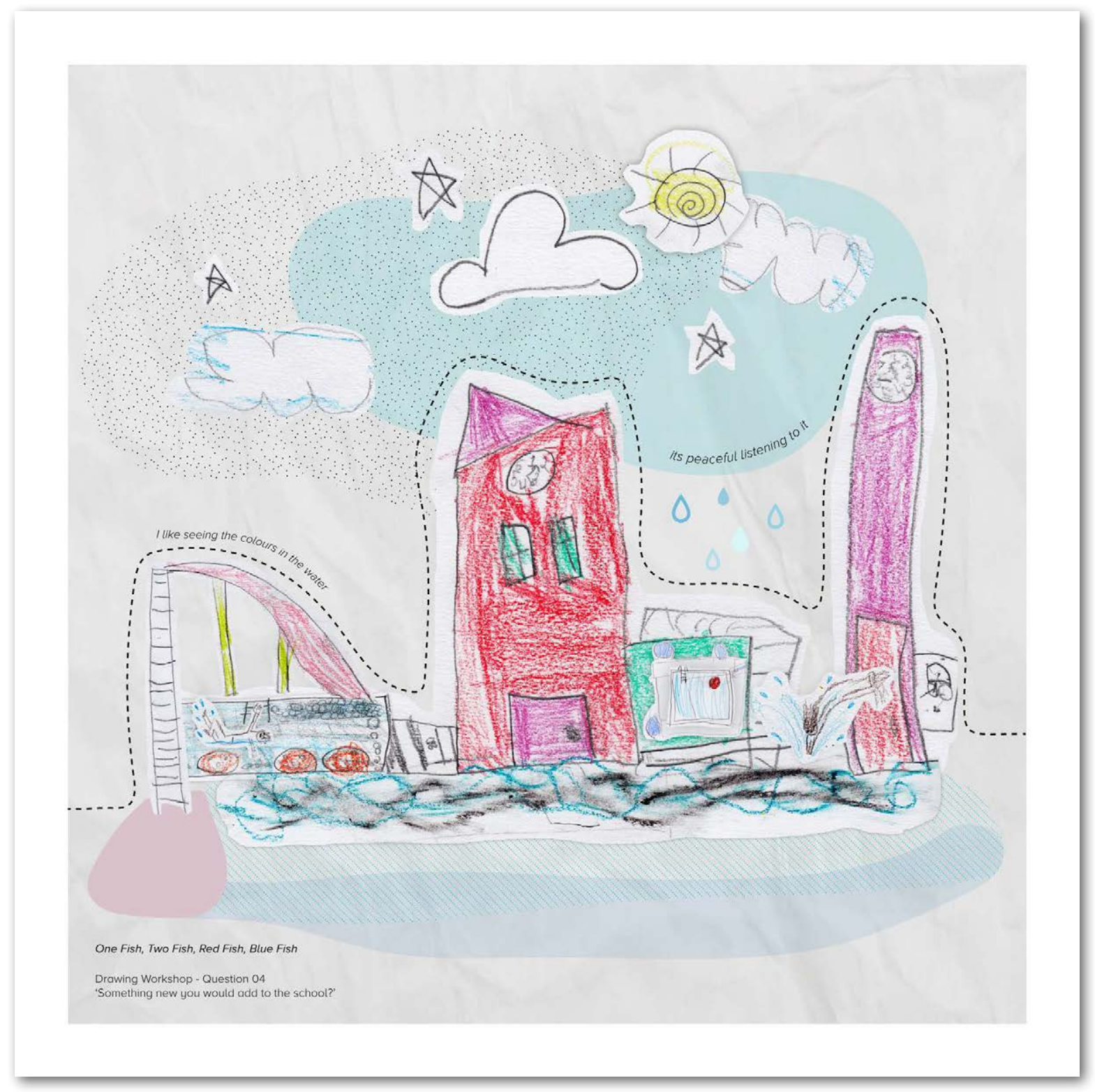

Fig. 48 Speculative Drawing Collage 


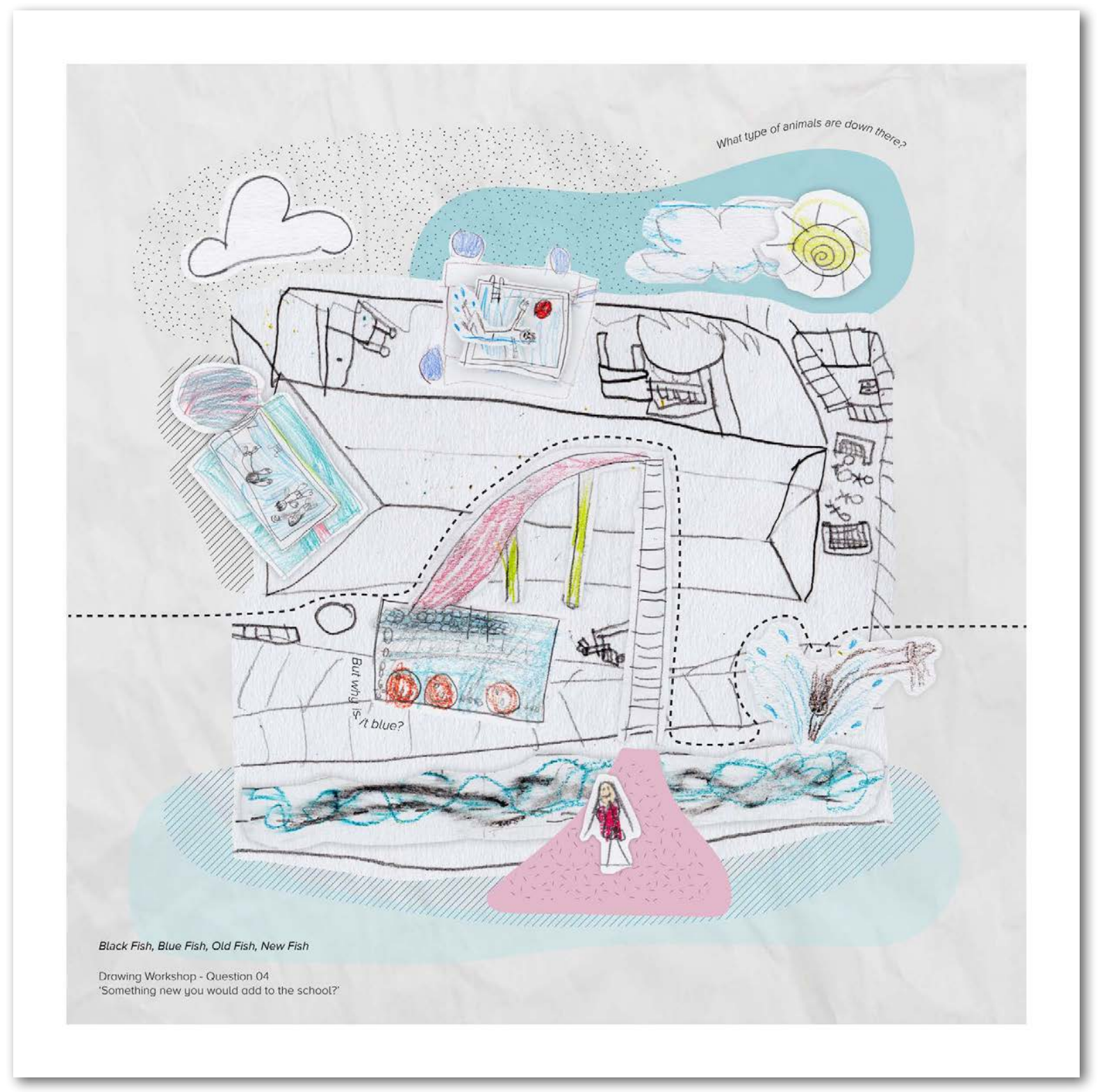

Fig. 49 Speculative Drawing Collage 


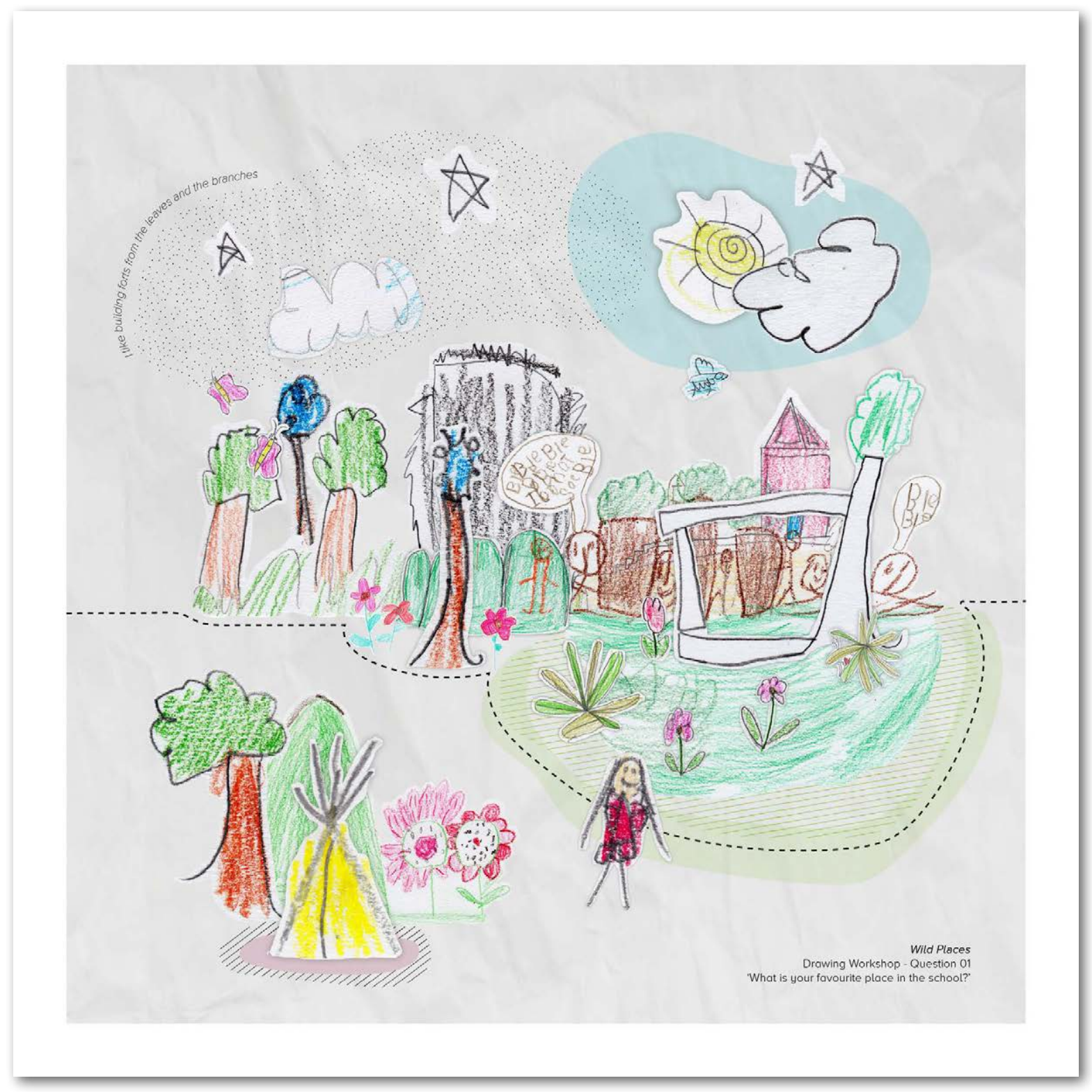

Fig. $\mathbf{5 0}$ Speculative Drawing Collage 


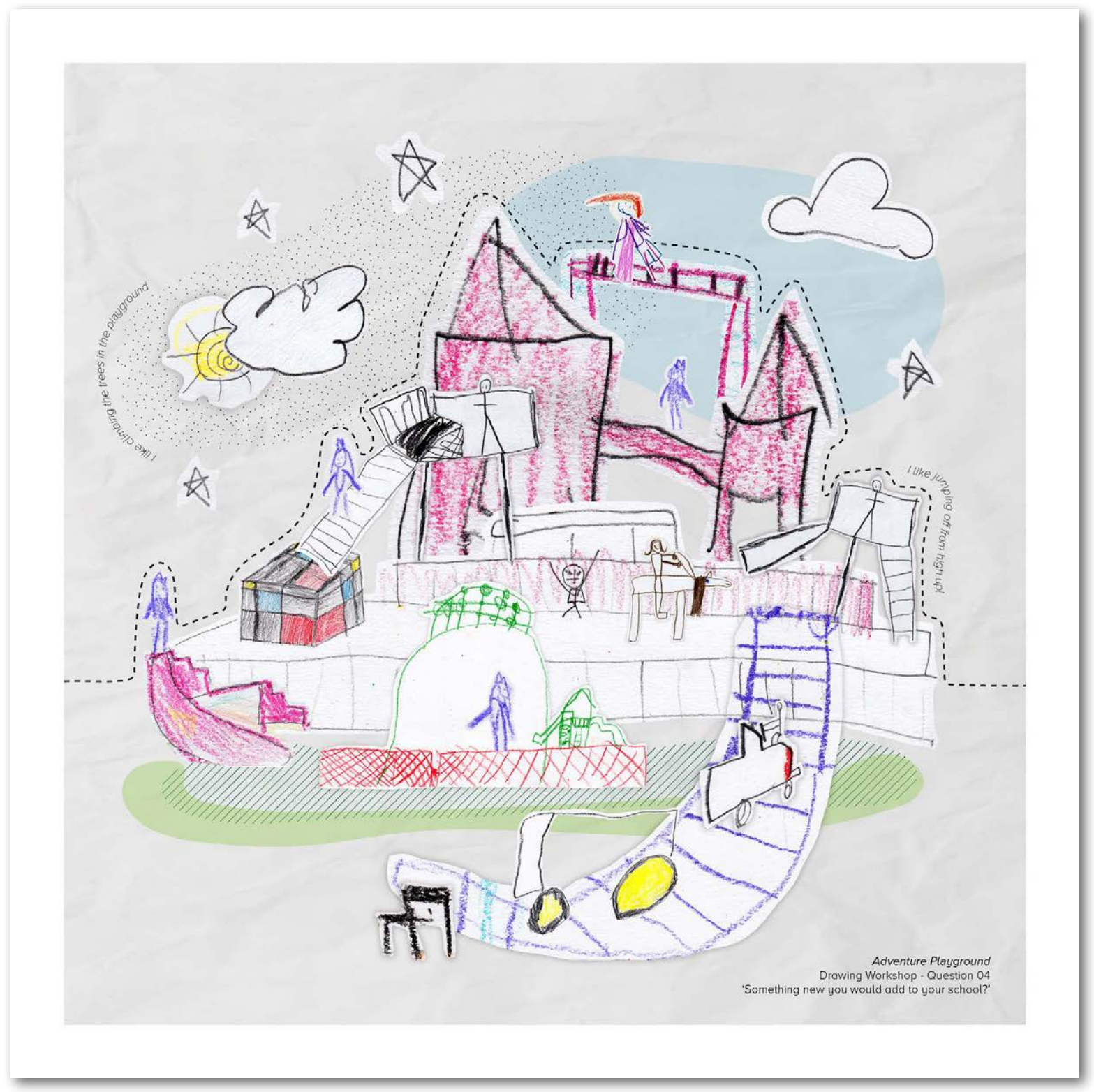

Fig. 51 Speculative Drawing Collage 


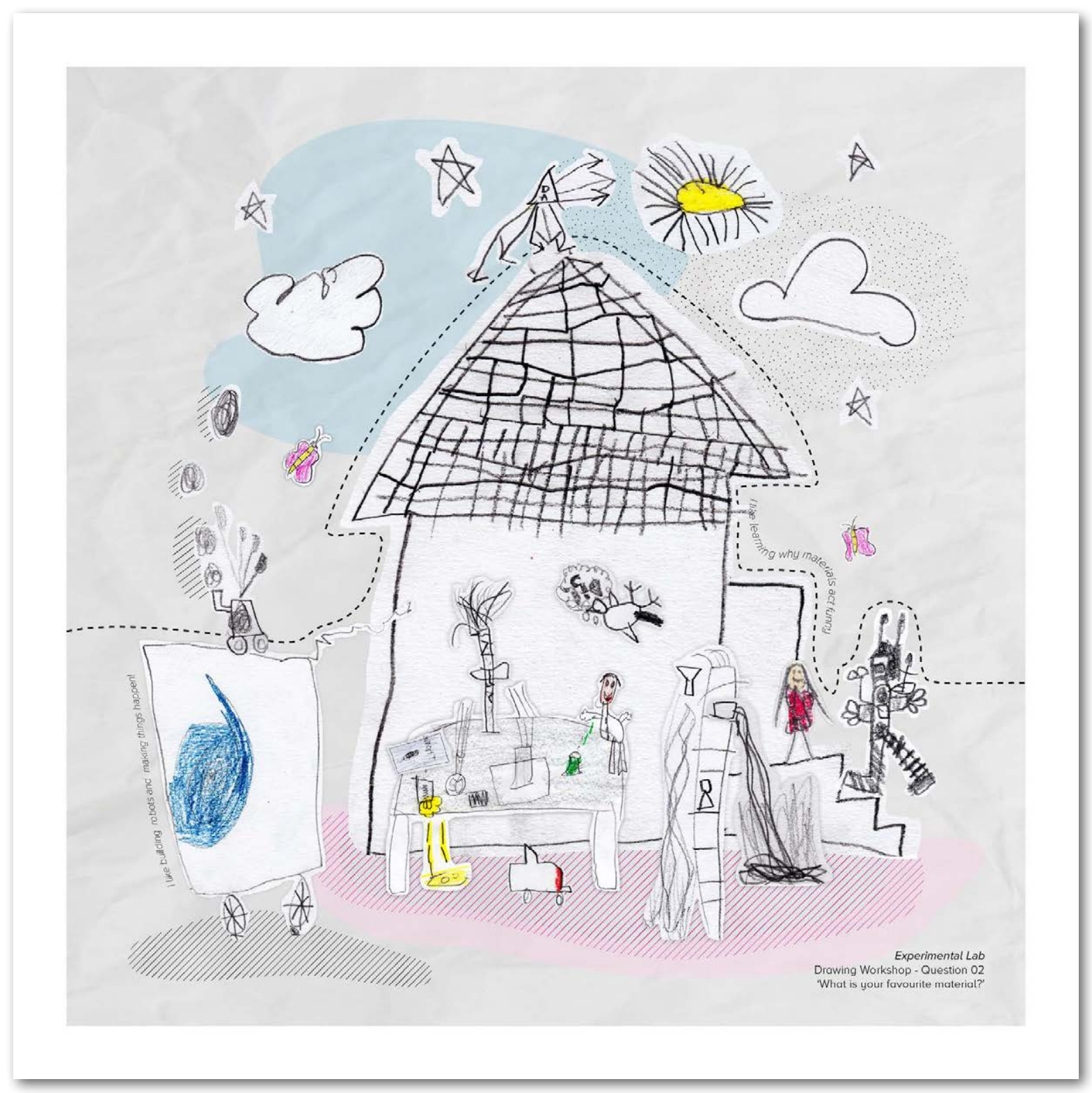

Fig. 52 Speculative Drawing Collage 


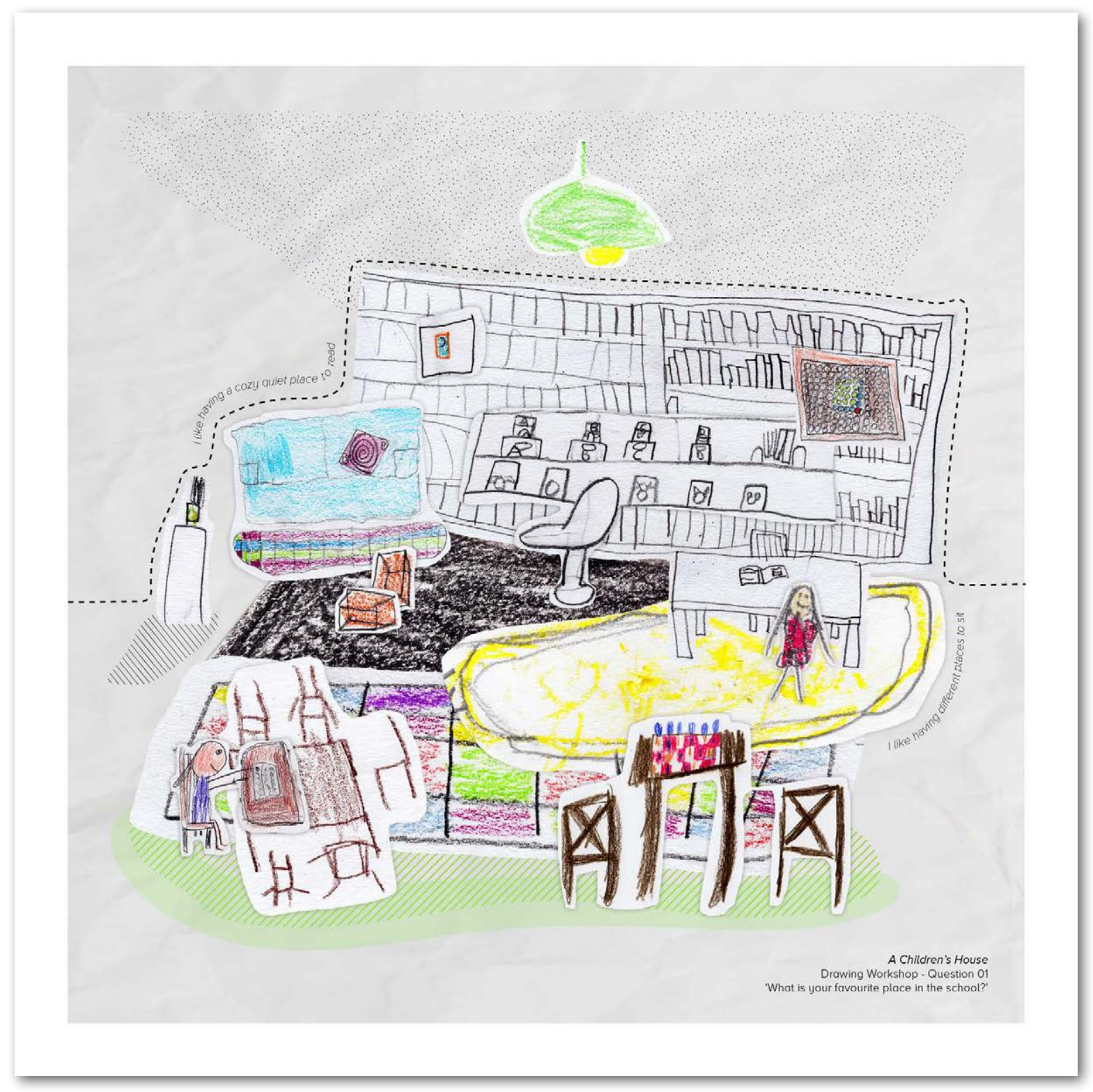

Fig. $\mathbf{5 3}$ Speculative Drawing Collage 


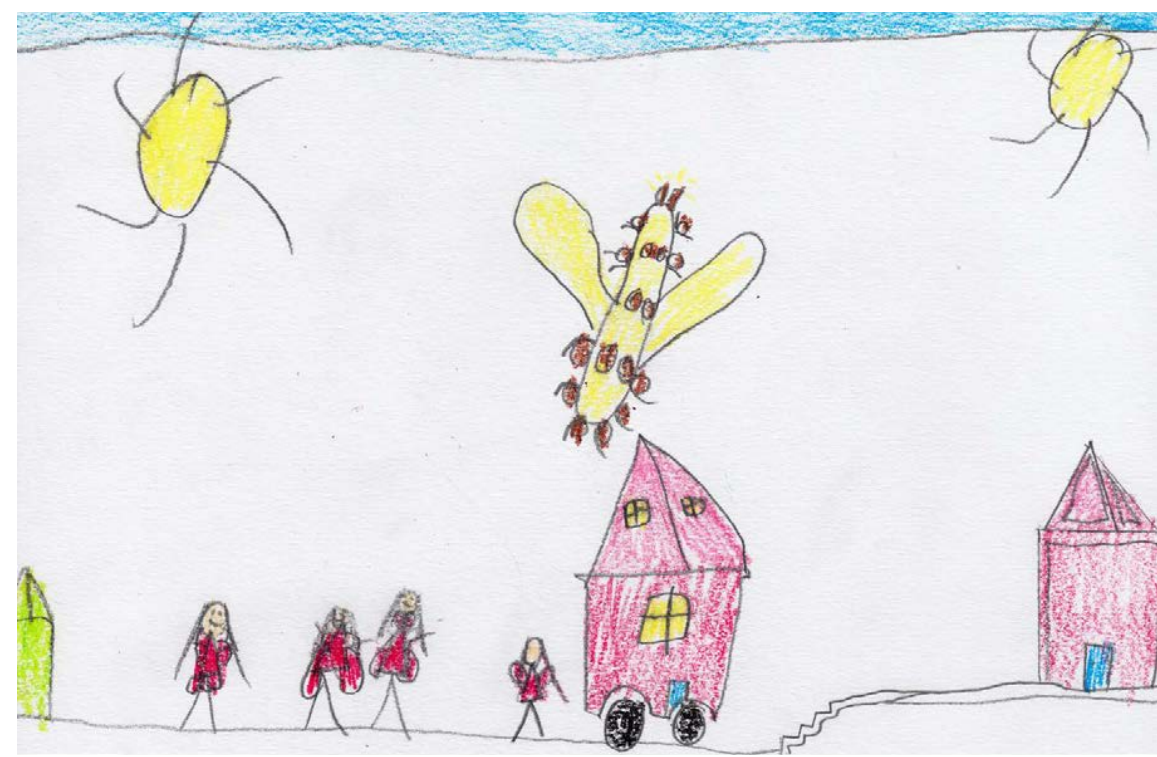

Fig. 54

School on wheels - Drawing Workshop

Fig. 54, although not depicted within the speculative collaged drawings is an interesting illustration of the patterns of freedom and community. This child portrayed an image of their school on wheels, as a way to describe the children's weekly field trip to the community grocery store. When asked to describe the experience the child explained that they 'learn on the move' and that they go to the grocery store 'to buy the food they need to make their recipes.' The child also revealed that they liked talking with the 'grocery store lady' because she would 'help them find the food they needed and was nice'. It was clear that this opportunity to go out into the community, not only fostered a relationship between the children and the people of the area, but gave the children a sense of empowerment and self-sufficiency. 


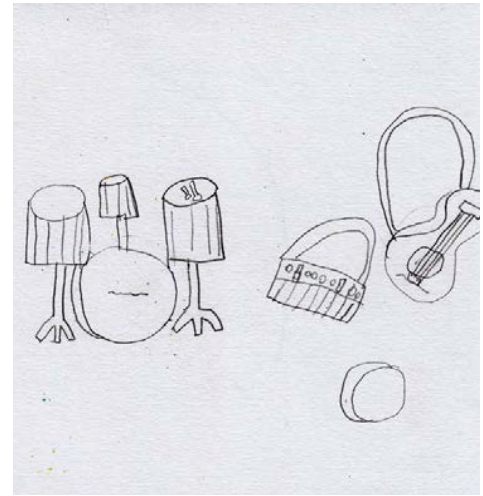

Fig. 55

Instruments - Drawing Workshop

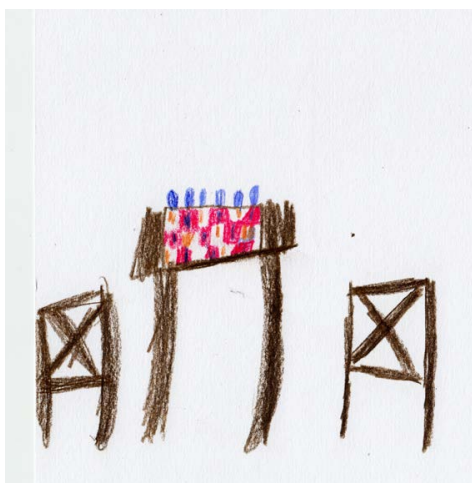

Fig. 58

Chess - Drawing Workshop

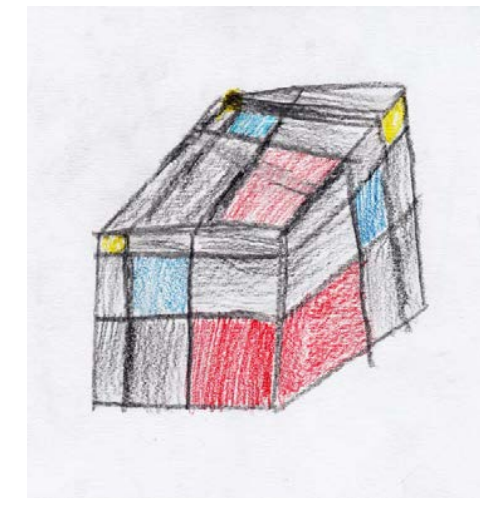

Fig. 56

Trinomial Cube - Drawing Workshop

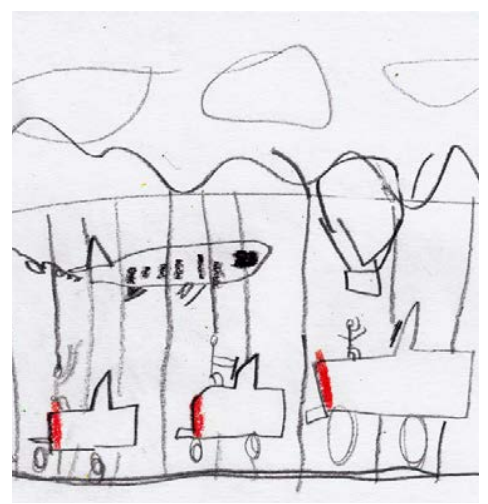

Fig. 59

Transportation - Drawing Workshop

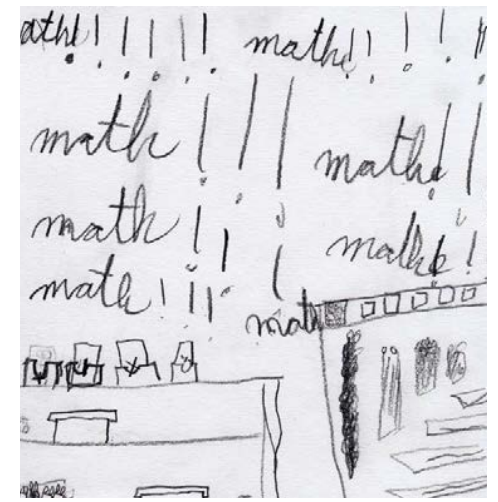

Fig. 57

Math - Drawing Workshop

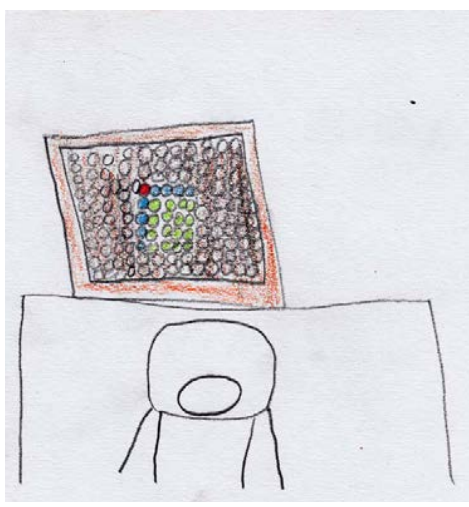

Fig. 60

Counting Material - Drawing Workshop
Figs. 55 - 60, illustrate the remaining patterns that emerged from the children's drawings. Many of the activities and materials from these drawings, such as the musical instruments and mathematical learning materials could be scaled into larger architectural elements, creating more unique and dynamic learning environments that encourage bigger physical movements. 
The perspective gained from observing and talking with the children during and after their drawing exercise helped reveal patterns between a number of children's drawings. However, it was the process of comparing the results from the various methodologies, which constructed a deeper understanding of children's relationships to their learning environments and revealed a detailed picture of children's knowledge of 'place use' and 'place preference'. ${ }^{27}$

Having a more defined understanding of the patterns that shape early childhood learning spaces, a new awareness guides the design process, one that will affect the architectural strategies re-imagined from the potentials at Kaban Montessori School .

Within the context of the workshop however, the purpose of the study was to explore a participatory approach to design in an authentic and interactive way. It was not enough to solely read about the process and findings from previous studies, participating in the progressive condition was essential to understanding its principles first hand.

Each school is unique; a mosaic of individuals and local cultures learning under one roof. For this reason, a relationship between the designer and school community is a fundamental part of interpreting children's and teachers experiences of their environments. Participatory design offers a channel through which society can perceive "the evolving nature of both education and school buildings as an architectural form." 28 However for this to occur, an exchange must take place between the architect, teachers and students; one acquiring a pedagogical, curricular and local understanding, while the other discovers how architecture can help them thrive. Succeeding might well foster a new generation of children who understand the influence architecture can have in their lives, becoming engaged citizens ready to play a role in shaping their environments. 


\section{Freedom}




\section{2 _ Freedom}

\section{A Progressive Approach to Design}

\section{risk}

/risk/

noun

"other parts of the environment [that] are simply 'unpredictable' to children; they await experimentation and learning."

- Roger Hart
"What we want to see in a child is the pursuit of knowledge, not knowledge in the pursuit of the child"

- George Bernard Shaw

As elucidated in previous chapters, the notion of 'freedom' as a principle for learning environments involves freedom of movement and choice. It "occurs when children spend unplanned and uncounted hours...investigating, experimenting, exploring and playing [in a variety of learning environments and of their own free will]." 29 Obtaining this level of freedom, where children can spontaneously and creatively design their own curriculum and environment, depends generally on the following design patterns and strategies.

\section{Learning spaces should encourage} independence and competence:

As suggested in the chapter 'learning spaces' as well as the workshop, children should be encouraged to move through the classroom, school and exterior learning spaces independently. This trust informs children that they are competent and intelligent beings capable of making the right decisions. This form of encouragement endows children with a sense 
of responsibility and empowerment, helping the child's process of cognitive and emotional maturation. ${ }^{30}$ "White argues that the desire for competence is one of the basic motivators of human behaviour [and that in] childhood this drive [is enhanced as] the child is constantly faced with new tasks and challenges." ${ }^{11}$ Thus, the designed environment should help children develop the skills needed to navigate and control their physical surroundings. This means that if children are to feel competent in their environment, learning spaces should be child-scaled, lessening their dependency on the adult (Fig. 61). Transitions between learning environments should also be fluid and flexible; transformable spaces, capable of being molded by the child's developmental impulses. For example, the indoor-outdoor continuum should be a gradual and blurred transition, that allows children to safely experience both learning spaces as one. This area should also be spacious enough to create its own environment where learning experiences can occur. However, for freedom to develop competence and independence, each learning environment should be developmentally appropriate for the children who inhabit it. For instance, infants and toddlers require learning spaces that encourage motor development (freedom to explore and interact with diverse environments), yet based on the maturity of the child, these learning spaces demand more open layouts where teachers can give unobtrusive supervision to all rooms, while being in one. ${ }^{32}$ Nevertheless, as children grow, so should their freedom. At the Casa and Lower Elementary age, learning spaces should expand to encompass the entire school campus, as well as provide more specialized and intimate areas for the children to explore. ${ }^{33}$

Although children in progressive schools enjoy a considerable amount of freedom, there is a general misconception of its value and extent. The concern in this regard is that children are allowed boundless freedom, through which they can indulge their every whim. However, this is rarely the case, especially in a Montessori environment where 'freedom within limits is practiced. ${ }^{34}$ For example, although children at the Montessori Fuji kindergarten in Japan are given free range of the school perimeters, the freedom in Montessori schools is linked with responsibilities, as well as the appropriate level of maturity of the child. In other words, children are expected to respect the limits set on the environment and their behaviour according to the ground rules of the community and landscape. ${ }^{35}$ It is these set limits that implement the necessary safety precautions and 
allow children to explore their learning spaces

independently and adventurously.

\section{Risk vs. Safety:}

In Canada, children's daily territory has

diminished. ${ }^{36}$ Although the landscapes of

childhood are everywhere, they are no longer

freely available to children (Fig. 62). ${ }^{37}$ Legal

feasibility, lawsuits, traffic dangers and the general

climate of increased health and safety regulations

have had a dramatic effect on the quality of

freedom extended to children. As the boundaries

of what is determined 'safe' shrink, children are

cut off from valuable opportunities to interact

and learn from their community environment.

As a result, children's developmental needs are

censored. Instead, the design, programming and

management of learning spaces should create

stimulating yet safe environments where children

are allowed to experience risk as a part of their

growth - trying, failing and trying again, are

essential to a child's learning process. ${ }^{38}$ These

dan.ger

learning environments should teach children how

/"danjer/

noun

to be in control within their surroundings, learning

how to safely navigate their world, rather than

avoiding it altogether. As designers we must,

"Elements and situations in the environment that defy learning through experimentation by certain aged infants and children because they are beyond their physical or perceptual abilities."

- Roger Hart

through the built landscape, give this freedom

back to the children so that they may "occupy,

alter and belong to their communities [once

again]." 39 


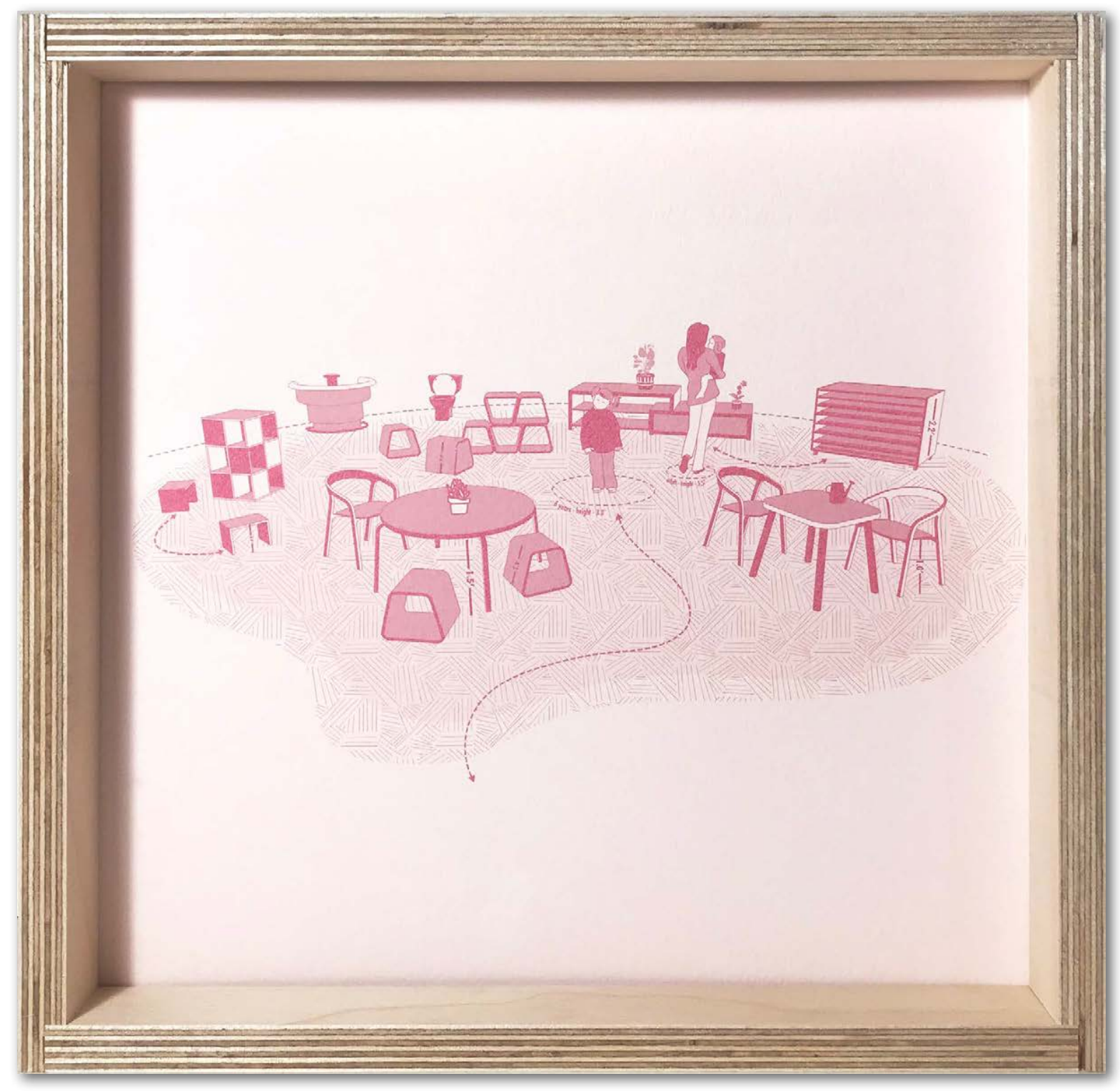

Fig. 61 Scale of the Child 


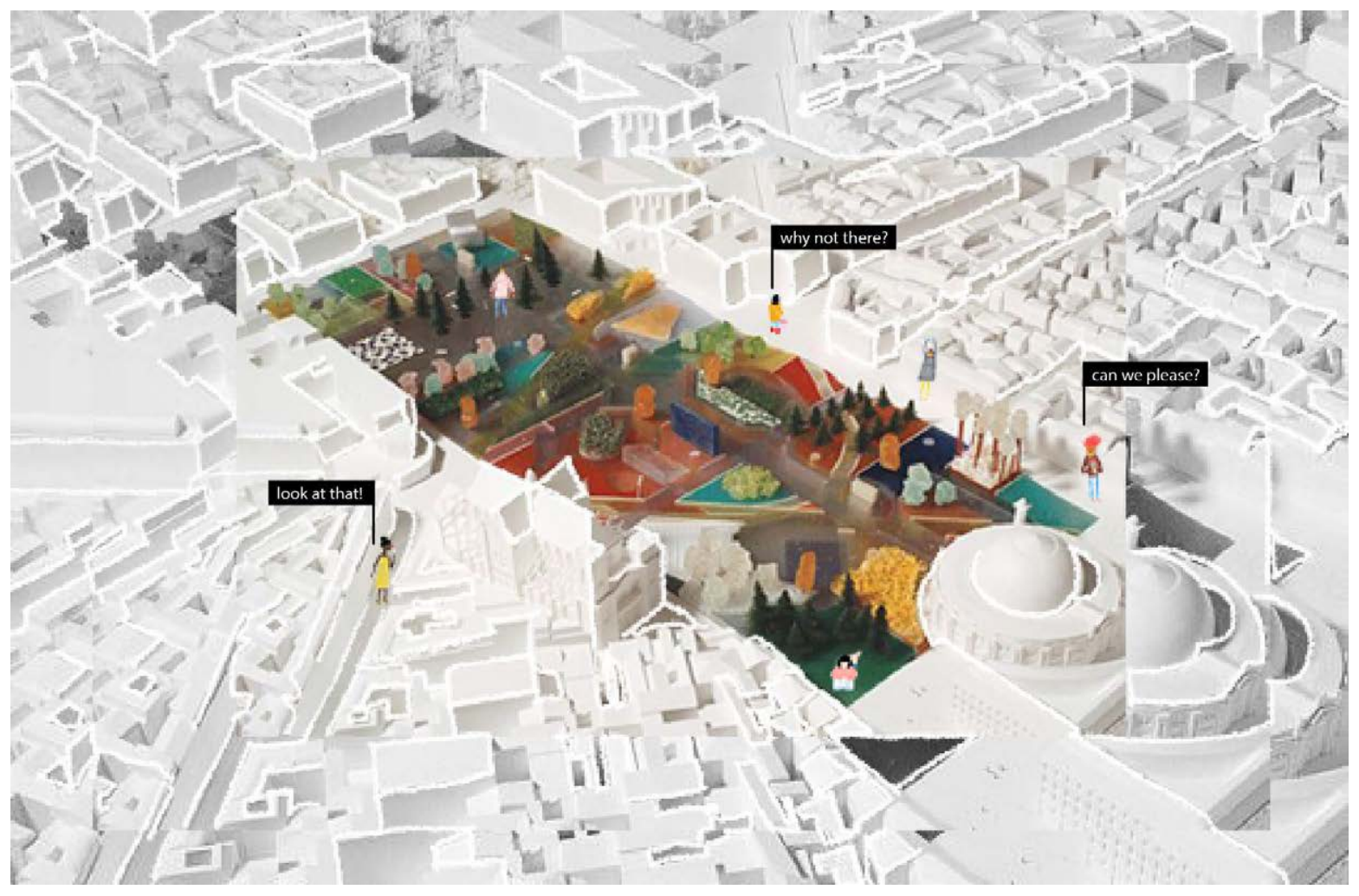




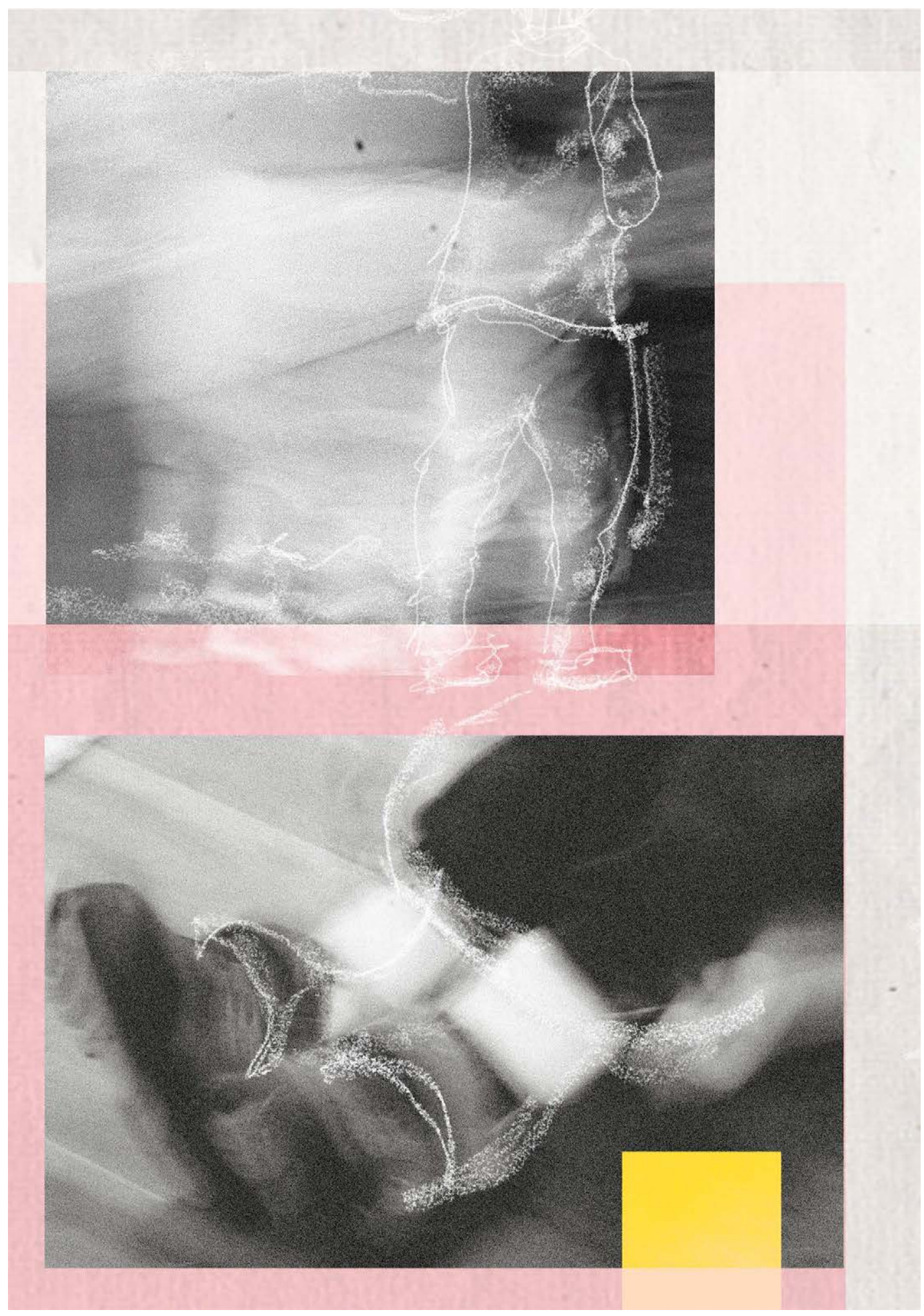

Fig. 63 Motions of Freedom 


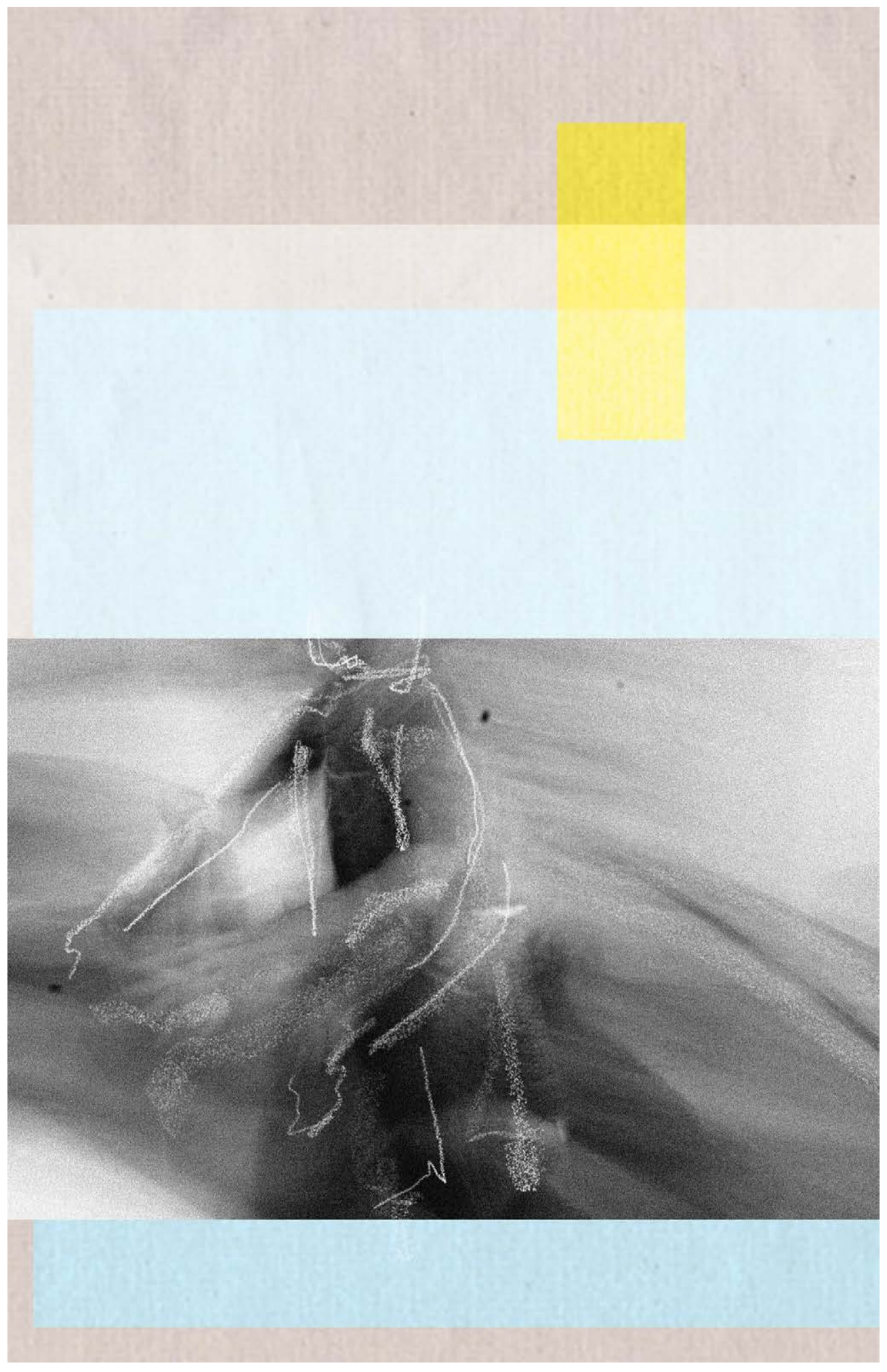

Fig. 64 Motions of Freedom 


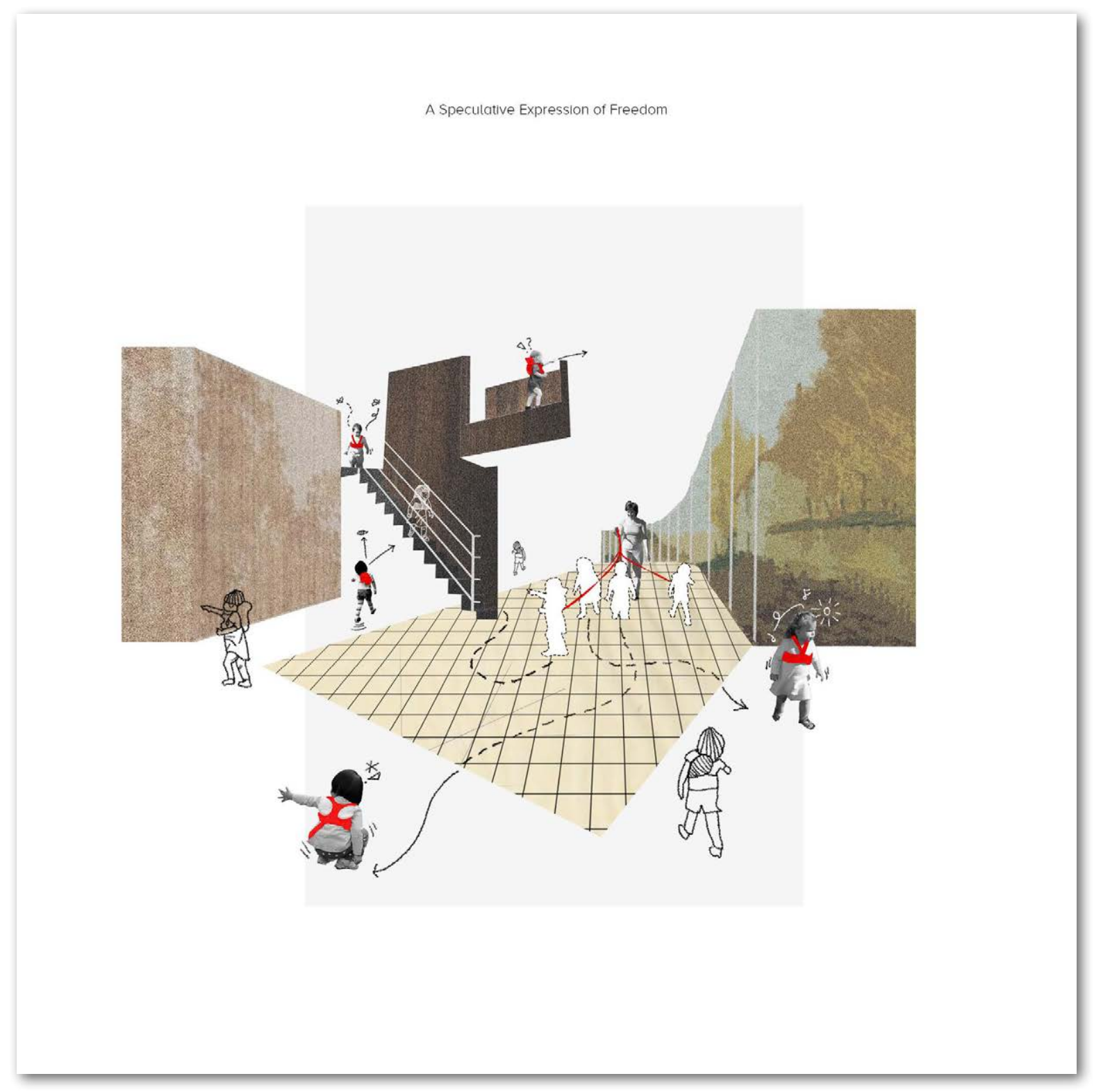

Fig. 65 A Speculative Expression of Freedom 
For example, as described in the chapter 'The

Problem with the Classroom' the following

design of a children's path, based around Kaban

Montessori School's neighbourhood, aims at

expanding a child's territory beyond the school.

Through implementing the patterns described

in the principles of 'Freedom', 'Community' and

'Integrated', the paths could empower children

to explore the learning experiences within the

greater community by creating safer and more

accessible, child-scale passages that connect

the various childhood landscapes sprawled

throughout a community.

The site plan shown in Fig. 66, locates all the

schools, daycares, parks, existing trails, and

surrounding shops and business that help expand

a child's learning environment. The map illustrates

how a diversity of paths (from hardscapes to loose

natural trails) could bridge these learning spaces

and create broader boundaries for learning. 


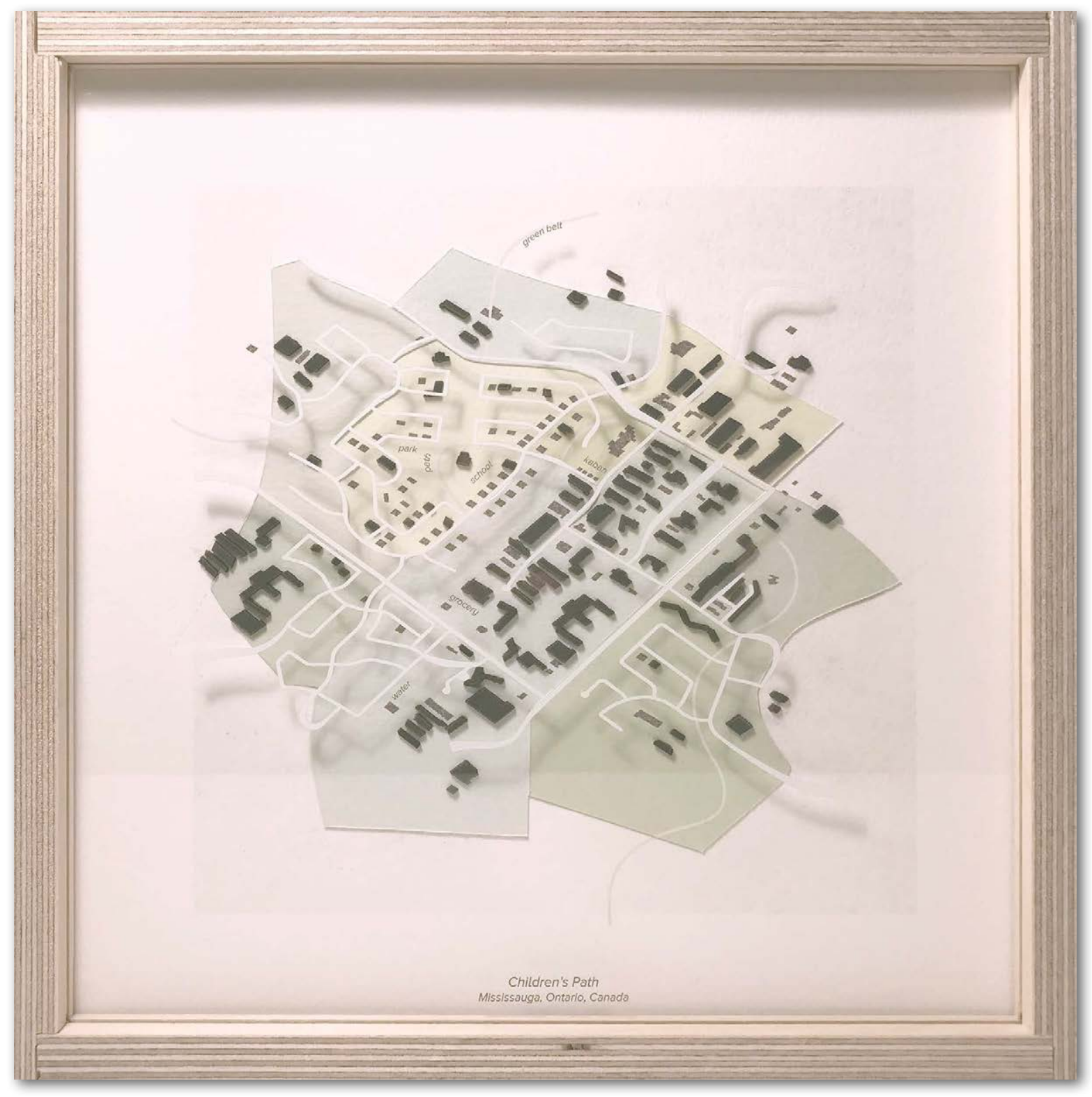

Fig. 66 Children's Path - Site Plan 


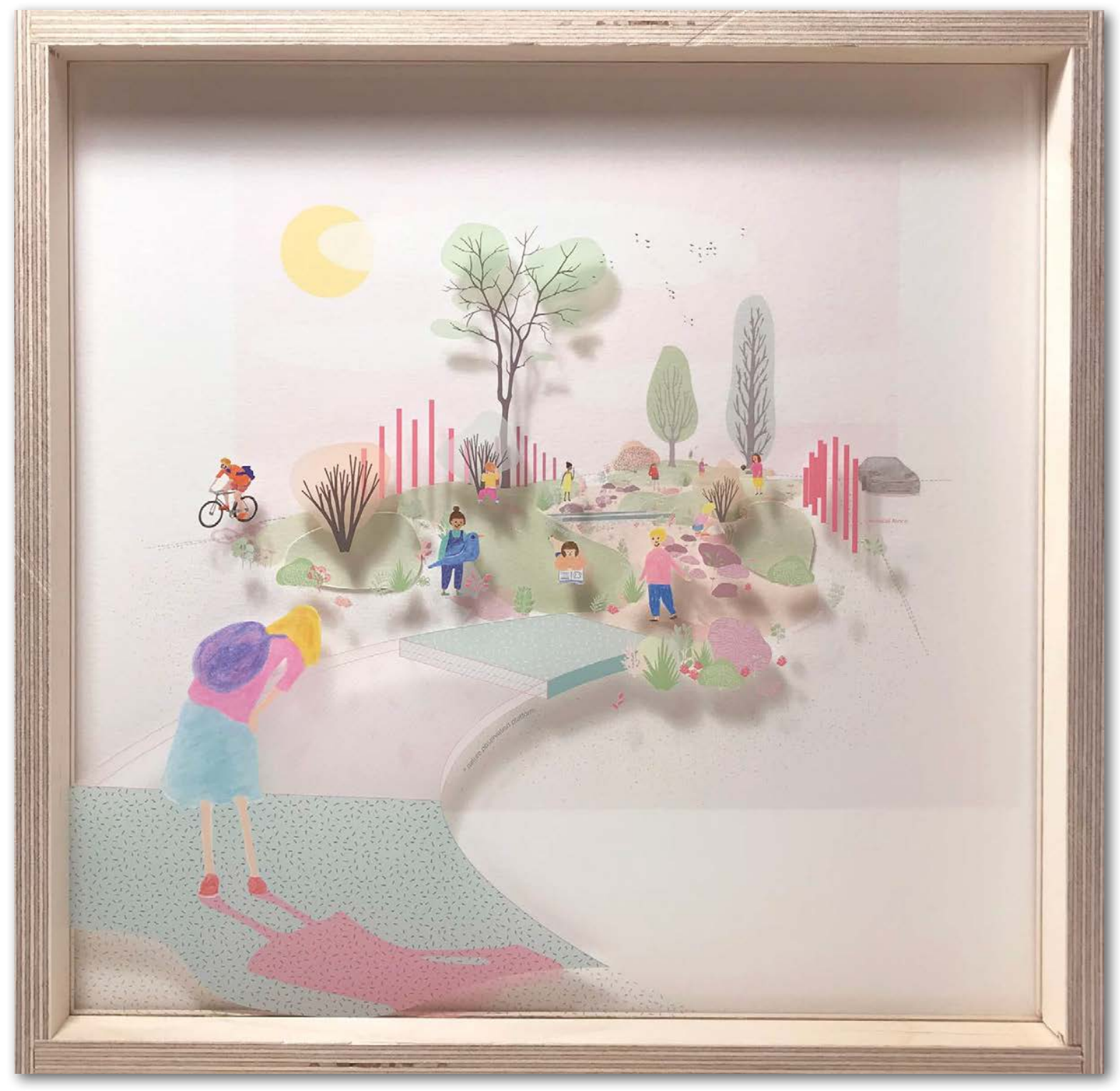

Fig. 67 Children's Path - A moment along the path 


\section{Community + Culture}




\section{3 _ Community + Culture}

\section{A Progressive Approach to Design}

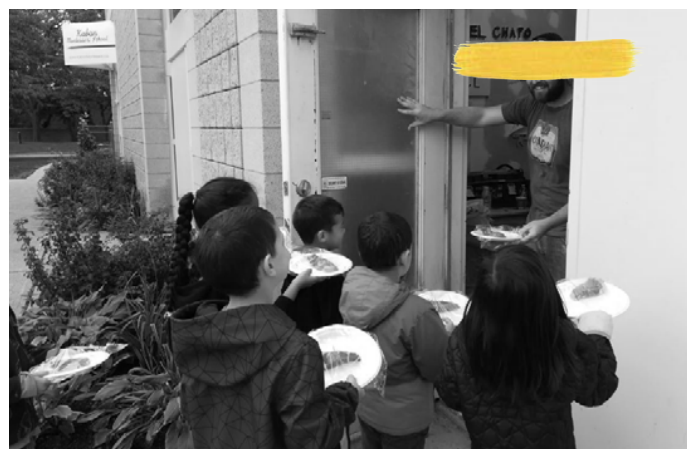

The significance of place-based education is that it supports and reflects the variety of cultures within its geographical area. It aims to connect children to their communities history, the culture of the people within it, its relationship to the surrounding environment, and its connection with the greater social fabric. The connections that

Fig. 68

Children sharing their baked goods with their neighbours. - Kaban Montessori School

"Pedagogy of place counters abstraction, it is the natural world embodying principles of learning that involve direct observation, investigation, experimentation, and manual skills." - David Orr broaden a child's awareness, enrich their lives, and help them become accepting of others should be embodied by the design and programming of learning spaces by drawing directly from the community's identity and history. ${ }^{40}$

As children reach two and a half years of age they experience a shift towards the second plane of development, as described in the Montessori Method. ${ }^{41}$ In this phase children begin to develop acute social interests, during which the environment should become a tool that helps children discern the social fabric allowing them to find their place within it. The following design strategies aim at providing children with the spaces necessary to begin making these connections 


\section{Visual and physical connections:}

Children create meaning from their environment.

This includes the visual and tactile experiences provided by learning spaces. One of the ways schools can familiarize children with the local scene is by providing portals to the street and surrounding businesses wherever possible.

Adjacent workshops where children can participate in similar activities as those seen in their communities would not only help them understand and connect to their surroundings and social fabric, but could, on occasion, create the opportunity for children to learn from the neighbours themselves. Similarly, as identified in the Vega Workshop, a connection to oneself as well as to others can be established through the artifacts created by the children and community when they are a present element within a child's daily life. The school should therefore include, within its design, spaces where student drawings, projects, photos, cultural fragments and landmarks can be reflected on or used by the children ultimately helping them construct an identity of "who I am - [and who we are] - in this place." 42

\section{Variation of social structure:}

As also observed in the Vega Workshop, the layout of a school can have a big impact on the way children perceive and feel in their environment. Like adults, children need both alone-time and time with other people. For this reason, learning spaces should provide children with a balance of private and public spaces. Hence, a school should house a range of spaces that people can inhabit as individuals, as pairs, in small groups (3-5), in large groups (5-15) and as an entire school community. Between these spaces it is important to design an intimacy gradient composed of space, light, noise and materials - that can organize the environments into a spatial "sequence, corresponding to their degree of privacy." ${ }^{43}$ This gradient helps children "discern the function and purpose of a space and to more clearly define [the] social relationships that are possible [within them]." ${ }^{44}$ In other words, it allows a child to develop a social awareness based on the spatial and atmospheric features and relationships of a space. Intimate alcoves, private nooks and distinct areas such as loud workshops help create fluid boundaries that insulate the majority from the minority or vise versa. In conjunction with the intimacy gradient, designing a variety of seating possibilities that reflect the intimacy and openness of learning spaces, creates opportunities for important social experiences and group adjustments, such as arguments and negotiations regarding possession of space and 'property', to occur. ${ }^{45}$ 
The principle of social structure emphasizes

valuable learning resources and design patterns both inside and outside the school, encouraging experiences as individuals but also with groups of different ages, cultures and vocations. While it may be necessary to maintain a degree of physical separation between the school and surrounding neighbourhood, for safety reasons, every effort should be made to integrate it with the life and activity of the community.

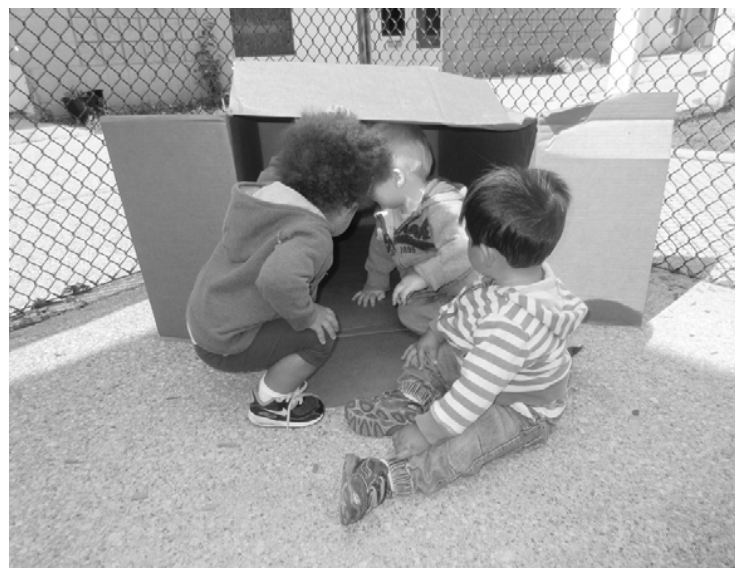

Fig. 69, 70

A group of toddlers playing inside the intimate space of a cardboard box - Kaban Montessori School

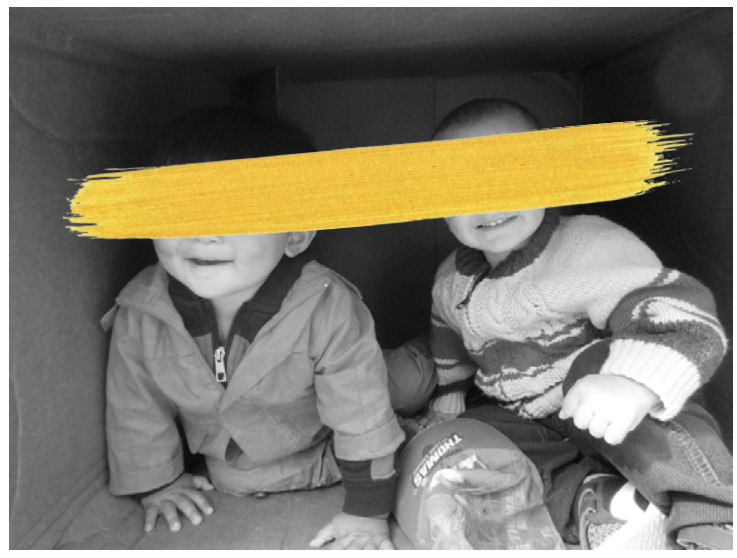




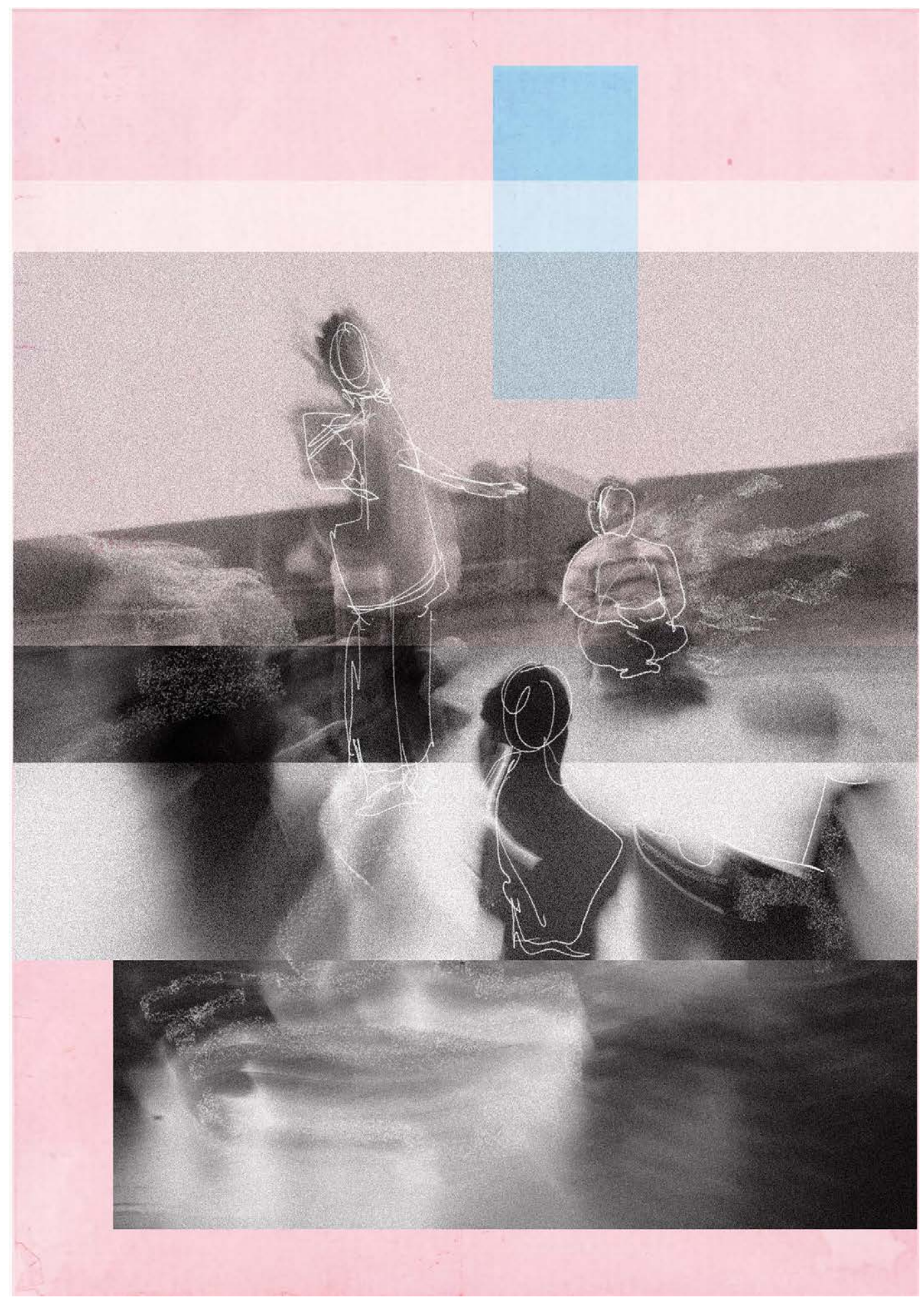

Fig. $\mathbf{7 1}$ Social Movements 


\section{The following design of a children's workshop}

(fig. 72) was inspired by the light industrial

workshops and studios neighbouring Kaban

Montessori School. The industrial language

within the school's existing architecture, such

as the garage doors, were also celebrated as a

piece of the local culture and as a transformable

architectural tool.

The children's workshop creates a safe space for

The garage doors allow for a fluid transition between workshop and community build-yard. When open they can transform into an extension the people within this close trades community to share their knowledge, tools and materials with the children. The transitional layout of the design also encourages a transformation of materials and knowledge as they are brought closer to the school's interior. For example, the edge of the workshop is designed as a point of connection between community and the children's 'house'. From this collection point not only is the culture and knowledge of the community brought into the school, but raw materials may be transformed into tools, projects or new creations, establishing new landmarks and personal connections for the children.

When clear of materials, the community buildyard can also transform into a community theater for the neighbouring theater group. 


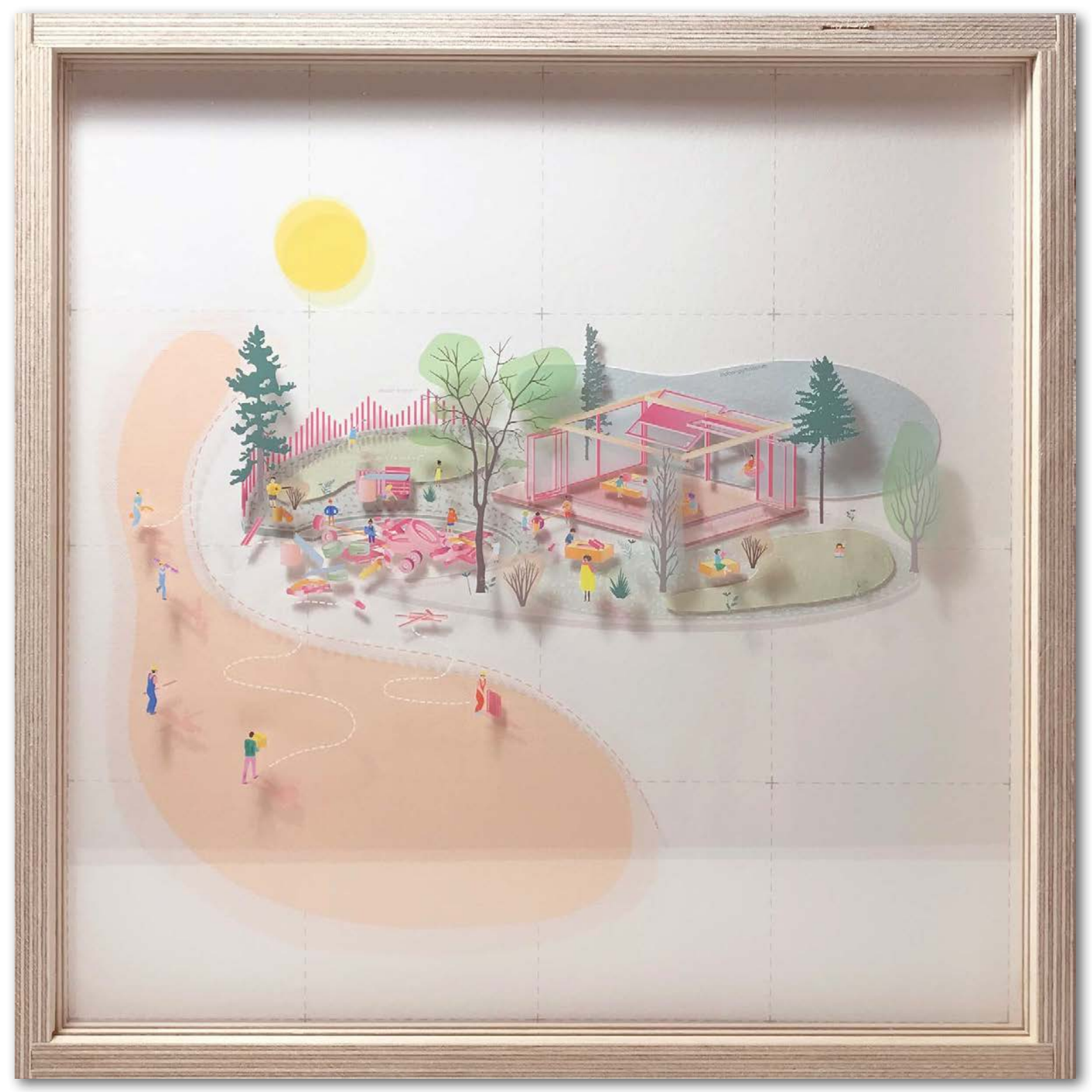

Fig. 72 Children's Workshop 


\section{Order}




\section{4 _ Order}

\section{A Progressive Approach to Design}

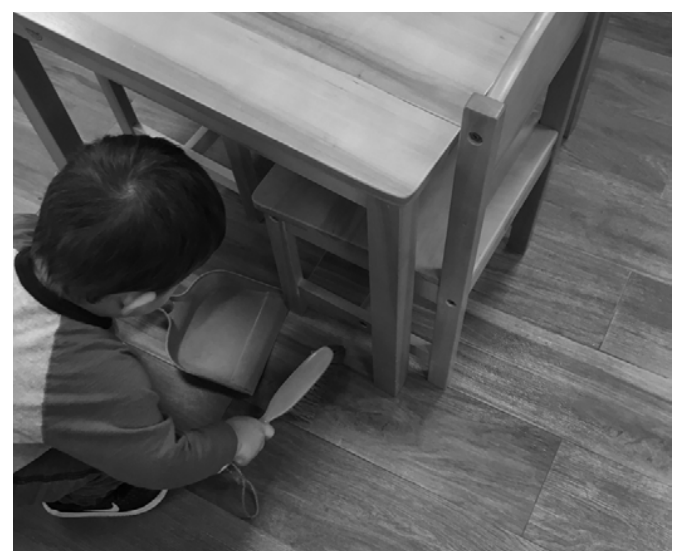

Fig. 73

Child cleaning up spilled material to put it back in its place - Kaban Montessori School
The concept of order, as mentioned in 'the Montessori Method', is a way of preparing learning environments so that the child may find a means of orienting themselves physically and psychologically. ${ }^{46}$ The simplicity and harmony of architectural elements is a key feature in helping children order their minds, make decisions, construct their identities and feel safe. ${ }^{47}$ Likewise, a child's ability to regulate their own behaviour and to thrive independently relies heavily on the environmental features and organization of the school described in the following design strategies and approaches. ${ }^{48}$

\section{Secure, and personal environments:}

As identified in the Vega Workshop, unless children feel secure and connected to their environment they will not enjoy or explore the spaces that surround them. This was quite clear in the children's behaviour throughout the child-led tours and coincided with the themes of ownership and personal connection that emerged quite frequently in the drawings and photographs the children created. So, how can learning environments be designed to feel more 
comfortable? Weinstein explains that "children are more likely to explore if [their] environment has a sense of order". ${ }^{49}$ This is due to creating spaces that are easily recognizable and understood by children. Having a sense of how a place works, through either memory or intuition, increases one's level of competence and as a result, one's confidence and independence. Thus, learning spaces should strive to incorporate elements and landmarks that not only make the space distinct, but that the child can relate to or bond with. Similar to the ideas of ownership described previously, it is this quality of connection that helps a child feel secure and at ease in their environment.

\section{Scale, simplicity and spatial definition:}

Another form of spatial security is derived from the simplicity and physical definition of a space. In terms of a child's natural intuition, during the ages of six months to four years, children experience an acute sensitivity to small details and changes in their environment. ${ }^{50}$ This considered, learning spaces, especially those for children going through this plane of development, should be more ordered, uncluttered and consistent if they are to provide a peaceful environment where children will not be overwhelmed or easily distracted.
Moreover, the plan of a school should be simple and compact, with high levels of differentiation between learning spaces. For example: views to exterior landmarks - orienting the school within the neighbourhood, the use of distinctive physical features, such as gradients of colour, light, and height, texture of building materials (both further defined within the interactive principle), as well as clear boundaries that determine the ease of one's flow through space. These conditions can not only help a child learn what type of activity takes place within an environment (as described through the intimacy gradient in community and culture), but it can also decrease a child's confusion and frustration when it comes to quickly gaining a sense of orientation..$^{51}$

It is also important to note that the size and proportion of a space has a great effect on how a child experiences their environment. During the 1960's, it was assumed that the larger a school was, the more it had to offer and thus the better it was. ${ }^{52}$ However, in recent years, the attitude towards school size has shifted. Halpin as well as groups such as the HSE (Small Scale Education), debate that human-scale spaces are more likely to foster more personalized learning, intimate relationships, and a sense of security and competence within children, overall encouraging 
a more holistic approach to education. ${ }^{53}$ These groups suggest that schools be designed more as pavilions, tending towards groups of seventy-five children. According to Halpin, schools exceeding this number tend to overwhelm young children with the shear number of staff and students, complexity as well as size of space. ${ }^{54}$ For this reason, it becomes very important to provide learning spaces that are attuned with the child's stage of development.

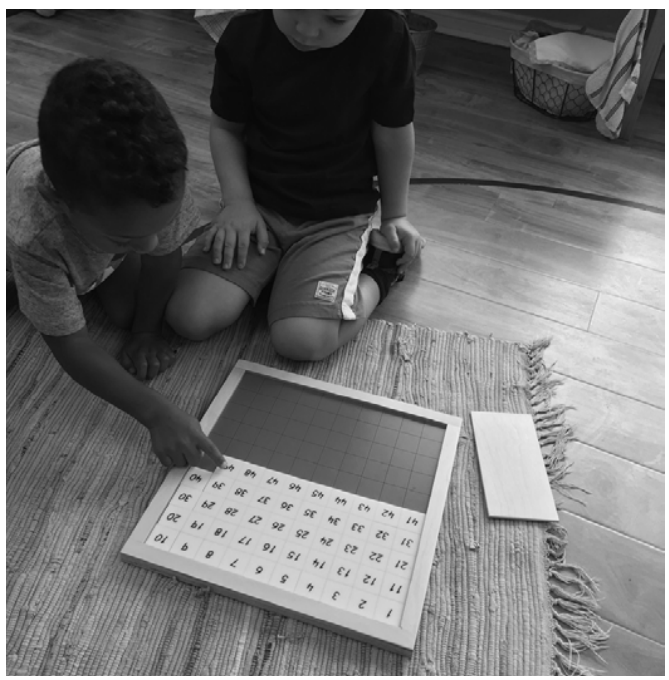

Fig. 74

Children using counting learning material and organizing the chips into rows - Kaban Montessori School 


\section{Interactive}




\section{5 _ Interactive}

\section{A Progressive Approach to Design}

During early childhood, children take the world in through their senses; as presented in the latest studies in experimental psychology. "Every stimuli of the physical and social environment becomes a discovery and learning experience which forms the fundamentals of intellectual, physical, social, emotional and perceptual development." ${ }^{55}$ Both Piaget and Montessori also described the first period of development as a sensorimotor phase, during which children, especially those under the age of 3 , experience their environment primarily through their senses. ${ }^{56}$ Therefore, learning spaces should be designed to not only support the program, but to nourish the child's sensory receptiveness through a rich and varied environment. Embracing this responsive approach, the following design strategies will explore how children's interactions with learning spaces can be structured to support the learning process.

\section{Variation in sensory stimulation:}

As mentioned in the chapter on 'order', children will not thrive in an environment in which they do not feel secure and competent. According to Weinstein, balanced tactile sensations are a key 
component in conveying security by fostering feelings of comfort and alertness. ${ }^{57}$ Thus, as architectural features invite touch, and other sensory stimuli, the more children can define that setting as a safe space. Accordingly, schools should design enough variation and complexity within its learning spaces that children are provided with a diversity of landscapes they can observe, manipulate, alter, interact with and learn from. For example, opening and closing windows and doors, controlling light fixtures, playing with water and learning materials, changes in ceiling heights, floors and boundaries, as well as baking, listening to music or playing instruments, and arranging flowers, not only provide recognizable, yet diverse conditions that further shape the sensory landscape, but should also allow children to produce self-induced experiences that provide immediate feedback of their own actions. ${ }^{58}$ Furthermore, apart from the relatively handscaled interactive Montessori learning material described in 'the Montessori Method', furniture and large scale architectural elements should contribute to a child's sensory and intellectual development. Designers should then conceive the whole building -floors, walls, partitions, ceilings, horizontal and vertical supports, apertures and building systems- as a potential for play and a tool that can reinforce and teach lessons. For instance, furniture and partitions throughout a school should be lightweight and flexible, not only "considering a child's ergonomics, but placing them as [co-designers of their environments, by allowing] spatial re-configuration, [and manipulation]." 59

However, while variation in sensory stimulation is crucial for child development, under stimulation can lead to restlessness, and difficulty in concentration. ${ }^{60}$ Conversely, dramatic fluctuations and excessive sensory stimuli will also frighten and disorient young children. ${ }^{61}$ In order to achieve optimal levels of stimulation that positively respond to the developmental needs of the child, moderate variations of rhythmic or recognizable changes in the environment, such as those previously suggested, must pose just enough diversity to stimulate a child's attention, while maintaining a sense of 'order'. ${ }^{62}$ 


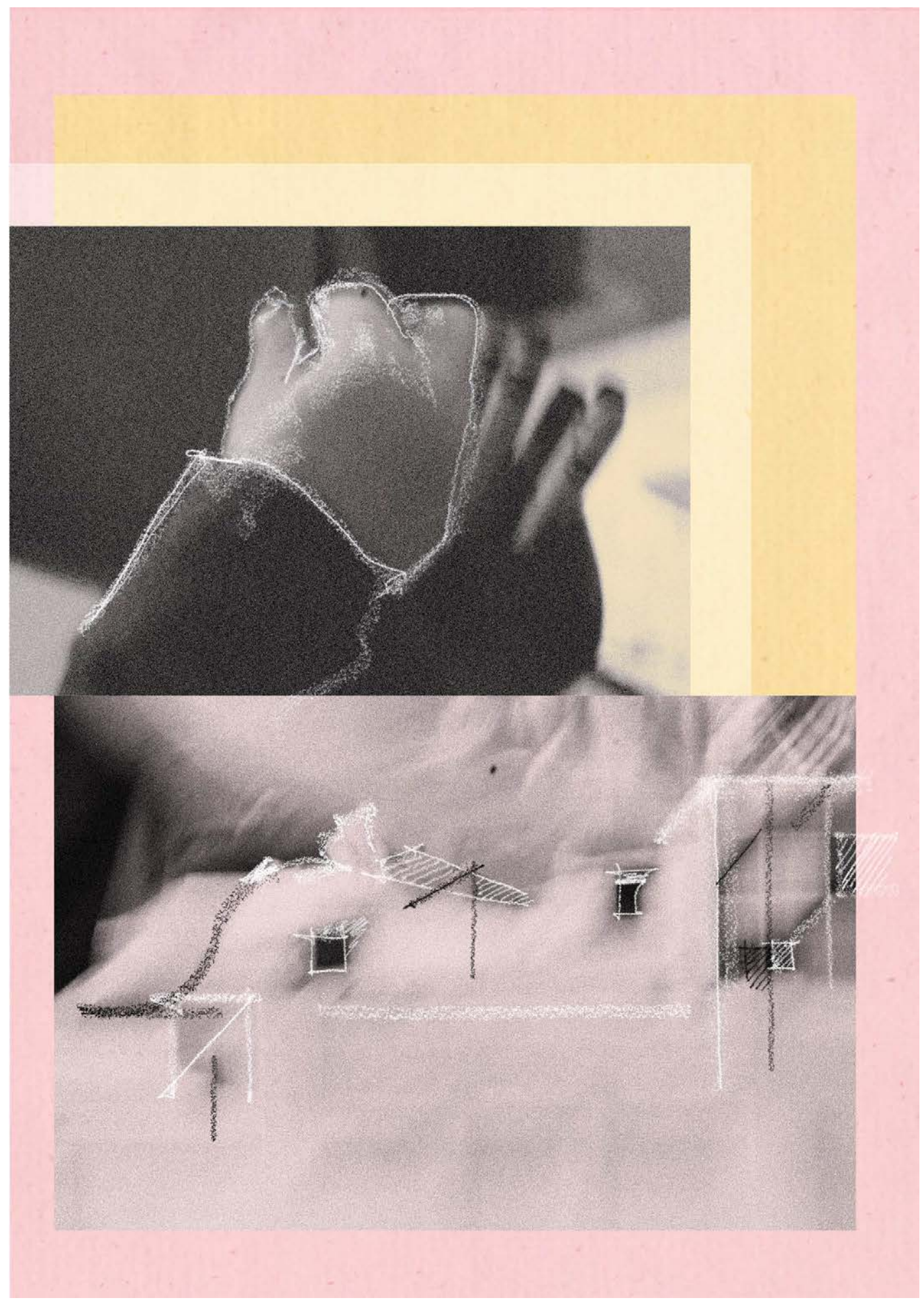

Fig. 75 Motions of the hand 


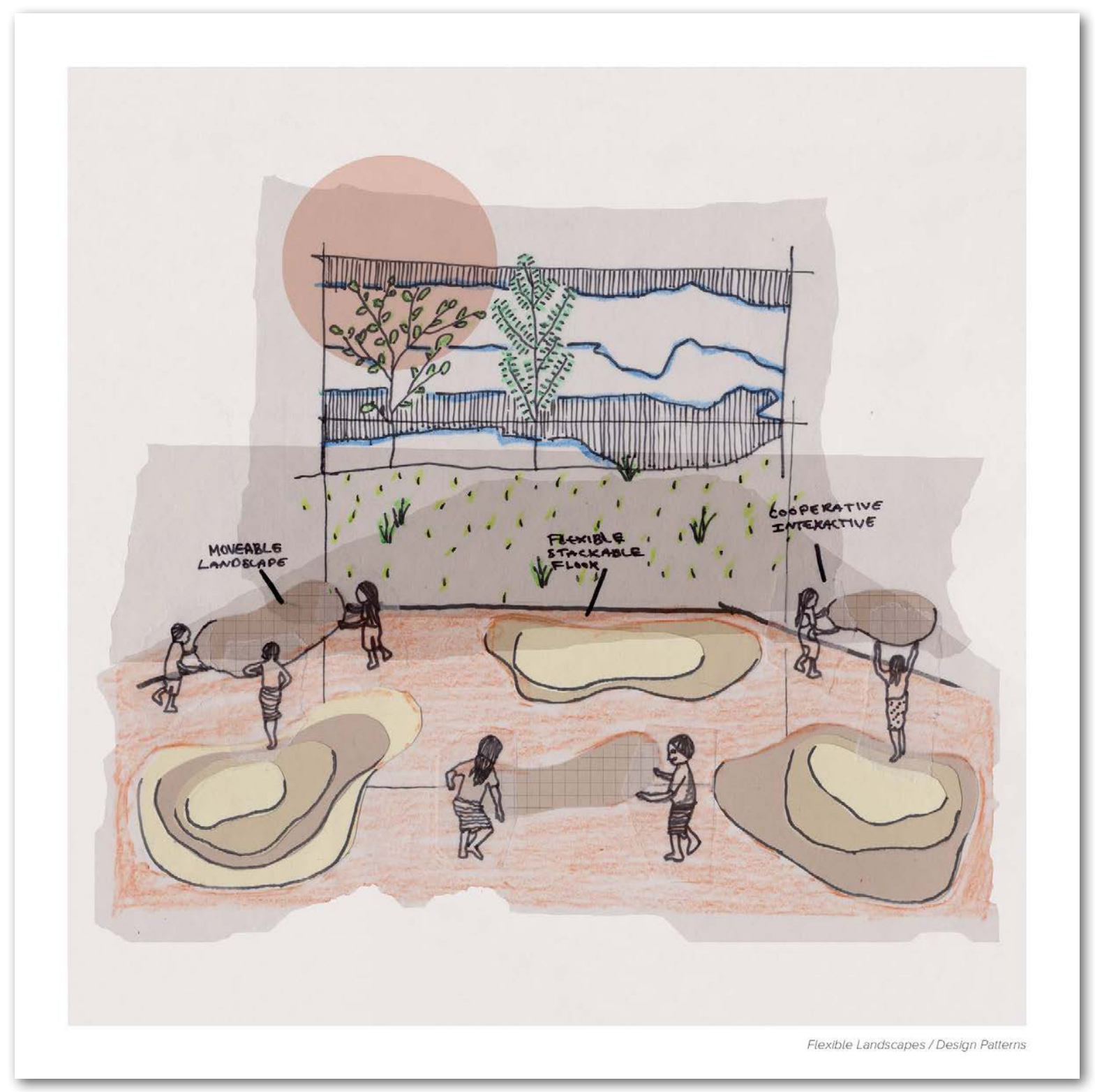

Fig. 76 Flexible Landscapes - Speculative Drawing 
The following learning space explores the interstices that occurs between classrooms and applies the design patterns described in the principles of 'Freedom', 'Community', and 'Interactive'.

The proposed interstitial space aims to expand

The rotating wall panels are designed to the scale of both the child and adult, each able to the classroom's boundaries beyond its four walls, define the boundaries of the learning space based on individual need. interconnecting the school's learning spaces into one. For this to occur, the interstitial spaces must themselves become a place of engagement and activity if they are to encourage both teacher and student to engage the interstices as a fluid continuation of the previous learning environment.

For example, the interchangeable hanging panels below skylights provide shadow play activities, such as movement inspired spelling games. Similarly, the child-scaled portion of the wall panels are also designed as light weight interchangeable materials. Some panel designs include:

- Textured sensory stimulus panel

- Weaving dream-catcher panel

(for cultural, social, and fine-motor development)

- diversity of seating

- customizable ball maze panel

- drawing panel

- interactive pinscreen panel 


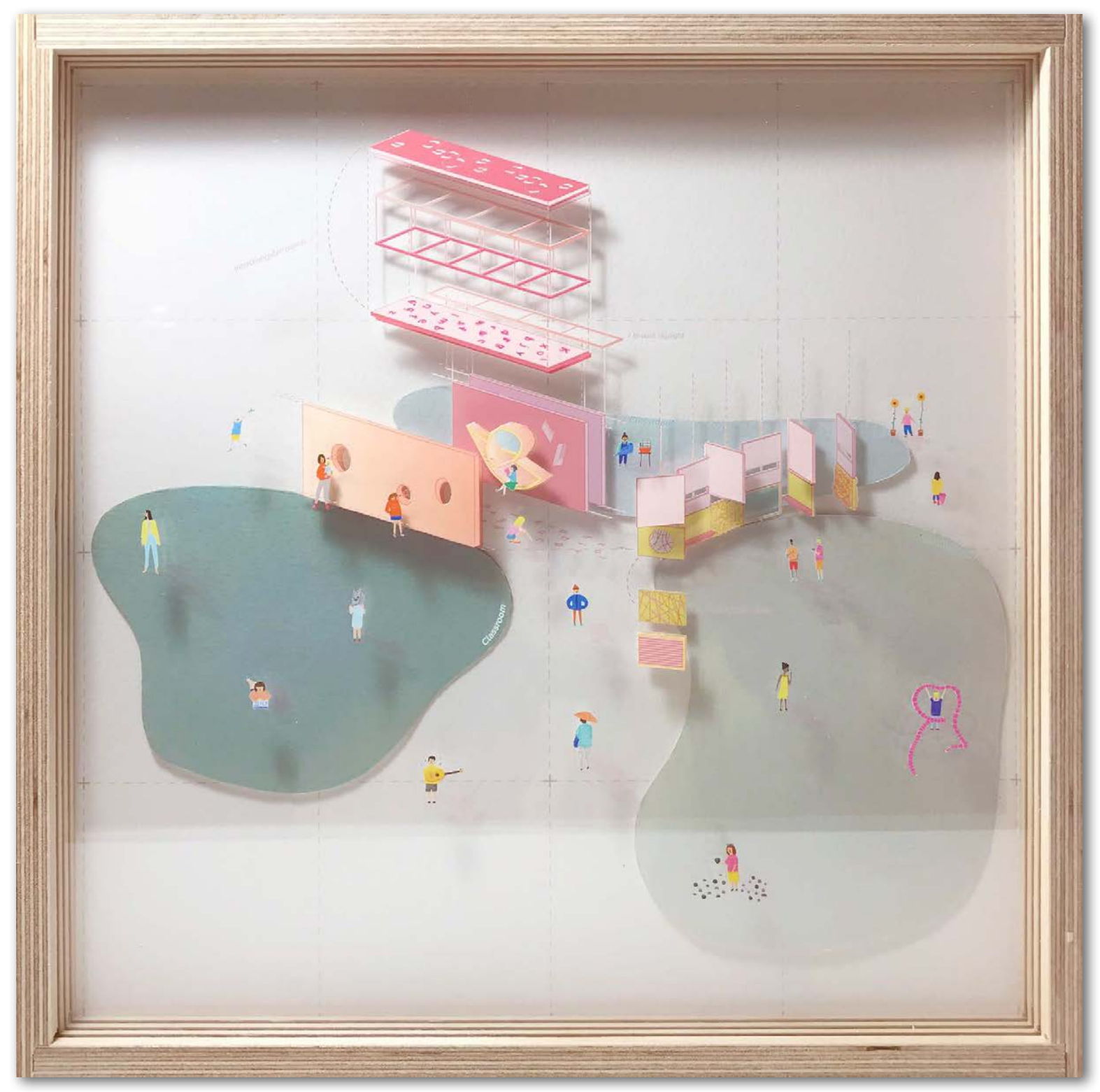

Fig. $\mathbf{7 7}$ Interstitial Space - between school and classroom 


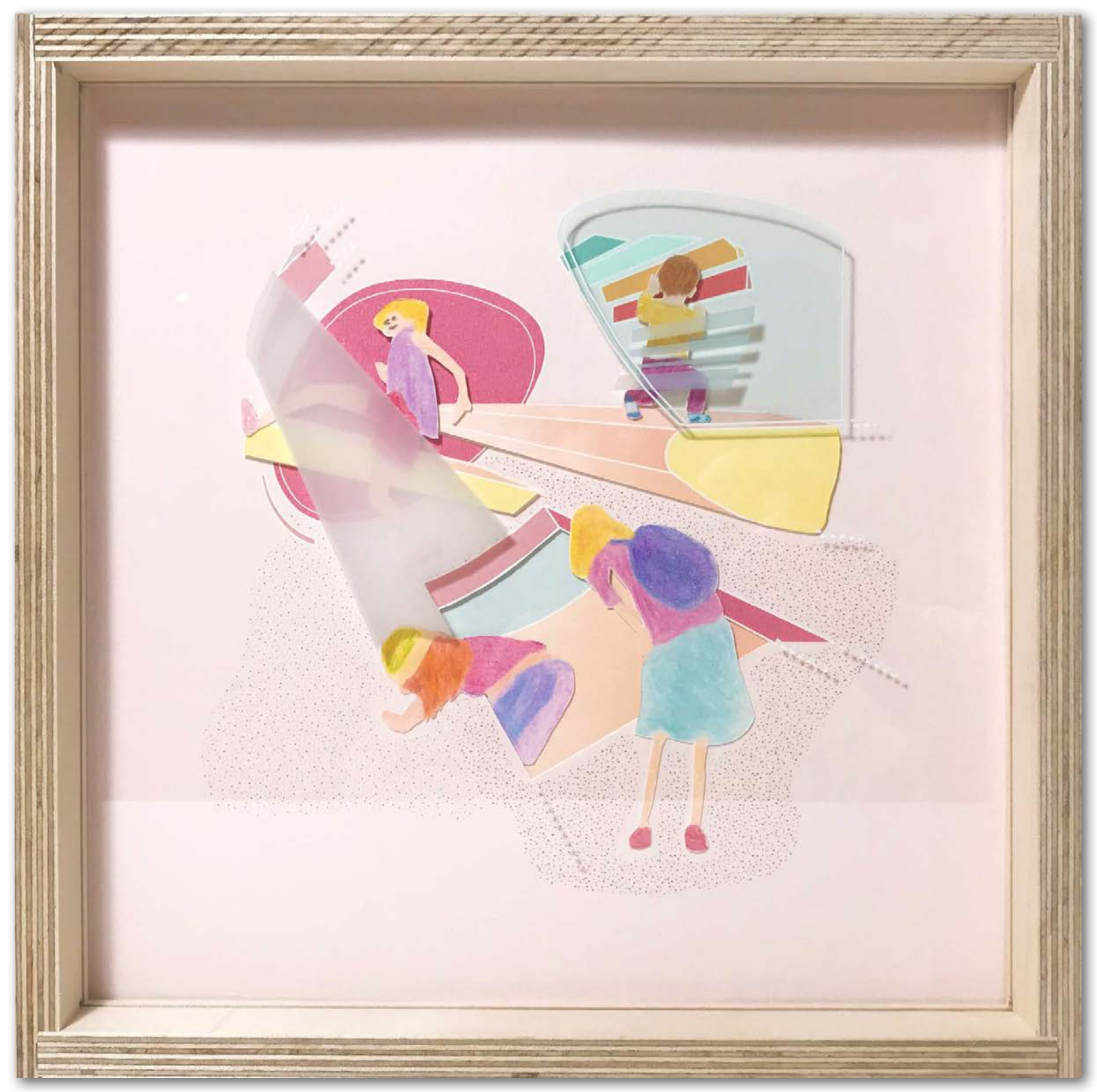

Fig. $\mathbf{7 8}$ Interstitial Space - Intimate spaces (within walls) 


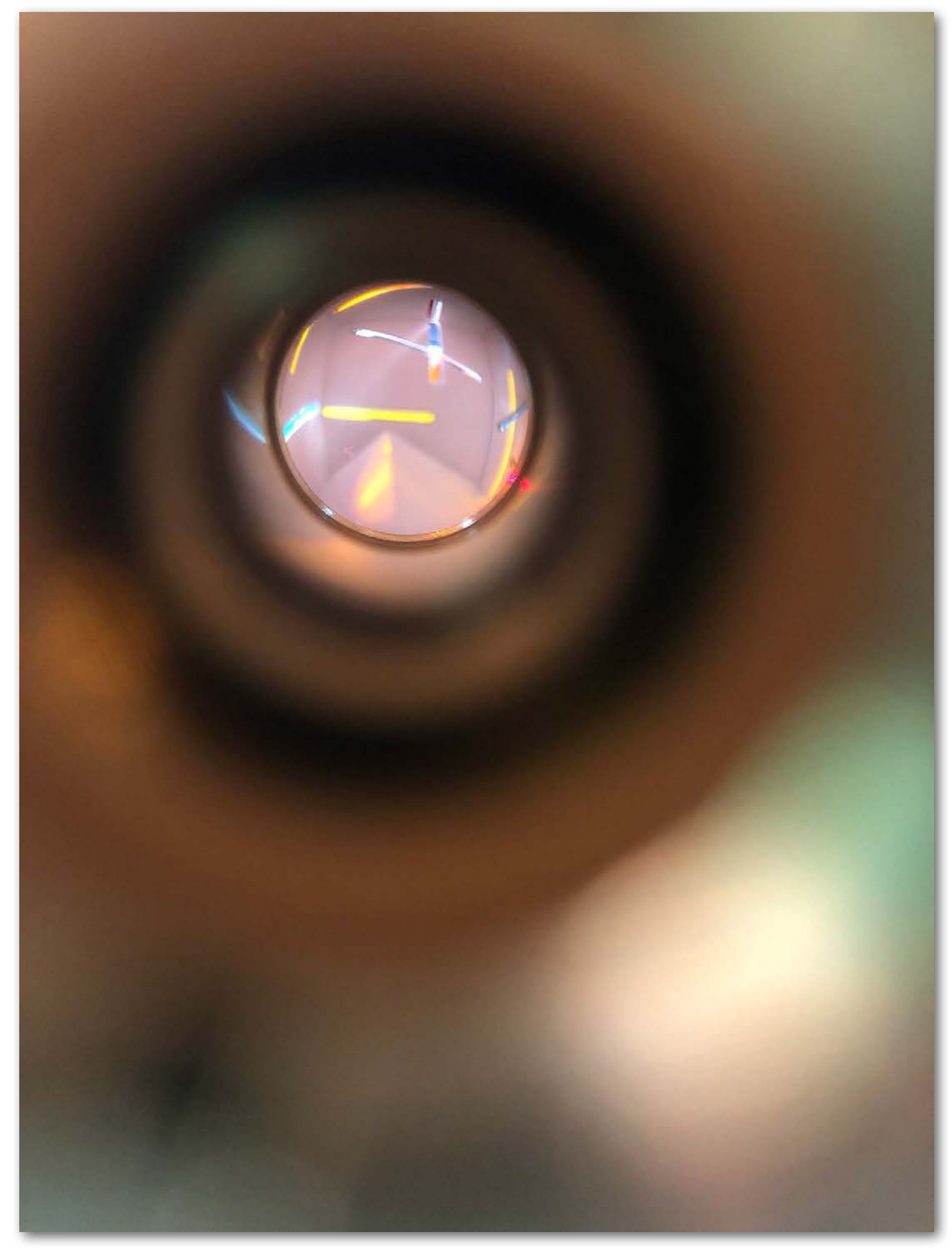

Fig. 79 Exploration of child's perspective - Shadow Play 


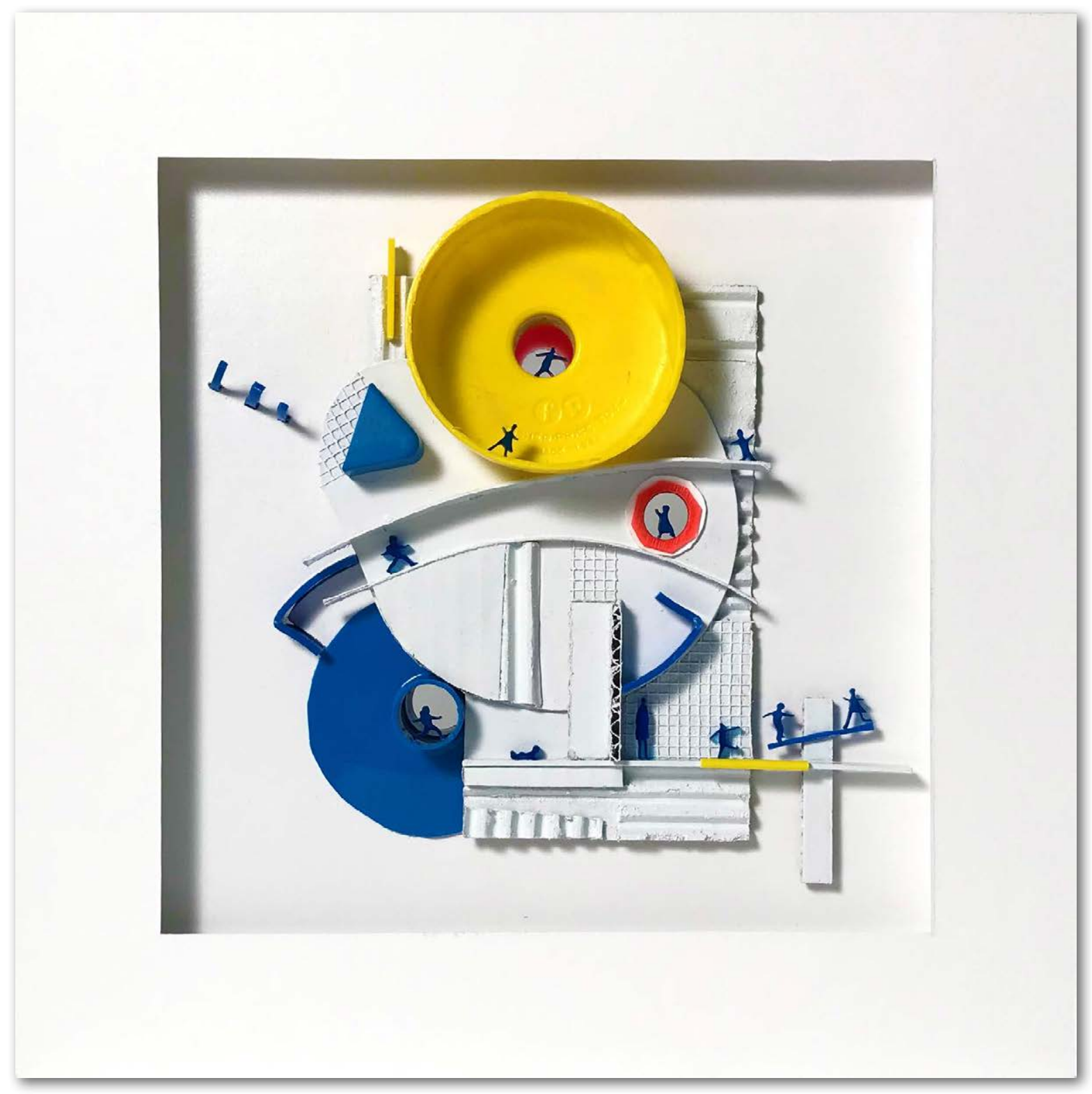

Fig. 80 Toy Exploration - Intimate Spaces 


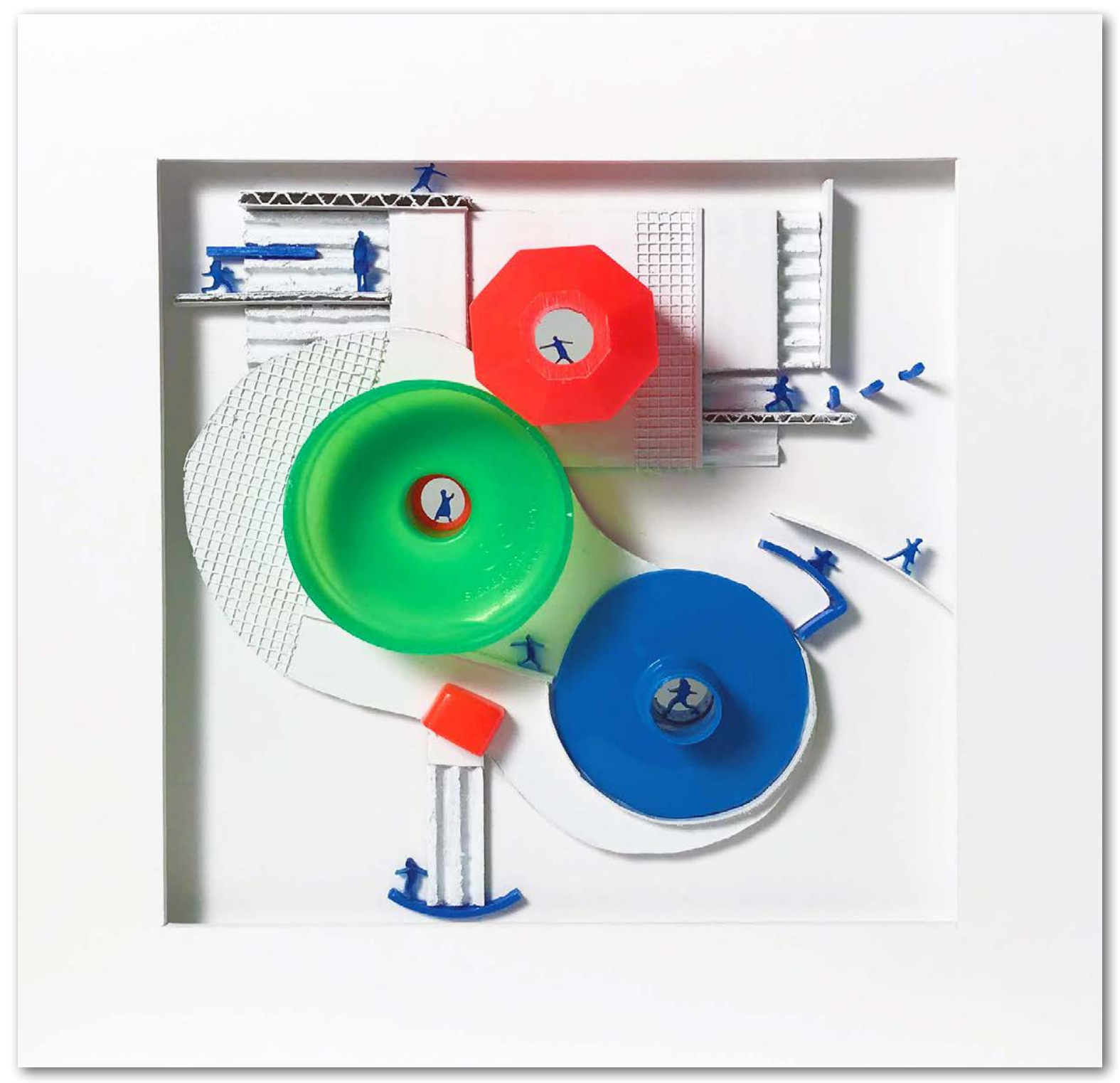




\section{Integrated}

는

\section{Innovative}




\section{6 _ Integrated + Innovative}

\section{A Progressive Approach to Design}

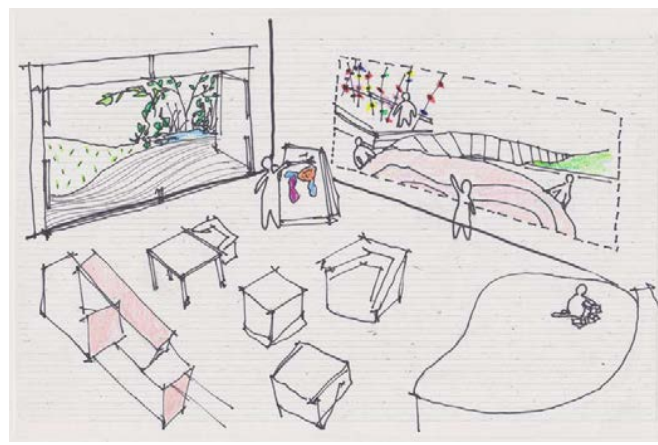

Learning is dynamic and diverse; integrated and innovative learning environments interrelate and coordinate the vast web of knowledge and technologies driving the world, presenting these ideas and elements to children through a holistic process and space. ${ }^{63}$ While pedagogies, such as the Montessori Method, practice a

Fig.82

Schematic sketch of virtually connected classrooms from across the globe

cross-disciplinary approach and are constantly observing and adjusting the curriculum to provide for a child's evolving developmental needs, the challenge remains in finding ways to fluidly integrate the complexities of a modern society into learning environments. Thus, "for the sake of the child's fluid transition between planes of development," it is essential that those same transitions are mirrored within the space and pedagogy. ${ }^{64}$ The following design strategies aim at addressing ways in which all forms of knowledge and new technologies can be implemented as a harmonious and interrelated whole.

\section{Integrated Spaces:}

As schools grow and integrate more specialized topics and activities within the curriculum (music, art, media centres, etc.), they risk fragmenting 
learning spaces and isolating learning experiences by subject or categories. In order to avoid this disjunction, learning spaces should be designed as flexible environments where many forms of learning can take place simultaneously. For example, schools may integrate lessons about science, math, geometry, baking, building, and drawing within the same learning space -allowing children to not only retain control of their time and 'freedom', but to explore and discover the connections that exists betweens life's many phenomenon. In other words, schools should provide architectural elements, materials and programs within each learning space that makes reference to multiple areas of study.

\section{Buildings that teach:}

Technology has revolutionized not only the built fabric of the world, but also the way in which we learn about it. Children's "learning tools, modes of thinking and skills needed [to thrive in today's dynamic society are continuously changing." ${ }^{55}$ According to Valle, "what makes a school modern is not technology [itself], but the scientific [methods] behind it." ${ }^{66}$ So, how should schools be designed when information is personalized, streamlined and available everywhere? Montessori materials, for example, are designed using scientific methods of observation and experimentation and are then prepared to reflect a pedagogy. Likewise, new information and sustainable technologies must also reflect the intentions of the pedagogy for it to be successfully integrated as a tool for development in a progressive learning environment. For example, information technology has made it possible to instantly communicate with cultures from all over the world. With live stream video, it is now possible to use virtual space as an architectural tool to connect diverse learning environments to each other, teaching children to both embrace identity and navigate difference. ${ }^{67}$ However, this strategy applies the benefits of technology only as far as it serves as a developmental tool -expanding the boundaries of the classroom across the globe. Similarly, as with information technology, sustainable technologies, like alternative systems, materials and processes that improve a buildings environmental impact, must not only serve the building, but respond and contribute to the social, emotional, cognitive and physical development of the child. These innovations can become an active participant within a learning environment, teaching the life cycles as well as improving them. "The best form of learning takes place within an integrated environment of architecture, technology and [pedagogy], which come together seamlessly." 68 
The following greenhouse design acts as a

transitional space between interior and exterior

environments. According to teachers interviewed

during the workshop, in cold climates such as

Canada, a space like this is crucial if children

are going to be able to fluidly move from inside

to outside without disrupting the flow inside the

classrooms.

However, a transitional space must be more than

The skylight creates a visual connection from inside and outside the school, creating just a space to prepare oneself for the exterior landmarks children can use to orient themselves.

climate. As mentioned in previous principles,

it must simultaneously be a space of its own,

offering children activities and experiences unique

to its own context.

For example, the structure and walls that make up

In a manner similar to the Children's Workshop, the Greenhouse and retractable facade is the greenhouse are designed as double paned vegetation observation panels, helping children see and understand the ecology behind living organisms. This design approach integrates the designed to be a continuous transitional space allowing for exterior access wherever possible, and fluidly merging the boundary between interior and exterior learning spaces.

Roof planters help to filter the rainwater as it makes its way to the playground water sources. science curriculum beyond classroom small scale projects and into the working fabric of the school. The rainwater and water building systems that maintain the greenhouse and playground water sources are also designed as an interactive component of this learning space where children can not only learn about the life cycles but how to manage their own environments. 


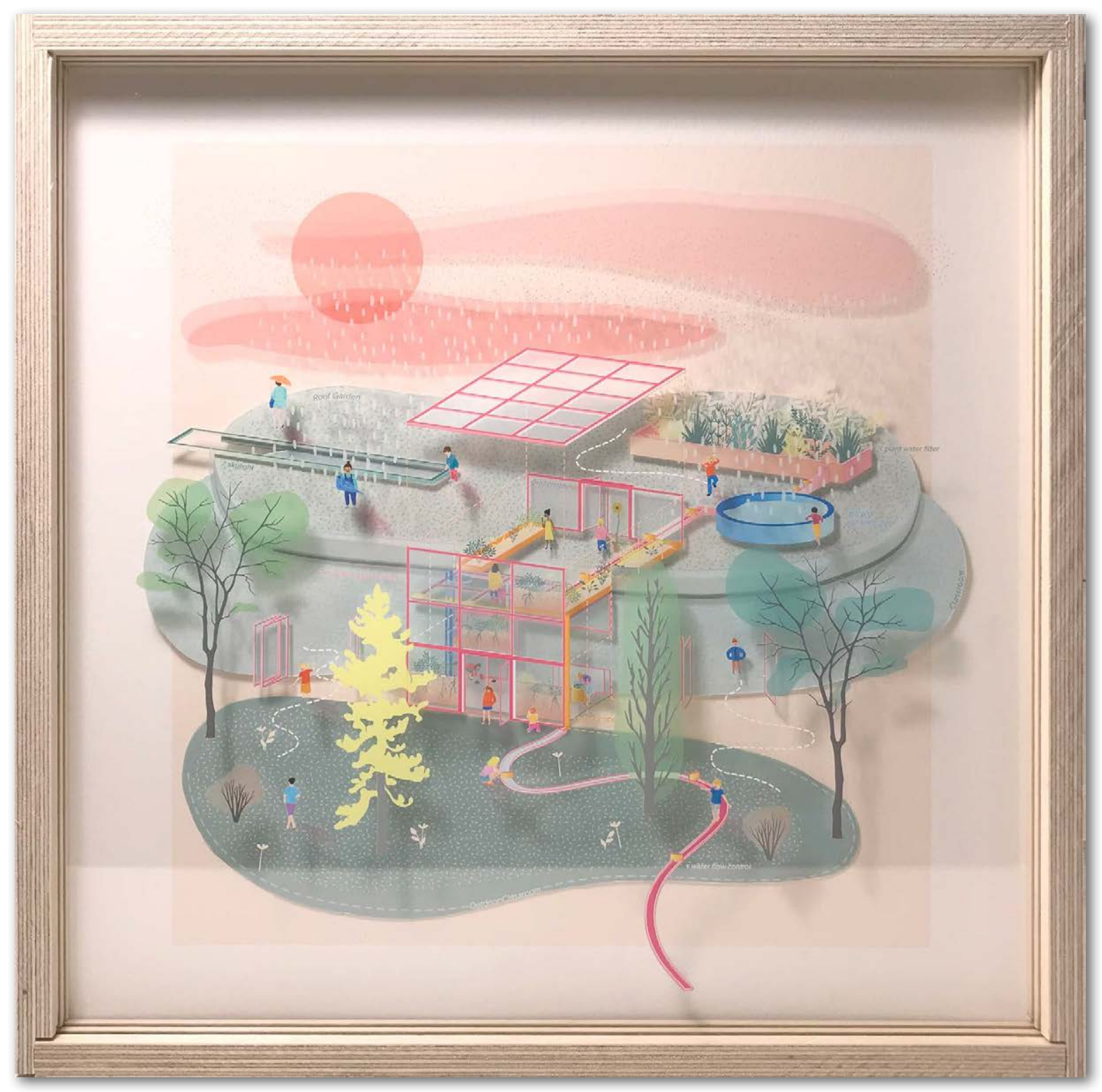

Fig. $\mathbf{8 3}$ Children's Greenhouse - Transitions (Interior/Exterior) 


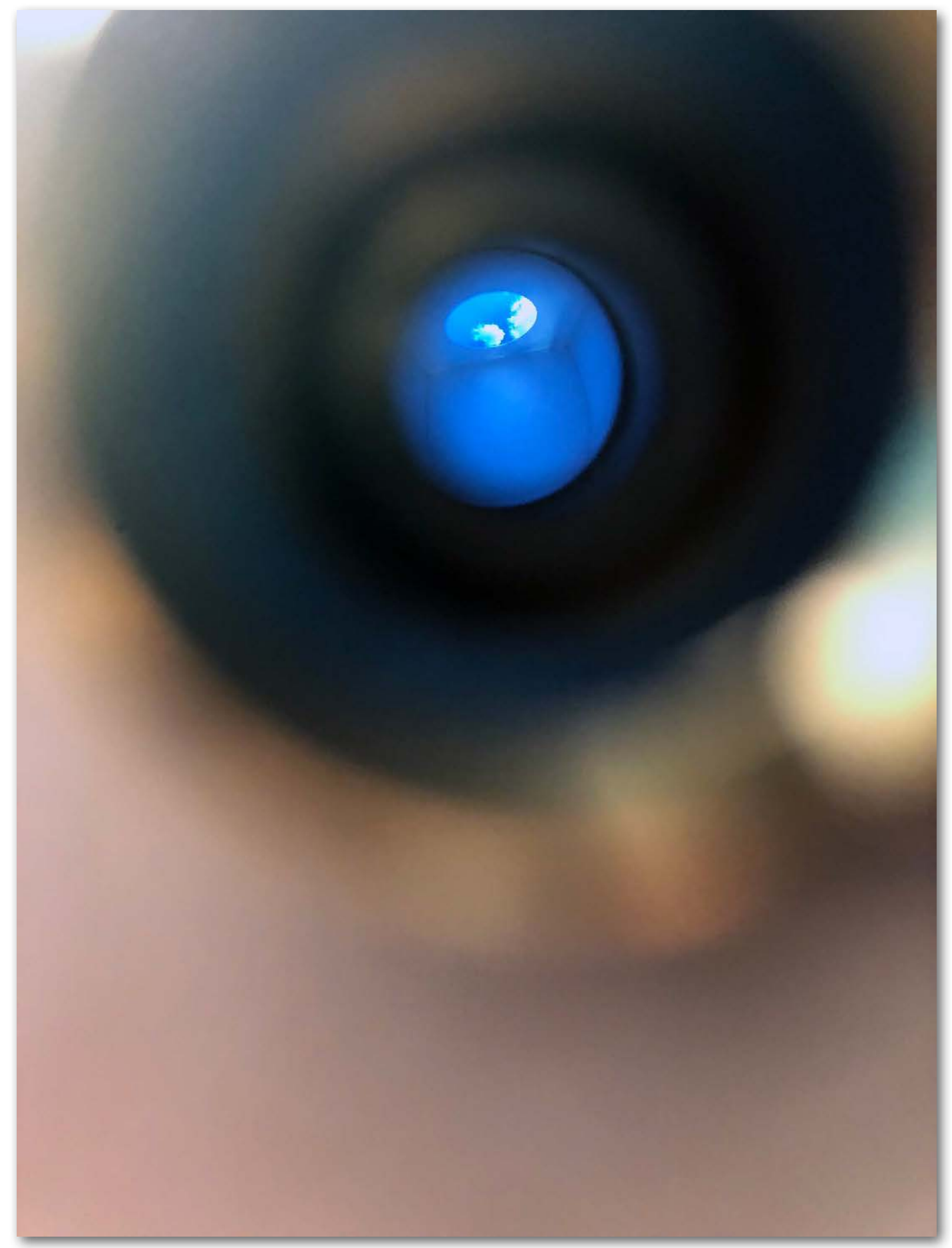

Fig. 84 Exploration of child's perspective - Captivated by the detail (skylight) 


\section{Erkinder}




\subsection{Erkinder}

\section{A Progressive Approach to Design}

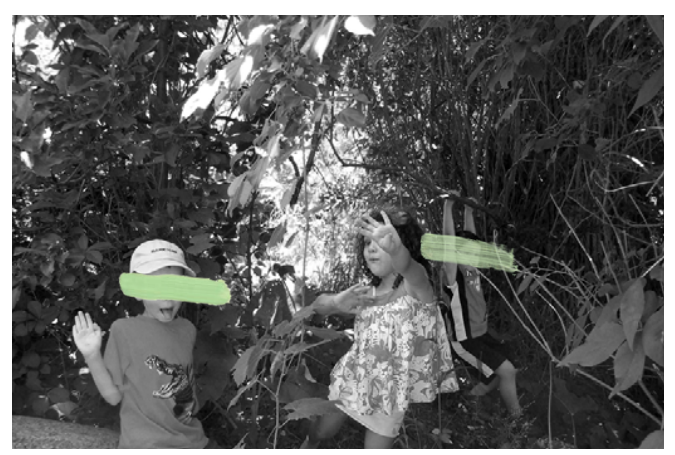

Fig. 85

Children drawn to wild natural places

er.kin.der

/"erkinder/

noun

is the German word for "child of the earth". This concept is a part of the Montessori philosophy and drives the school's sustainability and ecology program, activities and material.
"There was a child went forth everyday...and the first object he looked upon, that object he became, and that object became a part of him for the day...or many years...and these become of him or her that [are sought out far and near]." - Walt Whitman

As mentioned in the chapter on freedom, the expanse of a child's territory has been on the decline, especially the natural and wild domains outside the walls of the school. According to child psychologist Brian Sutton-Smith, the natural landscapes of childhood have become too barren and play too domesticated; the fields of pavement and freshly cut lawns "devoid of vegetation with which to form nests, shelters, wands, dolls, and other playthings." ${ }^{\circ}$ Even progressive schools, such as the Montessori Fuji Kindergarten, that allow children vast amounts of freedom, and balance a natural flow between indoor and outdoor environments, struggle to provide substantial outdoor practical life activities and supporting wild natural conditions for children to thrive. As discussed by several "progressive education philosophers such as Froebel, Montessori, Dewey and Rousseau, engagement with nature is essential to [the learning experience]", and in the case of Froebel and Montessori, it is not enough to order learning materials neatly on the 
shelves for children to play and learn from. ${ }^{70}$ The materials are only truly effective if they can be related to real life experiences and used in the process of exploration - rather than in isolation. ${ }^{71}$ The physical and psychological design of learning environments must offer the full spectrum of life's experiences and sensations, if it is to help children live in the most natural way possible - thus this includes all of nature's biospheres. ${ }^{72}$ Without introducing children to these realms, children's physical health and knowledge of the natural world fades. "To counter the historic trend towards [this] loss of wildness...it is clear that we need to find ways to let children roam beyond the pavement [and manicured lawns].”3 Our task is to design learning spaces that nourish the natural urge within a child to connect with the natural environment, in turn forging an emotional bond that will cultivate a child's land ethic and develop a "living ecological relationship...between a person and a place."74 Such environments will transform children into a new generation of healthy, active citizens who respect and understand their role and dependence on the world's ecosystems. ${ }^{75}$ The following design strategies aim at providing genuine natural environments and techniques that re-integrate the sensorial and psychological experience of nature back into childhood.

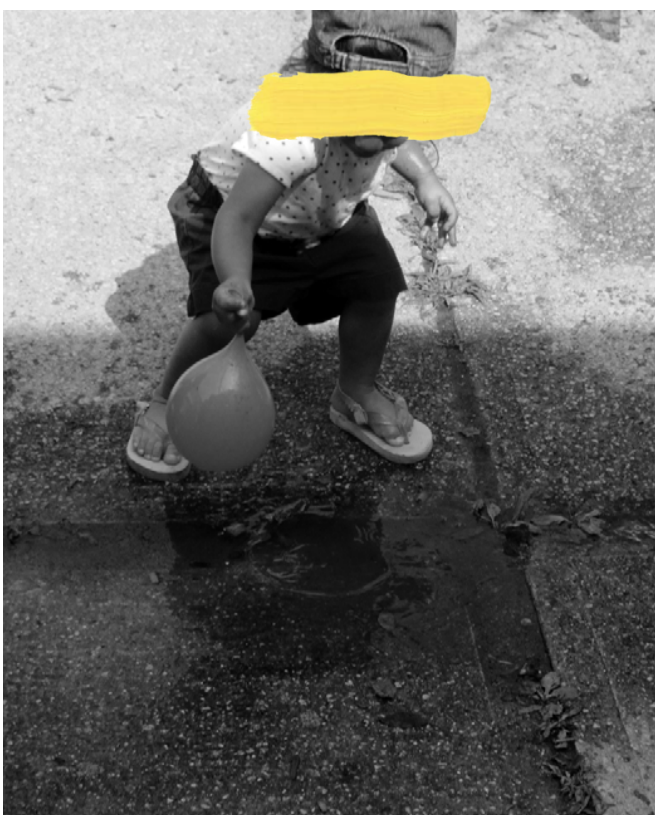

Fig. 86

Child playing with water
Nested spaces + natural materials and systems:

Just as with the indoor learning environments, natural play spaces should be designed to support the continuity of the developmental phases. This means that outdoor learning environments must also mirror the child's sensitivities according to their age. For example, according to Nabhan and as observed in the Vega Workshop, during a child's first and second plane of development, children favour nested spaces - intimate natural micro-habitats made up of "dirt, trees, bushes and loose parts to build and dabble with"- that foster emotional security and trust. ${ }^{76}$ Nabhan links the 'sense of wildness' 
in nature to this animal comfort that comes from a primordial connection to earthly sanctuaries. ${ }^{77}$ Moreover, some psychologists now believe that for young children, such as those in Toddler and Casa classrooms, these micro-habitats "extend a sphere of safety that humans experience during [pre and ] postnatal development."78 Thus a key spatial component that can help a child feel more comfortable within any learning environment are small semi-enclosed natural dens that provide shelter, landmarks and privacy.

Additionally, environmental psychologists Rachel and Stephen Kaplan explain that natural materials "such as plants (trees, shrubs, vines, ground covers), stones, water, dirt piles, fallen trees, hollowed-out logs, and a multitude of other natural elements designed to encourage handson manipulation and discovery", engage effortless "involuntary attention" that produces a sense of relaxation and promotes recovery from mental fatigue. ${ }^{7980}$ Likewise, similar observations were recorded in the Vega Workshop.

Thus schools should not only design wild natural landscapes, but extend their boundaries to include all those within the community. Such actions would not only expand a child's territory, but similar to the strategies suggested in the innovation-integration chapter, respond to the lessons contained within the life cycles of surrounding ecosystems. For instance, considering the natural environment as an extension of the school provides cross-curricular and overlapping opportunities. A few examples include: science (discussing life cycles), culture (stories of human connection and dependency of nature), math (building gardens) and language (learning the names of plant species) all provided by the natural learning spaces.

Similarly, the benefits children gain from natural settings, such as exposure to natural light and fresh air - which help create both physical and mental comfort through the control of atmosphere, temperature and air pollutants - ought to be translated and integrated within the architecture of a school. ${ }^{81}$ Furthermore, progressive learning spaces should enhance these qualities by introducing energy saving devices, such as recycled material, solar power, geothermal and grey water systems that teach the children how they can live in balance with their natural environments.

2.7 Erkinder - A Progressive Approach to Design 
The design of the following playground integrates the surrounding wild landscape into the school's site in order to provide the students with an accessible safe surrounding that is rich with diversity. The low shade garden below the netted beds, while still a natural component, provide a more controlled setting for children to experiment and continue to learn about life cycles.

The playground also includes many of the 'principles' within its experience, providing interactive and integrated components for the children to continue to develop their cultural, social, fine and gross motor skills.

For example, within the wild landscapes of the playground, children learn to build small nested huts using the raw material from the land and recycled bicycle tires from the children's workshop providing frames to hold their structures in place.

Similarly, the walking and climbing beams scattered and arranged throughout the playground are movable buildings blocks repurposed from the donated natural material from the community build yard that the children can compose and rearrange to suit their own designs. 


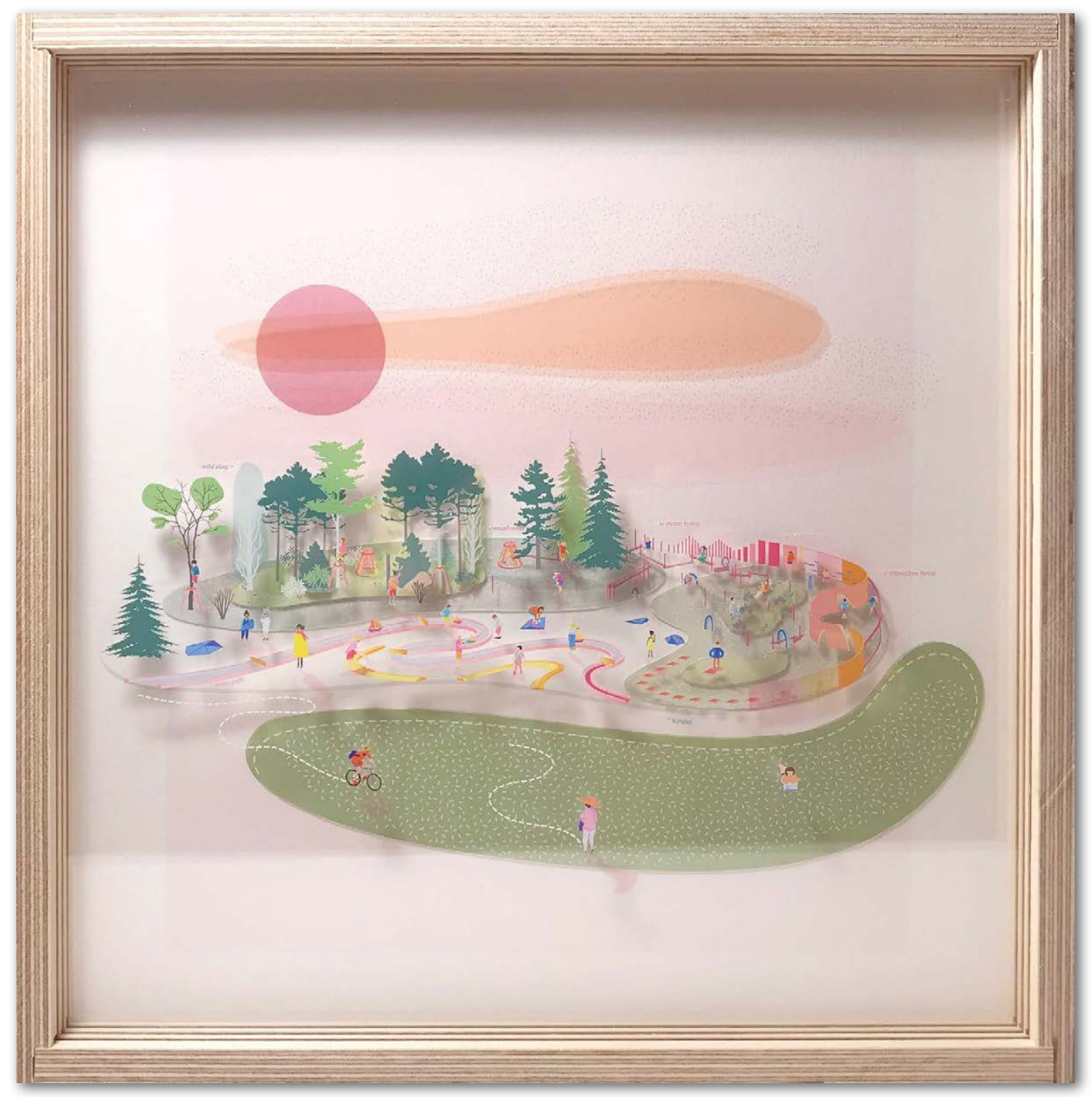

Fig. 87 Adventure Playground - Wild Landscapes 


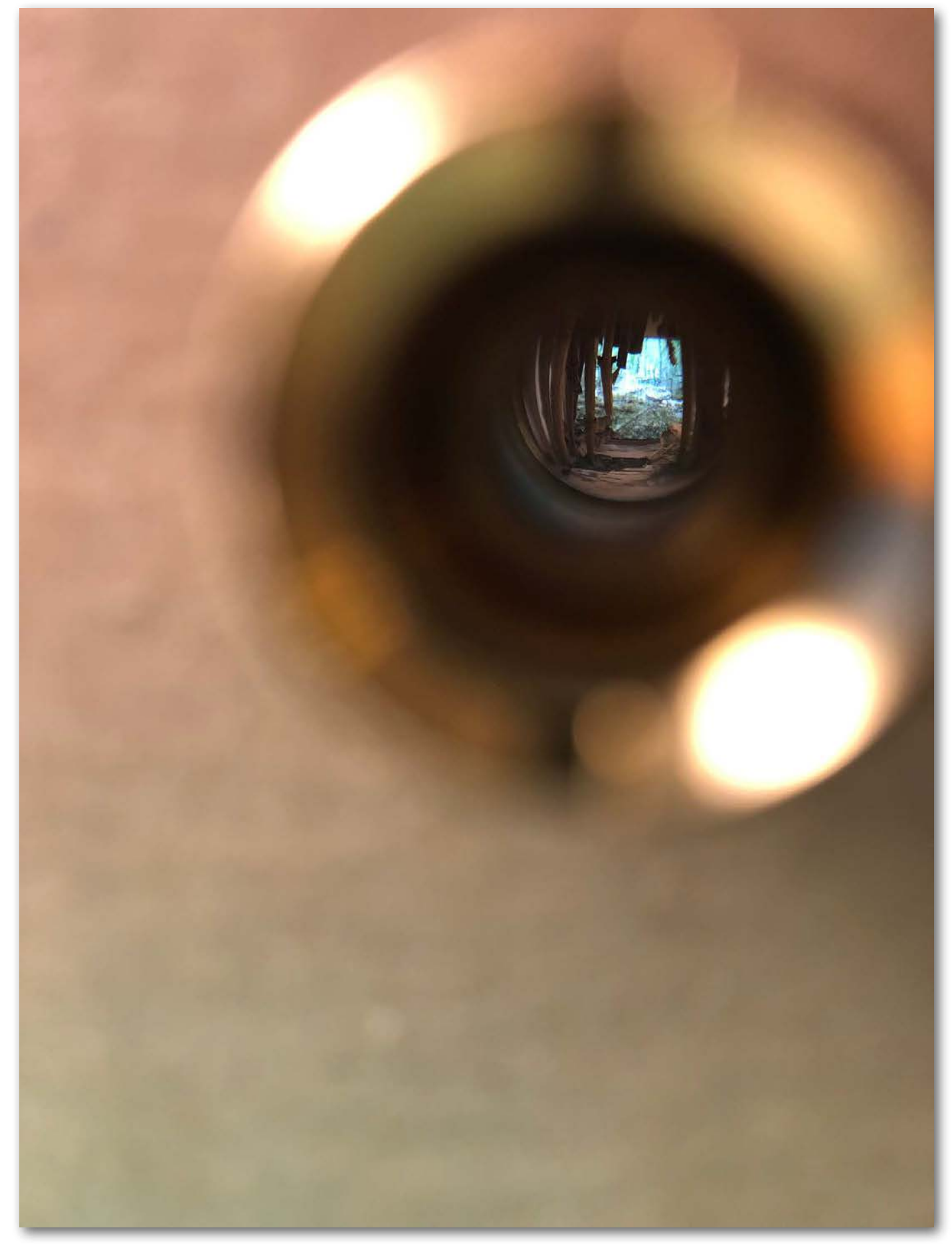

Fig. $\mathbf{8 8}$ Exploration of child's perspective - Nested spaces 
“...a ditch somewhere - or a creek, meadow, woodlot or marsh...These are places of initiation, where the borders between ourselves and other creatures break down, where the earth gets under our nails and a sense of place gets under our skin...

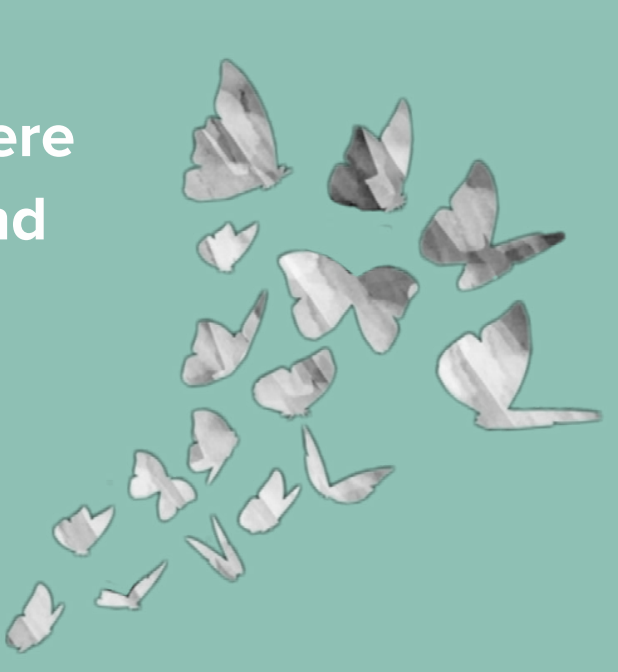

...Everybody has a ditch, or ought to. For only the ditches and the fields, the woods, the ravines can teach us to care enough for all the land." 


\section{8 _ Postscript}

\section{Translatable Patterns}

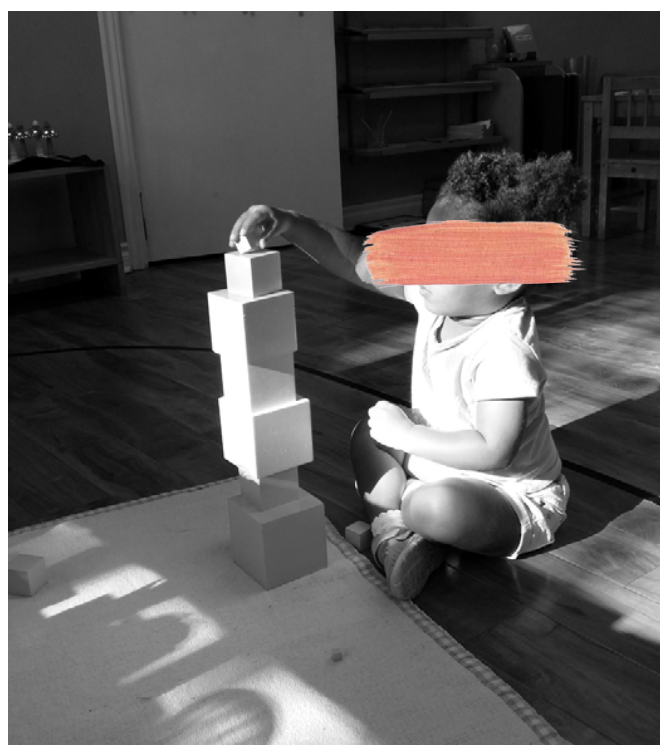

Fig. 89

Child playing with the 'Pink Tower' learning material - Kaban Montessori School
This thesis sought to understand, explore and deepen the architectural patterns that help shape the way children learn from their environment. Drawing on the pedagogical principles that form the core of progressive education, as well as the field work gathered from the author's workshop, this thesis develops ways in which architecture can reinforce the learning experience as a third teacher.

Through analyzing the program, conditions, site, and cultural context at Kaban Montessori School and its surrounding community, this thesis was able to propose the design of a variety of architectural moments of various scales (ranging from micro, mezo and macro) inspired from the latent potentials at Kaban.

However, it is important to clarify that the distinct designs proposed throughout the thesis project are not an all inclusive, universal solution for all progressive learning spaces. They are a combination of site responses and interpretation of the principles described. 
For this reason, the architectural moments designed herein have abstained from the realm of the absolute in order to illustrate the versatility not only within each moment but throughout the patterns themselves. Thus, Fig. 92 suggests only a potential - an unconstrained plan of Kaban Montessori School where the progressive patterns can be envisioned and overlaid on the existing grid.

If this thesis hopes to accomplish one thing it is to inspire and guide anyone interested in designing or improving progressive learning spaces on ways in which one could uniquely adopt the design patterns depicted and adapt them to any children's landscape. 


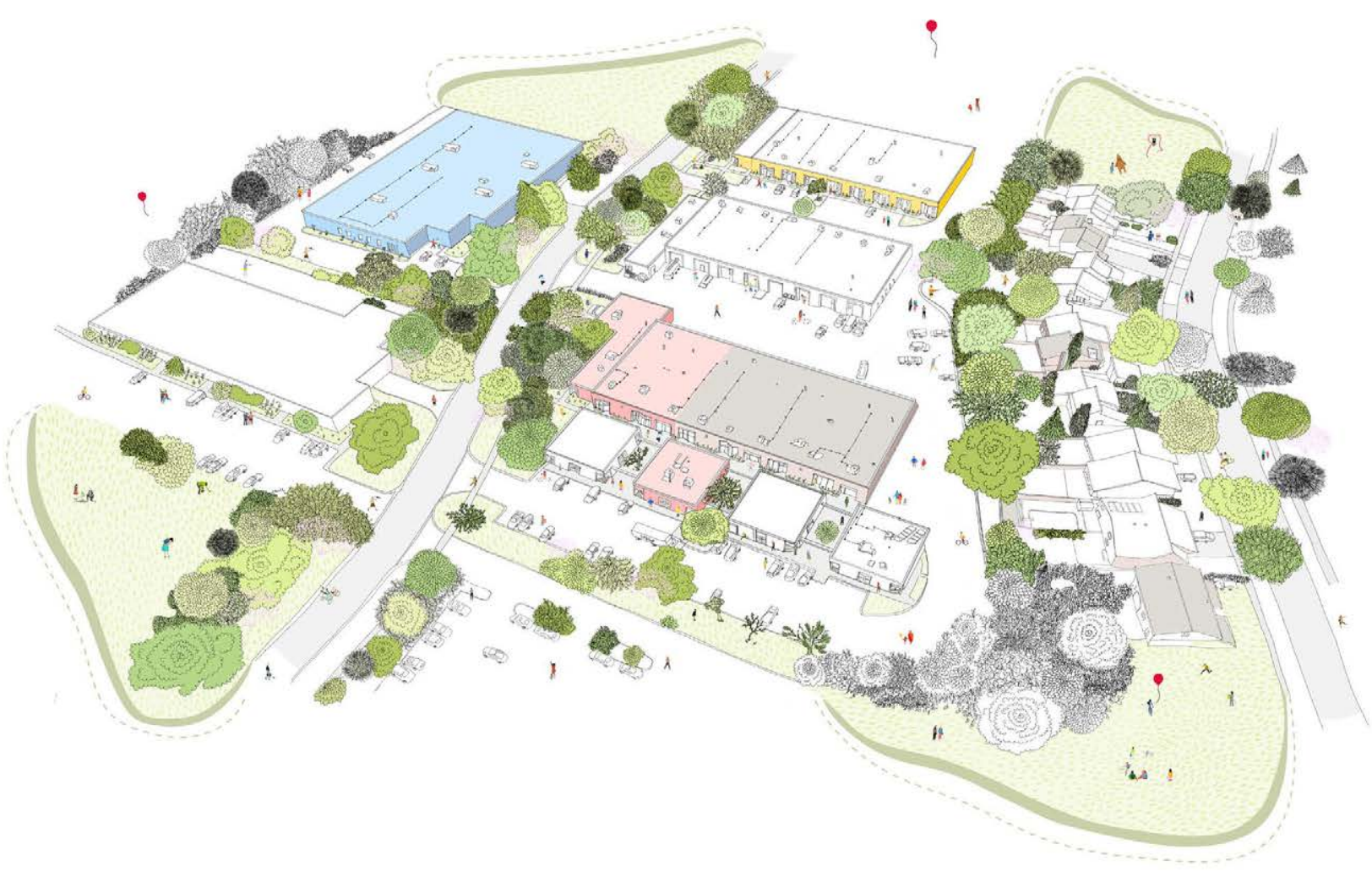

Fig. 90 Kaban Montessori School - Site Plan 


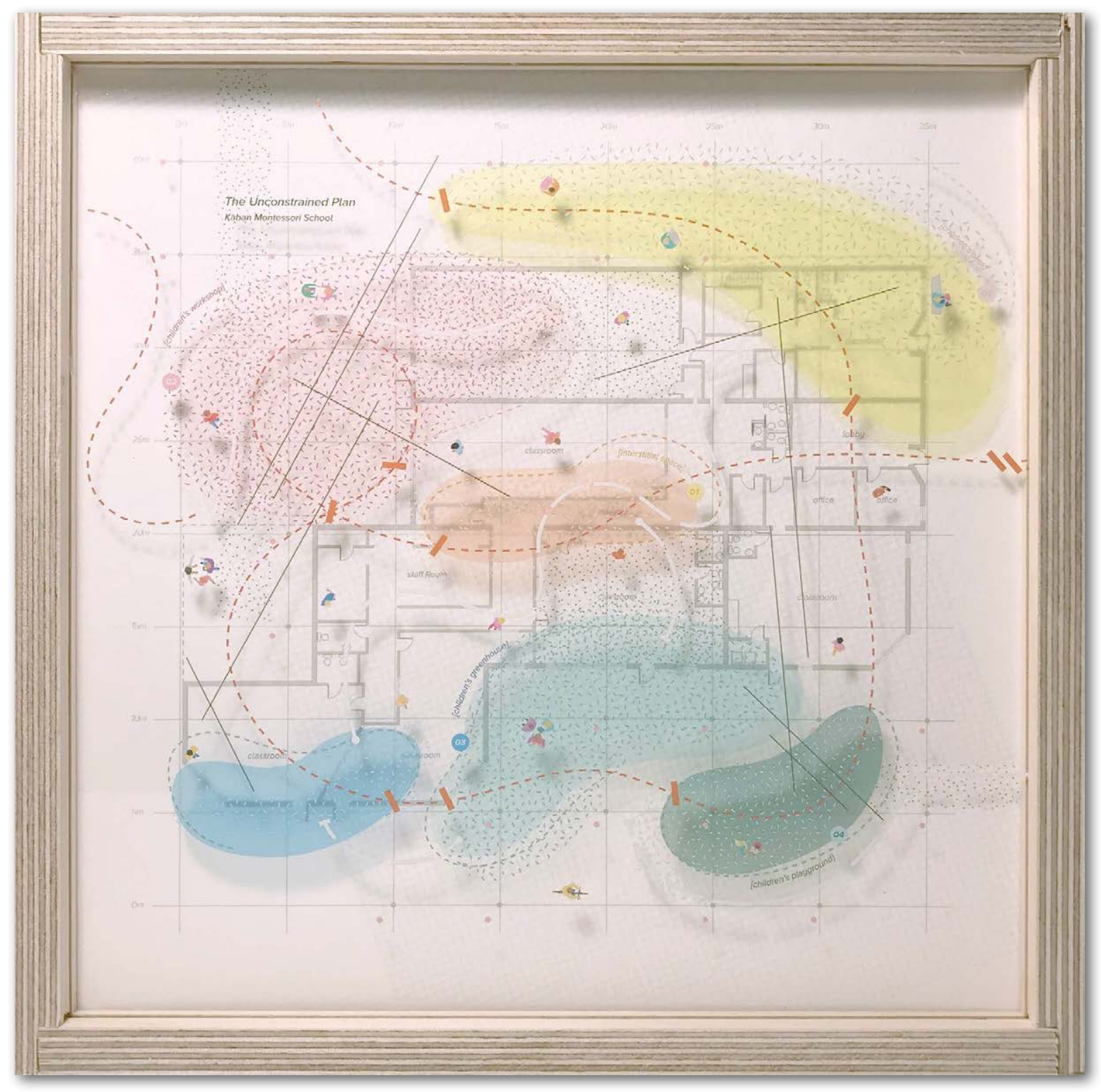

Fig. 91 Kaban Montessori School - Imagined progressive patterns superimposed on the grid 


\section{Endnotes}

\section{Part 01 _ Introduction}

\section{Abstract}

1. Linda M. Zane. Pedagogy and Space: Design Inspirations for Early Childhood Classrooms (St. Paul: Redleaf Press, 2015), 3

Glossary

2. Barbara, Isaacs, Understanding the Montessori Approach: Early years education in practice (New York: Routledge, 2012), 109

3. Barbara, Isaacs, Understanding the Montessori Approach: Early years education in practice (New York: Routledge, 2012), 109.

4. "The Montessori Dictionary", Living Montessori Education Community, accessed November 31, 2018, https:// livingmontessori.com/10-words-to-know-from-the-montessori-dictionary/.

5. Barbara, Isaacs, Understanding the Montessori Approach: Early years education in practice (New York: Routledge, 2012), 110

6. "The Montessori Dictionary", Living Montessori Education Community, accessed November 31, 2018, https:// livingmontessori.com/10-words-to-know-from-the-montessori-dictionary/.

7. Carol Weinstein and Thomas G. David, Spaces for Children: The Built Environment and Child Development (New York: Plenum Press, 1987), 80

8. David Kahn, Sharon L. Dubble, and D. Renee. Pendleton, The Whole-school Montessori Handbook: For Teachers and Administrators (Ohio: North American Montessori Teachers' Association, 1999), 117.

9. Barbara, Isaacs, Understanding the Montessori Approach: Early years education in practice (New York: Routledge, 2012), 112.

10. "Pedagogy," Dictionary.com: based on the Random House Unabridged Dictionary, Last Modified 2018, https://www.dictionary.com/browse/pedagogy.

11. Barbara, Isaacs, Understanding the Montessori Approach: Early years education in practice (New York: Routledge, 2012), 112

12. "The Montessori Dictionary", Living Montessori Education Community, accessed November 31, 2018, https:// livingmontessori.com/10-words-to-know-from-the-montessori-dictionary/.

13. "The Montessori Dictionary", Living Montessori Education Community, accessed November 31, 2018, https:// livingmontessori.com/10-words-to-know-from-the-montessori-dictionary/.

14. "Progressive", Merriam-Webster, Accessed January 02, 2019, https://www.merriam-webster.com/dictionary/ progressive.

15. Julianne Wurm, "How the Environment Inspires Curriculum", Community Playthings, last modified March 01, 2009, http://www.communityplaythings.com/resources/articles/2009/how-the-environment-inspires-curriculum. 
16. Denis Samarin, "Concept of Self-Construction of a Child" Creo School: A Montessori Community, Last modified April 13, 2017, http://www.creoschool.org/lowerelementary/2017/4/1/concept-of-self-construction-of-achild-is-the-corner-stone-of-drmontessoris-philosophy-and-psycology.

17. Barbara, Isaacs, Understanding the Montessori Approach: Early years education in practice (New York: Routledge, 2012), 112.

Preface

18. David Halpin, "Utopian Spaces of "Robust Hope": The architecture and nature of progressive learning environments," Asia - Pacific Journal of Teacher Education 35, No.3 (2007): 251.

Transactional Relationship

19. Peter Lippman, "Can the Physical Environment Have an Impact in the Learning Environment?", CELE Exchange, Center for Effective Learning Environments (Paris: OECD Publishing, 2010).

20. Peter Lippman, "Can the Physical Environment Have an Impact in the Learning Environment?", CELE Exchange, Center for Effective Learning Environments (Paris: OECD Publishing, 2010).

21. Carol Weinstein and Thomas G.David, Spaces for Children: The Built Environment and Child Development (New York: Plenum Press, 1987), 291.

A Brief History of Education: A Timeline (Refer to Historical Timeline Endnotes)

\section{The Progressive Condition}

22. Alfie Kohn, "Progressive Education: Why it's Hard to Beat, But Also Hard to Find", Bank Street College of Education, 2015: 2. Accessed November 29, 2018. http://educate.bankstreet.edu/progressive/2.

23. Alfie Kohn, "Progressive Education: Why it's Hard to Beat, But Also Hard to Find", Bank Street College of Education, 2015: 2. Accessed November 29, 2018. http://educate.bankstreet.edu/progressive/2.

24. Carol A. Kochhar-Bryant and Angela Heishman, "What Does it Mean to Educate the Whole Child?" In Effective Collaboration for Educating the Whole Child (Thousand Oaks, CA: Corwin Press, 2010), 6.

25. Carol A. Kochhar-Bryant and Angela Heishman, "What Does it Mean to Educate the Whole Child?" In Effective Collaboration for Educating the Whole Child (Thousand Oaks, CA: Corwin Press, 2010), 7.

26. Carol A. Kochhar-Bryant and Angela Heishman, "What Does it Mean to Educate the Whole Child?" In Effective Collaboration for Educating the Whole Child (Thousand Oaks, CA: Corwin Press, 2010), 15.

27. Carol A. Kochhar-Bryant and Angela Heishman, "What Does it Mean to Educate the Whole Child?" In Effective Collaboration for Educating the Whole Child (Thousand Oaks, CA: Corwin Press, 2010), 7.

28. Carol A. Kochhar-Bryant and Angela Heishman, "What Does it Mean to Educate the Whole Child?" In Effective Collaboration for Educating the Whole Child (Thousand Oaks, CA: Corwin Press, 2010), 15. 
29. Alfie Kohn, "Progressive Education: Why it's Hard to Beat, But Also Hard to Find", Bank Street College of Education, 2015: 4. Accessed November 29, 2018. http://educate.bankstreet.edu/progressive/2.

30. Alfie Kohn, "Progressive Education: Why it's Hard to Beat, But Also Hard to Find", Bank Street College of Education, 2015: 4. Accessed November 29, 2018. http://educate.bankstreet.edu/progressive/2.

31. Theodore M. Christou, "21st - Century Learning, Educational Reform, and Tradition," Teacher Learning and Professional Development 1, no. 1 (2016): 61.

32. Ted Dintersmith, "'the Innovation Playlist', Prepare Our Kids for Life, Not Standardized Tests," Published August 25, 2015 at TedxFargo, Accessed December 30, 2018, https://teddintersmith.com/about-ted/.

\section{The Montessori Method}

33. Paula Polk Lillard, Montessori: A Modern Approach (New York: Schocken Books, 1972), 29.

34. Maria Montessori, Education for a New World (India: Kalakshetra Publications, 1963), 4.

35. Ginni Sackett, "The Scientist in the classroom: The Montessori Teacher As Scientist," The NAMTA Journal 41, no. 2 (2016): 6.

36. Paula Polk Lillard, Montessori: A Modern Approach (New York: Schocken Books, 1972), 50.

37. Ginni Sackett, "The Scientist in the classroom: The Montessori Teacher As Scientist," The NAMTA Journal 41, no. 2 (2016): 10.

38. Barbara, Isaacs, Understanding the Montessori Approach: Early years education in practice (New York: Routledge, 2012), 47.

39. Tim Seldin and Paul Epstein, The Montessori Way: An Education for Life (Florida: The Montessori Foundation, 2003), 30.

40. Molly O'Shaughnessy, "Refining the 3-6 Prepared Environment" (presentation, North American Montessori Teacher's Association, Minnesota, 2003), 3.

41. Tim Seldin and Paul Epstein, The Montessori Way: An Education for Life (Florida: The Montessori Foundation, 2003), 33.

42. Molly O'Shaughnessy, "Refining the 3-6 Prepared Environment" (presentation, North American Montessori Teacher's Association, Minnesota, 2003), 4.

43. Tim Seldin and Paul Epstein, The Montessori Way: An Education for Life (Florida: The Montessori Foundation, 2003), 31.

44. Arleen Dodd-Nufrio, "Reggio Emilia, Maria Montessori, and John Dewey: Dispelling Teachers' Misconceptions and Understanding Theoretical Foundations," Early Childhood Educ J. Springer, 39 (2011): 236.

45. Paula Polk Lillard, Montessori: A Modern Approach (New York: Schocken Books, 1972), 50.

46. Tim Seldin and Paul Epstein, The Montessori Way: An Education for Life (Florida: The Montessori Foundation, 2003), 38. 
47. Barbara, Isaacs, Understanding the Montessori Approach: Early years education in practice (New York: Routledge, 2012), 47.

48. Barbara, Isaacs, Understanding the Montessori Approach: Early years education in practice (New York: Routledge, 2012), 49

49. Barbara, Isaacs, Understanding the Montessori Approach: Early years education in practice (New York: Routledge, 2012), 19.

50. Barbara, Isaacs, Understanding the Montessori Approach: Early years education in practice (New York: Routledge, 2012), 19.

51. Tim Seldin and Paul Epstein, The Montessori Way: An Education for Life (Florida: The Montessori Foundation, 2003), 42.

52. Tim Seldin and Paul Epstein, The Montessori Way: An Education for Life (Florida: The Montessori Foundation, 2003), 42.

53. Paula Polk Lillard, Montessori: A Modern Approach (New York: Schocken Books, 1972), 51.

54. Barbara, Isaacs, Understanding the Montessori Approach: Early years education in practice (New York: Routledge, 2012), 50.

55. Paula Polk Lillard, Montessori: A Modern Approach (New York: Schocken Books, 1972), 50

56. Barbara Isaacs, Understanding the Montessori Approach: Early years education in practice (New York: Routledge, 2012), 50

57. Angeline Stoll Lillard, Montessori: The Science Behind the Genius (New York: Oxford University Press, 2017), 39.

58. Tim Seldin and Paul Epstein, The Montessori Way: An Education for Life (Florida: The Montessori Foundation, 2003), 31.

59. Angeline Stoll Lillard, Montessori: The Science Behind the Genius (New York: Oxford University Press, 2017), 32.

60. Paula Polk Lillard, Montessori: A Modern Approach (New York: Schocken Books, 1972), 56.

61. Angeline Stoll Lillard, Montessori: The Science Behind the Genius (New York: Oxford University Press, 2017), 331.

62. Angeline Stoll Lillard, Montessori: The Science Behind the Genius (New York: Oxford University Press, 2017), 318.

63. Tim Seldin and Paul Epstein, The Montessori Way: An Education for Life (Florida: The Montessori Foundation, 2003), 34.

64. Tim Seldin and Paul Epstein, The Montessori Way: An Education for Life (Florida: The Montessori Foundation, 2003), 34. 
65. Tim Seldin and Paul Epstein, The Montessori Way: An Education for Life (Florida: The Montessori Foundation, 2003), 34.

66. David Kahn, Sharon L. Dubble, and D. Renee. Pendleton, The Whole-school Montessori Handbook: For Teachers and Administrators (Ohio: North American Montessori Teachers' Association, 1999), 2.

67. Tim Seldin and Paul Epstein, The Montessori Way: An Education for Life (Florida: The Montessori Foundation, 2003), 35.

68. Tim Seldin and Paul Epstein, The Montessori Way: An Education for Life (Florida: The Montessori Foundation, 2003), 35.

69. Tim Seldin and Paul Epstein, The Montessori Way: An Education for Life (Florida: The Montessori Foundation, 2003), 50.

70. Carol Weinstein and Thomas G.David, Spaces for Children: The Built Environment and Child Development (New York: Plenum Press, 1987), 174.

71. Julia Ann Kirkham and Evan Kidd, "The Effects of Steiner, Montessori and National Curriculum Education Upon Children's Pretence and Creativity," (The Journal of Creative Behaviour 51, no.1, 2017$), 22$.

72. Marlynn Levin, "Commentary: The Changing Dynamic of Working Family", Michigan Family Review 2, no. 2 (Winter 1996): 103-109, http://dx.doi.org/10.3998/mfr.4919087.0002.209.

73. Natalia Krysiak, "Making Space for Play," Archiparlour. September 17, 2018, http://archiparlour.org/makingspace-for-play/.

74. Paula Polk Lillard, Montessori: A Modern Approach (New York: Schocken Books, 1972), 58.

75. Molly O'Shaughnessy, "Refining the 3-6 Prepared Environment" (presentation, North American Montessori Teacher's Association, Minnesota, 2003), 32.

76. Paula Polk Lillard, Montessori: A Modern Approach (New York: Schocken Books, 1972), 90.

77. Paula Polk Lillard, Montessori: A Modern Approach (New York: Schocken Books, 1972), 138.

The Scientific Form

78. "A blueprint for scientific investigations", Understanding Science, University of California Museum of Paleontology, accessed December 1, 2018, https://undsci.berkeley.edu/article/_0_0/howscienceworks_03.

79. "A blueprint for scientific investigations", Understanding Science, University of California Museum of Paleontology, accessed December 1, 2018. https://undsci.berkeley.edu/article/_0_0/howscienceworks_03.

80. "The real process of science", Understanding Science, University of California Museum of Paleontology, accessed December 1, 2018. 


\section{Part 02 _ Guidelines \& Design Patterns}

Learning Spaces: Intro to Guidelines + Design Patterns

Learning Spaces: The Problem with the Classroom

1. Kahn, David, et al. The Whole-School Montessori Handbook: for Teachers and Administrators. Ohio: NAMTA, 1999, 131.

2. David Halpin, "Utopian Spaces of "Robust Hope": The architecture and nature of progressive learning environments," Asia - Pacific Journal of Teacher Education 35, No.3 (2007): 251.

3. Zane, Linda. M. Pedagogy and Space: Design Inspirations for Early Childhood Classrooms. St. Paul: Redleaf Press, 2015, 15.

4. $\quad \mathrm{IBID}$

Participatory Design

5. Eda Can and Goksenin Inalhan, "Having a voice, having a choice: Children's Participation in Educational Space Design," The Design Journal 20, no. 1 (2017): S3238-S3251.

6. Allison Clark, "Talking and Listening to children" in Children's Spaces edited by Mark Dudek (Oxford: Architectural Press, 2005), 1-14.

7. Ben Koralek and Maurice Mitchell, "The schools we'd like: young people's participation in architecture " in Children's Spaces edited by Mark Dudek (Oxford: Architectural Press, 2005), 114-154.

8. Allison Clark, "Talking and Listening to children" in Children's Spaces edited by Mark Dudek (Oxford: Architectural Press, 2005), 1-14.

9. Eda Can and Goksenin Inalhan, "Having a voice, having a choice: Children's Participation in Educational Space Design," The Design Journal 20, no. 1 (2017): S3238-S3251.

10. $\quad \mathrm{IBID}$

11. Roger A. Hart, "Children's Participation in Planning and Design" in Spaces for Children: The Built Environment and Child Development by Carol Weinstein and Thomas G.David (New York: Plenum Press, 1987), 217.

12. Eda Can and Goksenin Inalhan, "Having a voice, having a choice: Children's Participation in Educational Space Design," The Design Journal 20, no. 1 (2017): S3238-S3251.

13. Linda M. Zane, Pedagogy and Space: Design Inspirations for Early Childhood Classrooms (St. Paul: Redleaf Press, 2015), 20

14. Allison Clark, "Talking and Listening to children" in Children's Spaces edited by Mark Dudek (Oxford: Architectural Press, 2005), 1-14.

15. $\quad \mathrm{IBID}$

16. $\quad \mathrm{IBID}$

17. Ben Koralek and Maurice Mitchell, "The schools we'd like: young people's participation in architecture " in Children's Spaces edited by Mark Dudek (Oxford: Architectural Press, 2005), 114-154. 
18. Allison Clark, "Talking and Listening to children" in Children's Spaces edited by Mark Dudek (Oxford: Architectural Press, 2005), 1-14.

19. Carol Weinstein and Thomas G.David, Spaces for Children: The Built Environment and Child Development (New York: Plenum Press, 1987), 121.

20. $|\mathrm{B}| \mathrm{D}$

21. Carol Weinstein and Thomas G.David, Spaces for Children: The Built Environment and Child Development (New York: Plenum Press, 1987), 8.

22. Ben Koralek and Maurice Mitchell, "The schools we'd like: young people's participation in architecture " in Children's Spaces edited by Mark Dudek (Oxford: Architectural Press, 2005), 114-154.

23. Christopher Alexander, A Patterned Language: Towns, Buildings, Construction (New York: Oxford University Press, 1977), 136, 323, 324.

24. Christopher Alexander, A Patterned Language: Towns, Buildings, Construction (New York: Oxford University Press, 1977), 325.

25. Stuart Brown, "Play Is More than Just Fun" TED: Ideas worth Spreading, Accessed December 10, 2018 , https://www.ted.com/talks/stuart_brown_says_play_is_more_than_fun_it_s_vital?language=en.

26. Carol Weinstein and Thomas G.David, Spaces for Children: The Built Environment and Child Development (New York: Plenum Press, 1987), 119.

27. Allison Clark, "Talking and Listening to children" in Children's Spaces edited by Mark Dudek (Oxford: Architectural Press, 2005), 1-14.

28. Ben Koralek and Maurice Mitchell, "The schools we'd like: young people's participation in architecture " in Children's Spaces edited by Mark Dudek (Oxford: Architectural Press, 2005), 114-154.

Freedom

29. Cannon Design, VS Furniture, and Bruce Mau Design, The Third Teacher: 79 Ways You Can Transform Your Teaching and Learning (New York: Abrams, 2010), 14.

30. $|\mathrm{B}| \mathrm{D}$

31. Carol Weinstein and Thomas G. David, Spaces for Children: The Built Environment and Child Development (New York: Plenum Press, 1987), 8-9

32. David Kahn, Sharon L. Dubble, and D. Renee. Pendleton, The Whole-school Montessori Handbook: For Teachers and Administrators (Ohio: North American Montessori Teachers' Association, 1999), 161.

33. David Kahn, Sharon L. Dubble, and D. Renee. Pendleton, The Whole-school Montessori Handbook: For Teachers and Administrators (Ohio: North American Montessori Teachers' Association, 1999), 131.

34. Paula Polk Lillard, Montessori: A Modern Approach (New York: Schocken Books, 1972), 50. 
35. Barbara, Isaacs, Understanding the Montessori Approach: Early years education in practice (New York: Routledge, 2012), 31.

36. Mark Dudek, "Introduction” in Children's Spaces (Oxford: Architectural Press, 2005), ix-x.

37. Mark Dudek, "Introduction" in Children's Spaces (Oxford: Architectural Press, 2005), xxi.

38. Carol Weinstein and Thomas G. David, Spaces for Children: The Built Environment and Child Development (New York: Plenum Press, 1987), 8-9.

39. Natalia Krysiak, "Making Space for Play". Archiparlour. September 17, 2018. http://archiparlour.org/makingspace-for-play/.

Community + Culture

40. David Kahn, Sharon L. Dubble, and D. Renee. Pendleton, The Whole-school Montessori Handbook: For Teachers and Administrators (Ohio: North American Montessori Teachers' Association, 1999), 135.

41. Barbara, Isaacs, Understanding the Montessori Approach: Early years education in practice (New York: Routledge, 2012), 19.

42. Allison Clark, "Talking and Listening to children" in Children's Spaces edited by Mark Dudek (Oxford: Architectural Press, 2005), 1-14.

43. Zane, Linda. M. Pedagogy and Space: Design Inspirations for Early Childhood Classrooms. St. Paul: Redleaf Press, 2015, 25.

44. Zane, Linda. M. Pedagogy and Space: Design Inspirations for Early Childhood Classrooms. St. Paul: Redleaf Press, 2015, 25.

45. Zane, Linda. M. Pedagogy and Space: Design Inspirations for Early Childhood Classrooms. St. Paul: Redleaf Press, 2015, 67.

\section{Order}

46. Molly O'Shaughnessy, "Refining the 3-6 Prepared Environment" (presentation, North American Montessori Teacher's Association, Minnesota, 2003), 23.

47. Molly O'Shaughnessy, "Refining the 3-6 Prepared Environment" (presentation, North American Montessori Teacher's Association, Minnesota, 2003), 19.

48. Carol Weinstein and Thomas G. David, Spaces for Children: The Built Environment and Child Development (New York: Plenum Press, 1987), 162.

49. Carol Weinstein and Thomas G. David, Spaces for Children: The Built Environment and Child Development (New York: Plenum Press, 1987), 162.

50. David Kahn, Sharon L. Dubble, and D. Renee. Pendleton, The Whole-school Montessori Handbook: For Teachers and Administrators (Ohio: North American Montessori Teachers' Association, 1999), 135. 
51. David Kahn, Sharon L. Dubble, and D. Renee. Pendleton, The Whole-school Montessori Handbook: For Teachers and Administrators (Ohio: North American Montessori Teachers' Association, 1999), 165.

52. David Halpin, "Utopian Spaces of "Robust Hope": The architecture and nature of progressive learning environments," Asia - Pacific Journal of Teacher Education 35, No.3 (2007): 243-255.

53. IBID

54. IBID

Interactive

55. Meryem Yalcin, "Relationship of Montessori Approach with Interior Spaces in Preschool and Physical Set-up", Megaron 13, No. 3 (2018): 451-458.

56. Carol Weinstein and Thomas G. David, Spaces for Children: The Built Environment and Child Development (New York: Plenum Press, 1987), 119.

57. Carol Weinstein and Thomas G. David, Spaces for Children: The Built Environment and Child Development (New York: Plenum Press, 1987), 122.

58. IBID

59. "Why Our Schools Need Better Architecture", ArchDaily, September 12, 2018, https://www.archdaily. com/901870/why-our-schools-need-better-architecture.

60. Barrett, Zhang, Davies and Dr Lucinda Barrett, "Clever Classrooms: Summary report of the HEAD Project" (Salford: Raw Engine House, 2015), Accessed October 22, 2018, https://www.salford.ac.uk/cleverclassrooms/1503-Salford-Uni-Report-DIGITAL.pdf?utm_medium=website\&utm_source=archdaily.com.

61. Carol Weinstein and Thomas G. David, Spaces for Children: The Built Environment and Child Development (New York: Plenum Press, 1987), 121.

62. IBID

Integrated + Innovative

63. Ken Robinson, “Do Schools Kill Creativity?” TED: Ideas worth Spreading, https://www.ted.com/talks/ken_robinson_says_schools_kill_creativity.

64. David Kahn, Sharon L. Dubble, and D. Renee. Pendleton, The Whole-school Montessori Handbook: For Teachers and Administrators (Ohio: North American Montessori Teachers' Association, 1999$), 8$.

65. Cannon Design, VS Furniture, and Bruce Mau Design. The Third Teacher: 79 Ways You Can Transform Your Teaching and Learning (New York: Abrams, 2010), 19.

66. Mario Valle, "Montessori through the eyes of a scientist", lecture presented at the AMI Deutschland Tagung Conference, Bad Endorf, January 2014,Accessed October 23, 2018. http://mariovalle.name/montessori/ ami2014.html. 
67. Cannon Design, VS Furniture, and Bruce Mau Design. The Third Teacher: 79 Ways You Can Transform Your Teaching and Learning (New York: Abrams, 2010), 17.

68. Mark Dudek, "introduction" in Children's Spaces (Oxford: Architectural Press, 2005), xxi.

\section{Erkinder}

69. Gary Paul Nabhan and Stephen Trimble, "The Geography of Childhood: Why Children Need Wild Places" (Boston, Massachusetts: Beacon Press, 1994), 9.

70. Robin Moore, "Nature Play \& Learning Places: Creating and managing places where children engage with nature", National Guidelines (Raleigh, NC: Natural Learning Initiative and Reston, VA: National Wildlife Federation, 2014), 6.

71. Molly O'Shaughnessy, "Refining the 3-6 Prepared Environment" (presentation, North American Montessori Teacher's Association, Minnesota, 2003), 33.

72. Molly O'Shaughnessy, "Refining the 3-6 Prepared Environment" (presentation, North American Montessori Teacher's Association, Minnesota, 2003), 33.

73. Gary Paul Nabhan and Stephen Trimble, "The Geography of Childhood: Why Children Need Wild Places" (Boston, Massachusetts: Beacon Press, 1994), 9.

74. Gary Paul Nabhan and Stephen Trimble, "The Geography of Childhood: Why Children Need Wild Places" (Boston, Massachusetts: Beacon Press, 1994), 26.

75. Robin Moore, "Nature Play \& Learning Places: Creating and managing places where children engage with nature", National Guidelines (Raleigh, NC: Natural Learning Initiative and Reston, VA: National Wildlife Federation, 2014), 2.

76. Gary Paul Nabhan and Stephen Trimble, "The Geography of Childhood: Why Children Need Wild Places" (Boston, Massachusetts: Beacon Press, 1994), 27.

77. Gary Paul Nabhan and Stephen Trimble, "The Geography of Childhood: Why Children Need Wild Places" (Boston, Massachusetts: Beacon Press, 1994), 7.

78. Gary Paul Nabhan and Stephen Trimble, "The Geography of Childhood: Why Children Need Wild Places" (Boston, Massachusetts: Beacon Press, 1994), 8.

79. Robin Moore, "Nature Play \& Learning Places: Creating and managing places where children engage with nature", National Guidelines (Raleigh, NC: Natural Learning Initiative and Reston, VA: National Wildlife Federation, 2014), 5.

80. Robin Moore, "Nature Play \& Learning Places: Creating and managing places where children engage with nature", National Guidelines (Raleigh, NC: Natural Learning Initiative and Reston, VA: National Wildlife Federation, 2014), 15.

81. Barrett, Zhang, Davies and Dr Lucinda Barrett, "Clever Classrooms: Summary report of the HEAD Project" 


\title{
List of Illustrations
}

\author{
Part 01 _ Introduction \\ Preface \\ Fig. 1 Conceptual Photograph / by author \\ Introduction
}

Fig. 2 Figures / illustrated by HVASS\&HANNIBAL - http://hvasshannibal.dk/kulturnatten.html

Fig. 3 Conceptual Photo / by author

Transactional Relationship

Fig. 4 Conceptual Photo / by author

A Brief History of Education: A Timeline (Refer to Historical Timeline List of Figures)

The Progressive Condition

Fig. 5 The Park School of Buffalo (1912) / https://goo.gl/7BvLP1

Fig. 6 Photograph (Children absorbed in the process of discovery) / https://goo.gl/qgdzPv

Fig. 7 Photograph / by author

Fig. 8 Concept Matrix / by author

The Montessori Method

Fig. 9 Photograph / by author

Fig. 10 Photograph / by author

Fig. 11 Photograph / provided by Kaban Montessori School

Fig. 12 Photograph / provided by Kaban Montessori School

Fig. 13 Mind Map 02 / by author

Fig. 14 Mind Map 03 / by author

The Scientific Form

Fig. 15 Diagram / by author - referenced from https://undsci.berkeley.edu/article/scienceflowchart

Fig. 16 Mapping / by author

Fig. 17 Play Collage / edited by author - original illustration by Monica Ramos - https://goo.gl/G3LPP3 


\section{Part 02 _ Guidelines \& Design Patterns}

\section{Learning Spaces: Intro to Guidelines + Design Patterns}

Fig. 1 Fuji Kindergarten by Tezuka Architects / sketch by author - image from https://goo.gl/wqCZN6

Fig. 2 Nursery in la Chapelle-les-sciers by Lacroix Chessex / sketch by author - image from https://goo.gl/qaCFEa

Fig. 3 Farming Kindergarten by Vo Trong Nghia Architects / sketch by author - image from https://goo.gl/5tfnJ6

Fig. 4 HN Nursery by HIBINOSEKKEI, Youji no Shiro / sketch by author - image from https://goo.gl/2hi1Vo

Fig. 5 KM Kindergarten and Nursery by HIBINOSEKKEI, Youji no Shiro / sketch by author - image from https://goo.gl/zpPo1B

Fig. 6 Montpelier Community Nursery by AY Architects / sketch by author - image from https://goo.gl/P9Ujy7

Fig. 7 Comparative Index / by author

Learning Spaces: The Problem with the Classroom

Fig. 8 Photograph / by author

Fig. 9 Areas of a Montessori Classroom / drawn by author - refrenced from https://goo.glWG22ws, https://goo.gl/o7uxk

Fig. 10 Mapping / by author

Participatory Design

Fig. 11 Children's drawing / drawing workshop

Fig. 12 Catalogue 01 - Child-led Tour / by author

Fig. 13 Catalogue 01 - Child-led Tour / by author

Fig. 14 Children's Photograph / child-led tour workshop

Fig. 15 Children's Photograph / child-led tour workshop

Fig. 16 Children's Photograph / child-led tour workshop

Fig. 17 Children's Photograph / child-led tour workshop

Fig. 18 Conceptual Photograph / by author

Fig. 19 Children's Photograph / child-led tour workshop

Fig. 20 Children's Photograph / child-led tour workshop

Fig. 21 Children's Photograph / child-led tour workshop

Fig. 22 Children's Photograph / child-led tour workshop 
Fig. 23 Children's Photograph / child-led tour workshop

Fig. 24 Children's Photograph / child-led tour workshop

Fig. 25 Children's Photograph / child-led tour workshop

Fig. 26 Children's Photograph / child-led tour workshop

Fig. 27 Children's Photograph / child-led tour workshop

Fig. 28 Children's Photograph / child-led tour workshop

Fig. 29 Children's Photograph / child-led tour workshop

Fig. 30 Children's Photograph / child-led tour workshop

Fig. 31 Children's Photograph / child-led tour workshop

Fig. 32 Children's Photograph / child-led tour workshop

Fig. 33 Children's Photograph / child-led tour workshop

Fig. 34 Children's Photograph / child-led tour workshop

Fig. 35 Children's Photograph / child-led tour workshop

Fig. 36 Children's Photograph / child-led tour workshop

Fig. 37 Children's Drawing / drawing workshop

Fig. 38 Catalogue 02 - drawing workshop / by author

Fig. 39 Catalogue 02 - drawing workshop / by author

Fig. 40 Catalogue 02 - drawing workshop / by author

Fig. 41 Catalogue 02 - drawing workshop / by author

Fig. 42 Children's Drawing / drawing workshop

Fig. 43 Children's Drawing / drawing workshop

Fig. 44 Children's Drawing / drawing workshop

Fig. 45 Children's Drawing / drawing workshop

Fig. 46 Children's Drawing / drawing workshop

Fig. 47 Children's Drawing / drawing workshop

Fig. 48 Speculative Drawing Collage / by author
Fig. 49 Speculative Drawing Collage / by author

Fig. 50 Speculative Drawing Collage / by author

Fig. 51 Speculative Drawing Collage / by author

Fig. 52 Speculative Drawing Collage / by author

Fig. 53 Speculative Drawing Collage / by author

Fig. 54 Children's Drawing / drawing workshop

Fig. 55 Children's Drawing / drawing workshop

Fig. 56 Children's Drawing / drawing workshop

Fig. 57 Children's Drawing / drawing workshop

Fig. 58 Children's Drawing / drawing workshop

Fig. 59 Children's Drawing / drawing workshop

Fig. 60 Children's Drawing / drawing workshop 


\section{Freedom}

Fig. 61 Scale of the Child / by author

Fig. 62 Childhood Landscapes - Shrinking Territories / original model by OMA - modified by author

Fig. 63 'Motions of Freedom' photography-drawing collage / by author

Fig. 64 'Motions of Freedom' photography-drawing collage / by author

Fig. 65 'A Speculative Expression of Freedom' drawing / by author

Fig. 66 Children's path - Layered site plan / by author

Fig. 67 Children's path - A moment along the path / by author

Community + Culture

Fig. 68 Photograph / provided by Kaban Montessori School

Fig. 69 Photograph / provided by Kaban Montessori School

Fig. 70 Photograph / provided by Kaban Montessori School

Fig. 71 'Social Movements' photography-drawing collage / by author

Fig. 72 Children's workshop / layered drawing created by author

Order

Fig. 73 Photograph / provided by Kaban Montessori School

Fig. 74 Photograph / by author

Interactive

Fig. 75 'Motions of the Hand' photography-drawing collage / by author

Fig. 76 'Flexible Landscapes' Drawing / by author

Fig. 77 Interstitial space - between school and classroom / by author

Fig. 78 Interstitial space - Intimate space (within walls) / by author

Fig. 79 Exploration of child's perspective - shadow play / by author

Fig. 80 Toy Exploration - Intimate Space / by author

Fig. 81 Toy Exploration - Intimate Space / by author 
Integrated + Innovative

Fig. 82 Schematic Sketch / by author

Fig. 83 Children's greenhouse - Transitions (interior/exterior) / by author

Fig. 84 Exploration of child's perspective - Captivated by the details (skylights) / by author

Erkinder

Fig. 85 Photograph / by author

Fig. 86 Photograph / by author

Fig. 87 Adventure playground - Wild landscapes / by author

Fig. 88 Exploration of child's perspective - Nested spaces / by author

Postscript

Fig. 89 Photograph / provided by Kaban Montessori School

Fig. 90 Kaban Montessori School - Site plan / by author

Fig. 91 Kaban Montessori School - Progressive patterns superimposed on the grid / by author 


\section{Bibliography}

Alexander, Christopher. A Patterned Language: Towns, Buildings, Construction. New York: Oxford University Press, 1977.

"A blueprint for scientific investigations". Understanding Science. University of California Museum of Paleontology. Accessed December 1, 2018. https://undsci.berkeley.edu/article/_0_0/howscienceworks_03.

Barrett, Zhang, Davies and Dr Lucinda Barrett. Clever Classrooms: Summary report of the HEAD Project. Salford: Raw Engine House, 2015. Accessed October 22, 2018. https://www.salford.ac.uk/cleverclassrooms/1503-Salford-Uni-Report-DIGITAL.pdf?utm_medium=website\&utm_source=archdaily.com.

Brown, Stuart. "Play Is More than Just Fun" TED: Ideas worth Spreading. Accessed December 10, 2018. https:// www.ted.com/talks/stuart_brown_says_play_is_more_than_fun_it_s_vital?language=en.

Can, Eda and Goksenin Inalhan. "Having a voice, having a choice: Children's Participation in Educational Space Design," The Design Journal 20, no. 1 (2017): S3238-S3251.

Cannon Design, VS Furniture, and Bruce Mau Design. The Third Teacher: 79 Ways You Can Transform Your Teaching and Learning. New York: Abrams, 2010.

Christou, Theodore M. "21st - Century Learning, Educational Reform, and Tradition: Conceptualizing professional development in a progressive age." Teacher Learning and Professional Development 1, no. 1 (2016): 61 - 72.

Clark, Allison. "Talking and Listening to children". in Children's Spaces, edited by Mark Dudek, 1-14. Oxford: Architectural Press, 2005.

Dintersmith, Ted. "'the Innovation Playlist', Prepare Our Kids for Life, Not Standardized Tests”. Published August 25, 2015 at TedxFargo. Accessed December 30, 2018. https://teddintersmith.com/about-ted/.

Dodd-Nufrio, Arleen. "Reggio Emilia, Maria Montessori, and John Dewey: Dispelling Teachers' Misconceptions and Understanding Theoretical Foundations". Early Childhood Educ J. Springer, 39 (2011): 235-237.

Dudek, Mark. "Introduction" in Children's Spaces. Oxford: Architectural Press, 2005.

Halpin, David. "Utopian Spaces of "Robust Hope": The architecture and nature of progressive learning environments," Asia - Pacific Journal of Teacher Education 35, No.3 (2007): 243-255, https://doi. org/10.1080/13598660701447205.

Hart, Roger A. "Children's Participation in Planning and Design". in Spaces for Children: The Built Environment and Child Development by Carol Weinstein and Thomas G. David, 217. New York: Plenum Press, 1987.

Isaacs, Barbara. Understanding the Montessori Approach: Early years education in practice. New York: Routledge, 2012. 
Kahn, David, Sharon L. Dubble, and D. Renee. Pendleton. The Whole-school Montessori Handbook: For Teachers and Administrators. Ohio: North American Montessori Teachers' Association, 1999.

Kirkham, Julia Ann and Evan Kidd. "The Effects of Steiner, Montessori and National Curriculum Education Upon

Children's Pretence and Creativity," The Journal of Creative Behaviour 51, no.1 (2017): 20-34

Kochhar-Bryant, Carol A. Heishman, A. "What Does it Mean to Educate the Whole Child?" In Effective Collaboration for Educating the Whole Child (pp.1-34), Thousand Oaks, CA: Corwin Press, 2010.

Kohn, Alfie. "Progressive Education: Why it's Hard to Beat, But Also Hard to Find", Bank Street College of Education, 2015: 0-12. Accessed November 29, 2018. http://educate.bankstreet.edu/progressive/2.

Koralek, Ben and Maurice Mitchell. "The schools we'd like: young people's participation in architecture ". in Children's Spaces edited by Mark Dudek, 114-154. Oxford: Architectural Press, 2005.

Krysiak, Natalia. "Making Space for Play". Archiparlour. September 17, 2018. http://archiparlour.org/making-spacefor-play/

Levin, Marlynn. "Commentary: The Changing Dynamic of Working Family." Michigan Family Review 2, no. 2. (1996): 103-109. http://dx.doi.org/10.3998/mfr.4919087.0002.209

Lillard, Angeline Stoll. Montessori: The Science Behind the Genius. New York: Oxford University Press, 2017.

Lillard, Paula Polk. Montessori: A Modern Approach. New York: Schocken Books, 1972.

Lippmann, Peter. "Can the Physical Environment Have an Impact in the Learning Environment?", CELE Exchange, Centre for Effective Learning Environments. Paris: OECD Publishing, 2010.

Montessori, Maria. Education for a New World. India: Kalakshetra Publications, 1963.

Moore, Robin. "Nature Play \& Learning Places: Creating and managing places where children engage with nature." National Guidelines. Raleigh, NC: Natural Learning Initiative and Reston, VA: National Wildlife Federation, 2014

Nabhan, Gary Paul and Stephen Trimble. "The Geography of Childhood: Why Children Need Wild Places". Boston, Massachusetts: Beacon Press, 1994.

O'Shaughnessy, Molly. "Refining the 3-6 Prepared Environment." Paper presented at the North American Montessori Teacher's Association, Minnesota, 2003.

"Pedagogy". Dictionary.com: based on the Random House Unabridged Dictionary. Last Modified 2018, https:// www.dictionary.com/browse/pedagogy. 
Robinson, Ken. "Do Schools Kill Creativity?" TED: Ideas worth Spreading. https://www.ted.com/talks/ken_robinson_says_schools_kill_creativity.

Sackett, Ginni. "The Scientist in the classroom: The Montessori Teacher As Scientist" The NAMTA Journal 41, no. 2 (2016): 5-20.

Samarin, Denis. "Concept of Self-Construction of a Child". Creo School: A Montessori Community. Last modified April 13, 2017. http://www.creoschool.org/lowerelementary/2017/4/1/concept-of-self-construction-of-a-child-is-thecorner-stone-of-drmontessoris-philosophy-and-psycology.

Seldin, Tim and Paul Epstein. The Montessori Way: An Education for Life. Florida: The Montessori Foundation, 2003.

"The Montessori Dictionary". Living Montessori Education Community. Accessed November 31, 2018. https://livingmontessori.com/10-words-to-know-from-the-montessori-dictionary/.

Weinstein, Carol and Thomas G. David. Spaces for Children: The Built Environment and Child Development. New York: Plenum Press, 1987.

"Why Our Schools Need Better Architecture." ArchDaily. September 12, 2018. https://www.archdaily.com/901870/ why-our-schools-need-better-architecture.

Yalcin, Meryem. "Relationship of Montessori Approach with Interior Spaces in Preschool and Physical Set-up". Megaron 13, No. 3 (2018): 451-458.

Zane, Linda M. Pedagogy and Space: Design Inspirations for Early Childhood Classrooms. St. Paul: Redleaf Press, 2015. 


\title{
Historical Timeline Endnotes
}

\author{
A Brief History of Education: A Timeline
}

1. Bethany Hughes, "Socrates: a man for our times" The Guardian, Last modified, October 13, 2010, Accessed November 14, 2018. https://www.theguardian.com/books/2010/oct/17/socrates-philosopher-man-for-our-times.

2. James Fieser and Bradley Dowden, "Plato: The Academy", Internet Encyclopedia of Philosophy, Accessed November 14, 2018. https://www.iep.utm.edu/academy/.

3. Josefina Zordaida Vazquez and Nobuo Shimahara, "Education" Encyclopaedia Britannica. Last modified, August 29, 2018. Accessed November 14, 2018. https://www.britannica.com/topic/education/Athens, https:// www.iep.utm.edu/aristotl/.

4. $\quad \mathrm{IBID}$

5. Adolphe Erich Meyer and Robert Browning, "Education" Encyclopaedia Britannica, Last modified, August 29, 2018. Accessed November 14, 2018. https://www.britannica.com/topic/education/The-primary-school.

6. Harry Morgan, "Historical Imagination", In The Imagination of Early Childhood Education, California: Bergin \& Garvey, 1999.

7. Henry Sanoff and Rotraut Walden, School Environments (North Carolina: ResearchGate, 1994) See esp. Chap. 15, “The Progressive Movement", (276-278).

8. Brian Tate, "A History of Education Timeline", Tiki-Toki, Accessed November 14, 2018, https://www.tiki-toki. com/timeline/entry/56733/A-History-of-Education-Timeline/\#vars!date=2019-09-30_13:41:26.

9. Harvey Mccue, "Education of Indigenous People in Canada", The Canadian Encyclopedia, Last modified, July 18, 2018, Accessed November 14, 2018, https://www.thecanadianencyclopedia.ca/article/aboriginal-people-education.

10. Chad Gaffield, "History of Education in Canada", The Canadian Encyclopedia, Last modified, March 4, 2015, Accessed November 14, 2018, https://www.thecanadianencyclopedia.ca/en/article/history-of-education.

11. Harvey Mccue, "Education of Indigenous People in Canada", The Canadian Encyclopedia, Last modified, July 18, 2018, Accessed November 14, 2018, https://www.thecanadianencyclopedia.ca/article/aboriginal-people-education.

12. Harry Morgan, "Historical Imagination", In The Imagination of Early Childhood Education, California: Bergin \& Garvey, 1999.

13. "The Reggio Emilia Approach", North American Reggio Emilia Alliance, Accessed November 14, 2018, https:// www.reggioalliance.org/narea/.

14. Sophie Winer, "Theories on Education: Rousseau, Locke, and Montessori in the Modern Lesson Plan (United States, Ages 0-6 years)", A Life of Reading, Last modified, November 20, 2015, Accessed November 14, 2018. https://sophiewiner.com/2015/11/20/theories-on-education-rousseau-locke-and-montessori-in-the-modern-lesson-plan-united-states-ages-0-6-years/.

15. $\quad \mathrm{IBID}$ 
16. Harry Morgan, "Historical Imagination", In The Imagination of Early Childhood Education, California: Bergin \& Garvey, 1999.

17. $\quad \mathrm{IBID}$

18. Chad Gaffield, "History of Education in Canada", The Canadian Encyclopedia, Last modified, March 4, 2015, Accessed November 14, 2018, https://www.thecanadianencyclopedia.ca/en/article/history-of-education.

19. Dimitry Anastakis, "Industrialization in Canada" The Canadian Encyclopedia, Last modified, March 14, 2017, Accessed November 14, 2018, https://www.thecanadianencyclopedia.ca/en/article/industrialization.

20. Galloway, "The Life and Times of Canadian Education: A Timeline" TimeToast, Accessed November 14, 2018, https://www.timetoast.com/timelines/the-life-and-times-of-canadian-education-a-timeline.

21. Chad Gaffield, "History of Education in Canada", The Canadian Encyclopedia, Last modified, March 4, 2015, Accessed November 14, 2018, https://www.thecanadianencyclopedia.ca/en/article/history-of-education.

22. $|\mathrm{B}| \mathrm{D}$

23. Miller, J.r, " Residential Schools in Canada", The Canadian Encyclopedia, Last modified, June 14, 2018, Accessed November 14, 2018, https://www.thecanadianencyclopedia.ca/en/article/residential-schools.

24. Henry Sanoff and Rotraut Walden, School Environments (North Carolina: ResearchGate, 1994) See esp. Chap. 15, "The Progressive Movement", (276-278).

25. "Our History", Canadian association of Montessori Teachers, Accessed November 14, 2018, https://www. camt100.ca/our-history.

26. $I B I D$

27. Brian Tate, "A History of Education Timeline", Tiki-Toki, Accessed November 14, 2018, https://www.tiki-toki. com/timeline/entry/56733/A-History-of-Education-Timeline/\#vars!date=2019-09-30_13:41:26.

28. Pamela Carol Jewett, "Waldorf School Education" Encyclopaedia Britannica, Last modified, July 14, 2015, Accessed November 14, 2018, https://www.britannica.com/topic/Waldorf-school.

29. Galloway, "The Life and Times of Canadian Education: A Timeline" TimeToast, Accessed November 14, 2018, https://www.timetoast.com/timelines/the-life-and-times-of-canadian-education-a-timeline.

30. "Timeline: A History of Education" The Times Educational Supplement, Last modified, November 1, 2015, Accessed November 14, 2018, https://www.tes.com/news/timeline-history-education.

31. "The Story of the Canadian Pacific Railway", Canadian Pacific Railway: Communications and Public Affairs, Last modified, 2006, Accessed November 14, 2018, https://www.cpr.ca/en/about-cp-site/Documents/cp-history-for-students.pdf.

32. "Timeline of Dr. Maria Montessori's Life", Montessori Australia Foundation, Accessed November 14, 2018 , https://montessori.org.au/timeline-dr-maria-montessoris-life. 
33. "The Reggio Emilia Approach", North American Reggio Emilia Alliance, Accessed November 14, 2018, https:// www.reggioalliance.org/narea/.

34. "Timeline: A History of Education" The Times Educational Supplement, Last modified, November 1, 2015, Accessed November 14, 2018, https://www.tes.com/news/timeline-history-education.

35. Harvey Mccue, "Education of Indigenous People in Canada", The Canadian Encyclopedia, Last modified, July 18, 2018, Accessed November 14, 2018, https://www.thecanadianencyclopedia.ca/article/aboriginal-people-education.

36. Brian Tate, "A History of Education Timeline", Tiki-Toki, Accessed November 14, 2018, https://www.tiki-toki. com/timeline/entry/56733/A-History-of-Education-Timeline/\#vars!date=2019-09-30_13:41:26!.

37. Henry Sanoff and Rotraut Walden, School Environments (North Carolina: ResearchGate, 1994) See esp. Chap. 15, “The Progressive Movement”, (276-278).

38. Brian Tate, "A History of Education Timeline", Tiki-Toki, Accessed November 14, 2018, https://www.tiki-toki. com/timeline/entry/56733/A-History-of-Education-Timeline/\#vars!date=2019-09-30_13:41:26!

39. "An Evaluation of Piaget's Theory of development in the Classroom" Piaget in the Classroom, Accessed November 14, 2018, https://piagetintheclassroom.wordpress.com/piagets-theory/the-theory/.

40. Janice Weiss, "Back to Basics Through the Years" The Chicago Reporter, Last modified, July 22, 2005, Accessed November 14, 2018, https://www.chicagoreporter.com/back-basics-through-years/.

41. Galloway, "The Life and Times of Canadian Education: A Timeline" TimeToast, Accessed November 14, 2018, https://www.timetoast.com/timelines/the-life-and-times-of-canadian-education-a-timeline.

42. $|\mathrm{B}| \mathrm{D}$

43. $\mid \mathrm{BID}$

44. Brian Tate, "A History of Education Timeline", Tiki-Toki, Accessed November 14, 2018, https://www.tiki-toki. com/timeline/entry/56733/A-History-of-Education-Timeline/\#vars!date=2019-09-30_13:41:26.

45. IBID

46. Harvey Mccue, "Education of Indigenous People in Canada", The Canadian Encyclopedia, Last modified, July 18, 2018, Accessed November 14, 2018, https://www.thecanadianencyclopedia.ca/article/aboriginal-people-education. 


\title{
Historical Timeline Image Index
}

\author{
A Brief History of Education: A Timeline \\ Fig. 1 One room school house / https://amays.coetail.com/tag/curiosity/ \\ Fig. 2 Canadian residential school/https://goo.gl/XeVynu \\ Fig. 3 Instructional television broadcasting / https://goo.gl/VrznXW \\ Fig. 4 Canadian CPR school car / https://goo.gl/MXP94G \\ Fig. 5 École de plein-air, Suresnes / https://goo.gl/BKNgiD \\ Fig. 6 Giovanni Da Verrazzano Ship / https://goo.gl/w11cvn
}




\section{Historical Timeline Bibliography}

Anastakis, Dimitry. "Industrialization in Canada." The Canadian Encyclopedia. Last modified, March 14, 2017. Accessed November 14, 2018. https://www.thecanadianencyclopedia.ca/en/article/industrialization.

"An Evaluation of Piaget's Theory of development in the Classroom." Piaget in the Classroom. Accessed November 14, 2018.

Fieser, James and Bradley Dowden. "Plato: The Academy." Internet Encyclopedia of Philosophy. Accessed November 14, 2018. https://www.iep.utm.edu/academy/

Gaffield, Chad. "History of Education in Canada." The Canadian Encyclopedia. Last modified, March 4, 2015. Accessed November 14, 2018. https://www.thecanadianencyclopedia.ca/en/article/history-of-education

Galloway. "The Life and Times of Canadian Education: A Timeline." TimeToast. Accessed November 14, 2018. https://www.timetoast.com/timelines/the-life-and-times-of-canadian-education-a-timeline

Hughes, Bethany. "Socrates: a man for our times." The Guardian. Last modified, October 13, 2010. Accessed November 14, 2018. https://www.theguardian.com/books/2010/oct/17/socrates-philosopher-man-for-our-times

Jewett, Pamela Carol. "Waldorf School Education." Encyclopaedia Britannica. Last modified, July 14, 2015. Accessed November 14, 2018. https://www.britannica.com/topic/Waldorf-school

Mccue, Harvey. "Education of Indigenous People in Canada." The Canadian Encyclopedia. Last modified, July 18, 2018. Accessed November 14, 2018. https://www.thecanadianencyclopedia.ca/article/aboriginal-people-education

Meyer, Adolphe Erich and Robert Browning. "Education." Encyclopaedia Britannica. Last modified, August 29, 2018. Accessed November 14, 2018. https://www.britannica.com/topic/education/The-primary-school

Miller, J.r. "Residential Schools in Canada." The Canadian Encyclopedia. Last modified, June 14, 2018. Accessed November 14, 2018. https://www.thecanadianencyclopedia.ca/en/article/residential-schools

Morgan, Harry. "Historical Imagination." In The Imagination of Early Childhood Education. California :Bergin \& Garvey, 1999

"Our History." Canadian association of Montessori Teachers. Accessed November 14, 2018. https://www.camt100. ca/our-history

Sanoff, Henry and Rotraut Walden. School Environments. North Carolina: ResearchGate, 1994. See esp. Chap. 15, "The Progressive Movement". (276-278) 
Tate, Brian. "A History of Education Timeline." Tiki-Toki. Accessed November 14, 2018. https://www.tiki-toki.com/ timeline/entry/56733/A-History-of-Education-Timeline/\#vars!date=2019-09-30_13:41:26.

"Timeline: A History of Education." The Times Educational Supplement. Last modified, November 1, 2015. Accessed November 14, 2018. https://www.tes.com/news/timeline-history-education

"Timeline of Dr. Maria Montessori's Life." Montessori Australia Foundation. Accessed November 14, 2018. https:// montessori.org.au/timeline-dr-maria-montessoris-life

"The Story of the Canadian Pacific Railway." Canadian Pacific Railway: Communications and Public Affairs. Last modified, 2006. Accessed November 14, 2018. https://www.cpr.ca/en/about-cp-site/Documents/cp-history-for-students.pdf

"The Reggio Emilia Approach." North American Reggio Emilia Alliance. Accessed November 14, 2018. https://www. reggioalliance.org/narea/

Vazquez, Josefina Zordaida and Nobuo Shimahara. "Education." Encyclopaedia Britannica. Last modified, August 29, 2018. Accessed November 14, 2018. https:/www.britannica.com/topic/education/Athens

Winer, Sophie. "Theories on Education: Rousseau, Locke, and Montessori in the Modern Lesson Plan (United States, Ages 0-6 years)." A Life of Reading. Last modified, November 20, 2015. Accessed November 14, 2018. https://sophiewiner.com/2015/11/20/theories-on-education-rousseau-locke-and-montessori-in-the-modern-lessonplan-united-states-ages-0-6-years/

Weiss, Janice. "Back to Basics Through the Years." The Chicago Reporter. Last modified, July 22, 2005. Accessed November 14, 2018. https://www.chicagoreporter.com/back-basics-through-years/. 


\title{
Appendix _A
}

\author{
Workshop/ Ethics Clearance - 01
}

\section{CERTIFICATION OF INSTITUTIONAL ETHICS CLEARANCE}

The Carleton University Research Ethics Board-B (CUREB-B) has granted ethics clearance for the research project described below and research may now proceed. CUREB-B is constituted and operates in compliance with the Tri-Council Policy Statement: Ethical Conduct for Research Involving Humans (TCPS2)

Ethics Protocol Clearance ID: Project \# 109833

Research Team: Ms. Paola Vega (Primary Investigator)

Roger Connah (Research Supervisor)

Project Title: Architecture: The Third Teacher

Funding Source (If applicable):

Effective: November 28, 2018

Expires: November 30, 2019

Please ensure the study clearance number is prominently placed in all recruitment and consent materials: CUREB-B Clearance \# 109833.

\section{Restrictions:}

This certification is subject to the following conditions:

1. Clearance is granted only for the research and purposes described in the application.

2. Any modification to the approved research must be submitted to CUREB-B via a Change to Protocol Form. All changes must be cleared prior to the continuance of the research.

3. An Annual Status Report for the renewal of ethics clearance must be submitted and cleared by the renewal date listed above. Failure to submit the Annual Status Report will result in the closure of the file.If funding is associated, funds will be frozen.

4. A closure request must be sent to CUREB-B when the research is complete or terminated.

5. During the course of the study, if you encounter an adverse event, material incidental finding, protocol deviation or other unanticipated problem, you must complete and submit a Report of Adverse Events and Unanticipated Problems Form, found here: https://carleton.ca/researchethics/forms-and-templates/ 
Workshop/ Ethics Clearance - 02

Failure to conduct the research in accordance with the principles of the Tri-Council Policy Statement: Ethical Conduct for Research Involving Humans 2ndedition and the Carleton University Policies and Procedures for the Ethical Conduct of Research may result in the suspension or termination of the research project.

Upon reasonable request, it is the policy of CUREB, for cleared protocols, to release the name of the PI, the title of the project, and the date of clearance and any renewal(s)

Please contact the Research Compliance Coordinators, at ethics@carleton.ca, if you have any questions.

CLEARED BY:

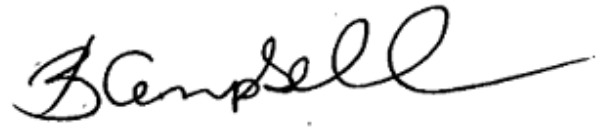

Bernadette Campbell, PhD, Chair, CUREB-B

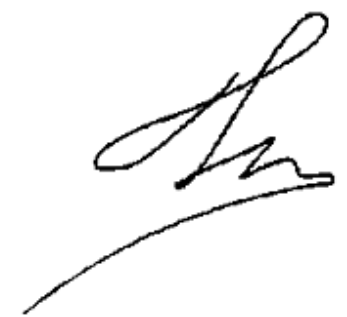

Natasha Artemeva, PhD, Vice-Chair, CUREB-B

Date: November 28, 2018 
Workshop/Script

Script

Assent script:

introduction of researcher, child-led tour and the drawing workshop.

> Hello, my name is Paola, I'm a student just like you, and I study architecture at Carleton University!

$>$ does anyone know what architecture is?

$>$ Architecture is all around you, it's the buildings where people live, work and play

$>$ It's this school and the house you live in! It can even be the built landscapes in your schoolyard

> As an architecture student we use drawing and photography to talk about our ideas of space

> So for today, I want us all to put on our architecture student hats and look at the spaces around us really carefully

$>$ I'm working on a project where l'm researching schools just like yours! And I hope that at the end of my project, with your help, I can design new materials and learning spaces that you would love

$>$ but in order for us to design new spaces we need to first think about what you like and dislike about the spaces in your school

$>$ So to start, your going to choose a friend, and in groups of two your going to take Miss__ and myself on a tour of your favourite places of the school, inside or outside, and take a photo of them with this camera

> After all the groups have shown their favourite places and taken a photo of them, we're going to sit all together and draw

$>$ Does anyone have any questions? 
Workshop/ Activities

Script_

\section{The workshop:}

Participants

12 Children, ages 5 - 9, and two teachers from each school.

Participant Information

The only information requested from the participants was the child participant's age.

Activity 1

Child-led tour of the school and grounds. In this activity, two children guided a school staff member and the researcher to four spaces in or around the school.

I. The children were individually asked to show the researcher and the teacher their three favorite spaces in the school (places that make them happy). At each location, the researcher asked the children to describe what they liked about the place.

II. The children were individually asked to show one space that is their least favourite. At each location, the researcher asked the children what they disliked about the place.

III. Throughout the place expedition the researcher recorded, in written fieldnotes, each of the children's answers, as well as noted the order in which the places were shown.

IV. At each of the locations, the children were asked to take a photograph of the important element, or elements that contributed to them choosing the location.

Activity 2

Mapping-drawing exercise. In this activity, children were provided with paper and a variety of drawing tools and were asked to draw, in this specific order:

I. Their school from above (as if they were flying over it).

II. Their favourite space in or around the school (where they are the happiest).

III. Their favourite learning material.

IV. Something new they would add to the school, that would make them happy (ie. space, activity, material).

*Note all the questions were written out for the children to be able to reference them while they drew.

Activity 3

Teacher interview. In this activity, the teachers were asked:

I. If they had ever had an idea for a lesson, activity or material that had been restricted by space o other architectural elements and if so, what were they?

II. The researcher recorded the teacher's answers as written fieldnotes. 


\section{Appendix_B}

Workshop/ Children's Photographs
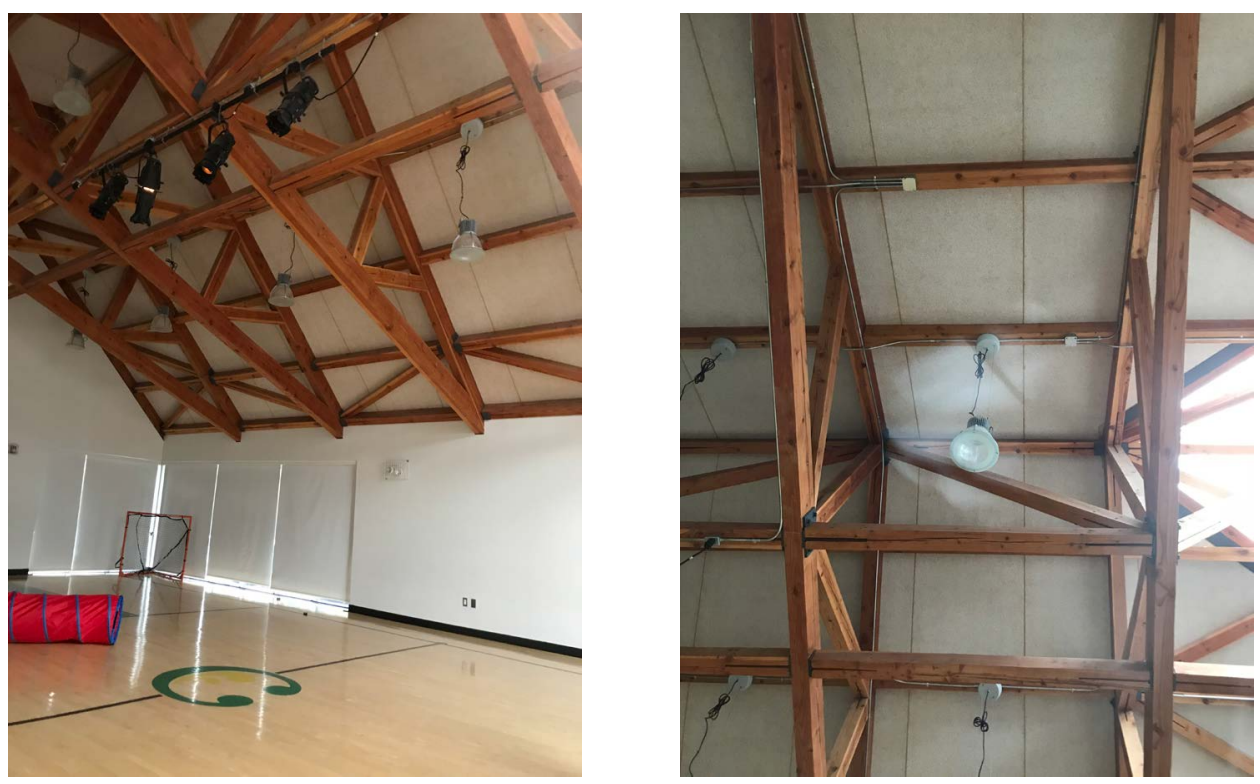

Gym /Clanmore

Gym /Clanmore
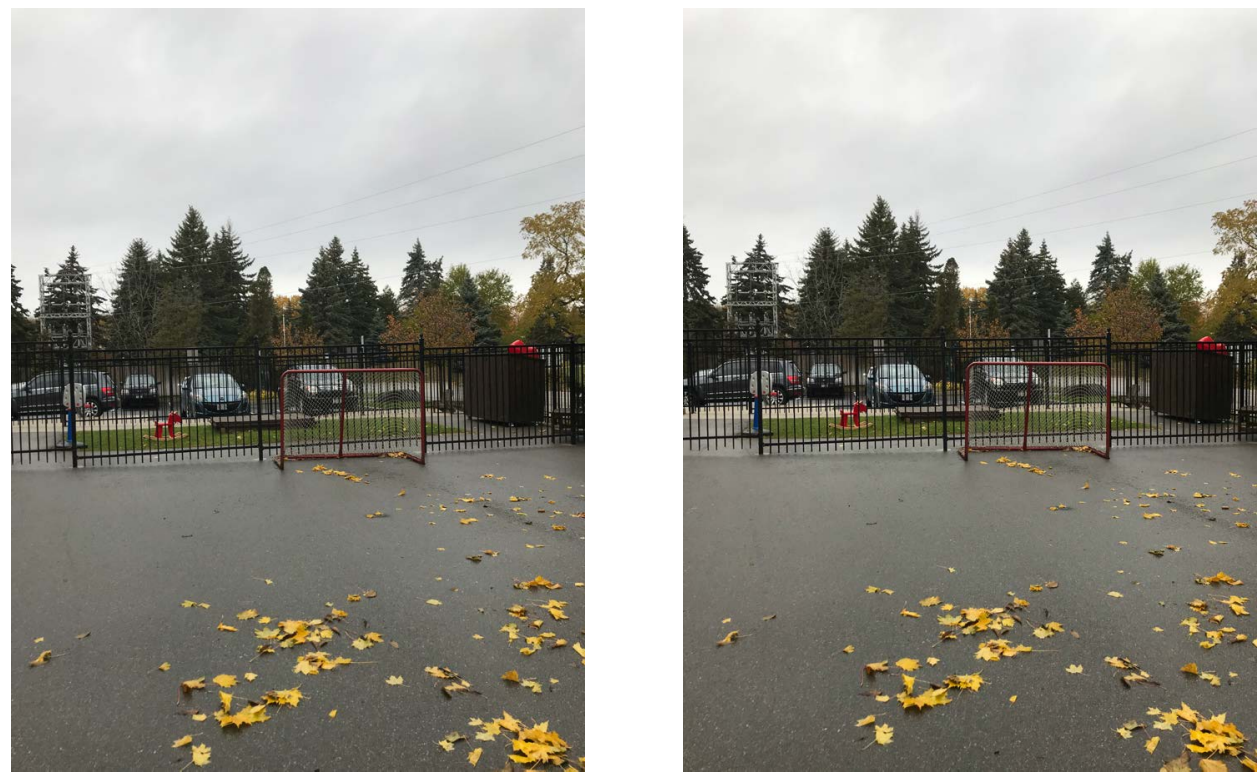

Soccer Turf/Clanmore 


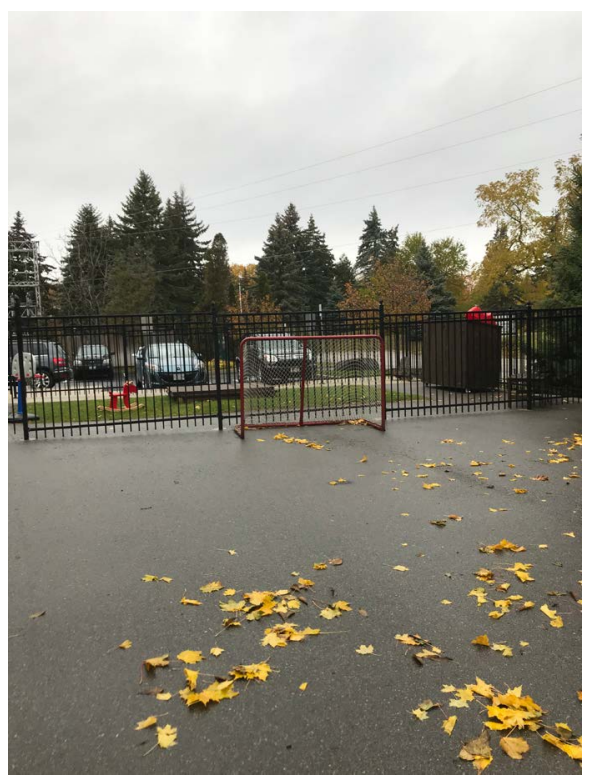

Soccer Turf /Clanmore

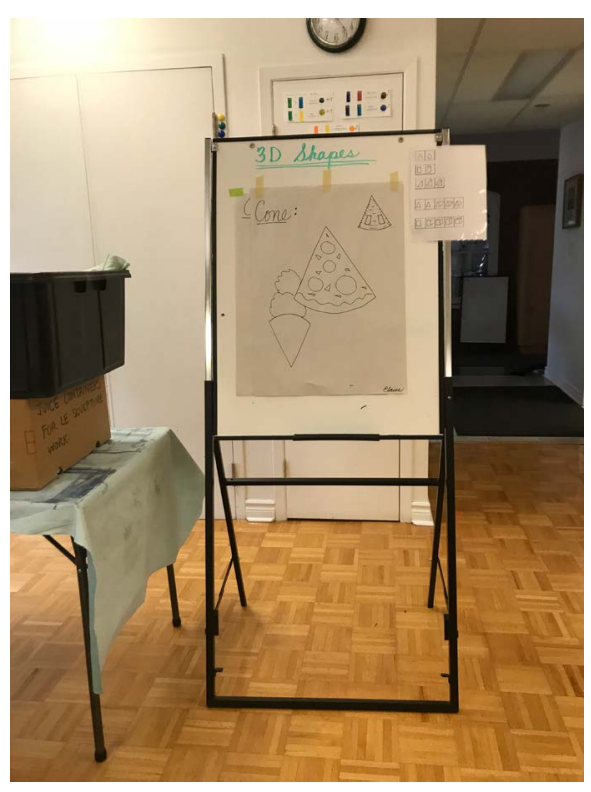

Art Room /Clanmore

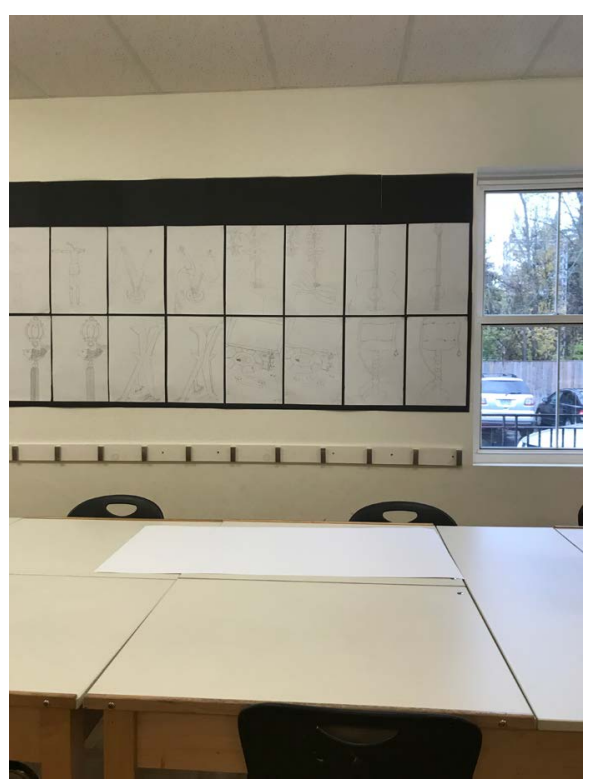

Art Room /Clanmore

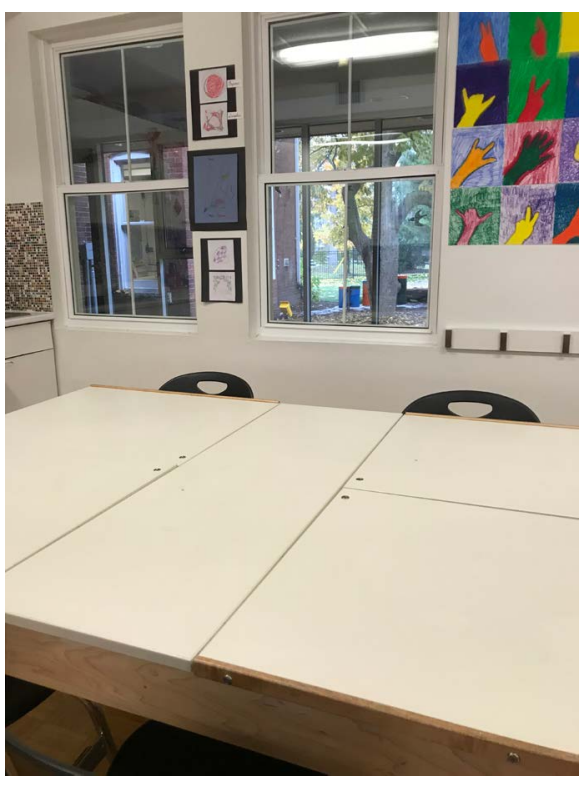

Art Room /Clanmore 


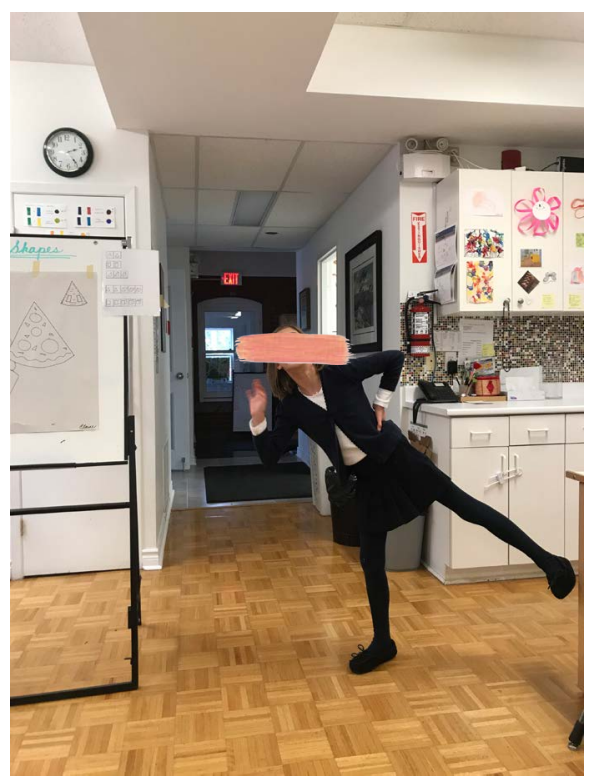

Art Room /Clanmore

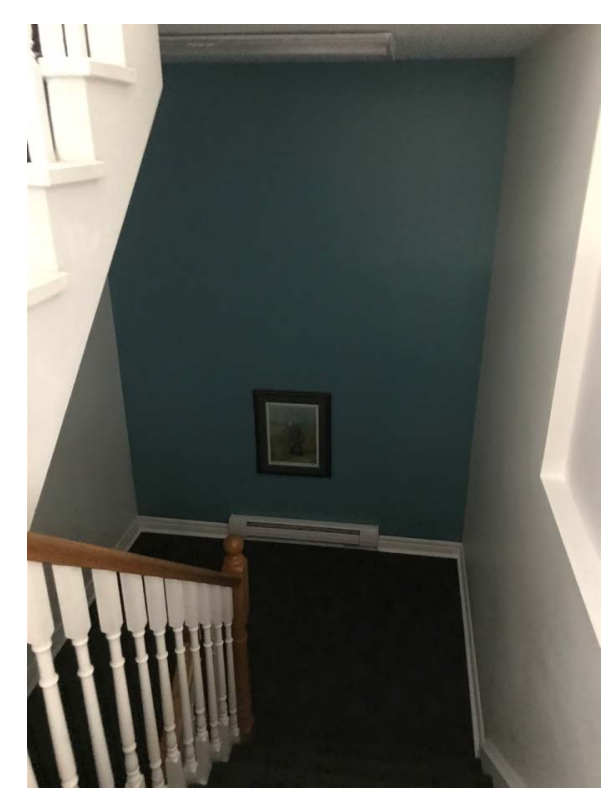

Toddler Stairwell /Clanmore

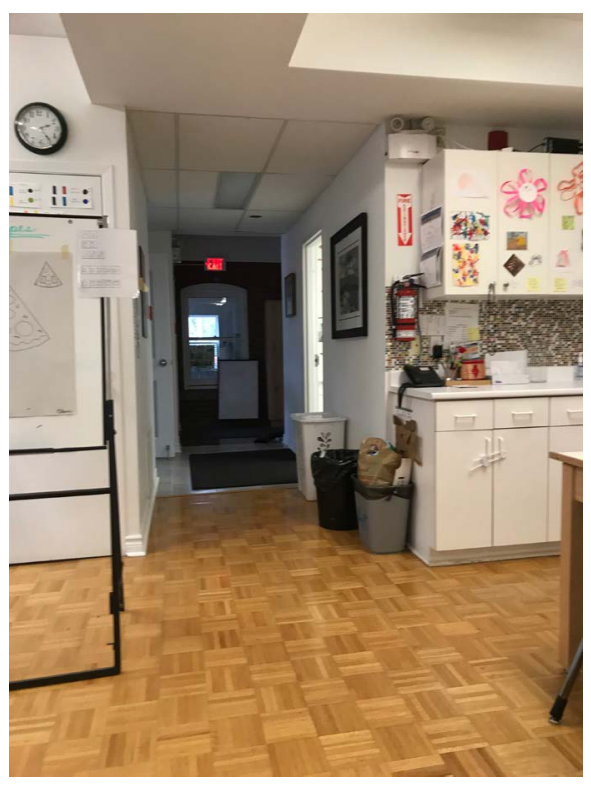

Art Room /Clanmore

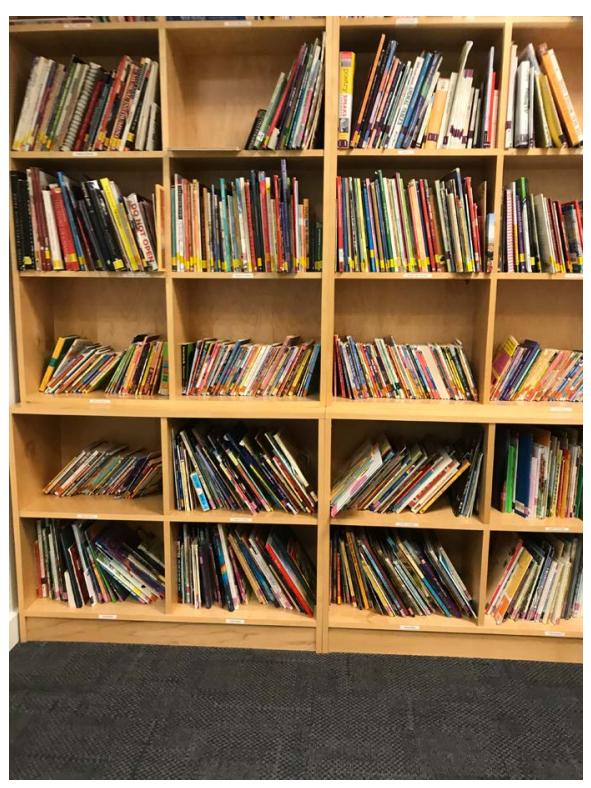

Library /Clanmore 

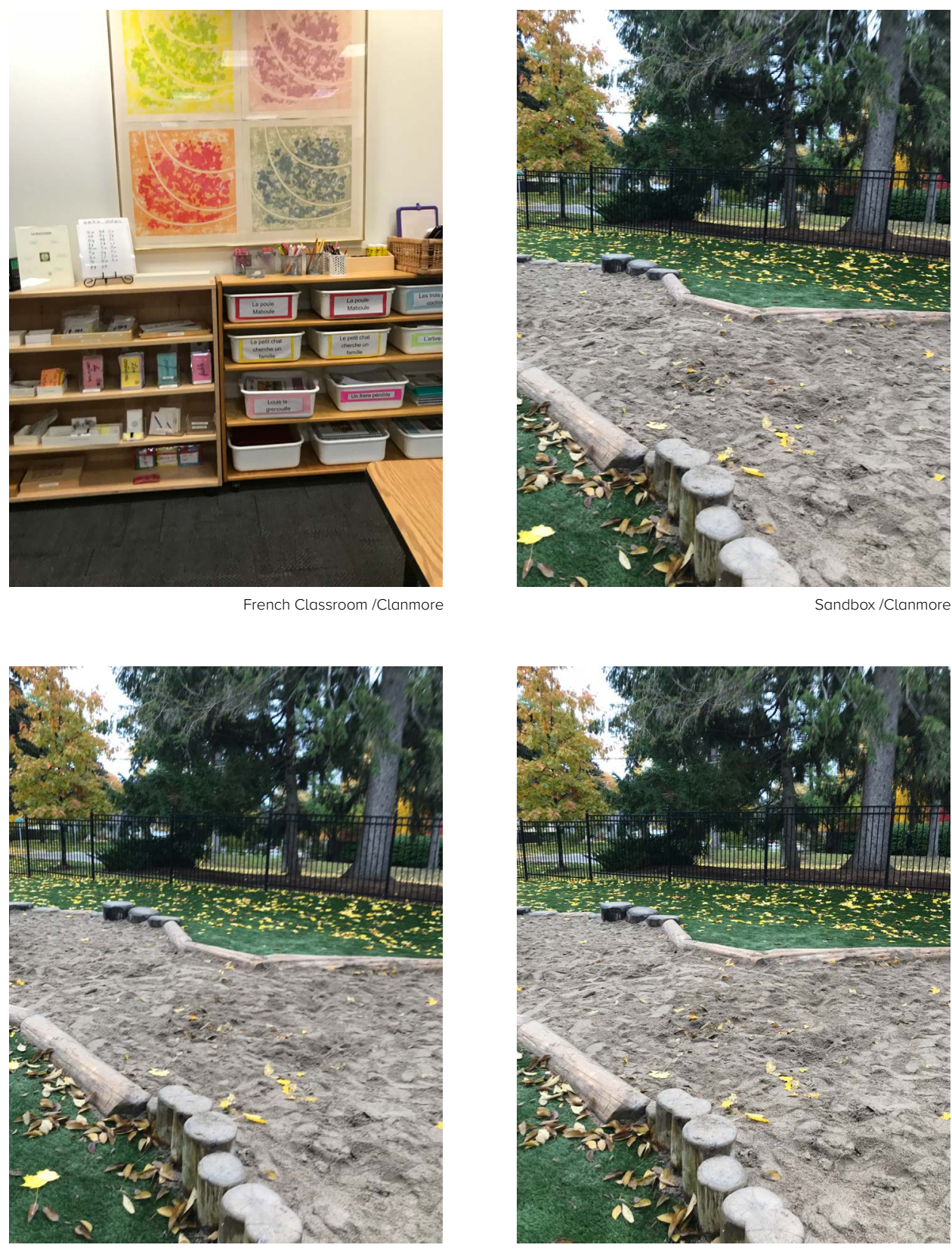

Sandbox/Clanmore 

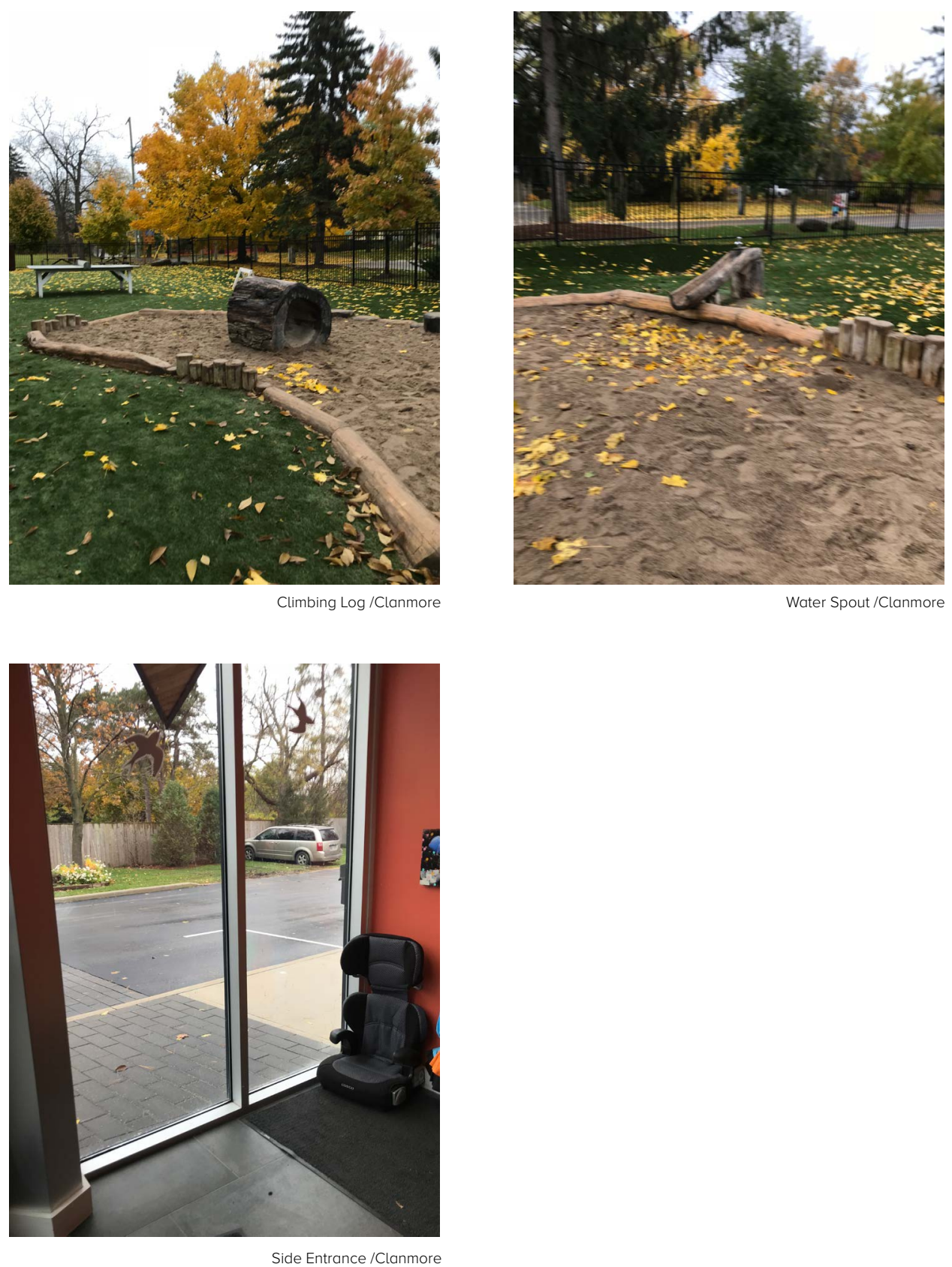

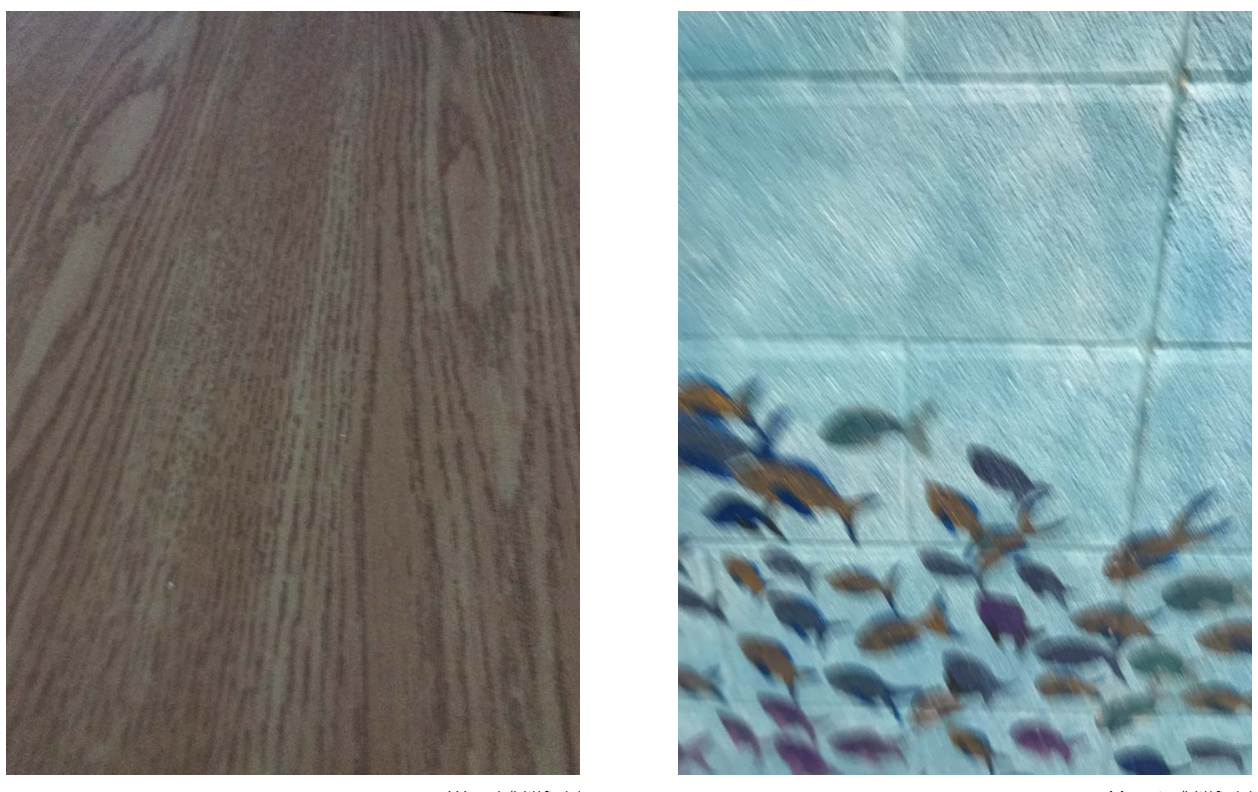

Wood/Hillfield

Mosaic/Hillfield
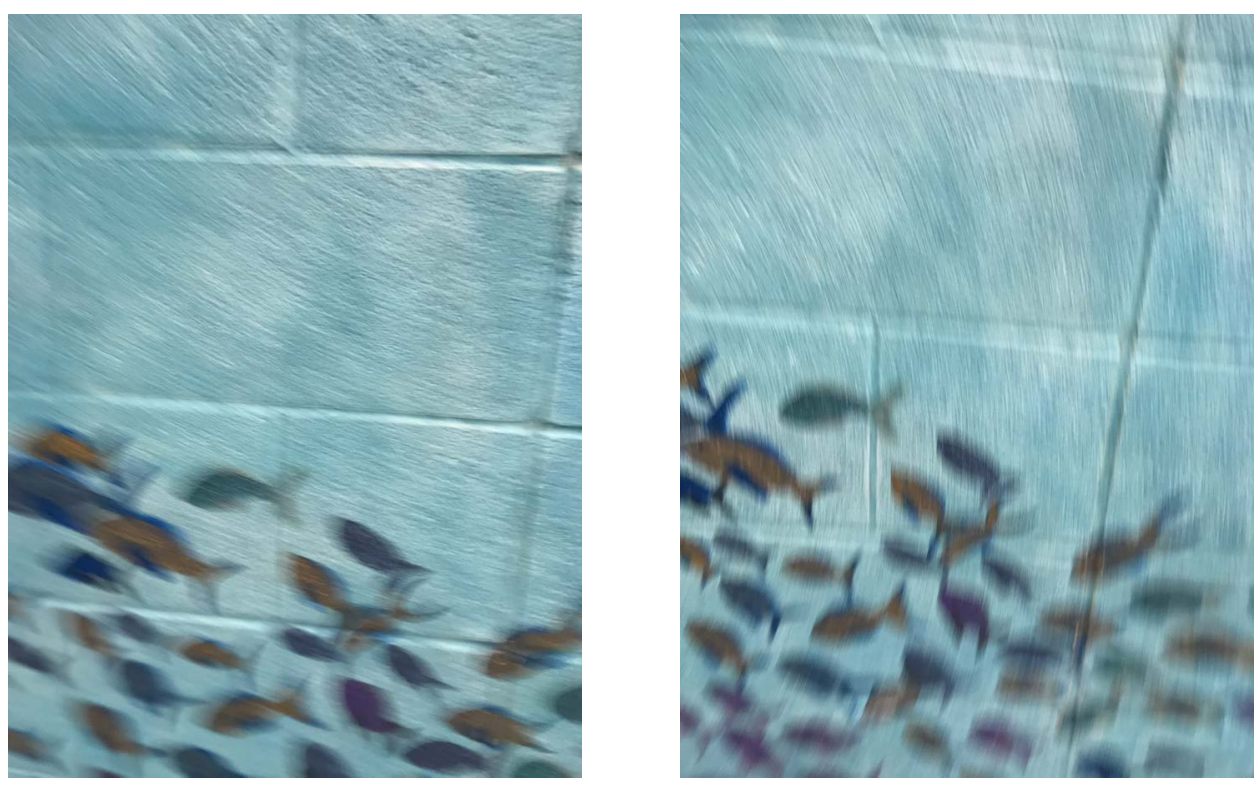

Mosaic /Hillfield

Mosaic/Hillfield 

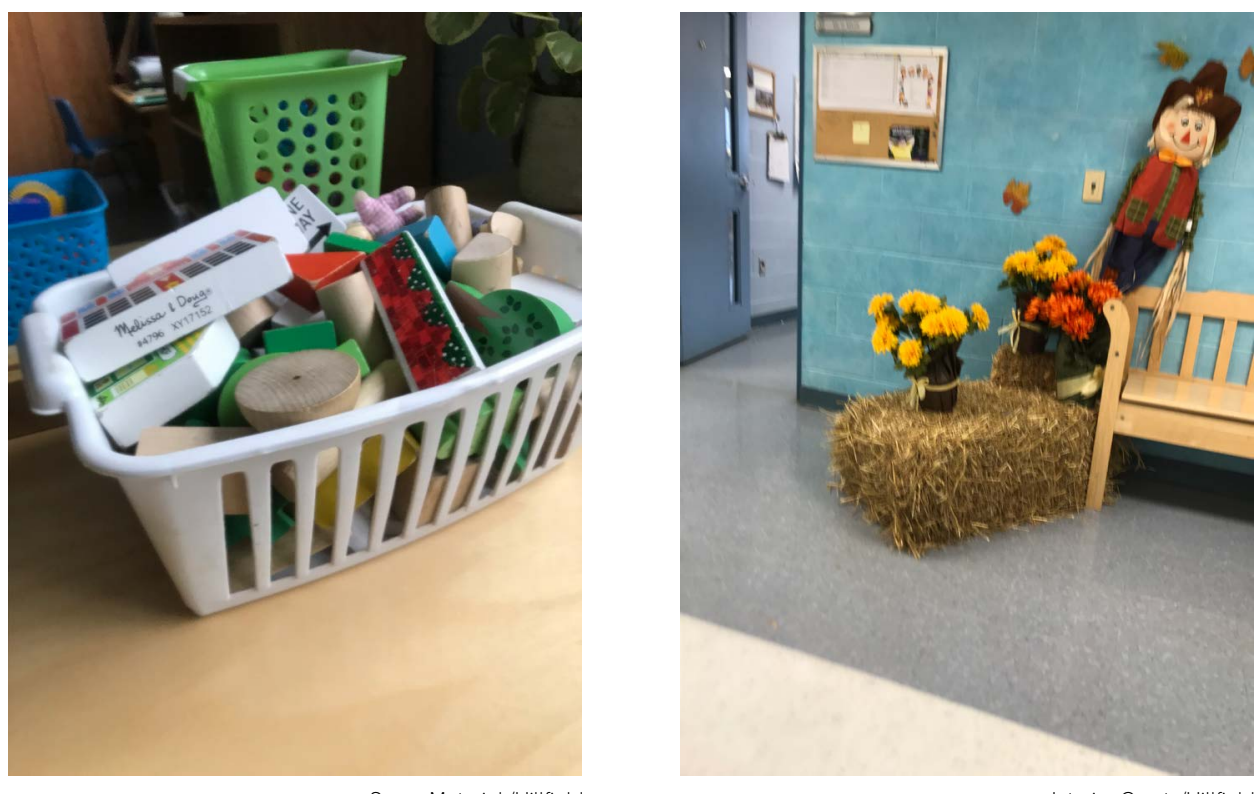

Spare Material /Hillfield

Interior Court /Hillfield
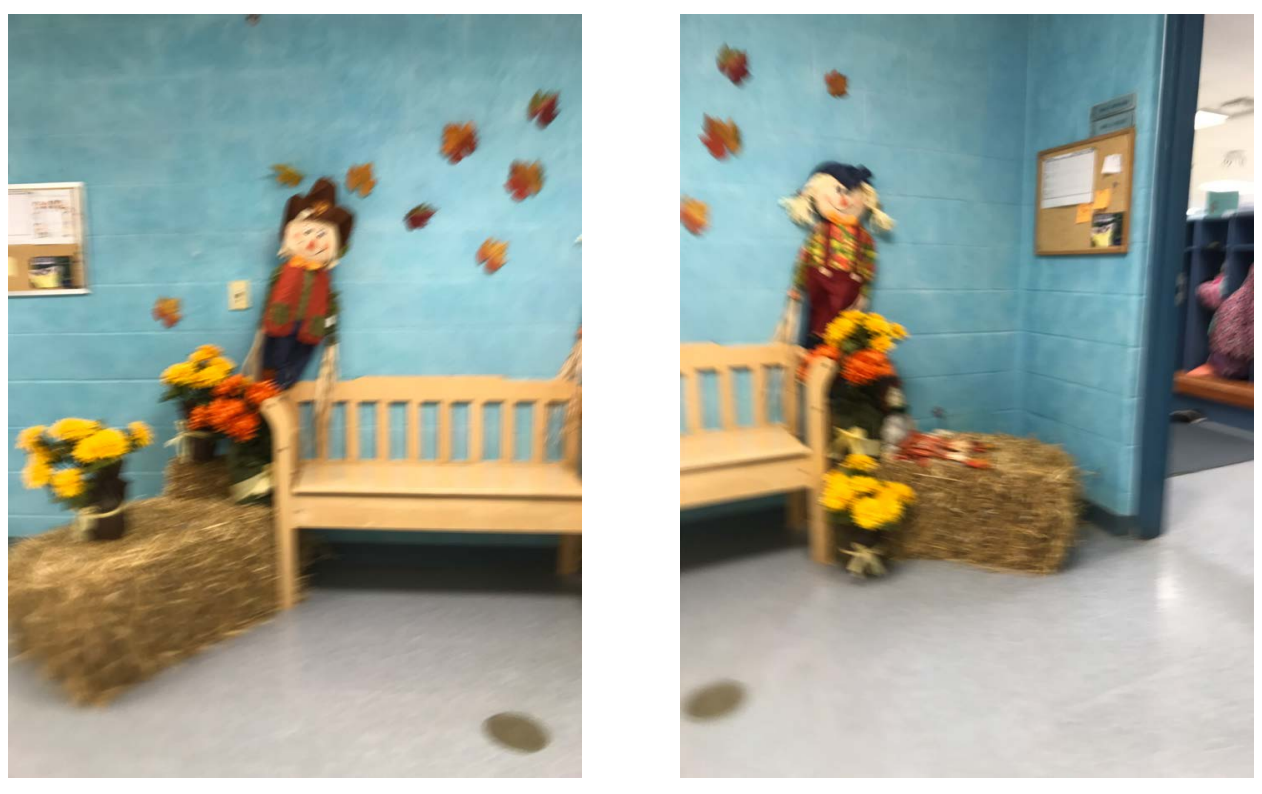

Interior Court /Hillfield 

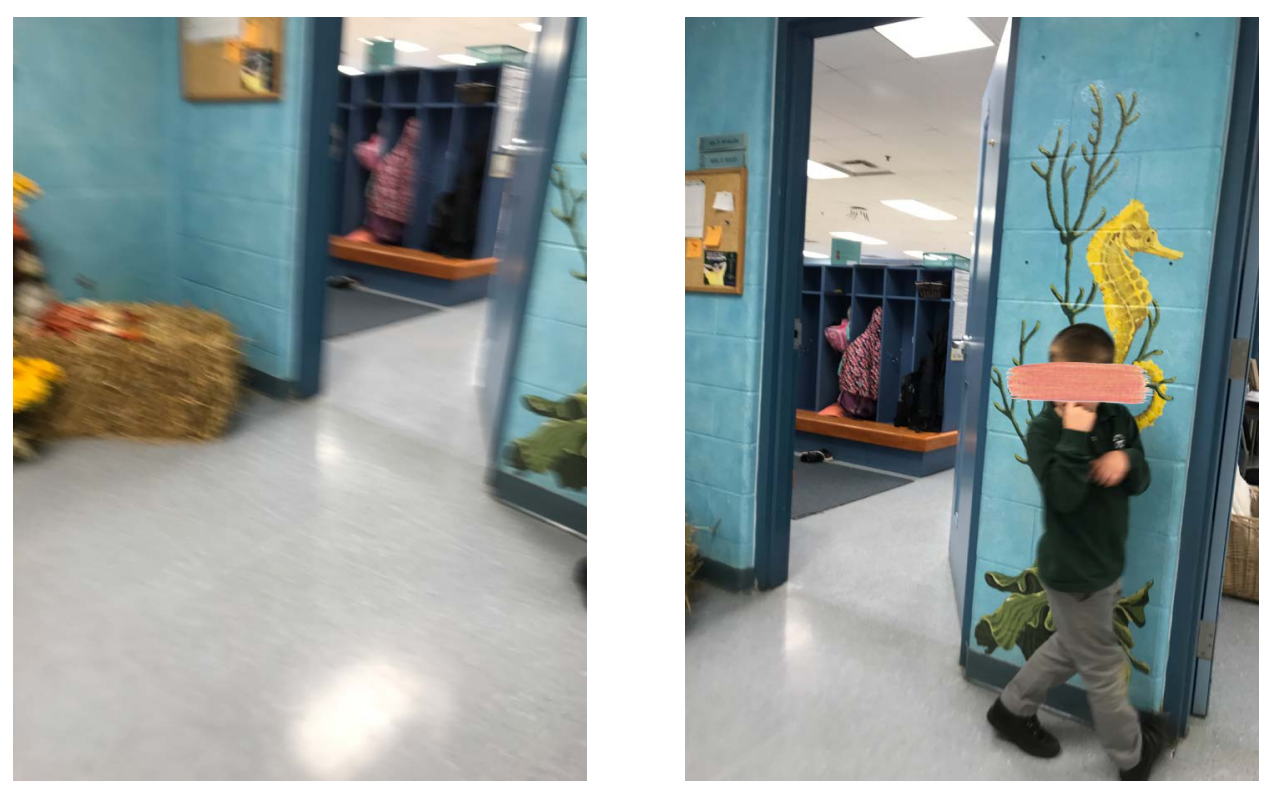

Interior Court /Hillfield

Interior Court /Hillfield
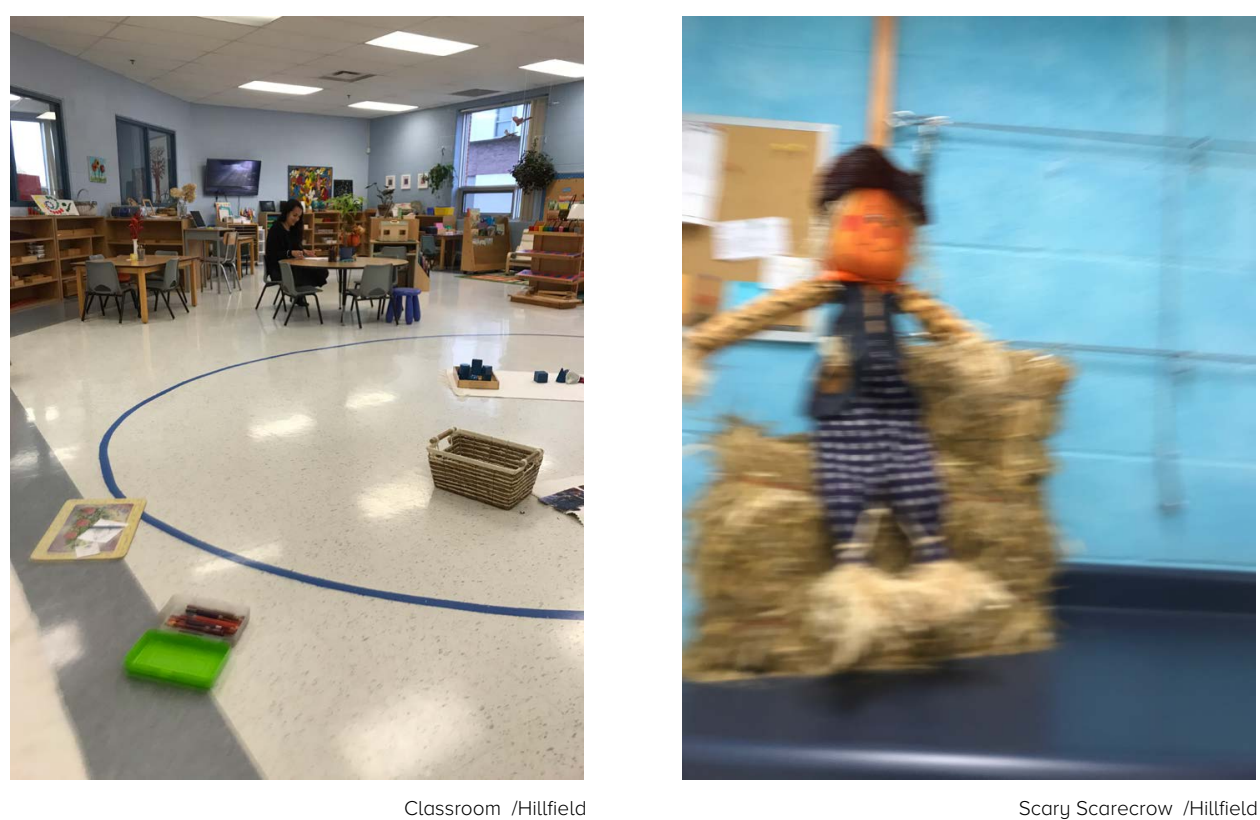

Scary Scarecrow /Hillfield 

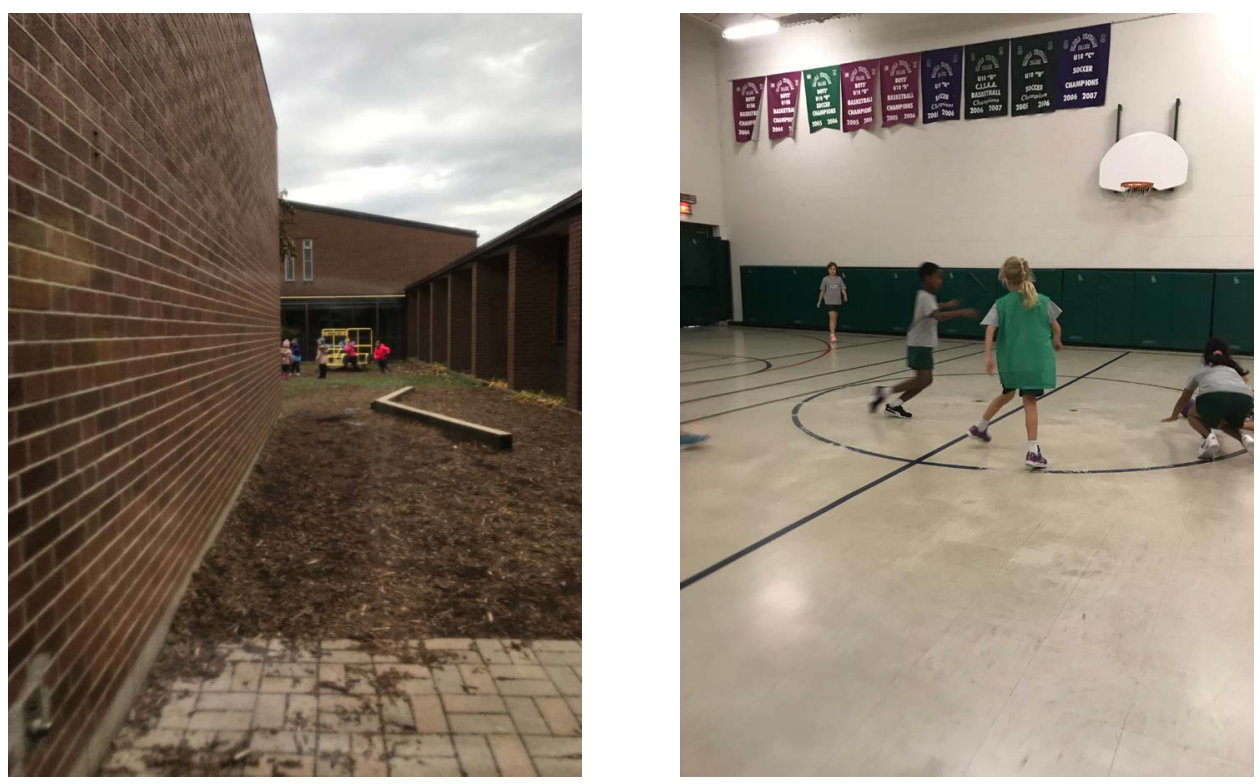

Side of Interior Playground /Hillfield

Small Gym/Hillfield
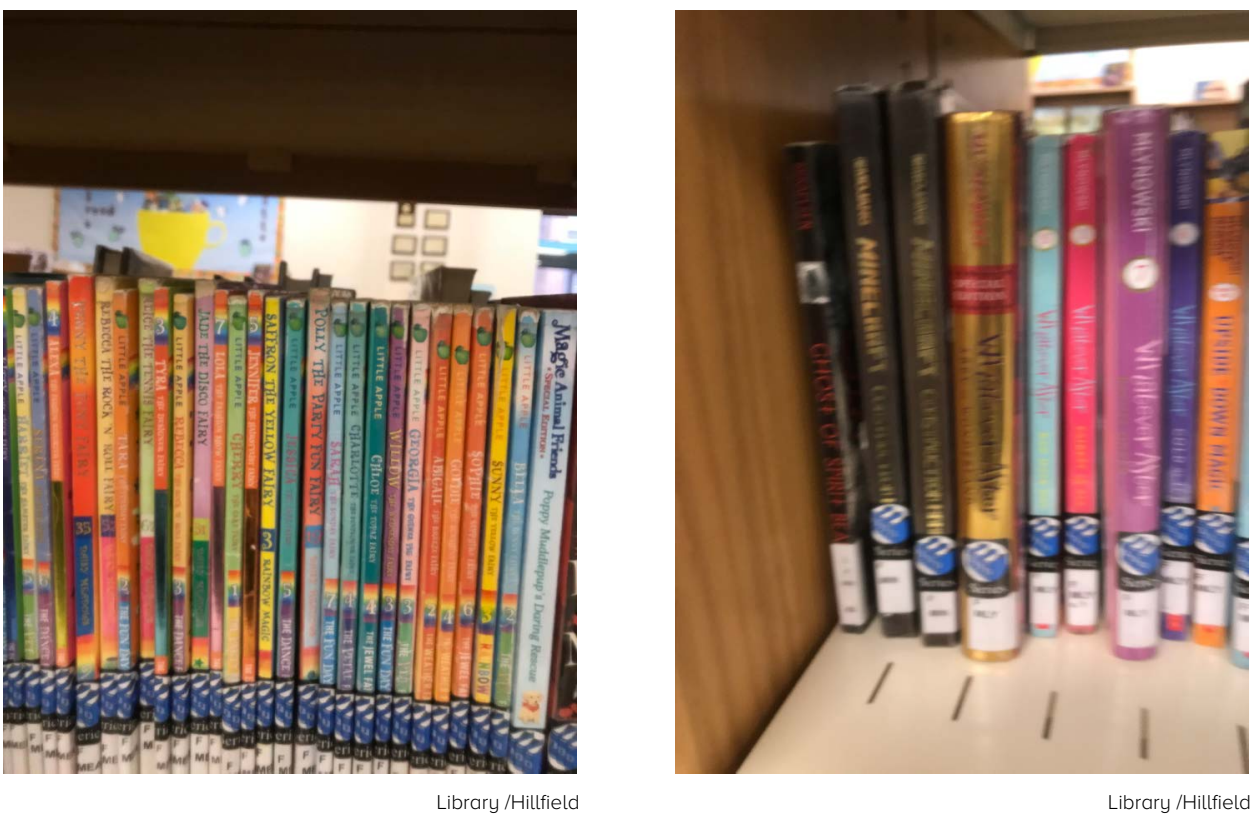

Library /Hillfield 


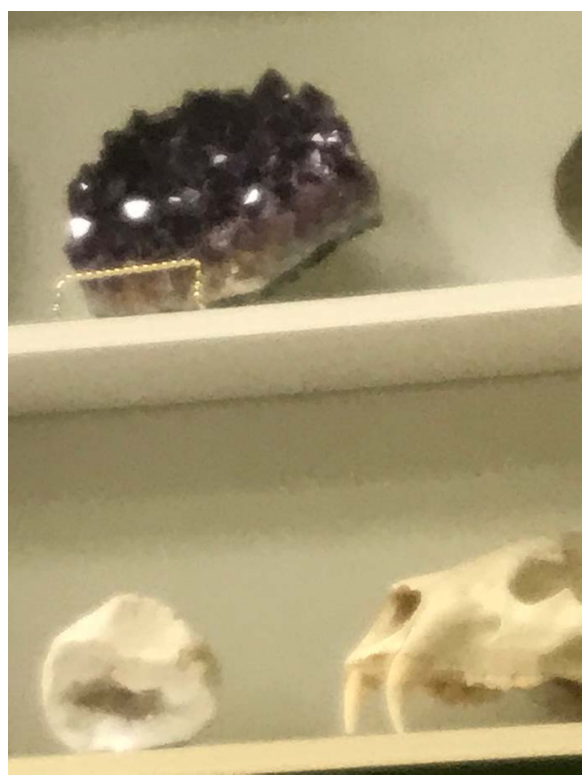

Library Artifacts /Hillfield

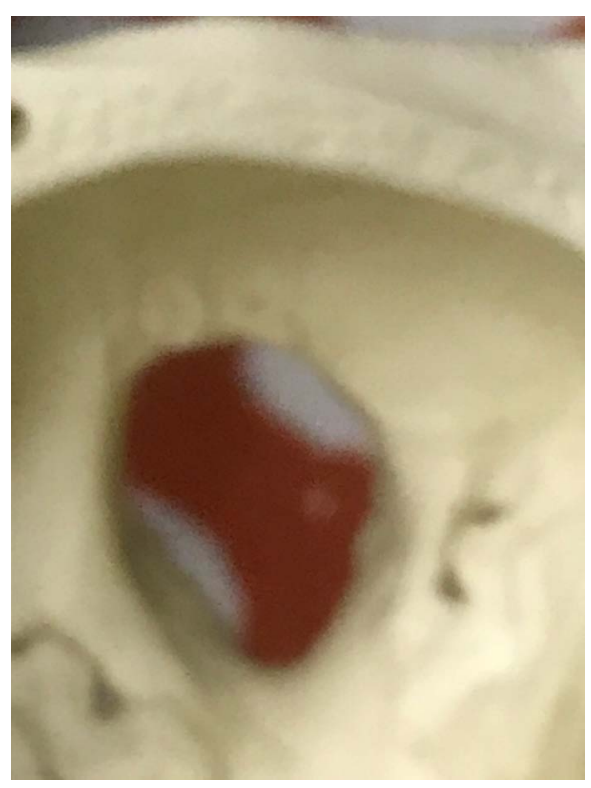

Library Artifacts /Hillfield

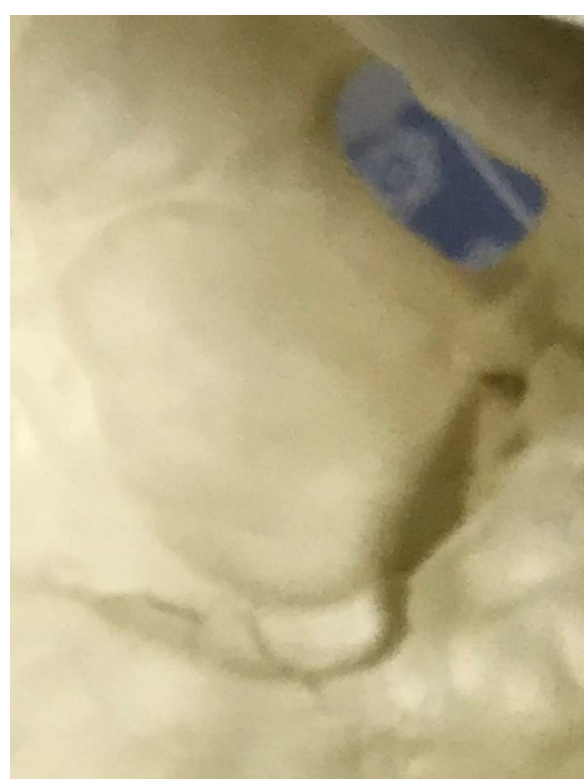

Library Artifacts /Hillfield

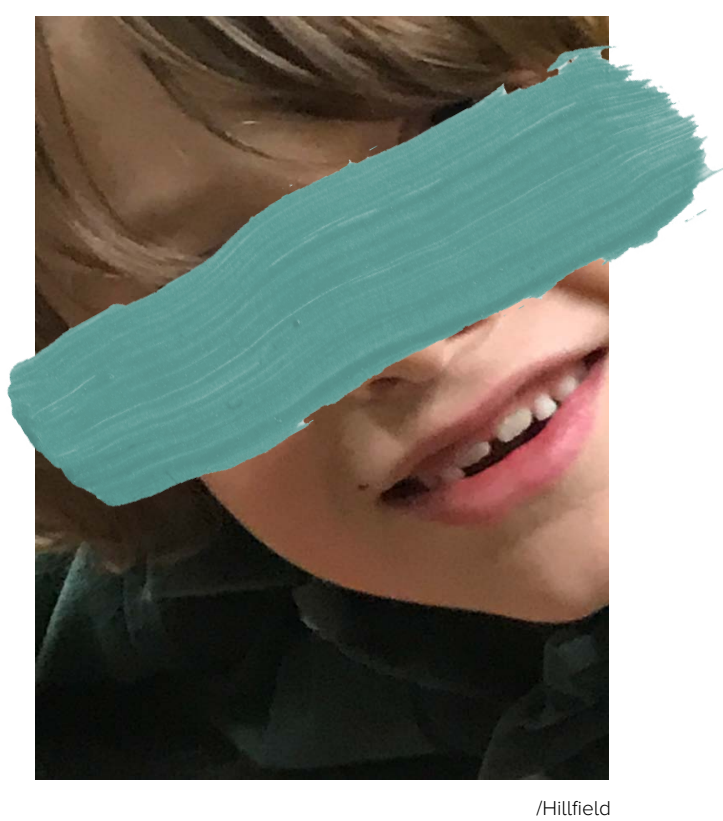



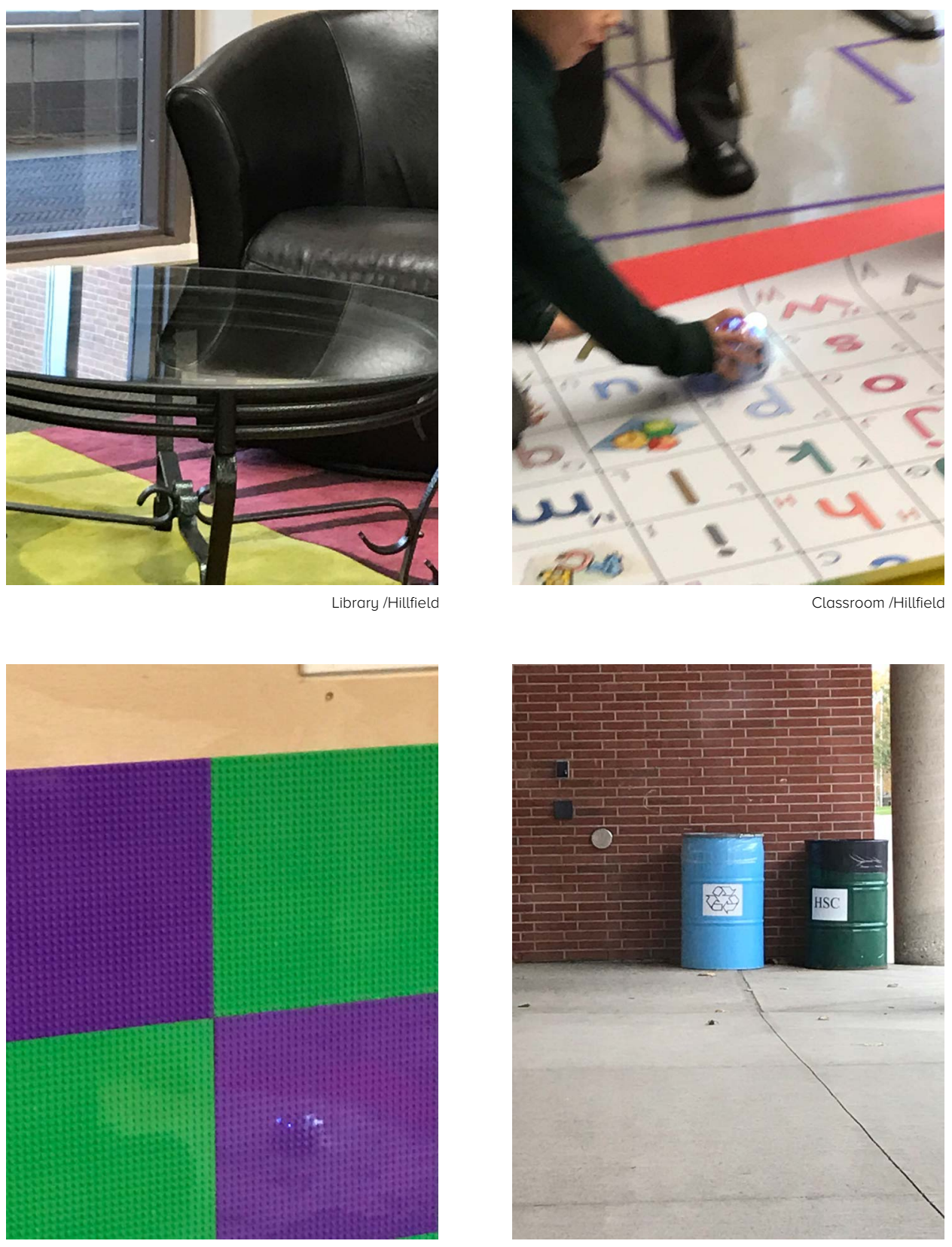

Launch Pad Wall /Hillfield

Bricktop/Hillfield 

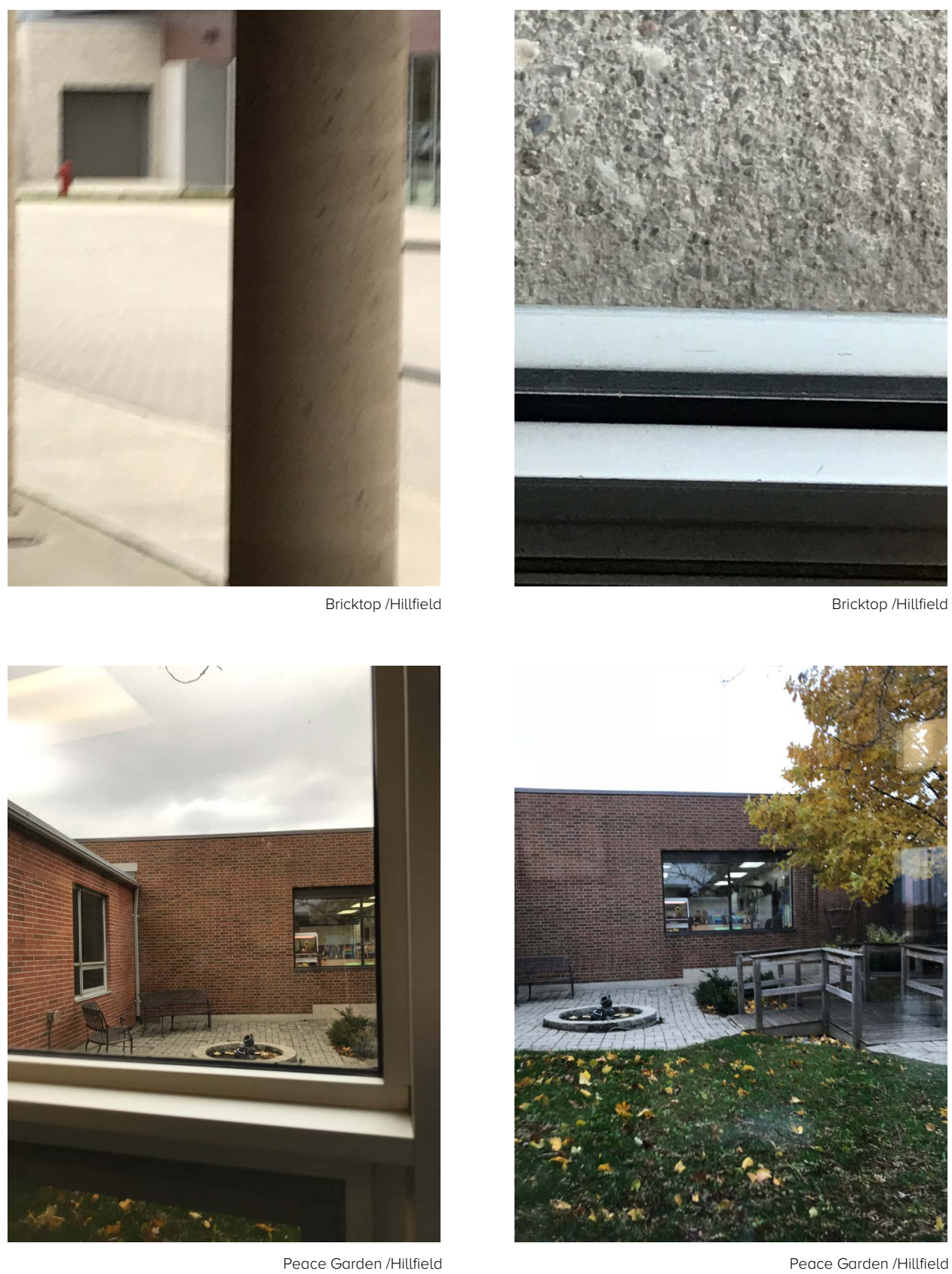

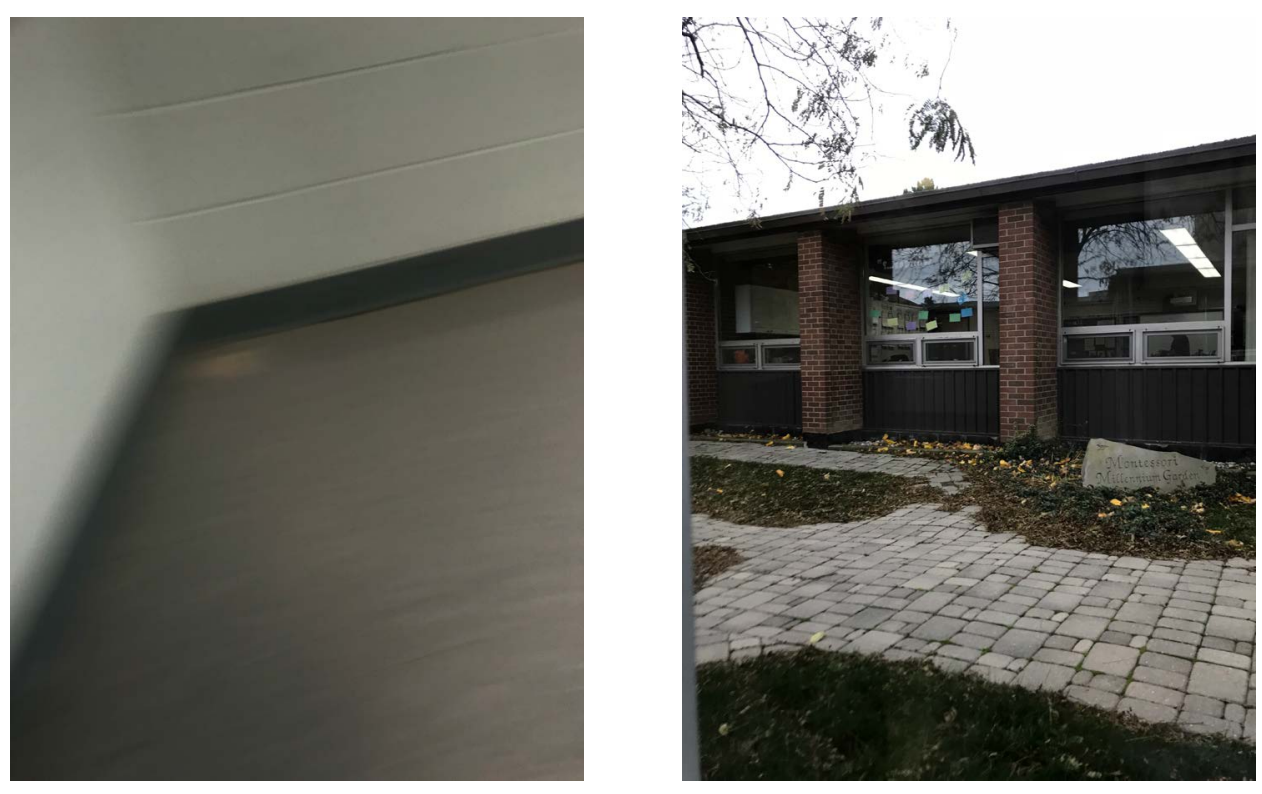

Stairwell /Hillfield

Peace Garden /Hillfield
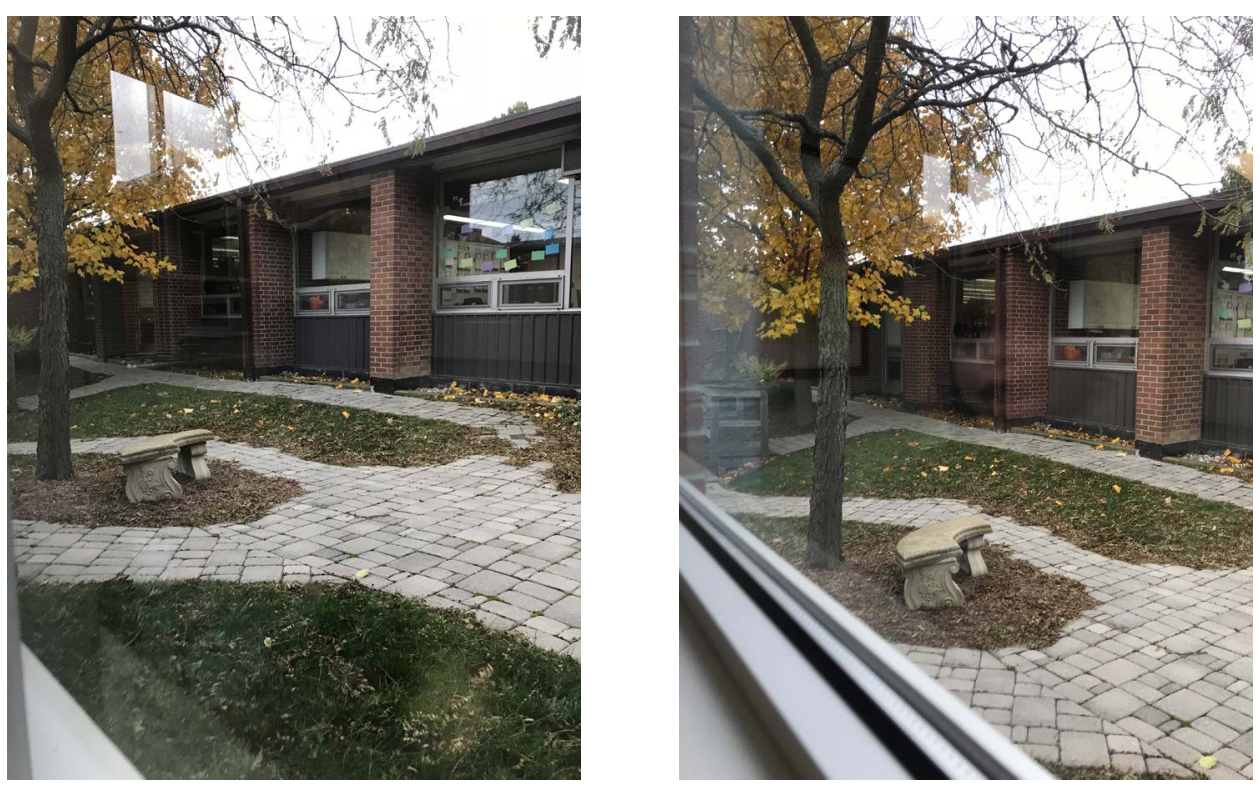

Peace Garden /Hillfield

Peace Garden /Hillfield 

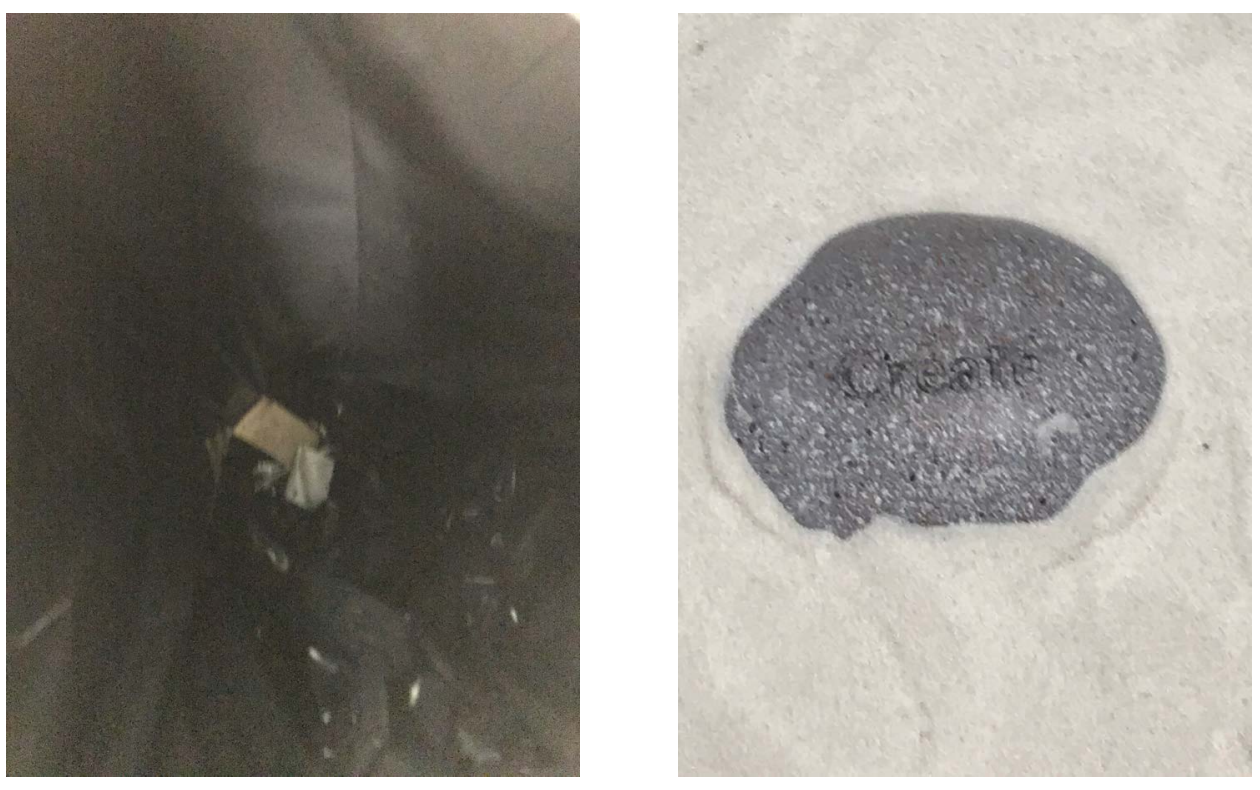

Garbage /Hillfield

Zen Sandbox /Hillfield
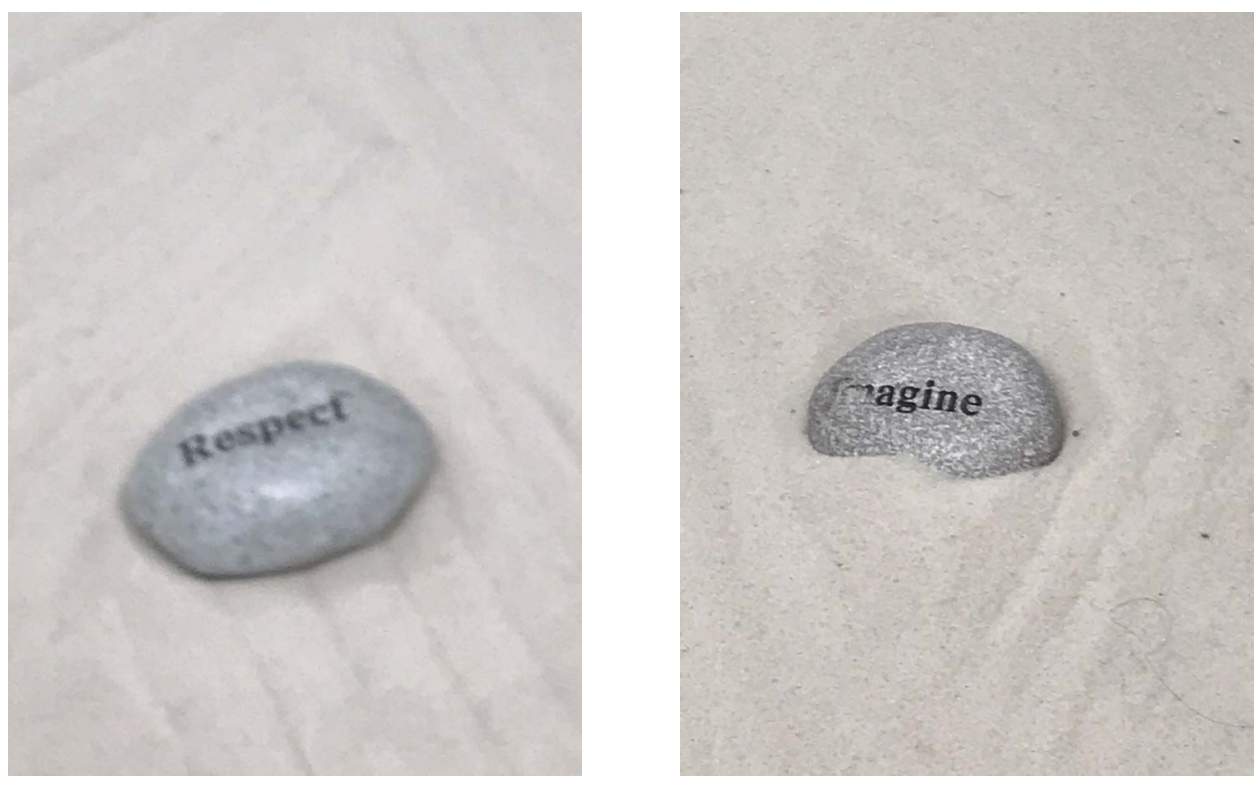

Zen Sandbox/Hillfield 

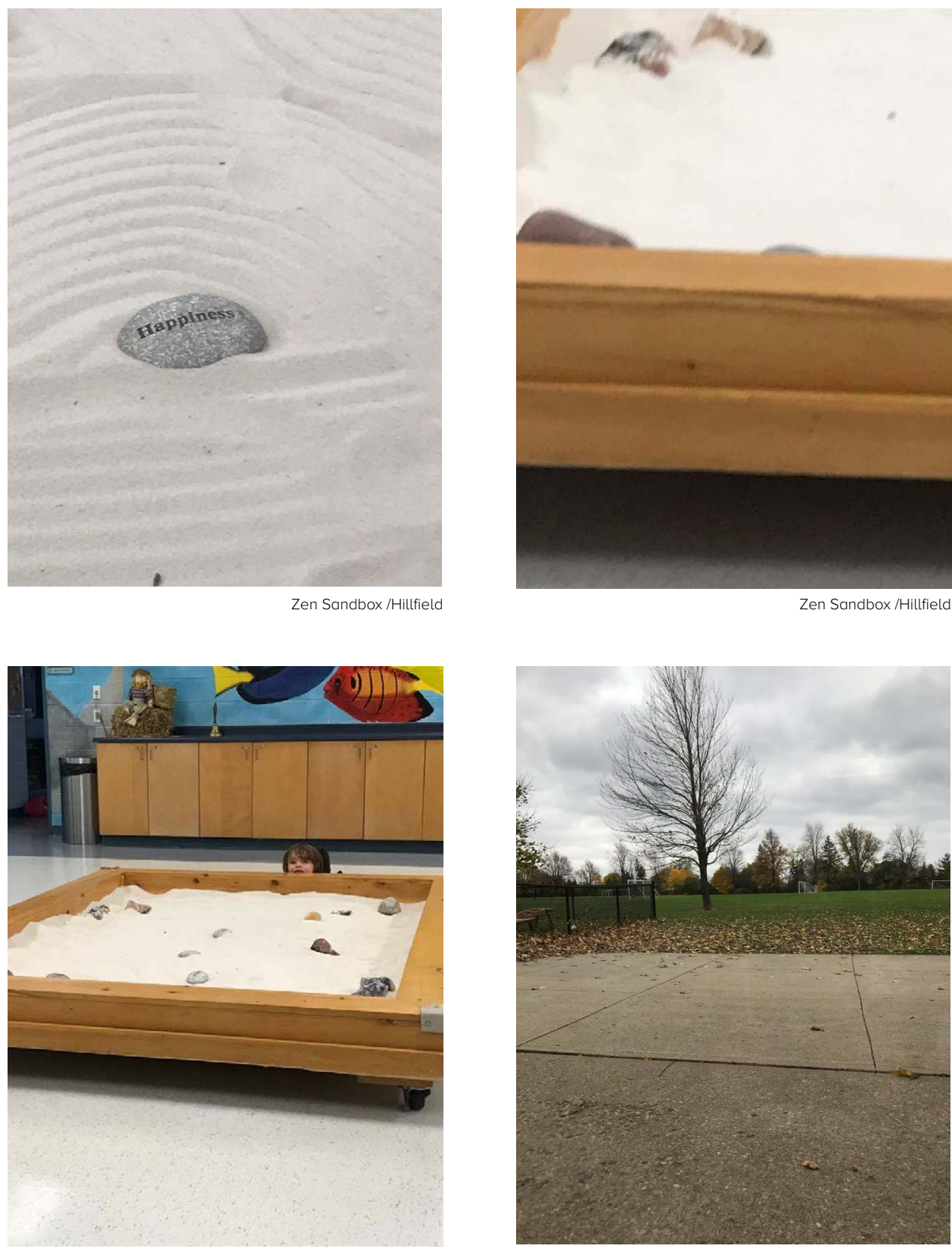

Field /Hillfield 

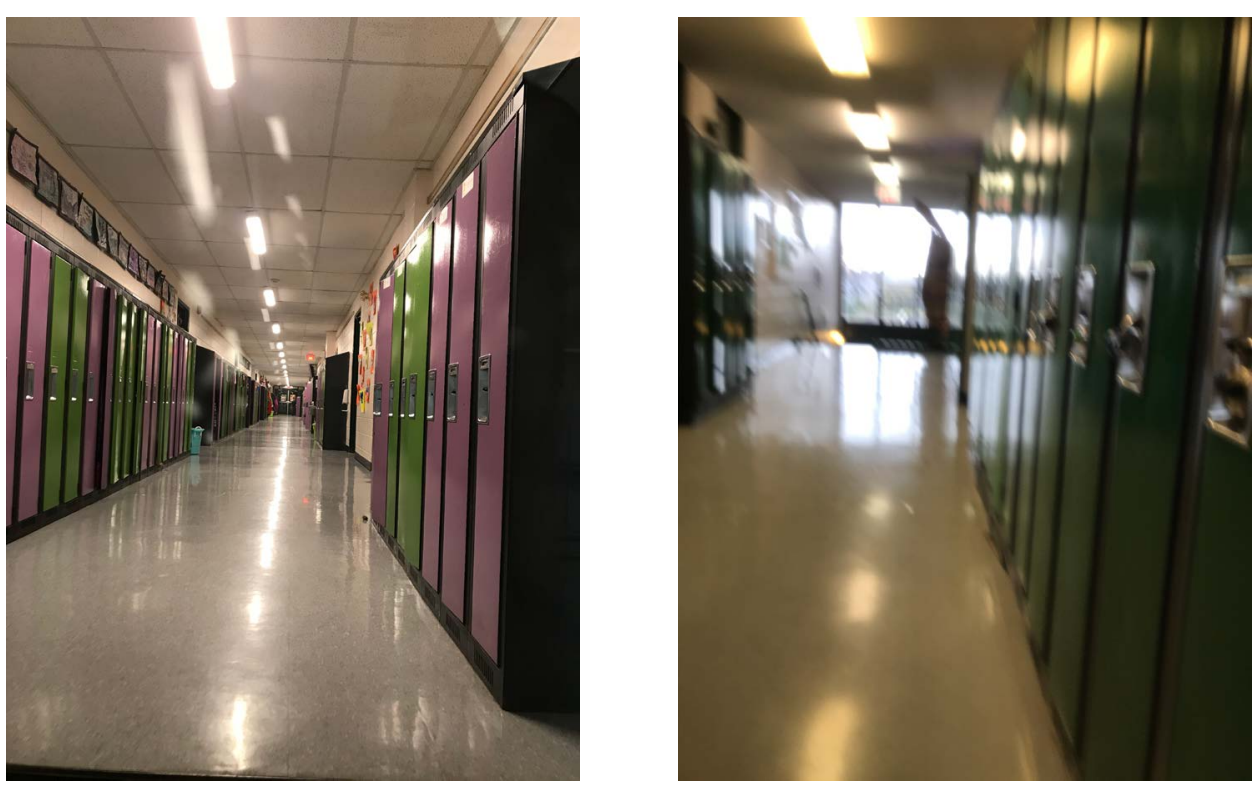

Personal Lockers /Hillfield

Personal Lockers /Hillfield
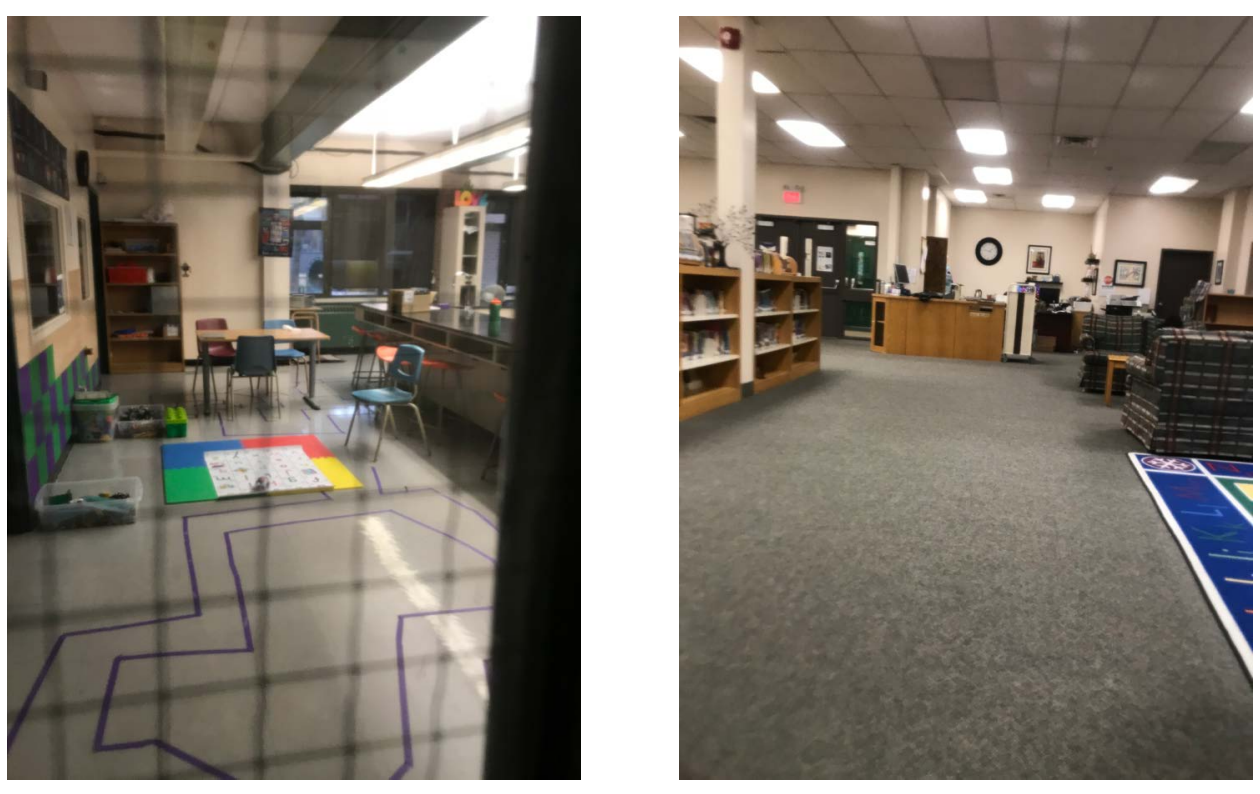

Library /Hillfield 

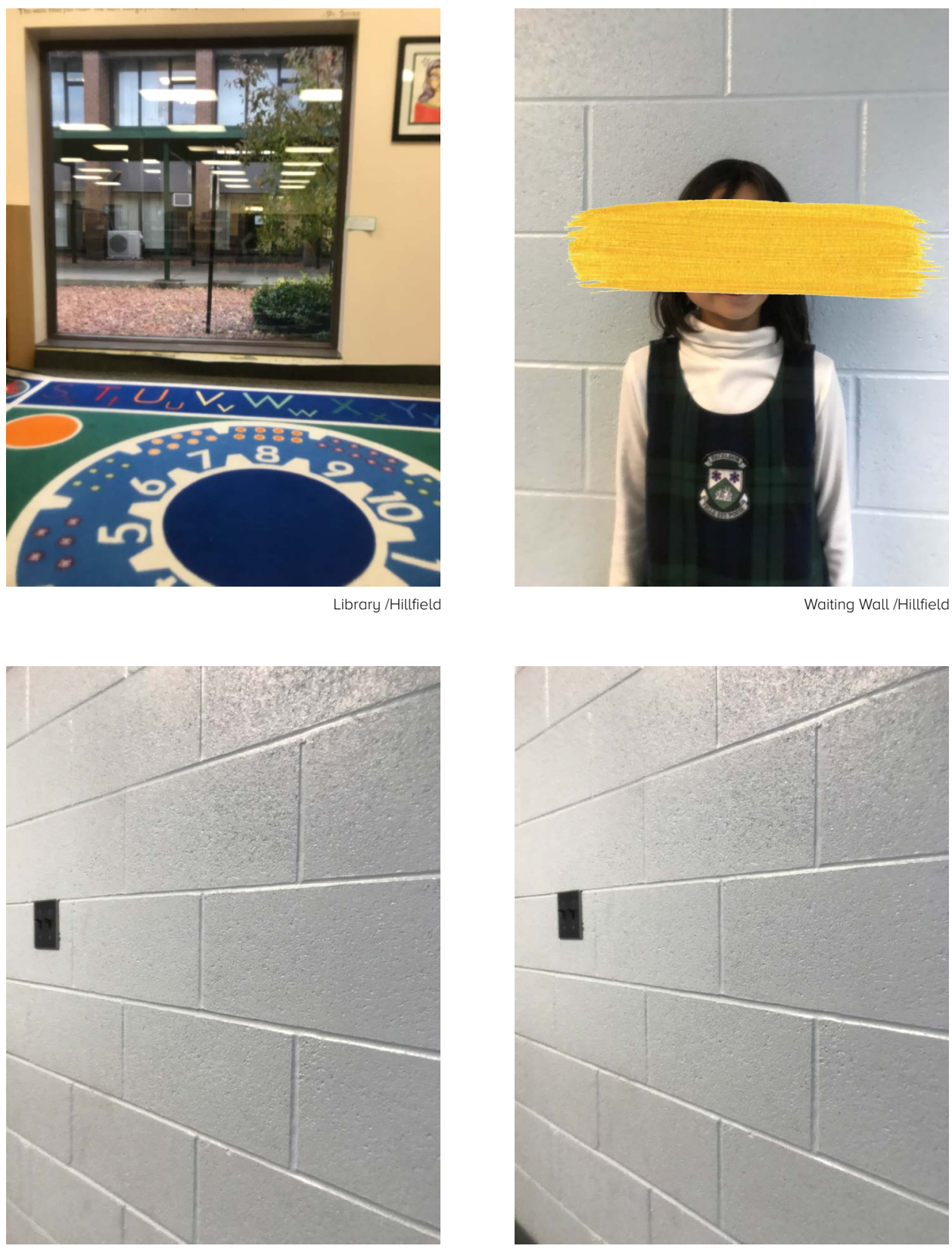

Waiting Wall /Hillfield

Waiting Wall/Hillfield 

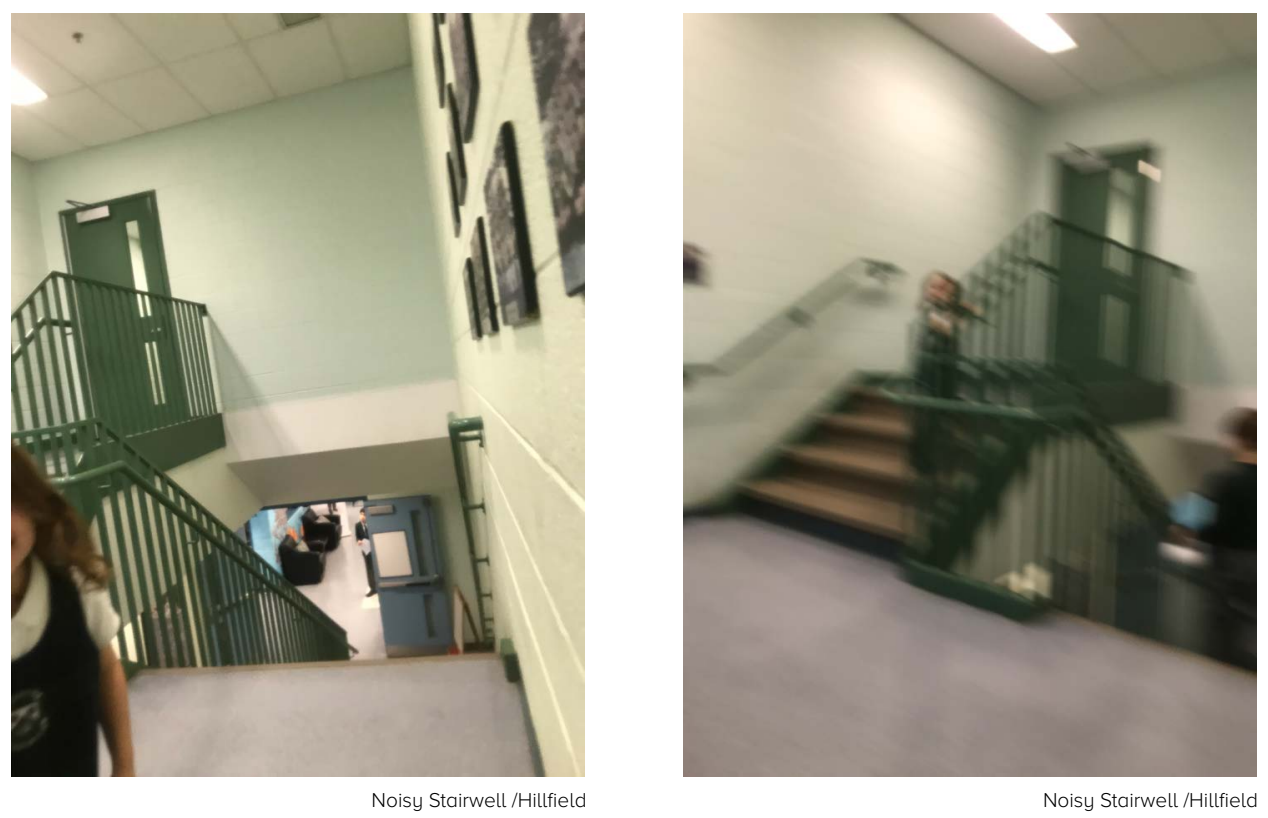


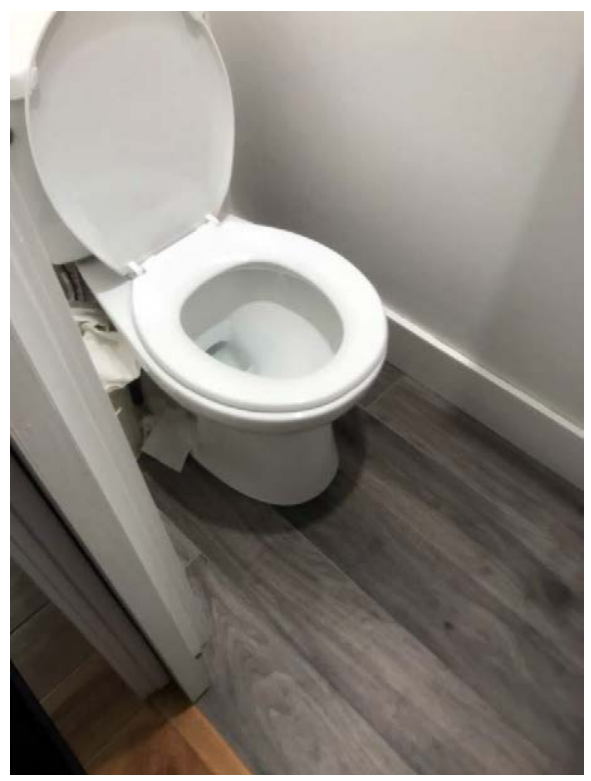

Elementary Washroom /Kaban

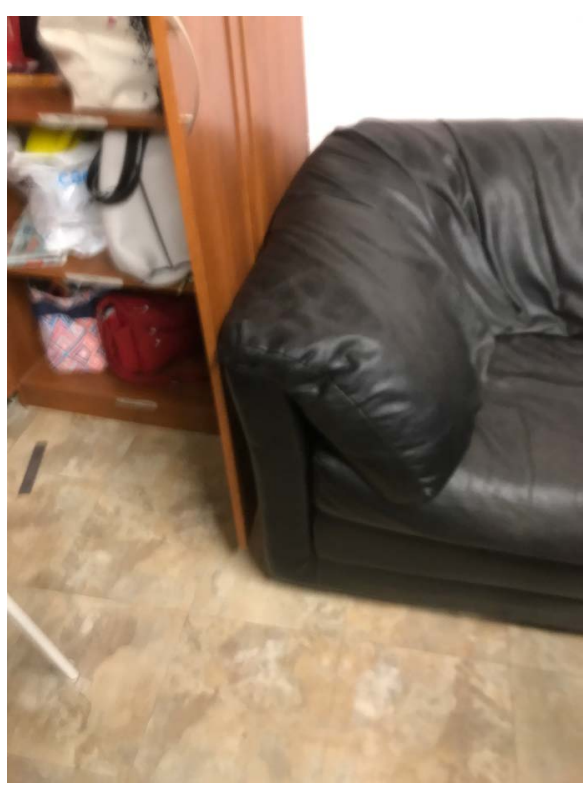

Personal Cubby /Kaban

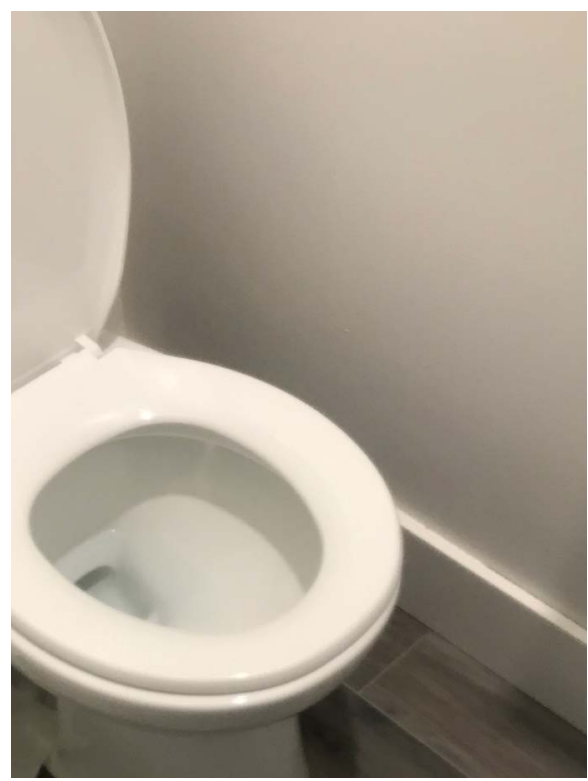

Elementary Washroom /Kaban

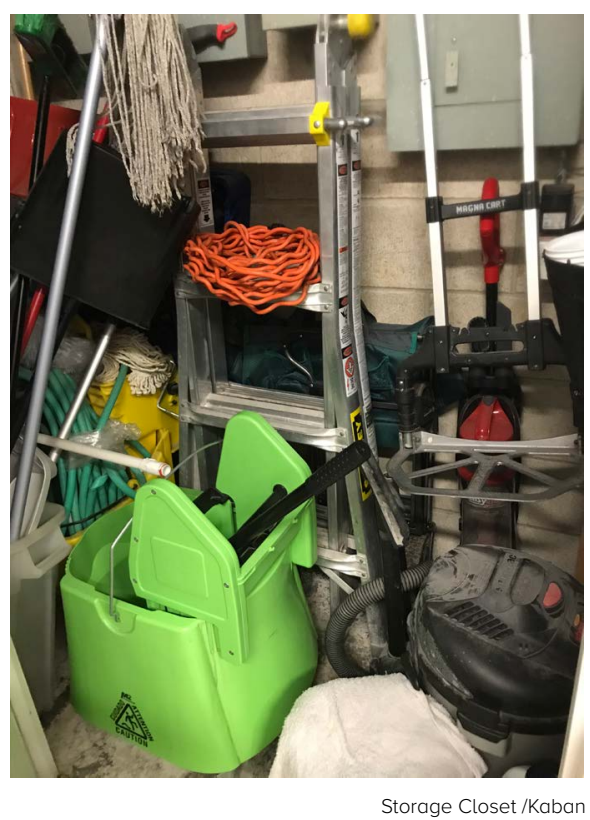

Appendix B - Workshop/ Children's Photographs 

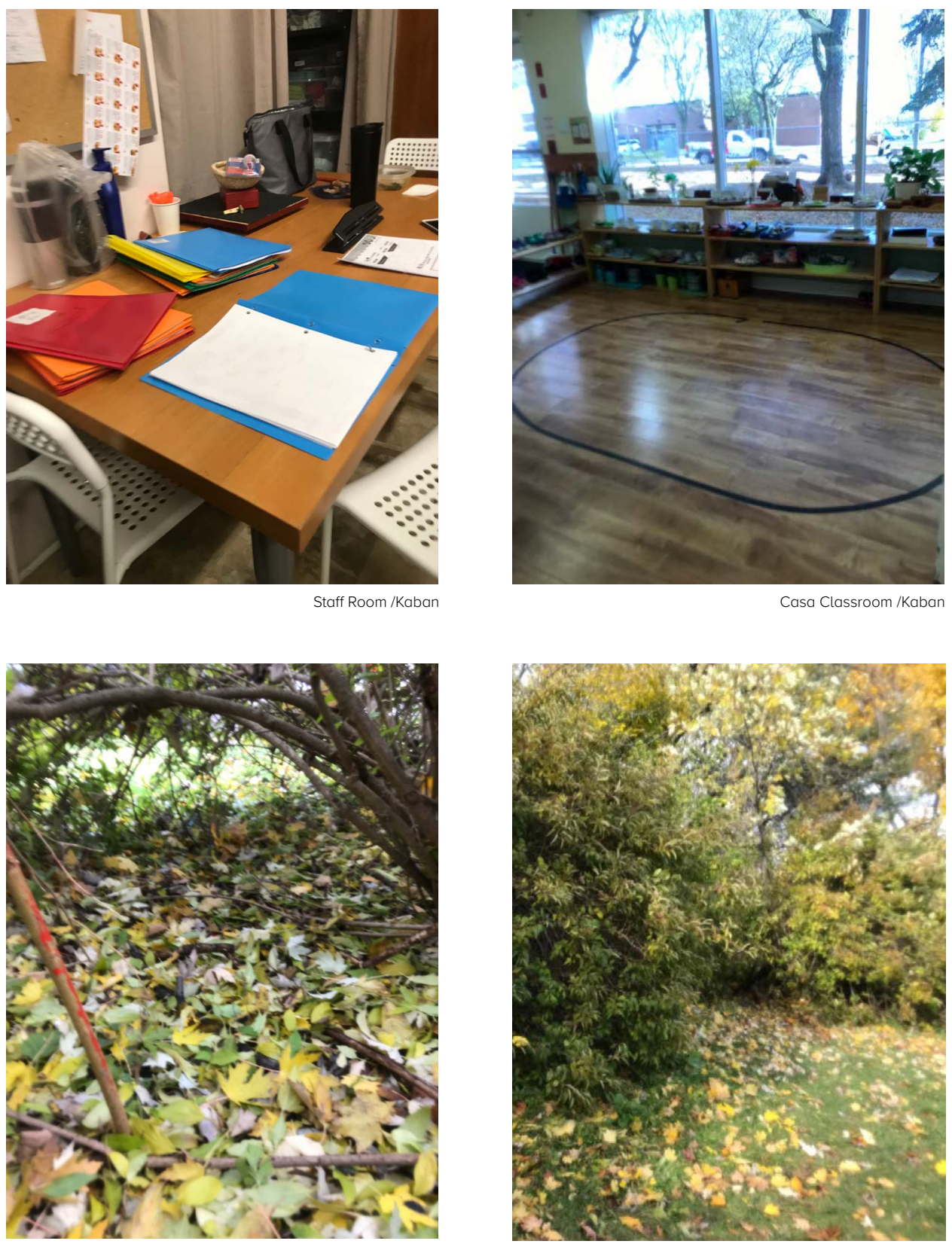

‘Flower Garden' Wild Ravine /Kaban 


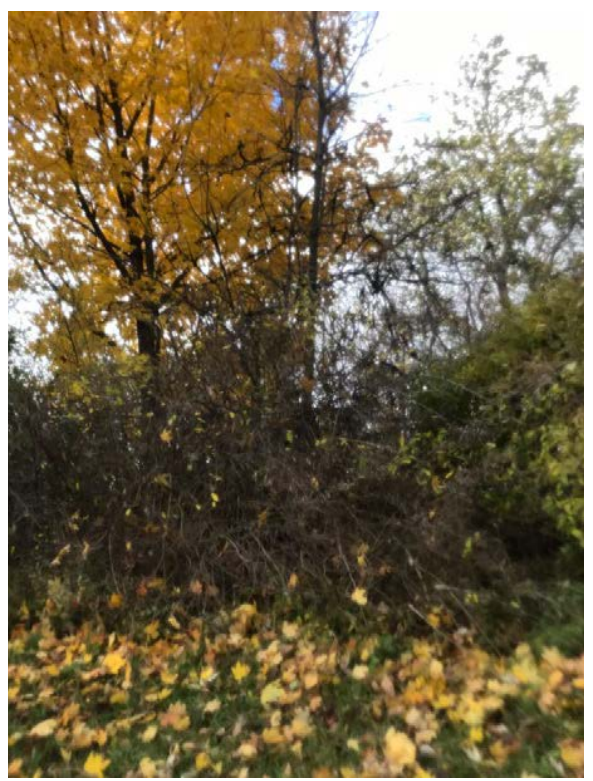

'Flower Garden' Wild Ravine /Kaban

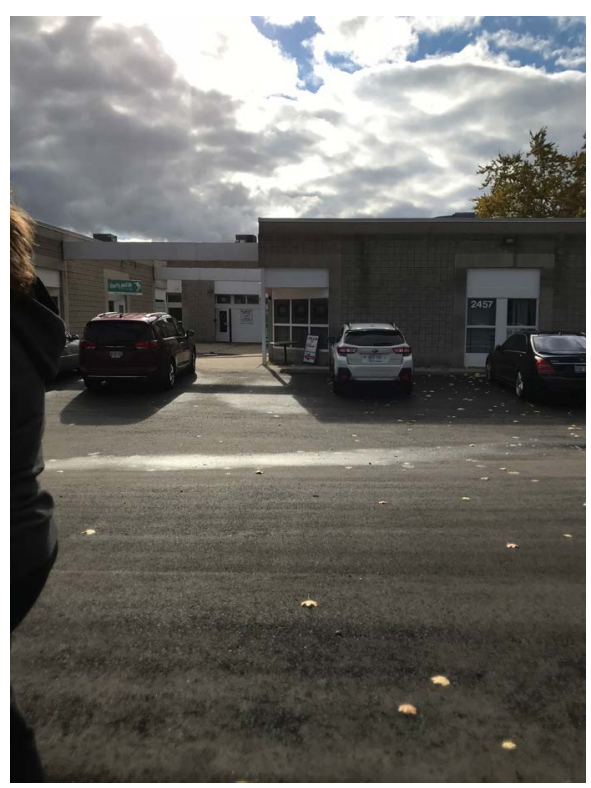

Exterior Courtyard (Transition space) /Kaban

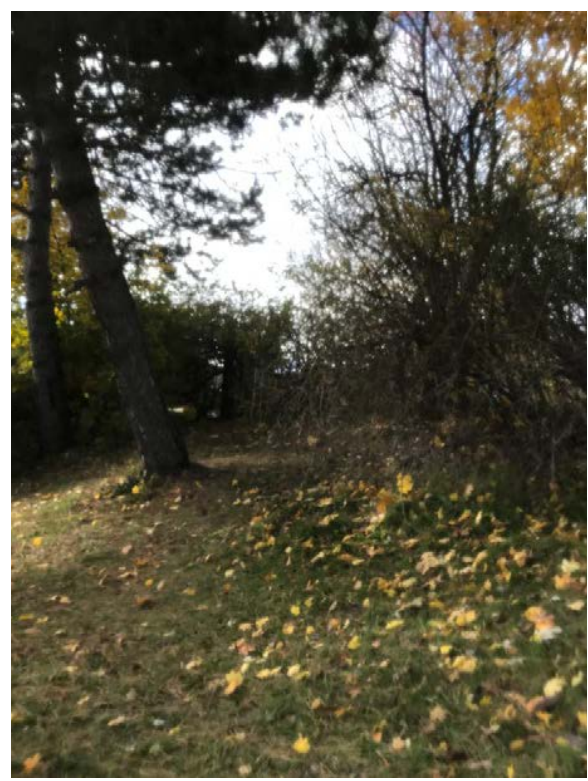

'Flower Garden' Wild Ravine /Kaban

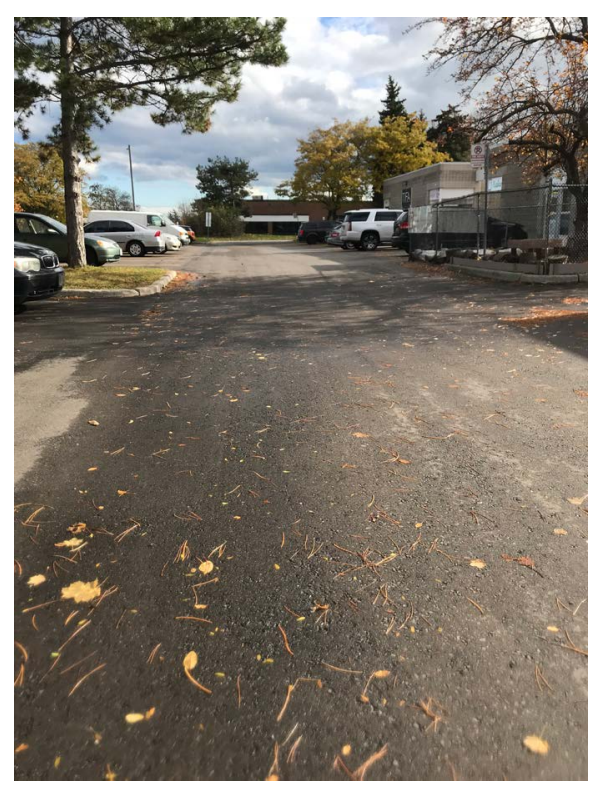

Parking Lot /Kaban 


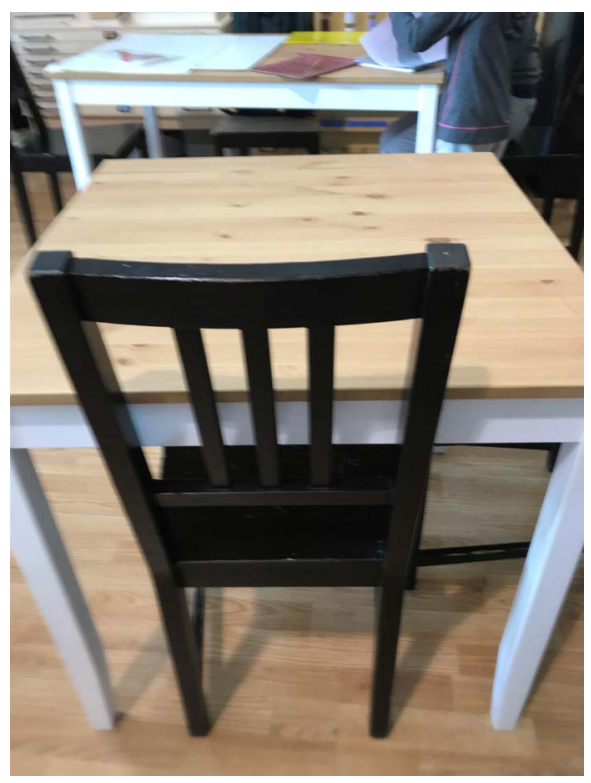

Table and Chair Set/Kaban

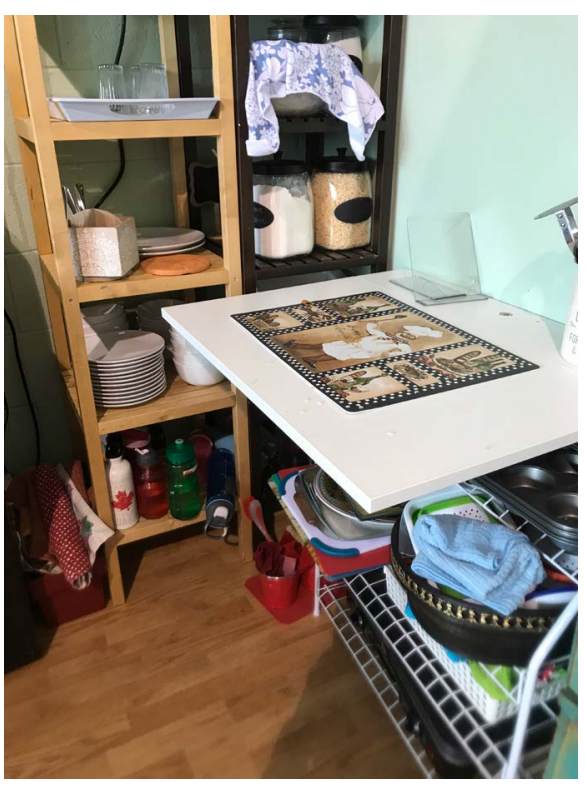

Classroom Kitchen/Kaban

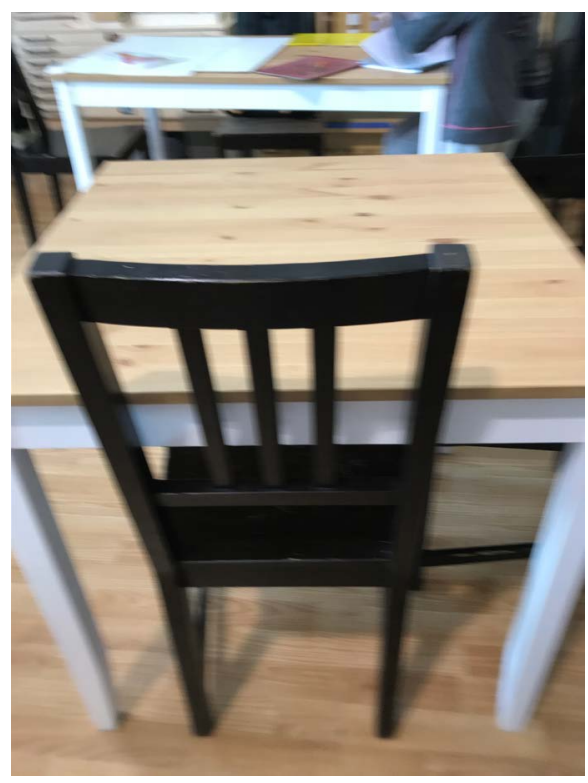

Table and Chair Set/Kaban

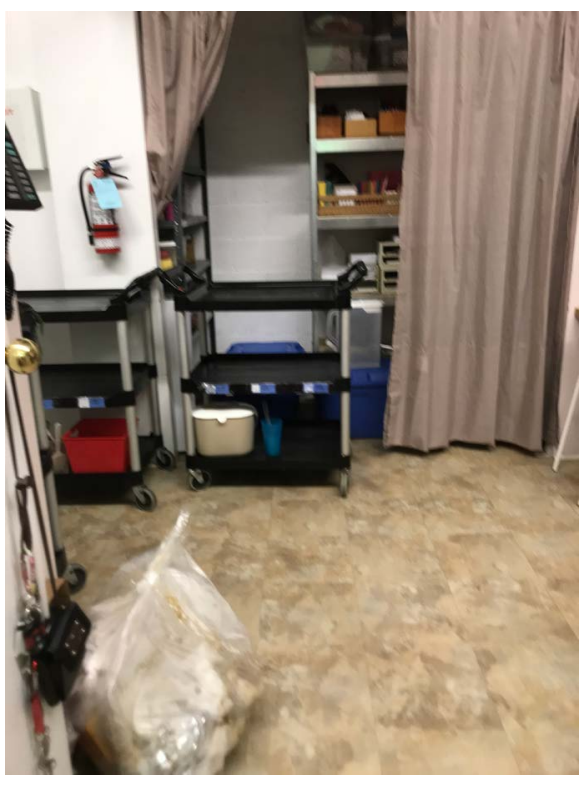

Staff Room Shared Space /Kaban 


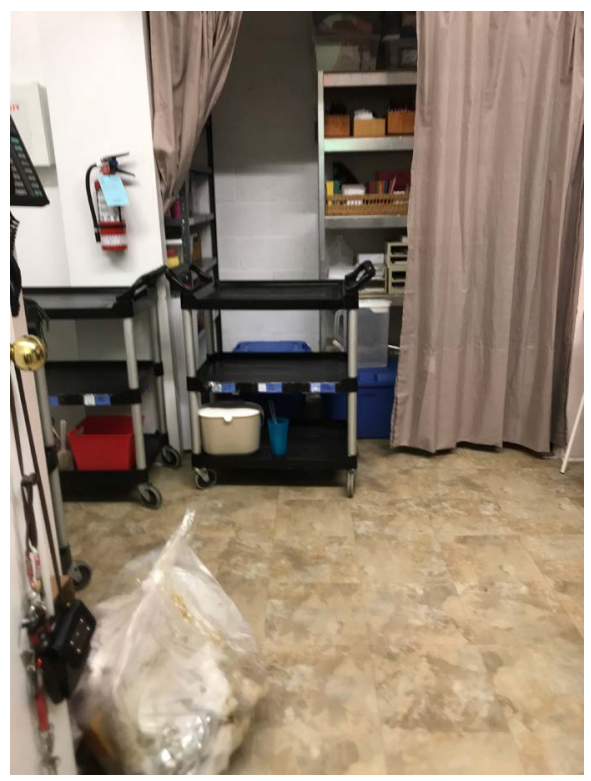

Staff Room Shared Space /Kaban

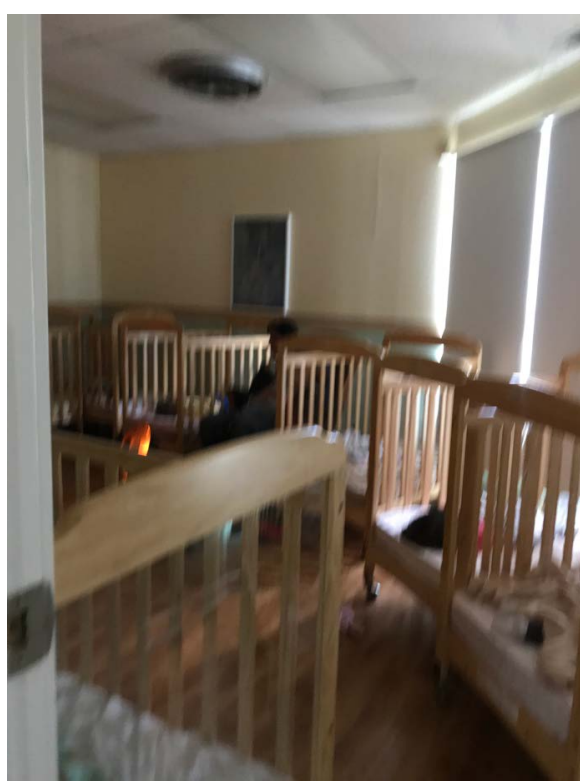

Infants Sleeping Room /Kaban

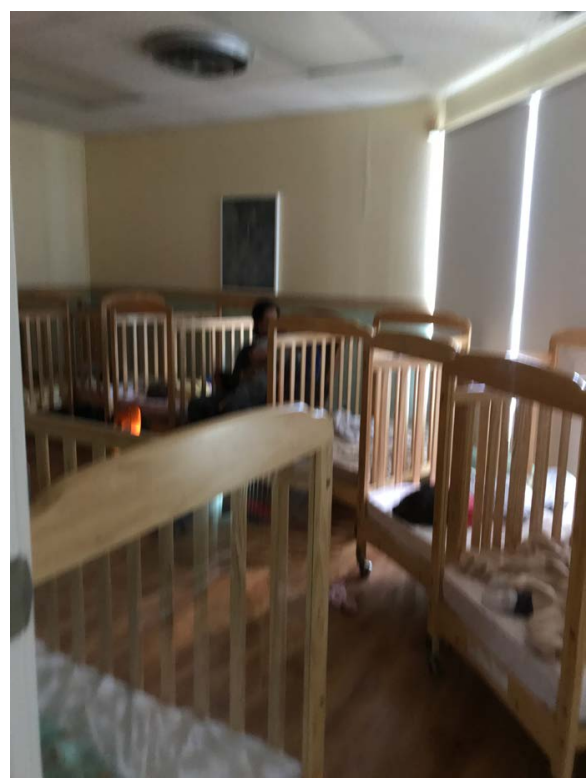

Infants Sleeping Room /Kaban

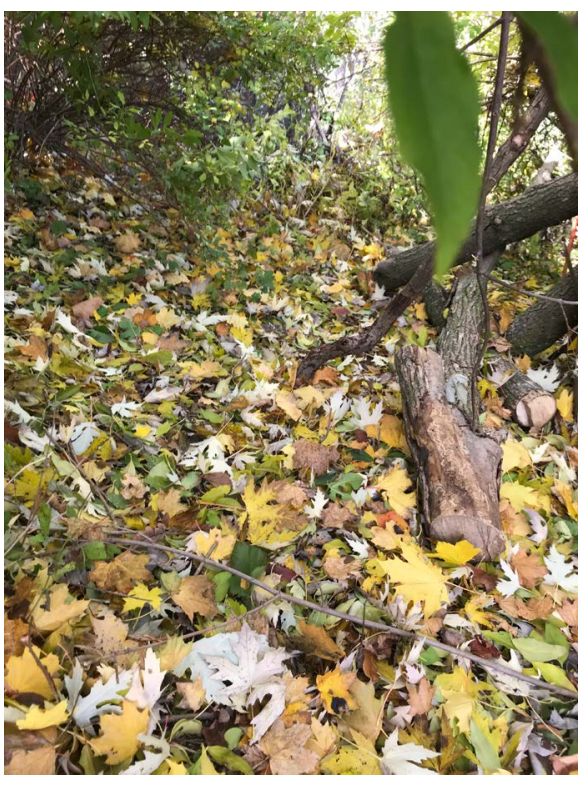

'Flower Garden' Wild Ravine /Kaban 


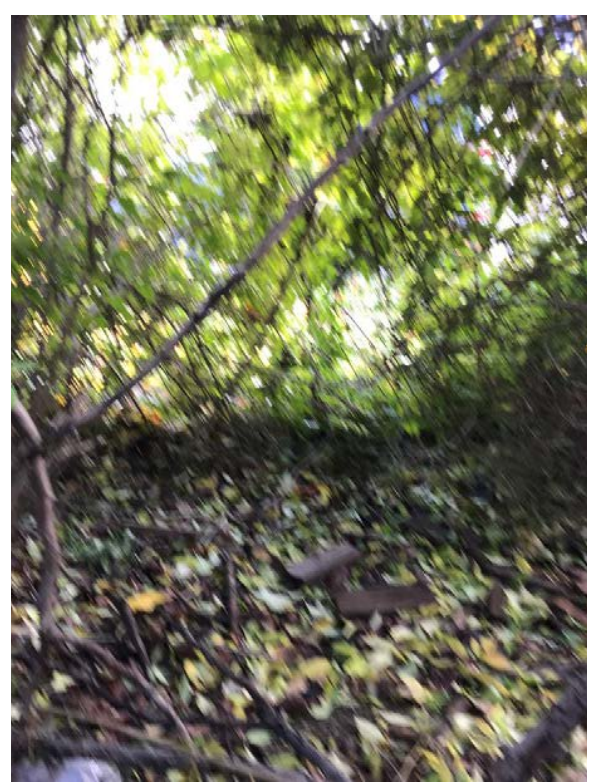

'Flower Garden' Wild Ravine /Kaban

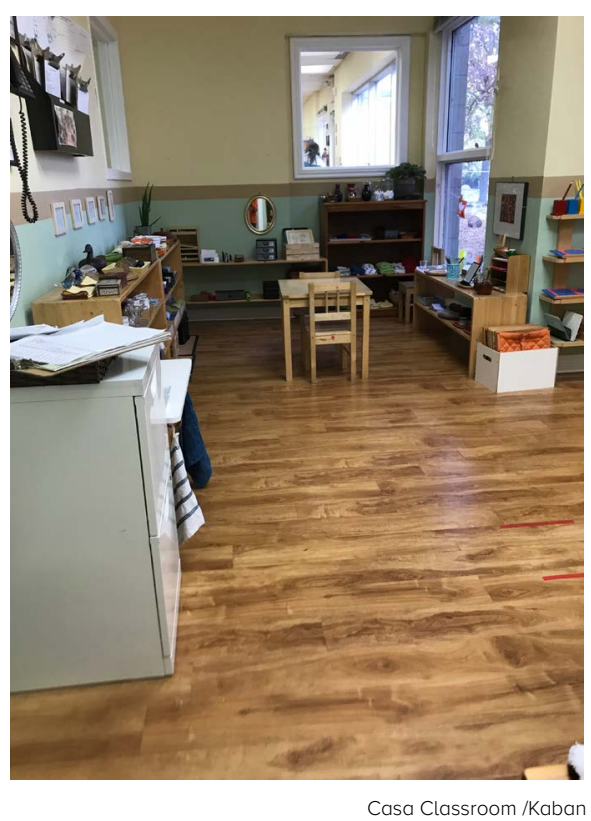

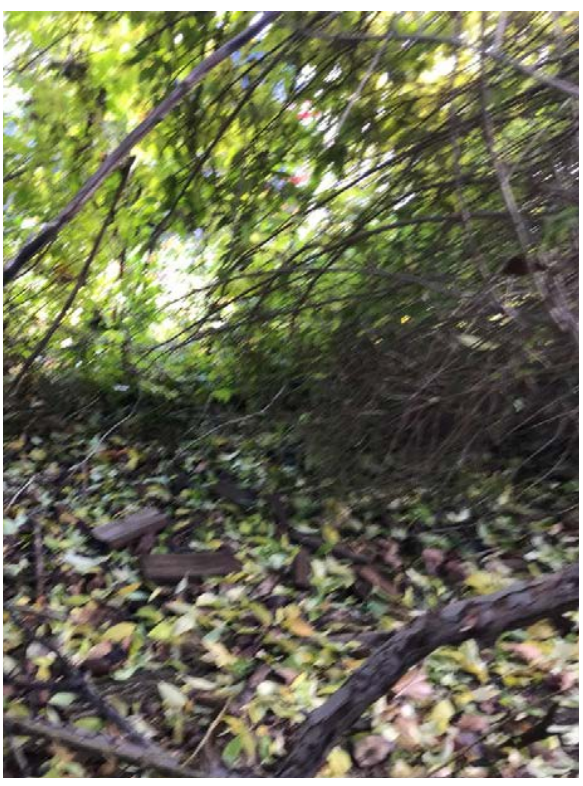

'Flower Garden' Wild Ravine /Kaban

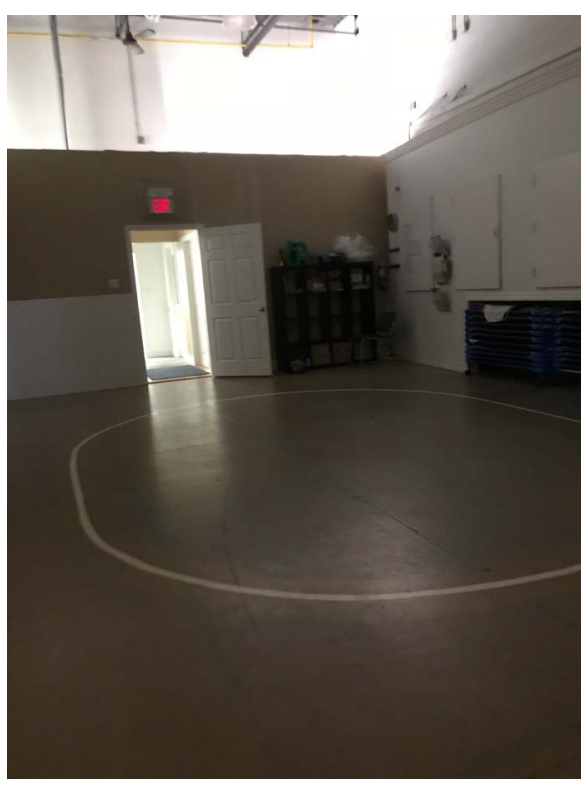

Gym /Kaban 


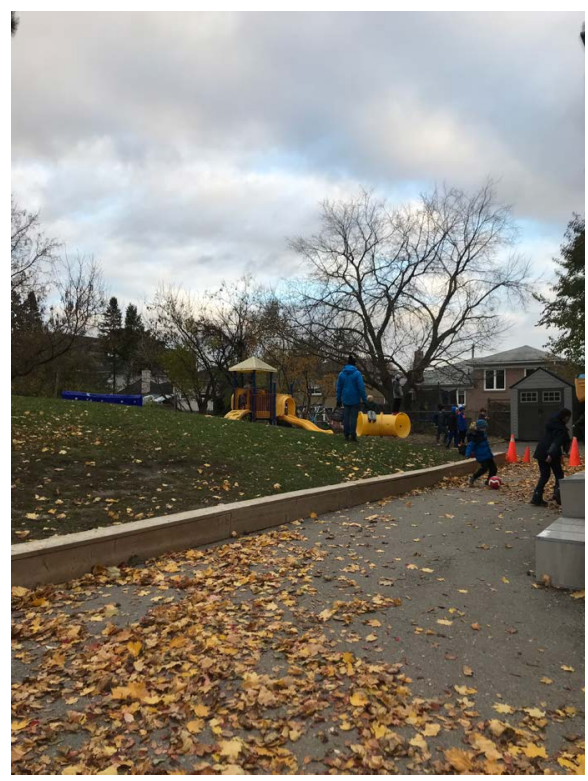

Playground /MJDS

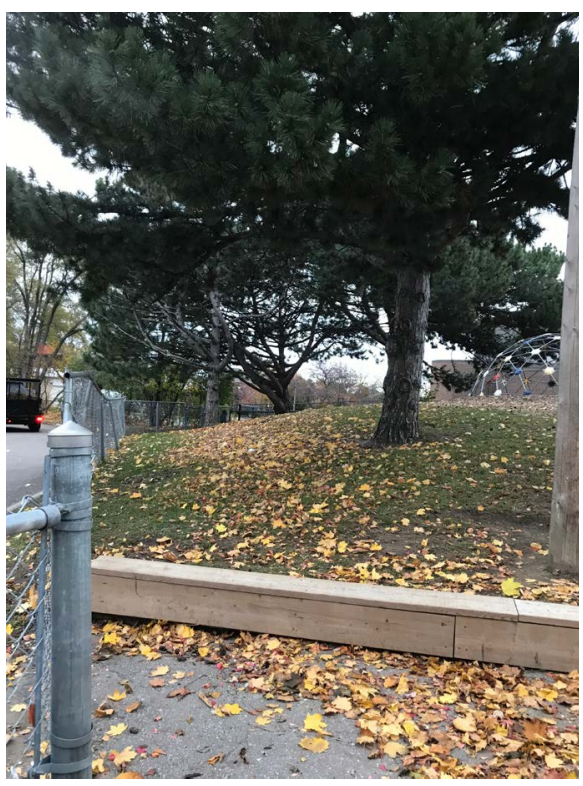

Hill /MJDS

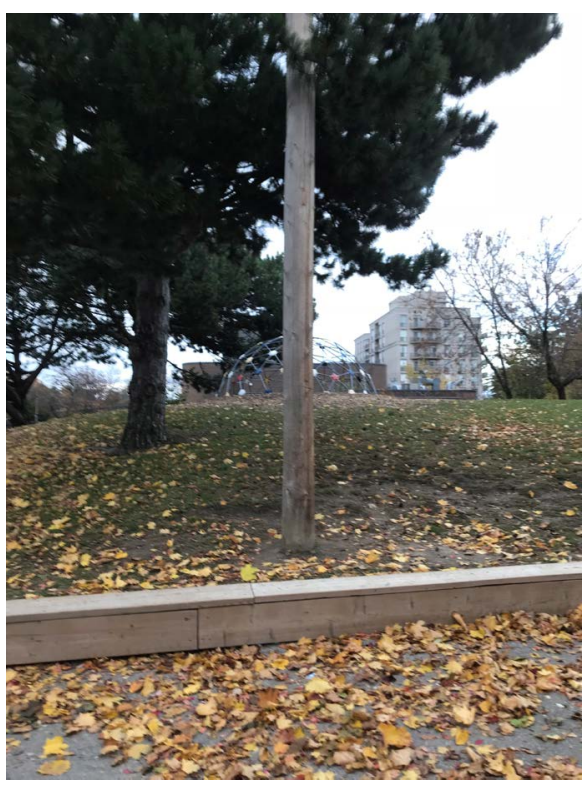

Climbing Structure /MJDS

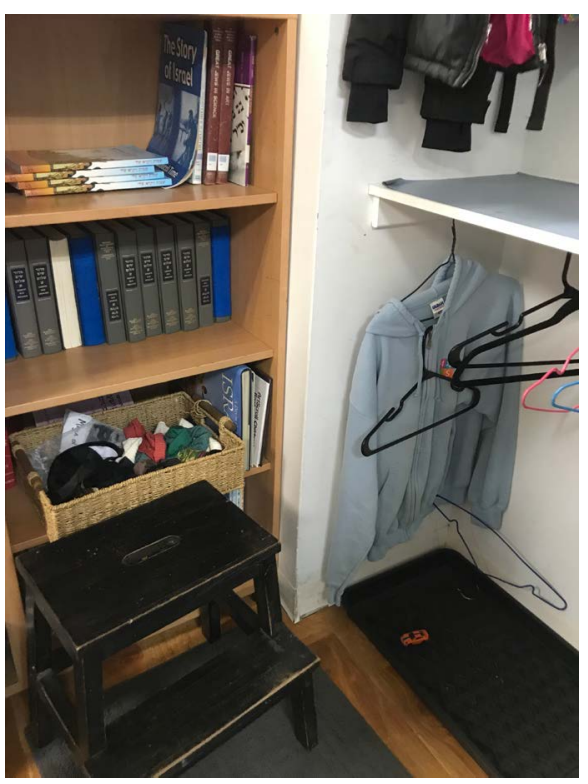

Private Reading Space /MJDS 


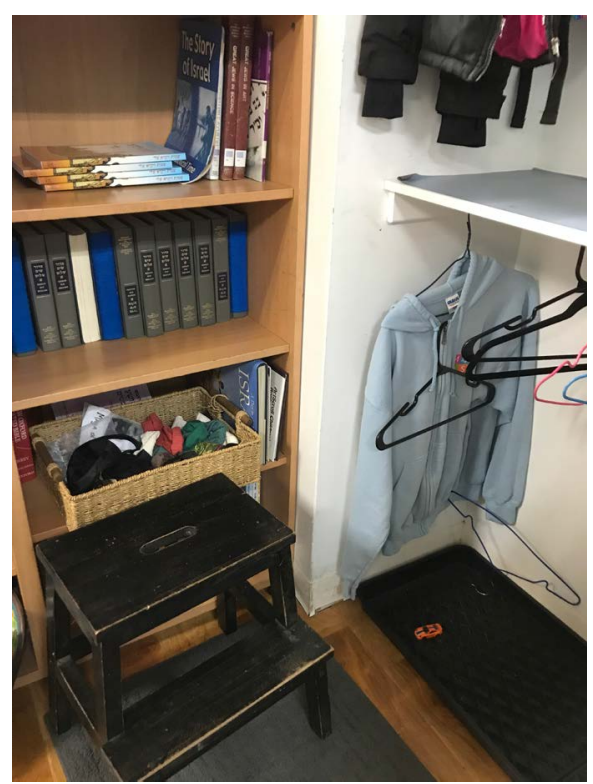

Private Reading Space /MJDS

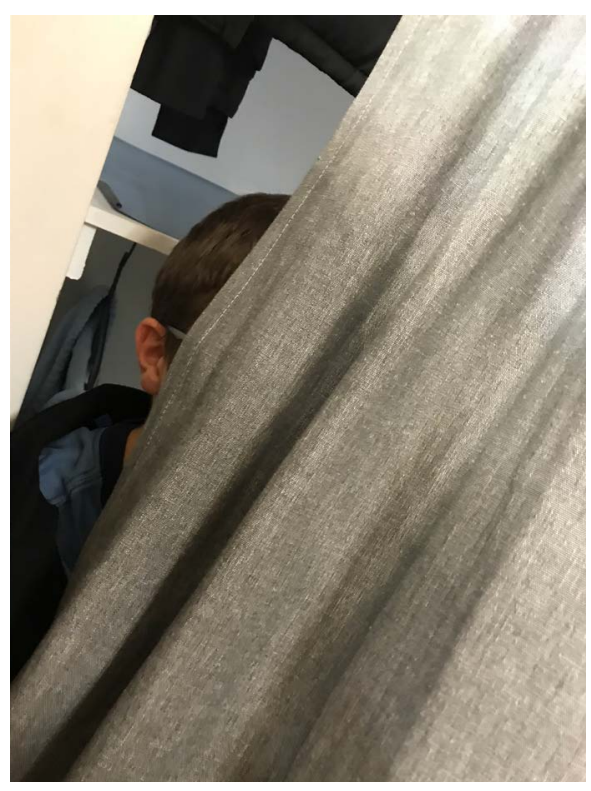

Private Reading Space /MJDS

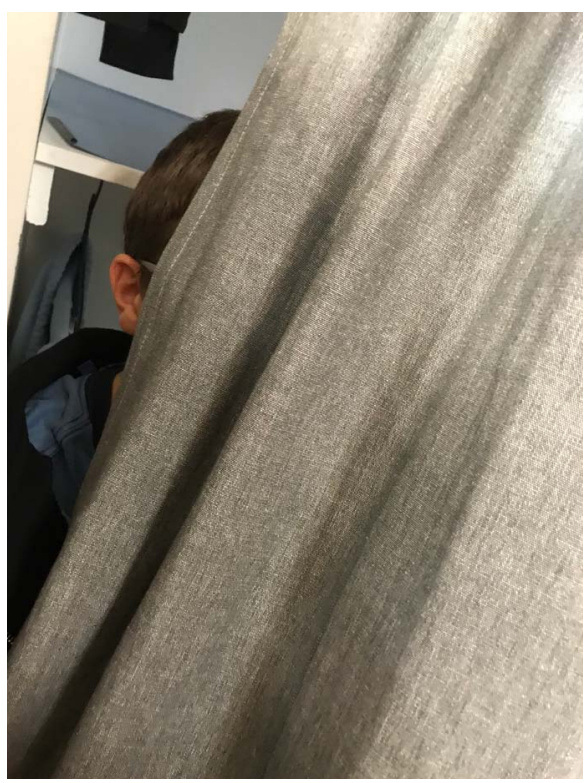

Private Reading Space /MJDS

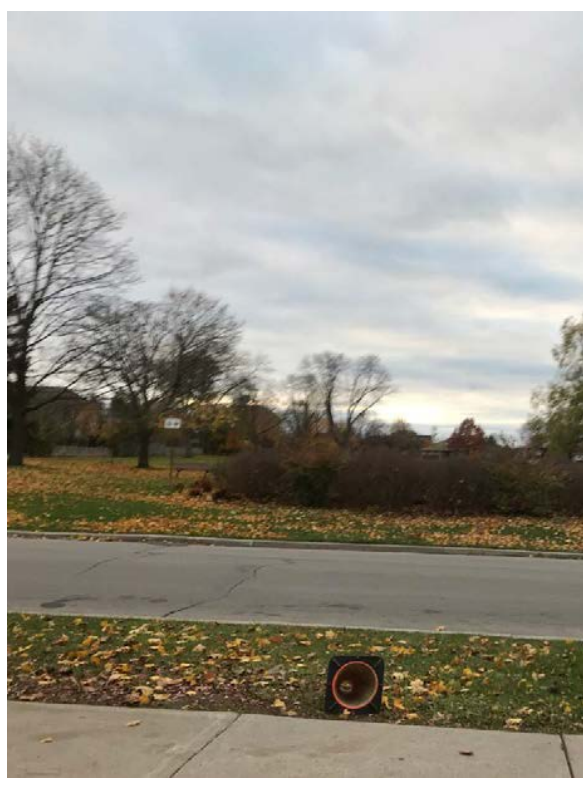

Field /MJDS 


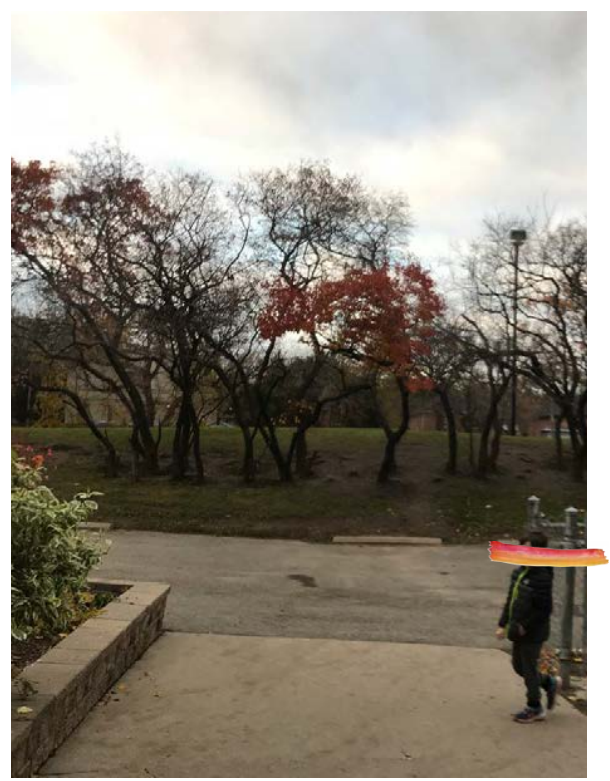

Wild Hill /MJDS

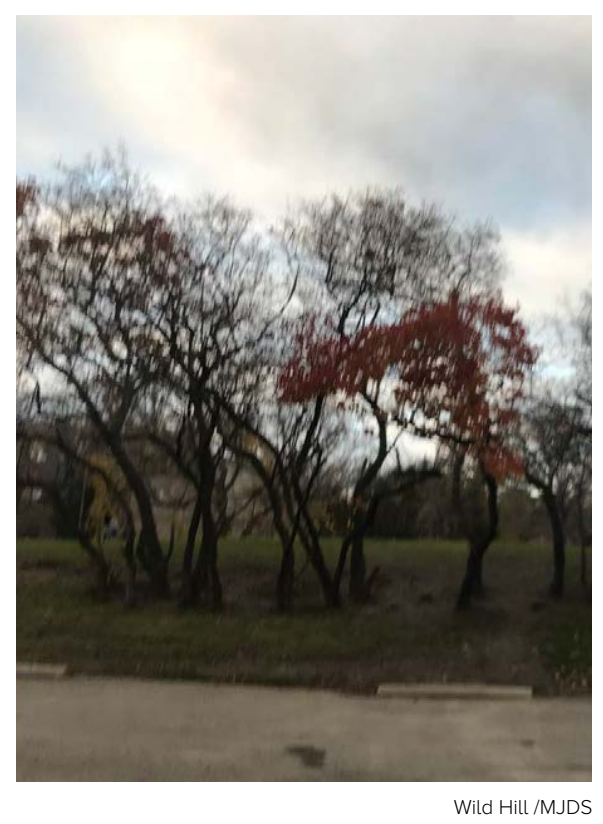

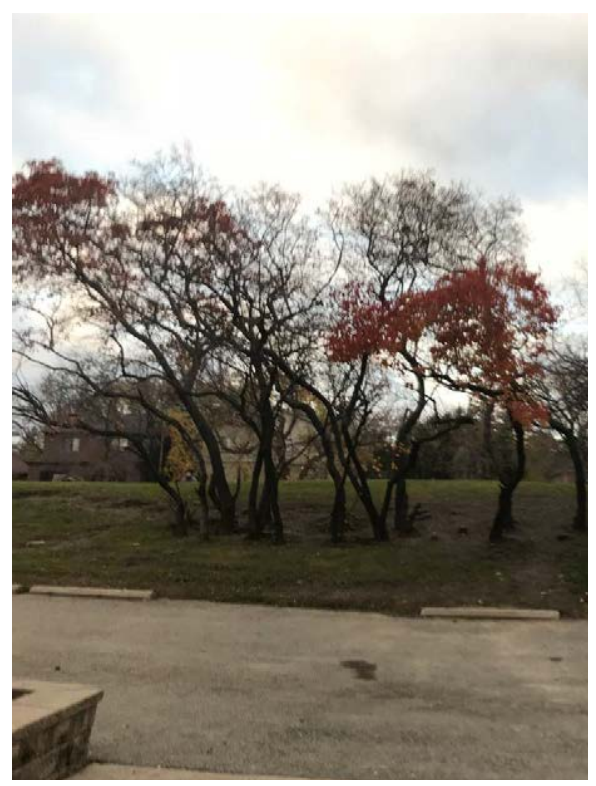

Wild Hill /MJDS

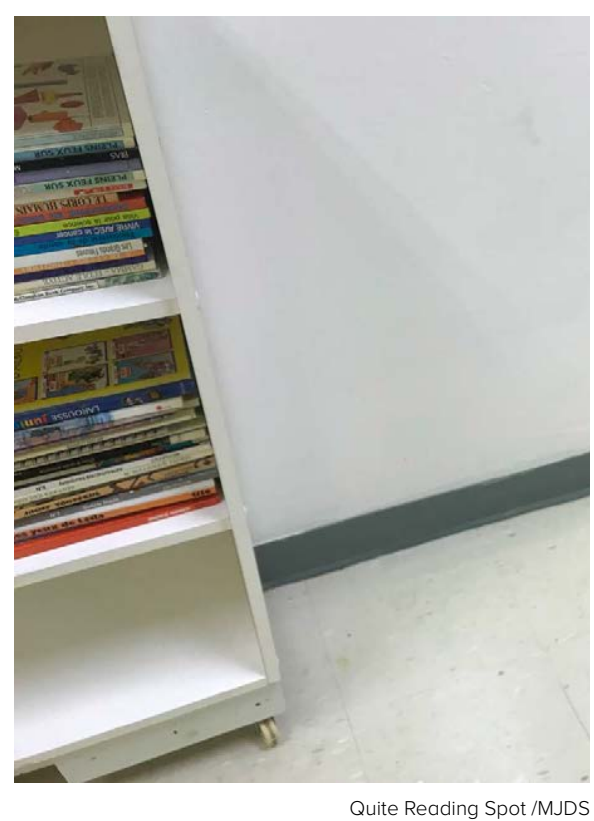



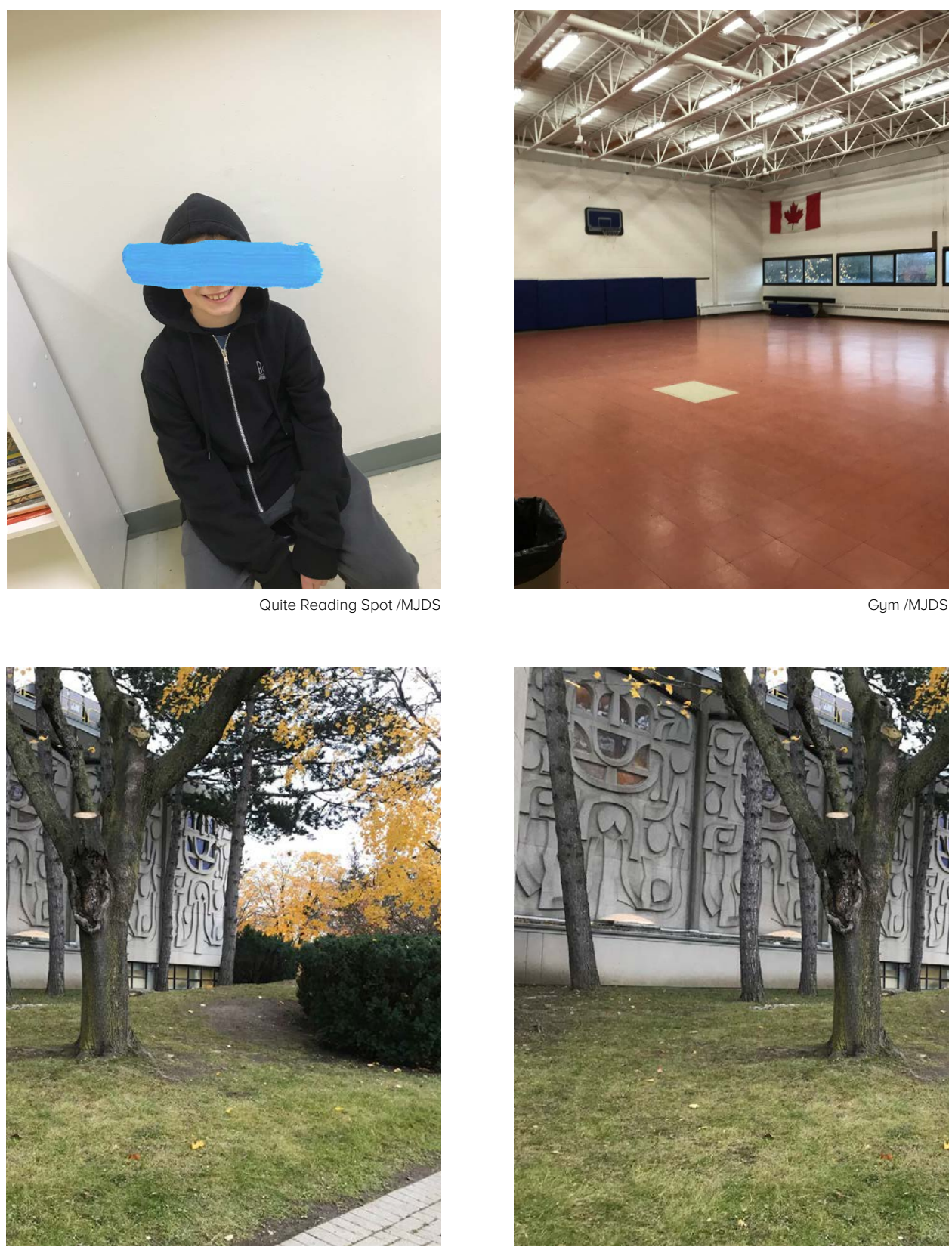

Big Tree /MJDS 

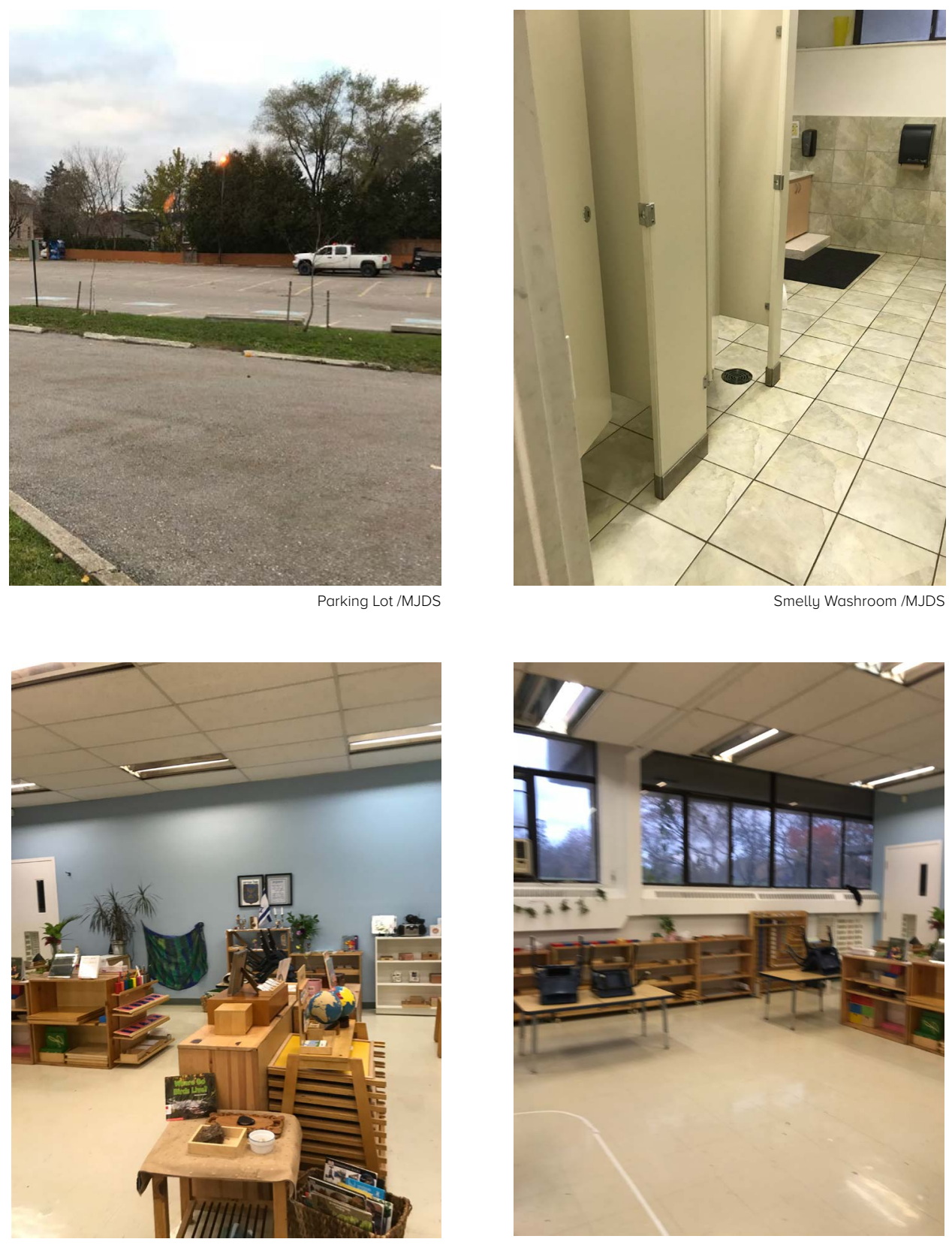

Casa Classroom /MJDS

Casa Classroom /MJDS 

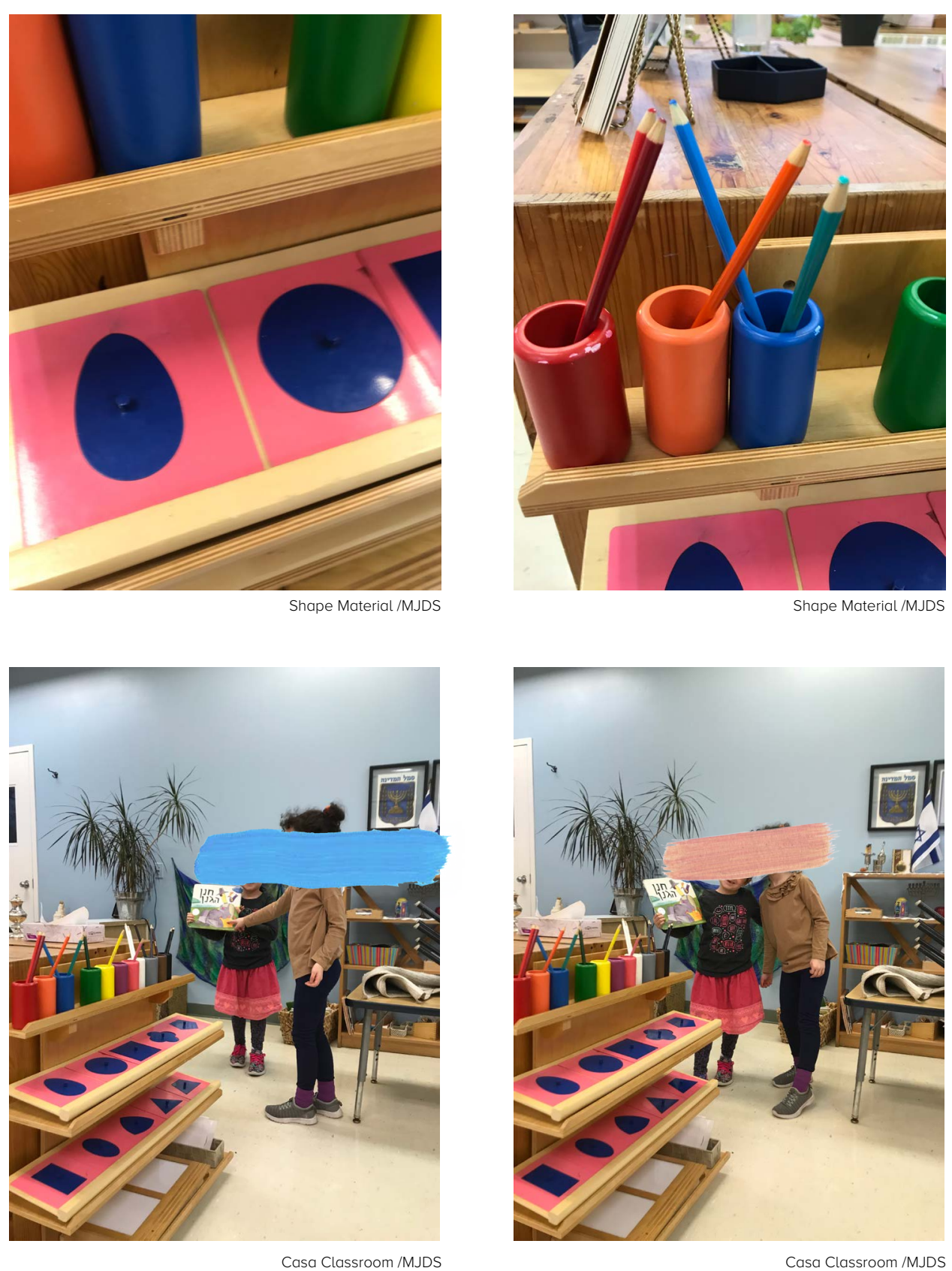

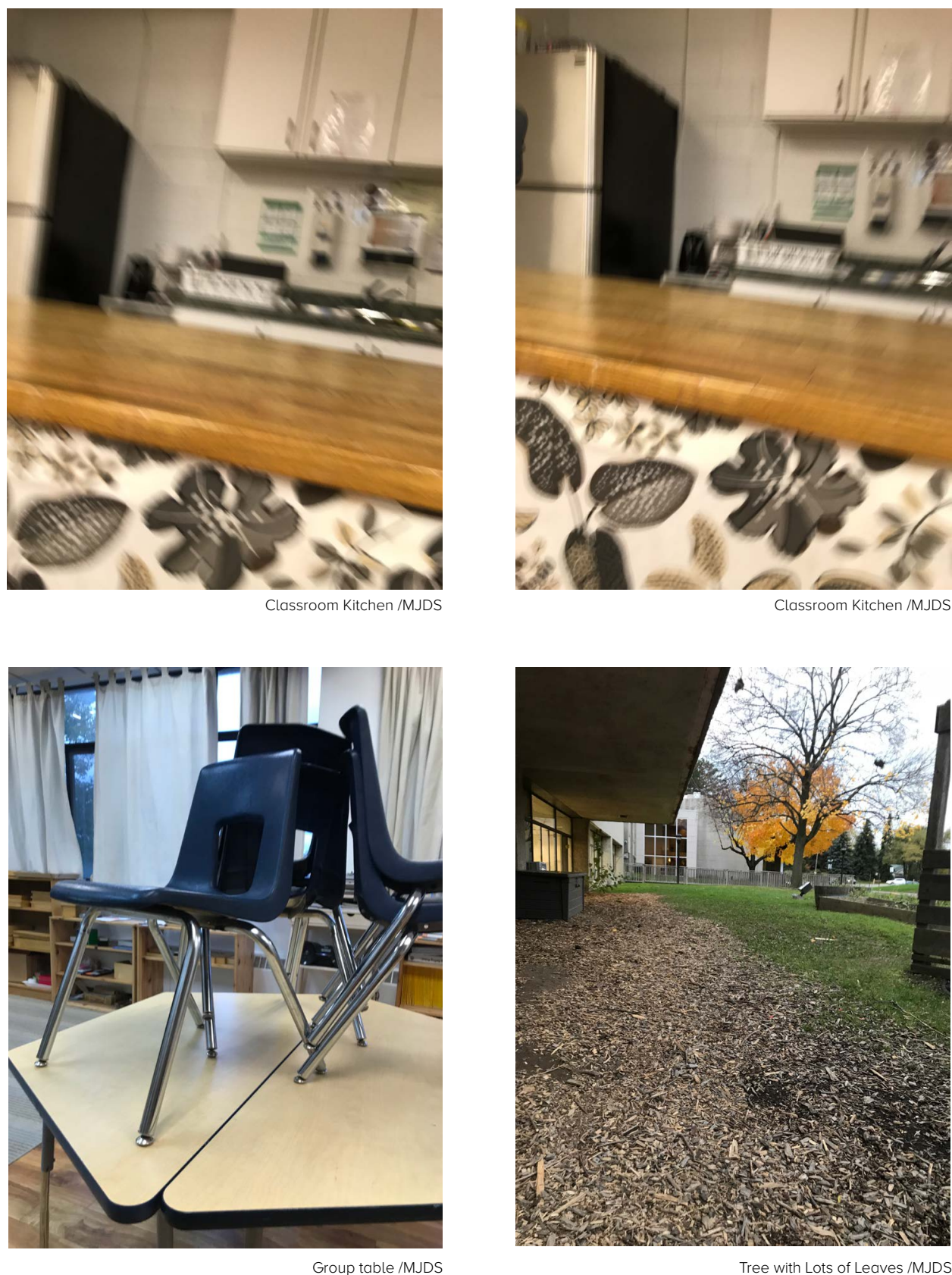

Tree with Lots of Leaves /MJDS 


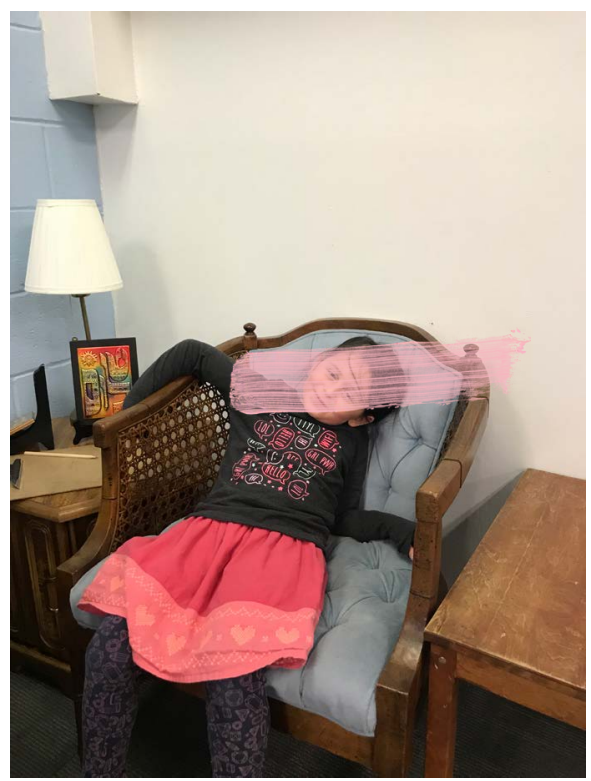

Comfy Reading Chair /MJDS

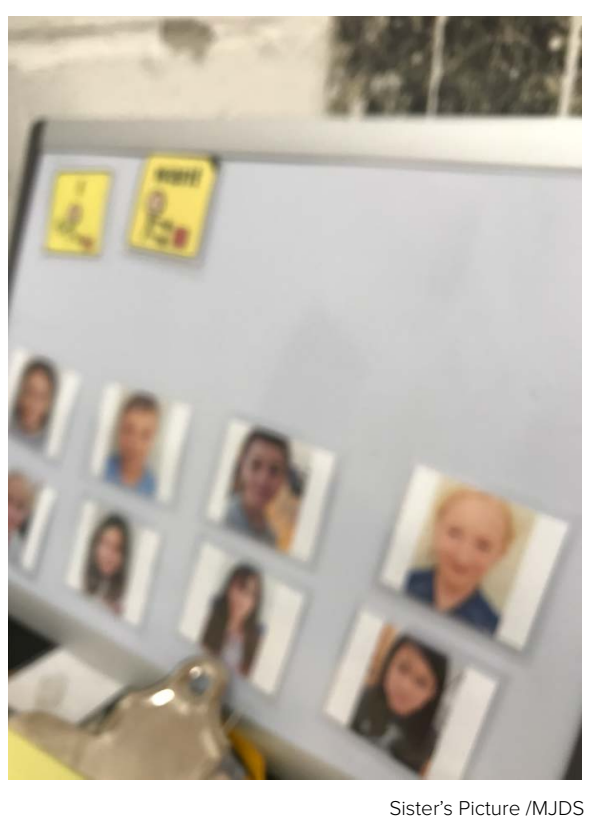

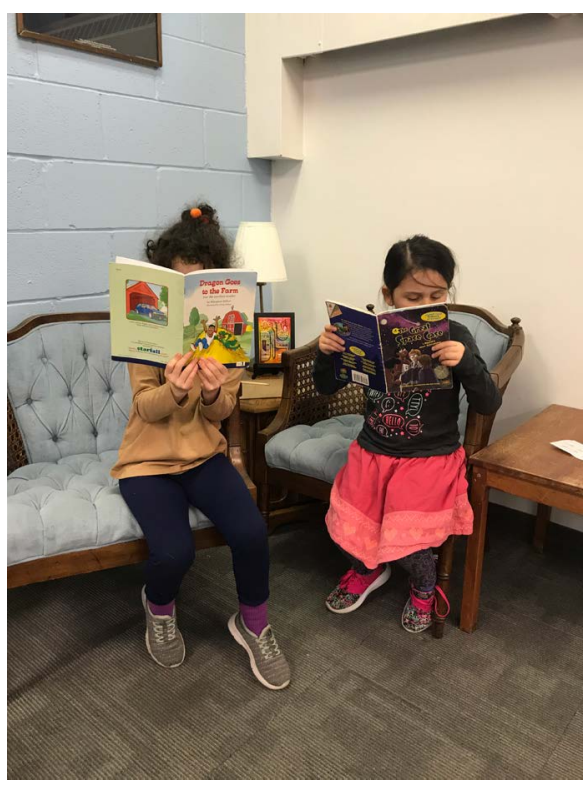

Comfy Reading Corner /MJDS

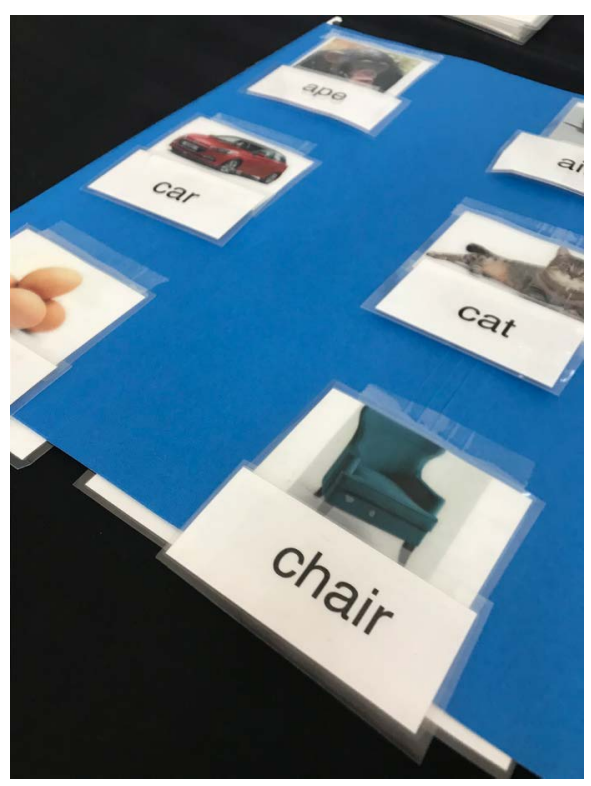

Language Material /MJDS 

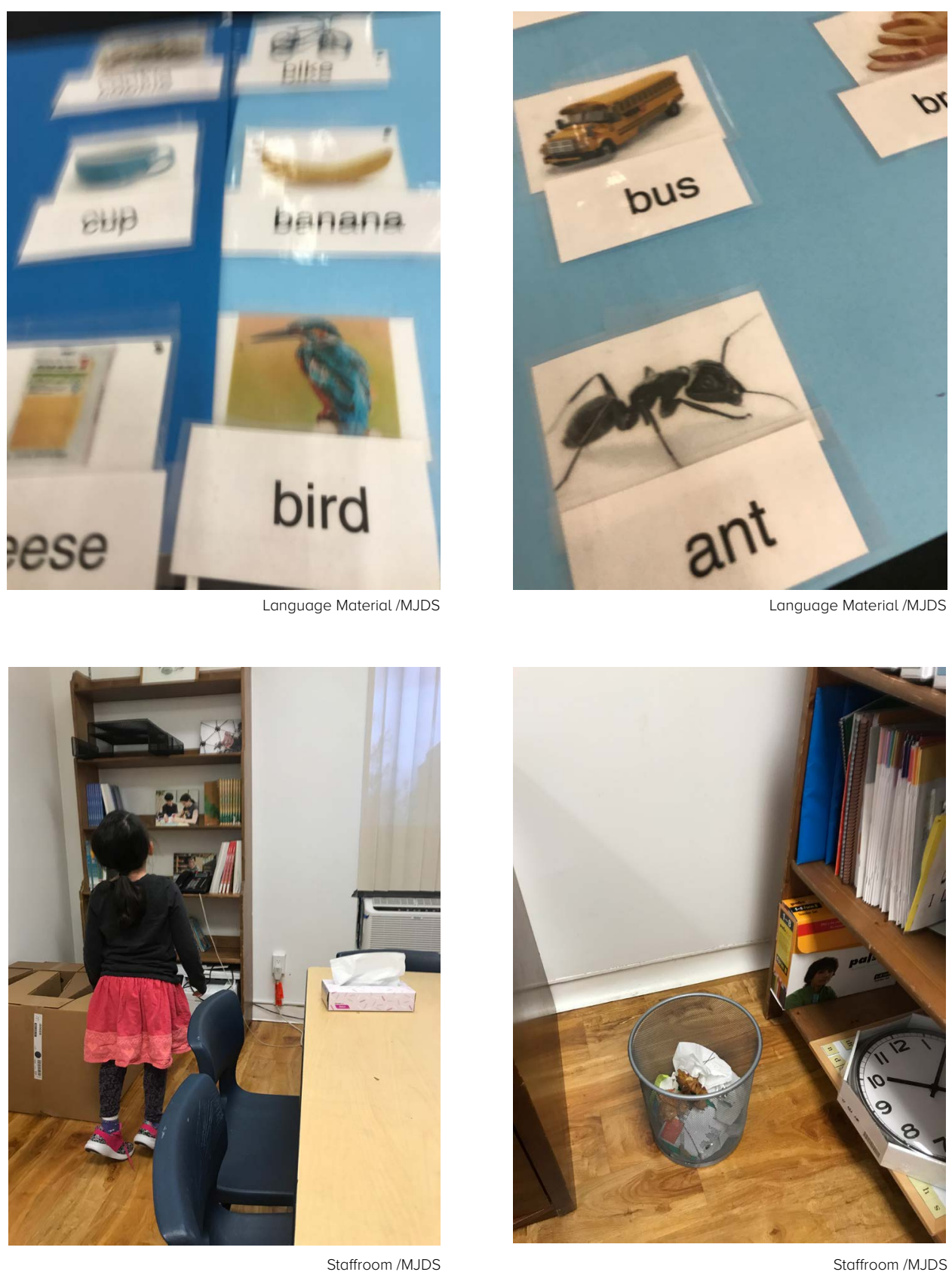


\section{Appendix _ C}

\section{Workshop/ Children's Drawings}

Question 01 - Draw Your School From Above

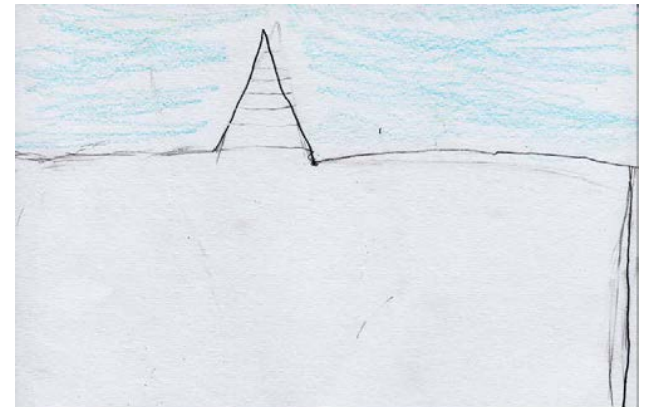

Question 01/Clanmore

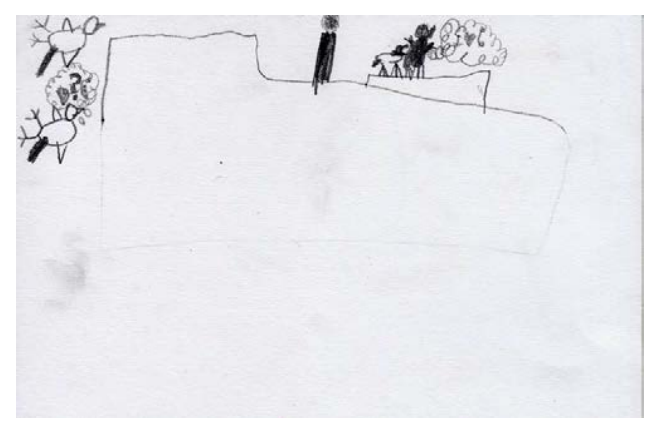

Question 01/Clanmore

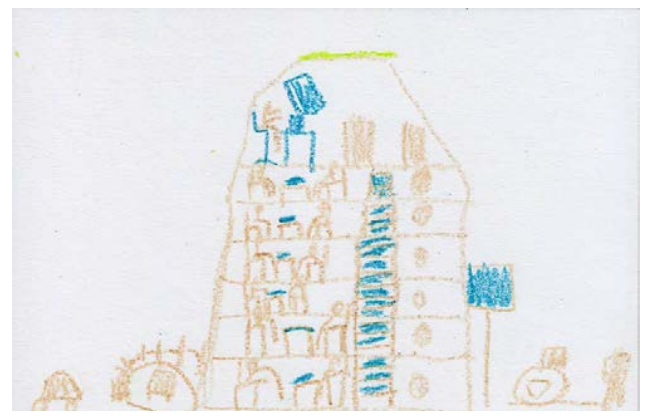

Question 01/Clanmore

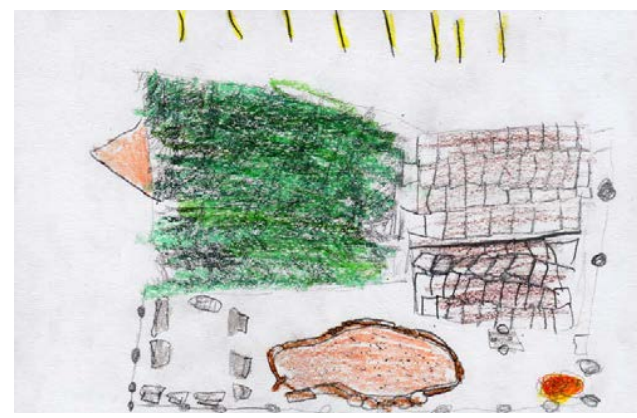

Question 01/Clanmore

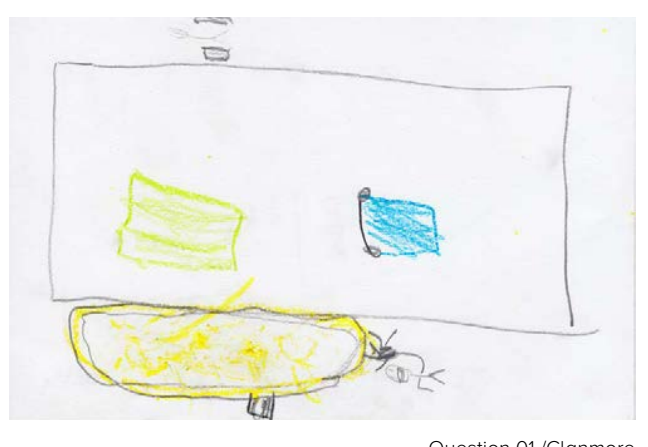

Question 01/Clanmore

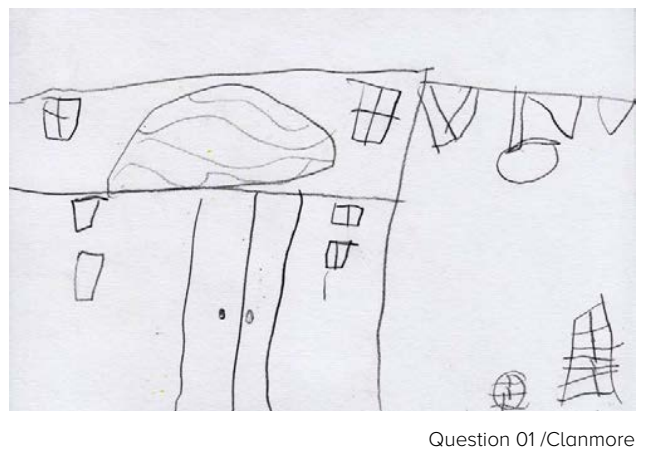



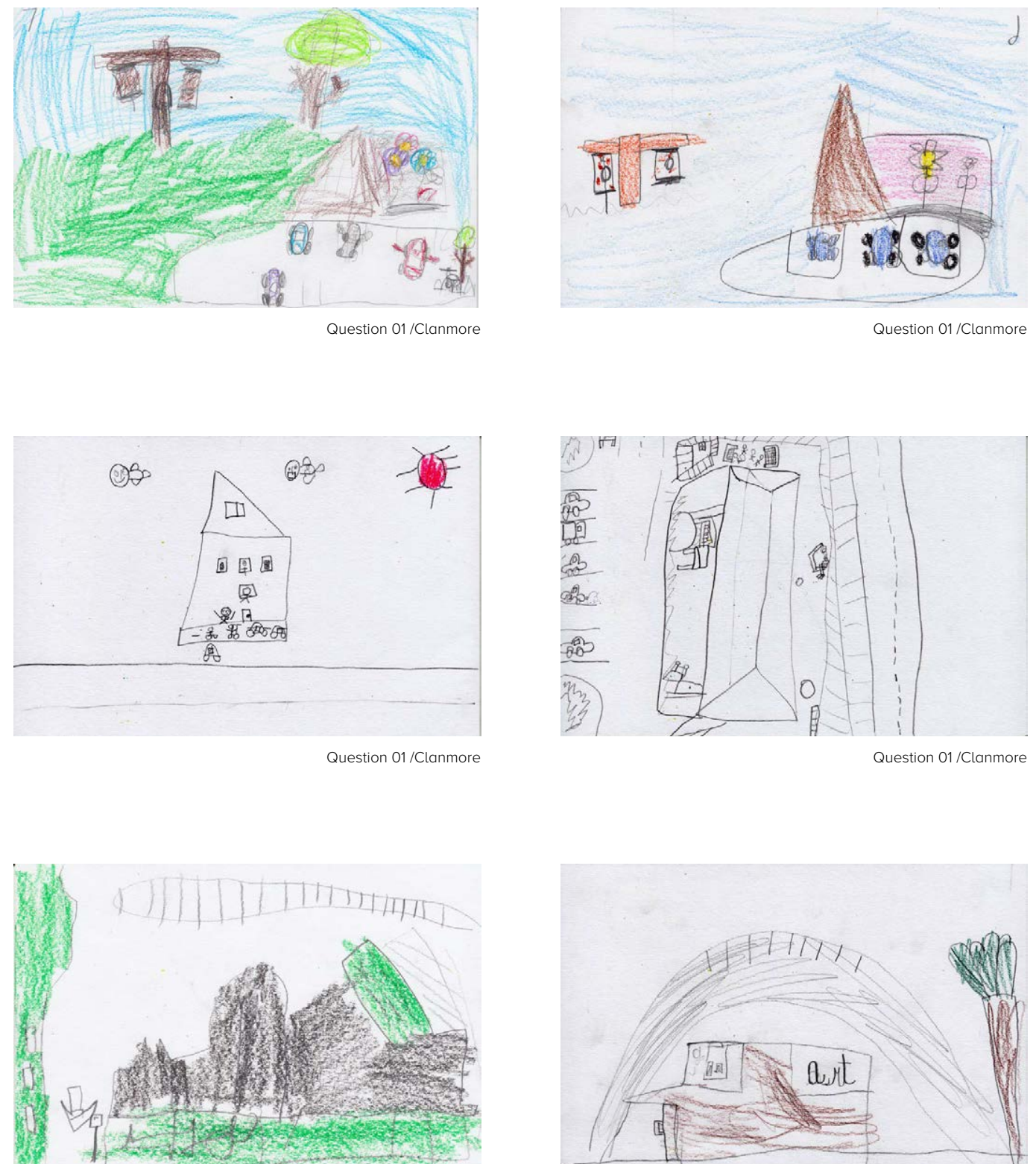

Question 01/Clanmore

Question 01/Clanmore 


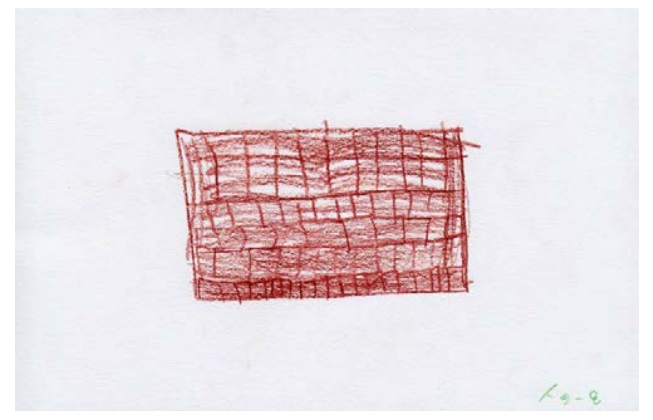

Question $01 /$ Hillfield
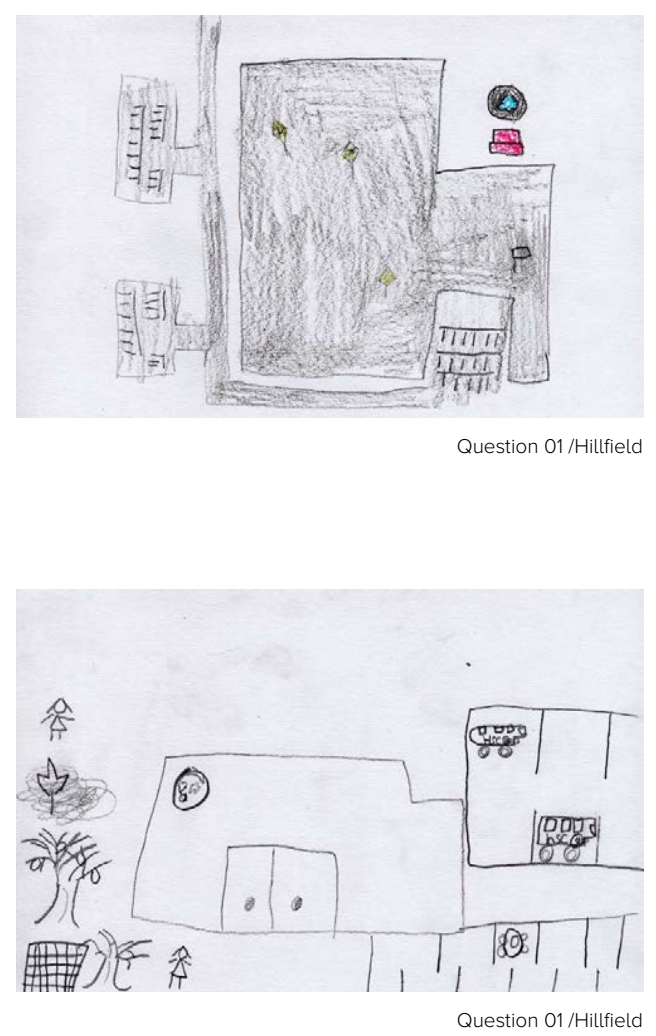

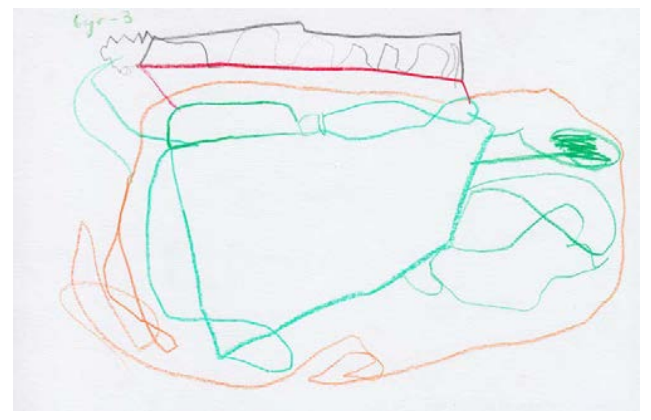

Question 01/Hillfield
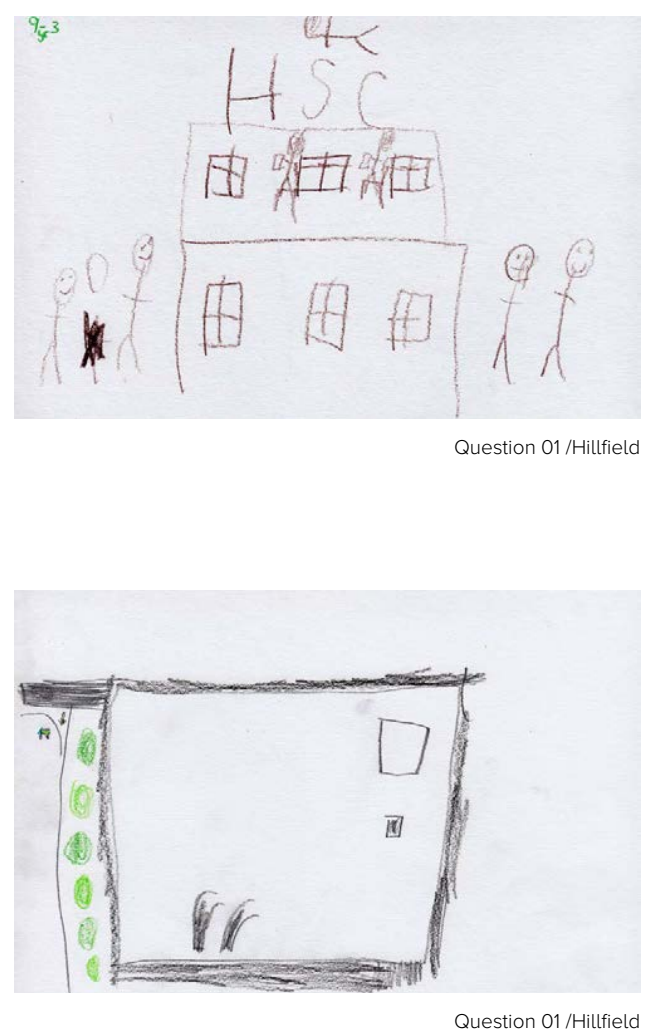


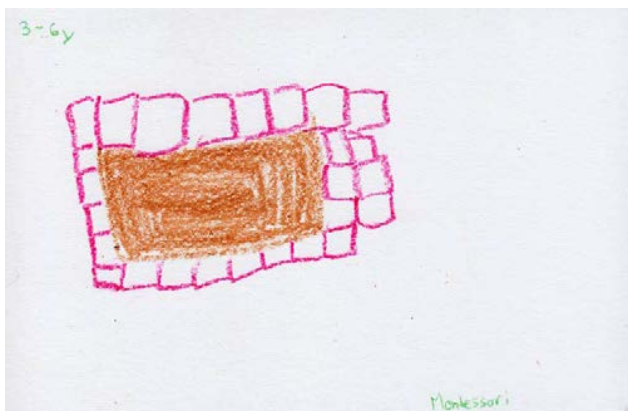

Question 01/Hillfield

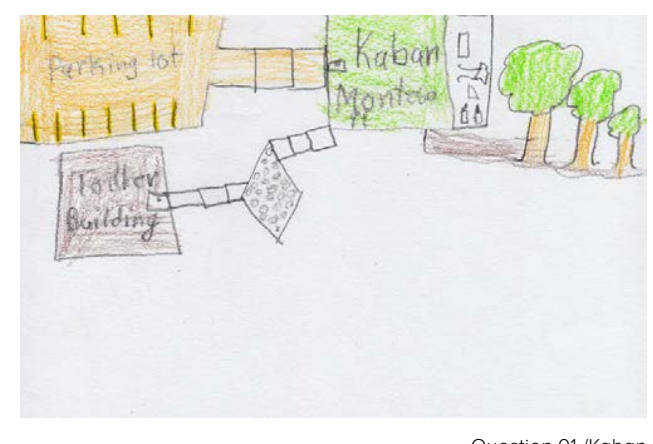

Question 01/Kaban

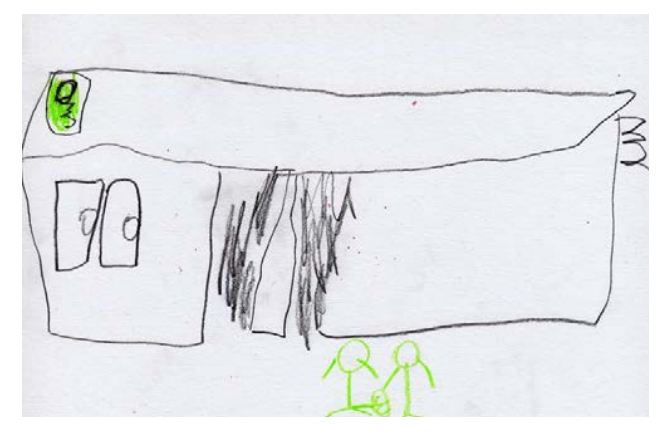

Question $01 /$ Kaban

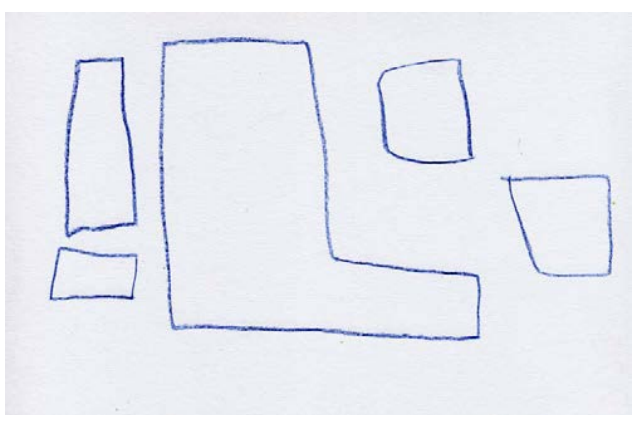

Question 01/Hillfield
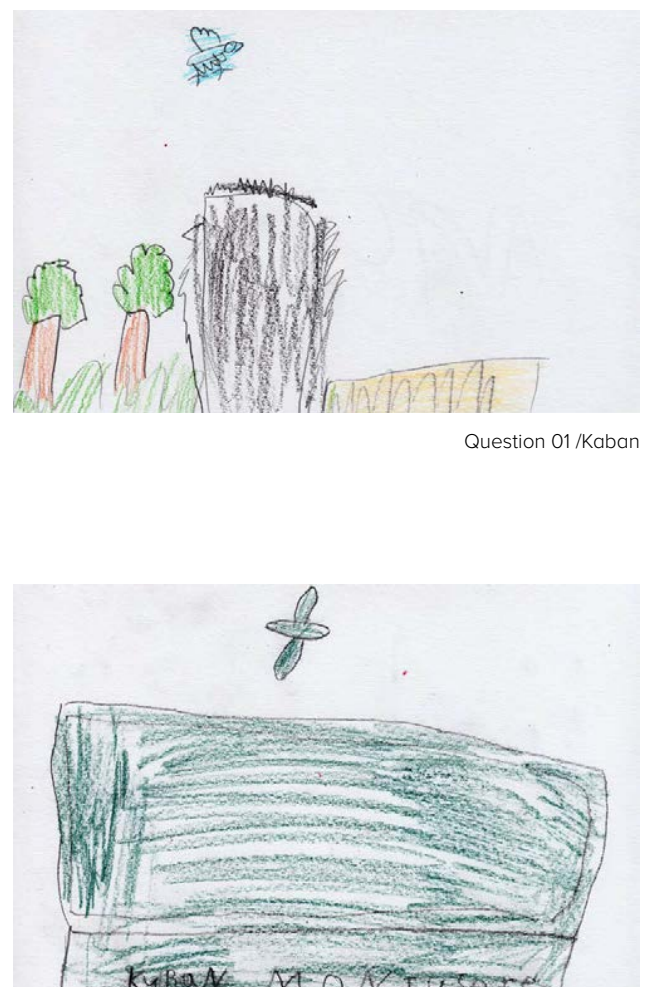

Question $01 /$ Kaban 

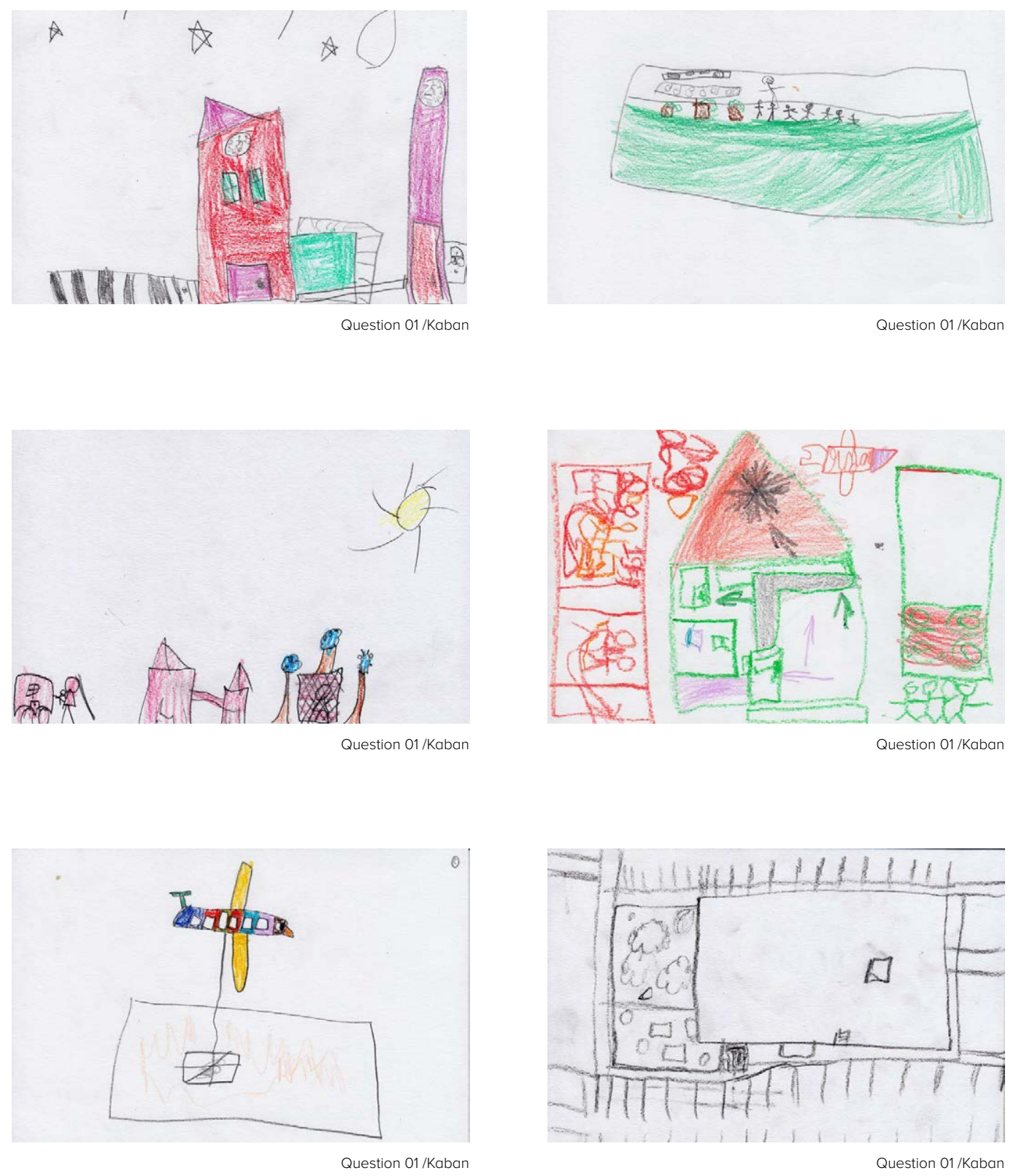

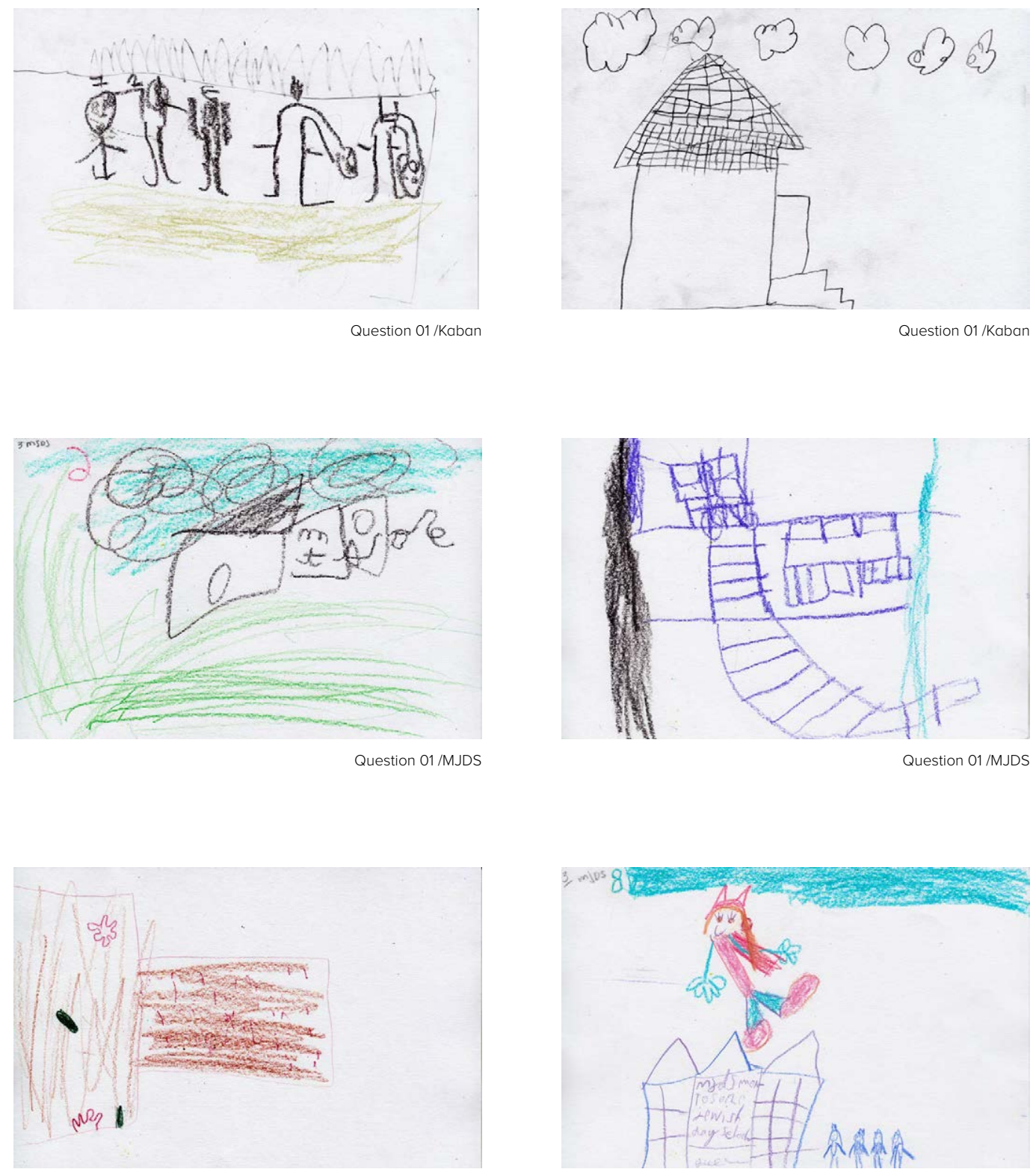

Question 01/MJDS 

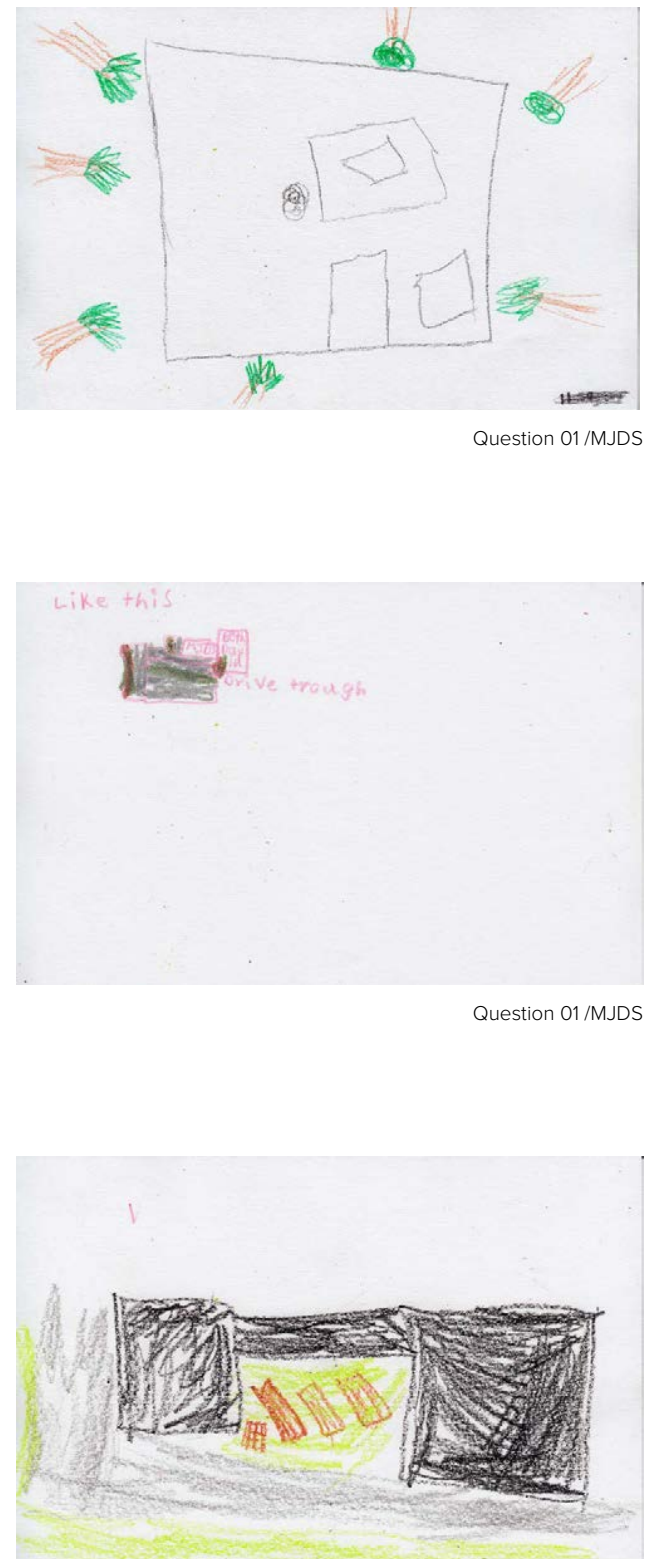

Question 01/MJDS
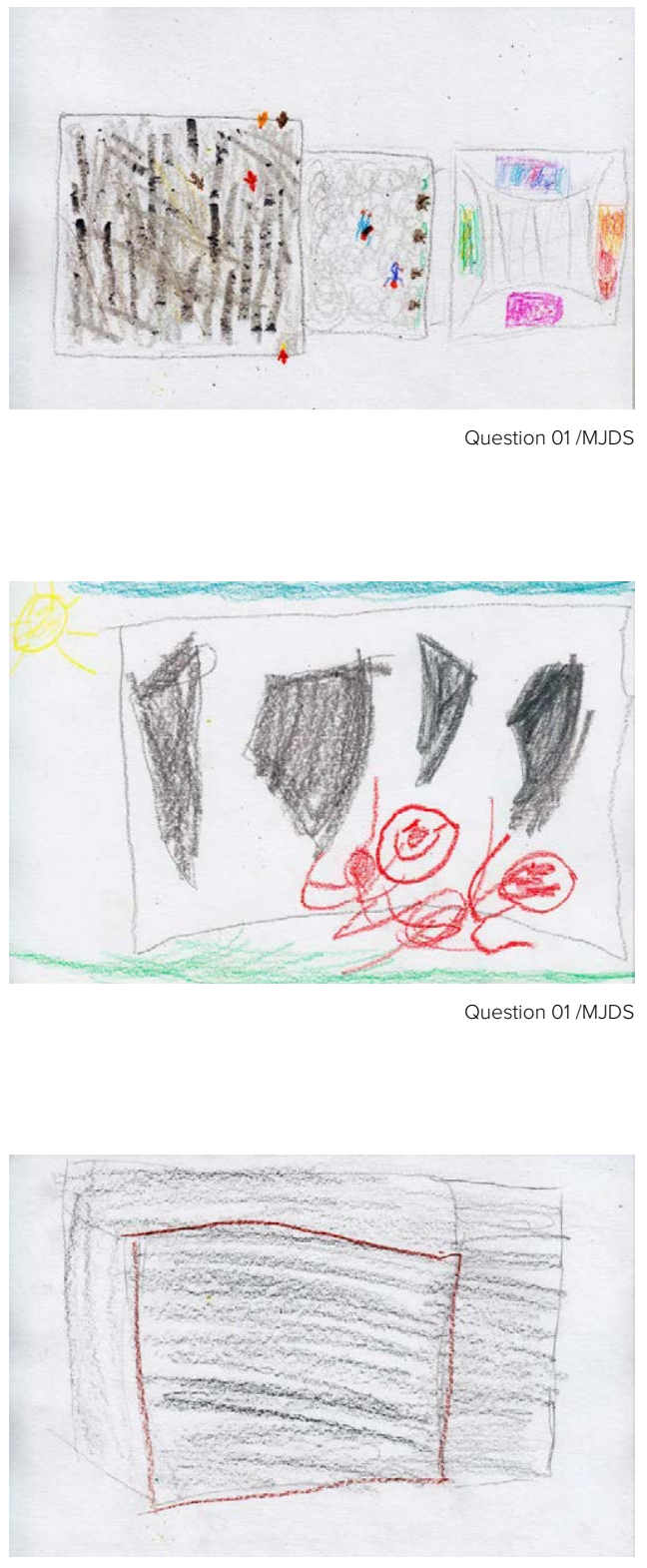

Question 01/MJDS 

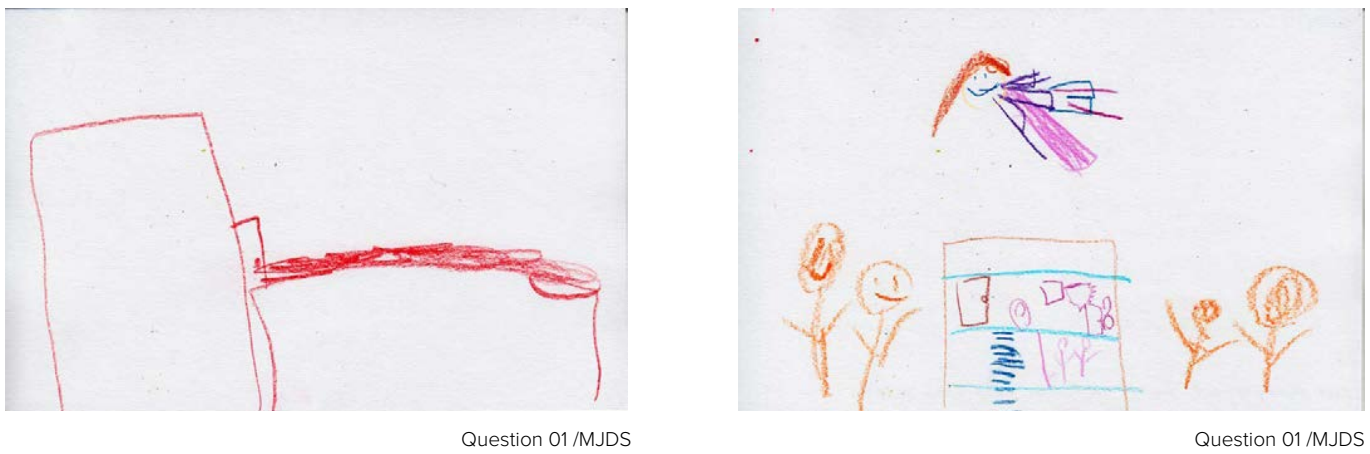


\section{Workshop/ Children's Drawings}

Question 02 - Draw Your Favourite Space In or Around the School

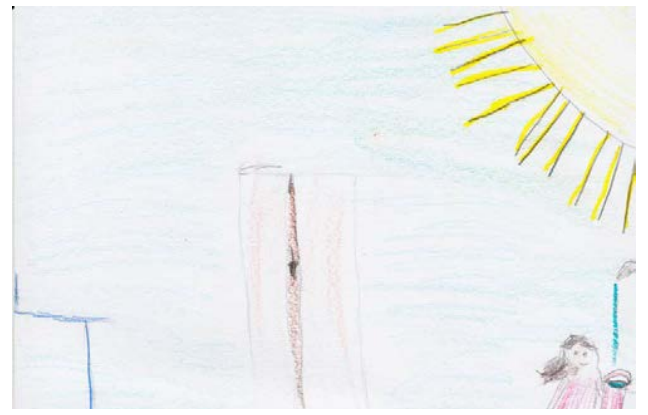

Question 02 /Clanmore

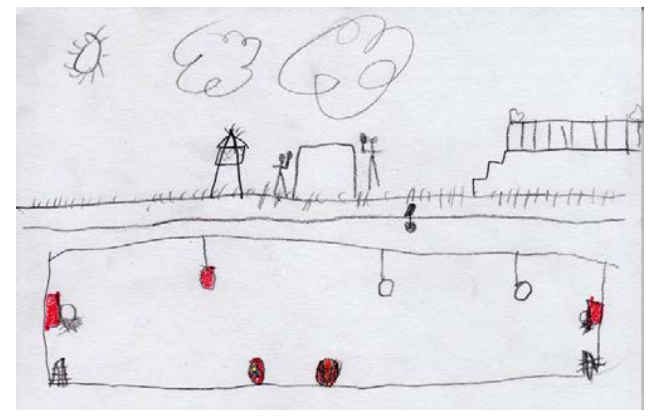

Question 02 /Clanmore

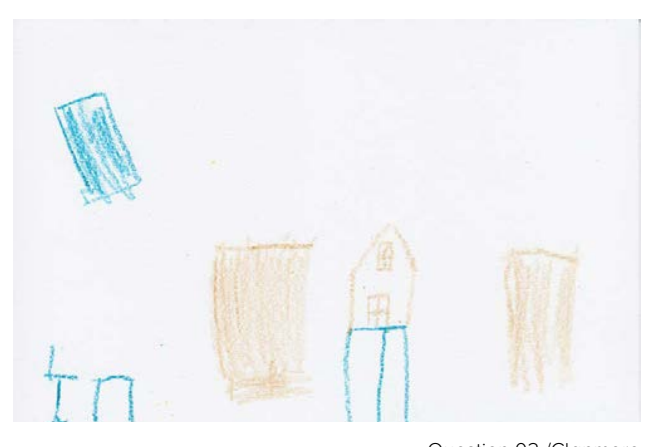

Question 02 /Clanmore

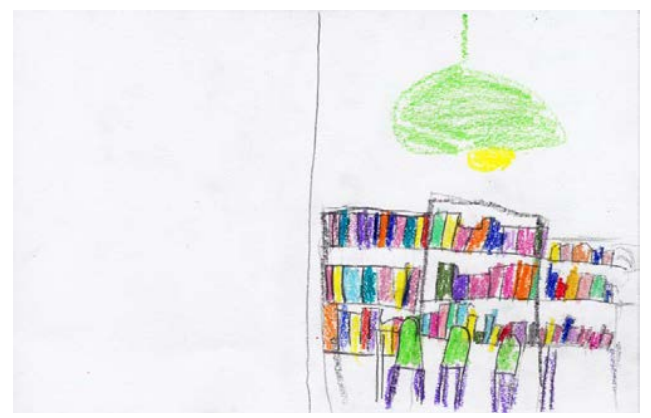

Question 02 /Clanmore
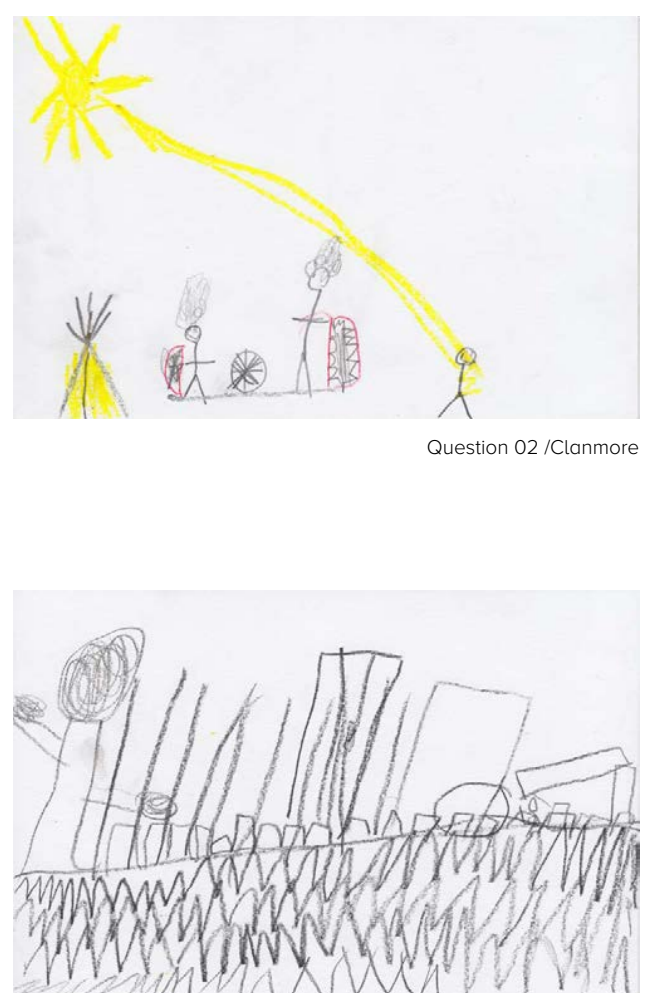

Question 02 /Clanmore 


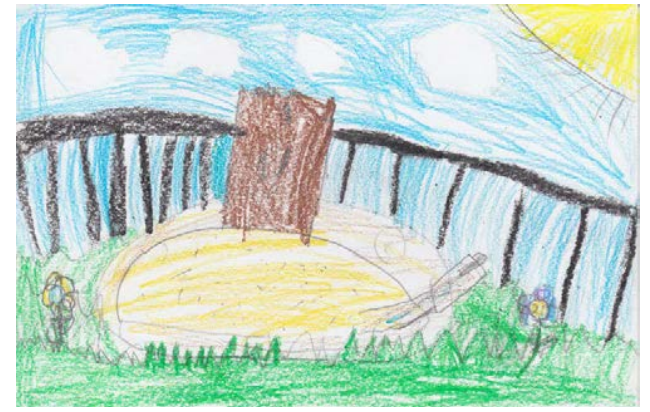

Question 02 /Clanmore
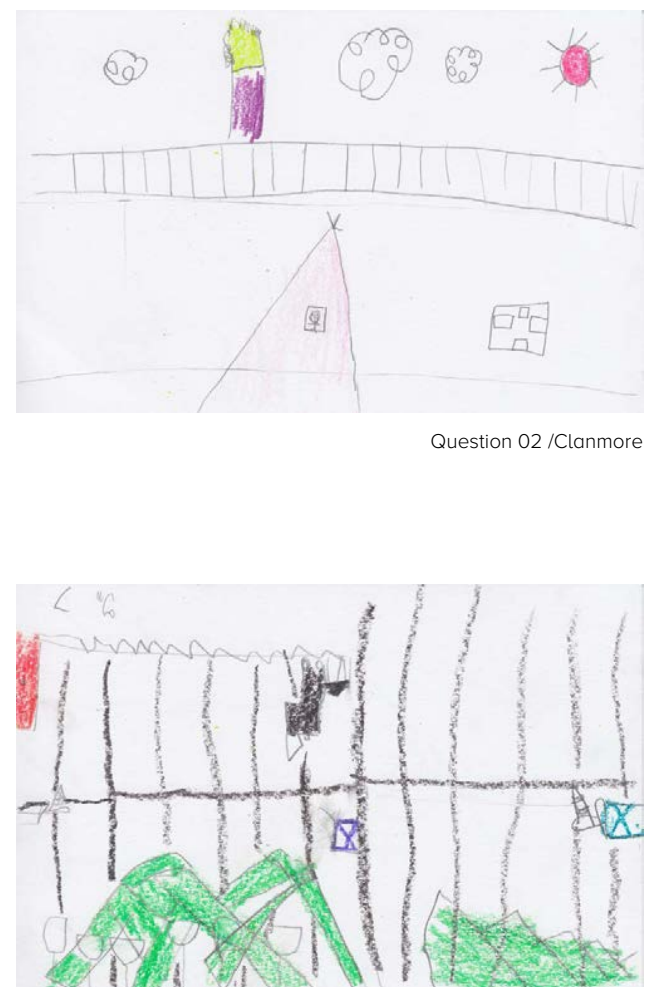

Question 02 /Clanmore
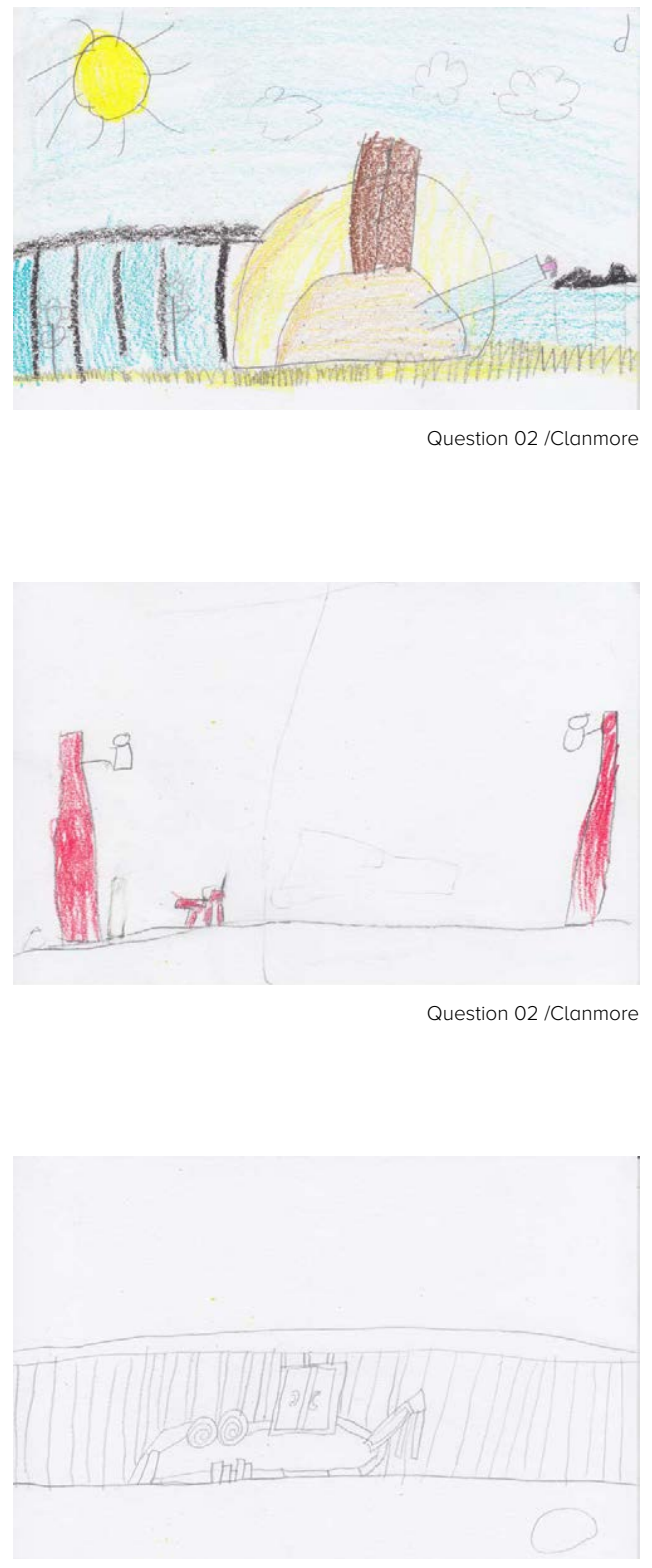

Question 02 /Clanmore 


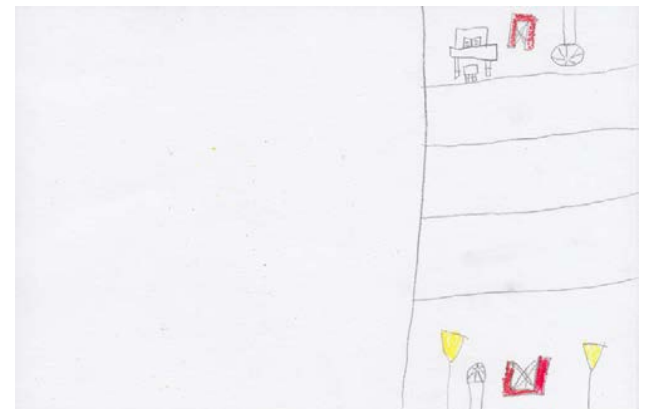

Question 02 /Clanmore
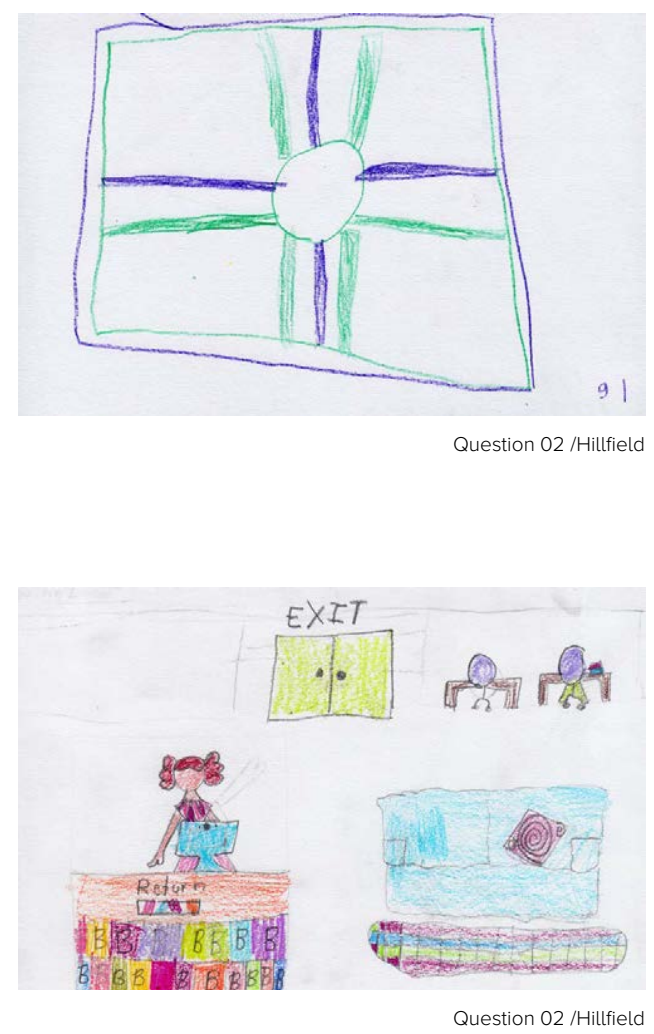

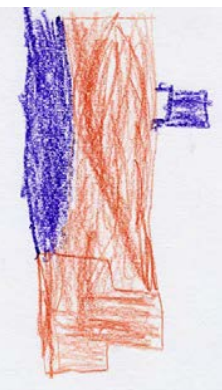

Question 02 /Hillfield
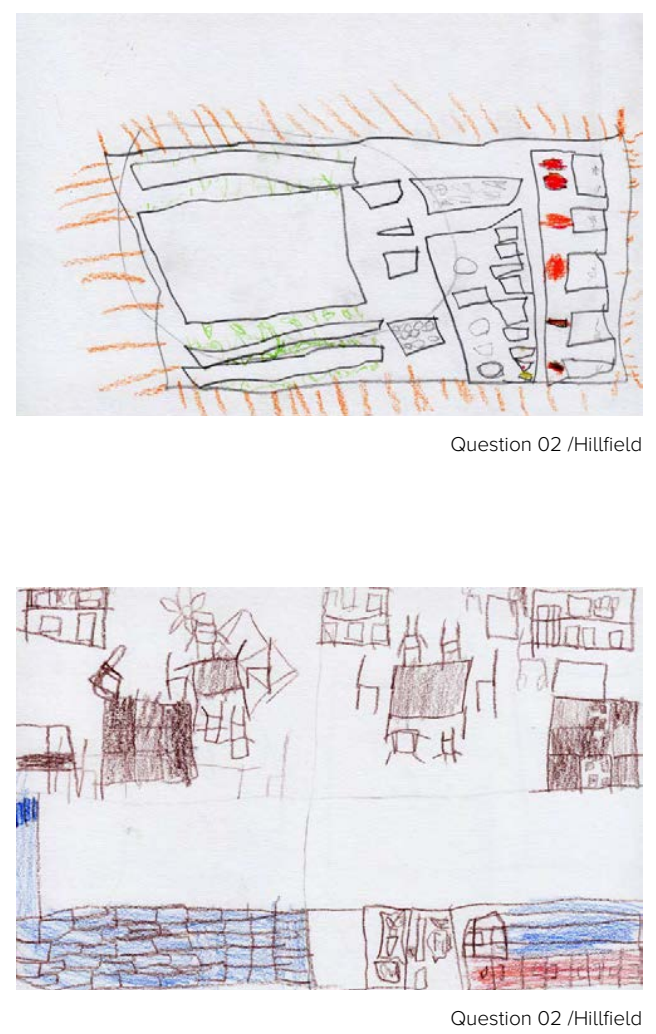


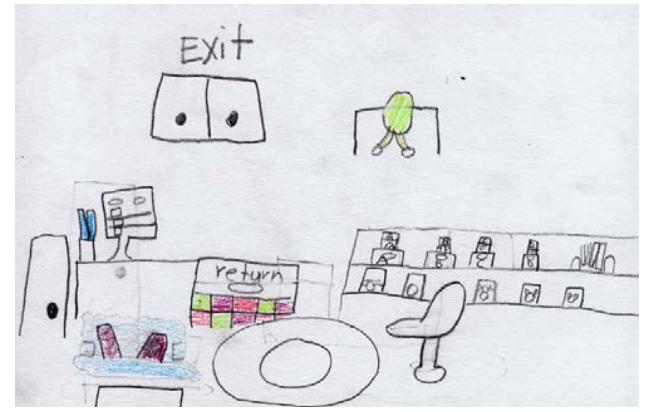

Question 02 /Hillfield
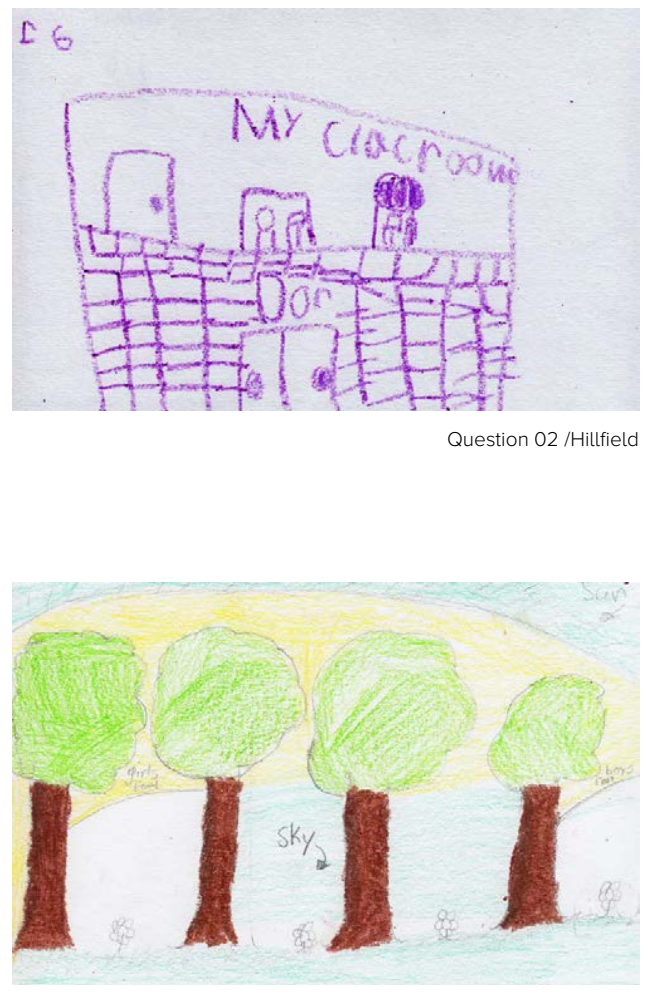

Question 02 /Hillfield
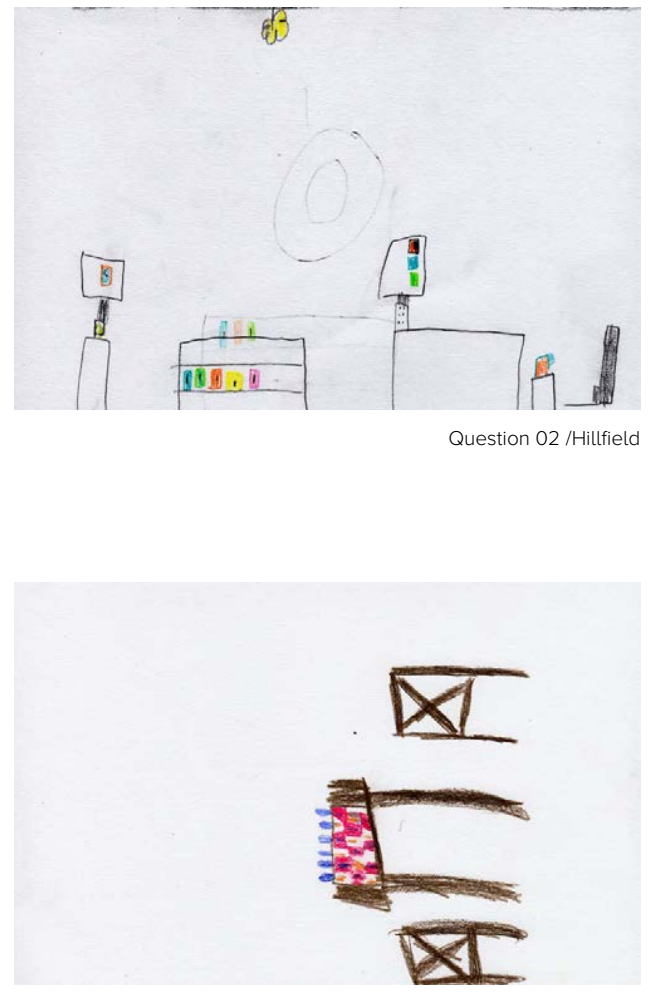

Question 02 /Hillfield

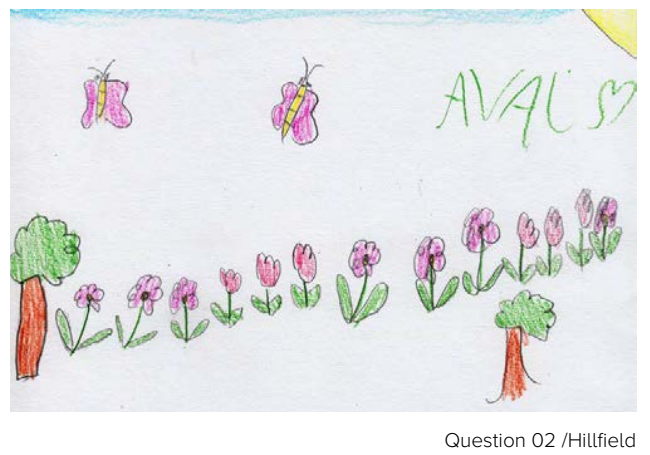




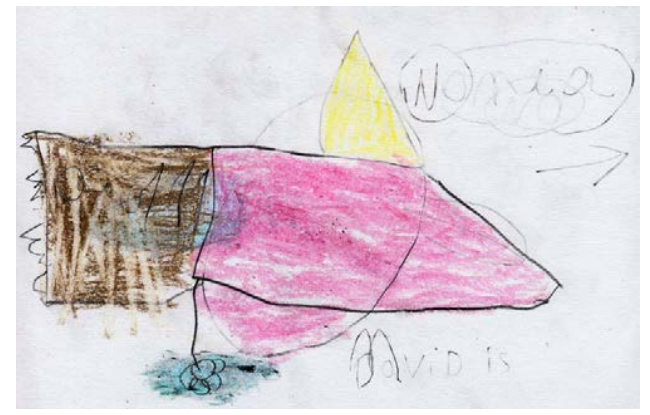

Question 02 /Kaban

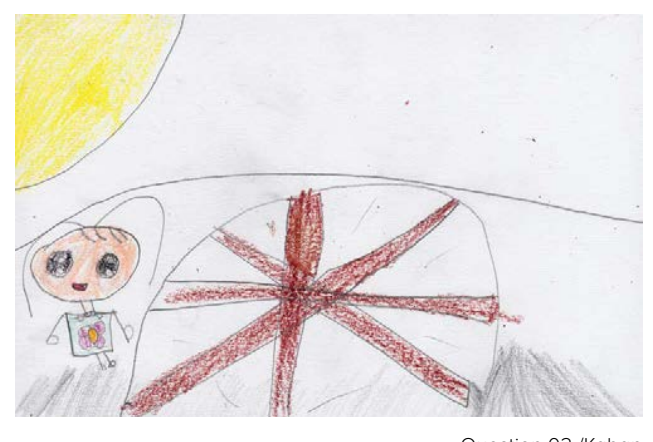

Question 02 /Kaban

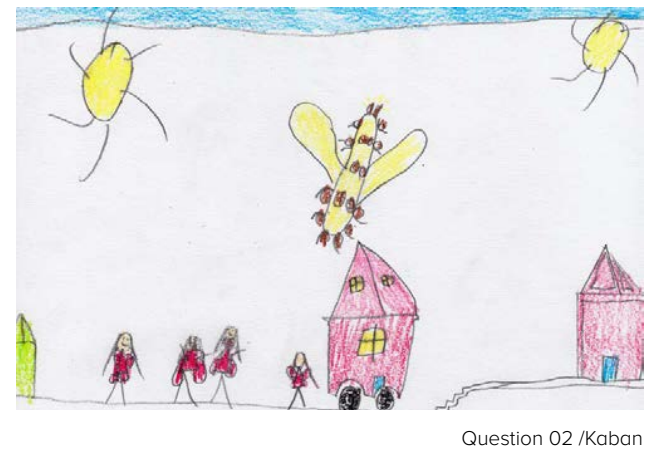

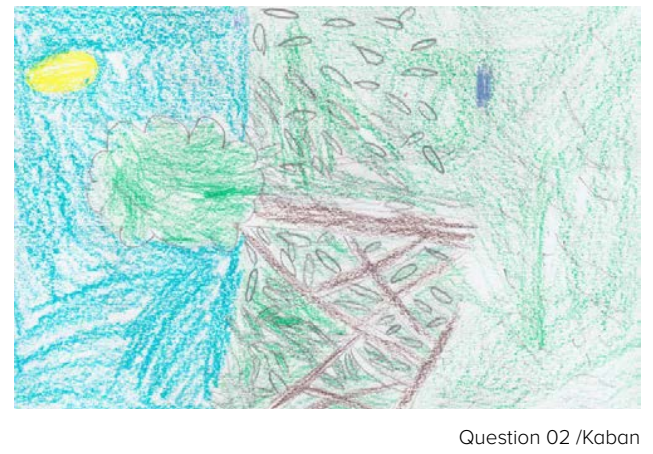

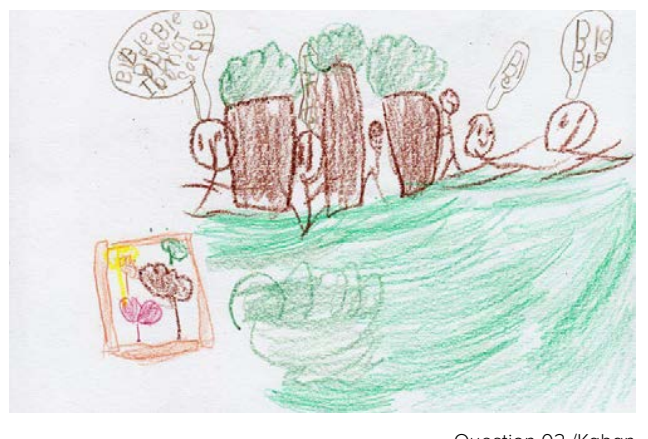

Question 02 /Kaban

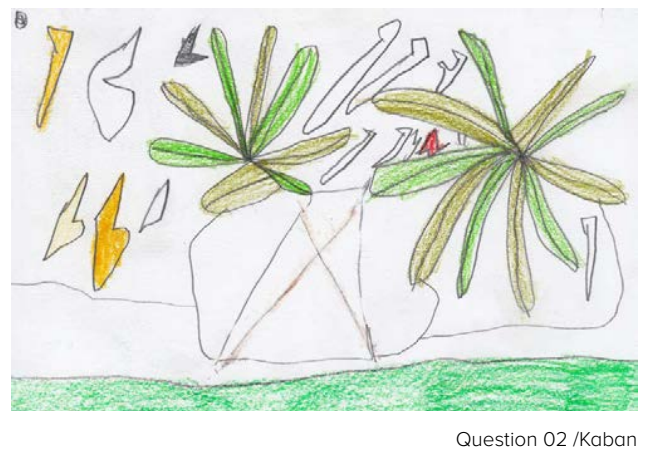



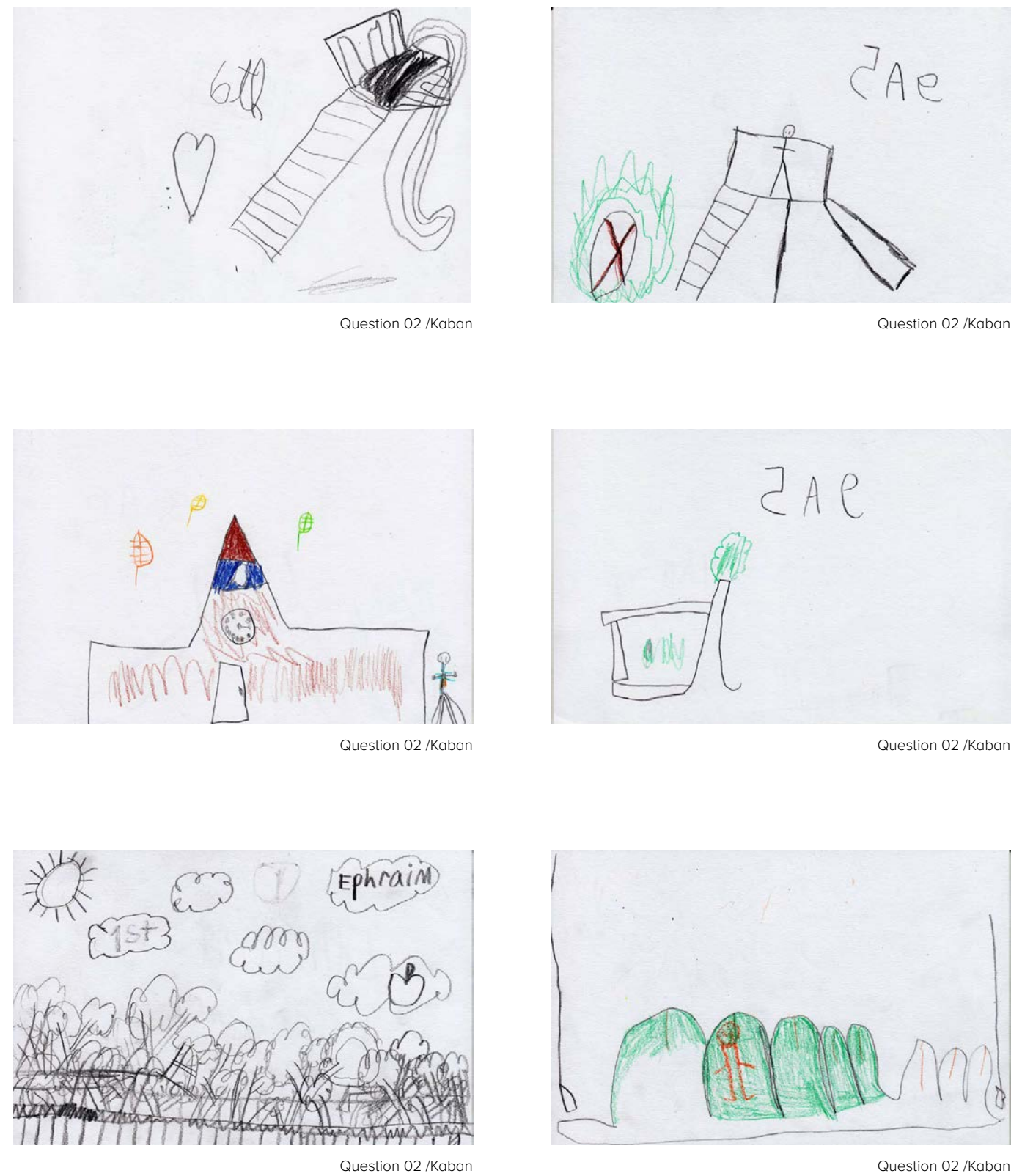


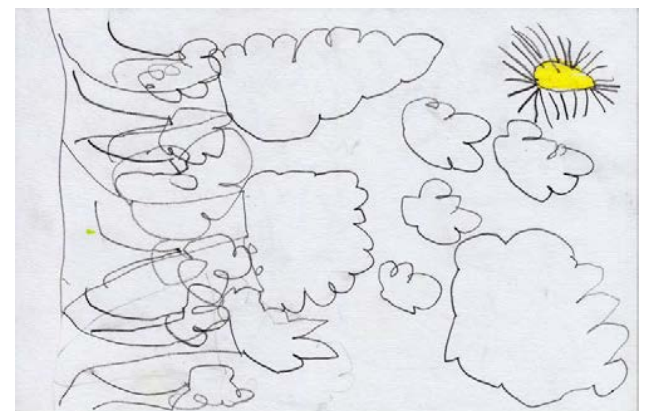

Question 02 /Kaban
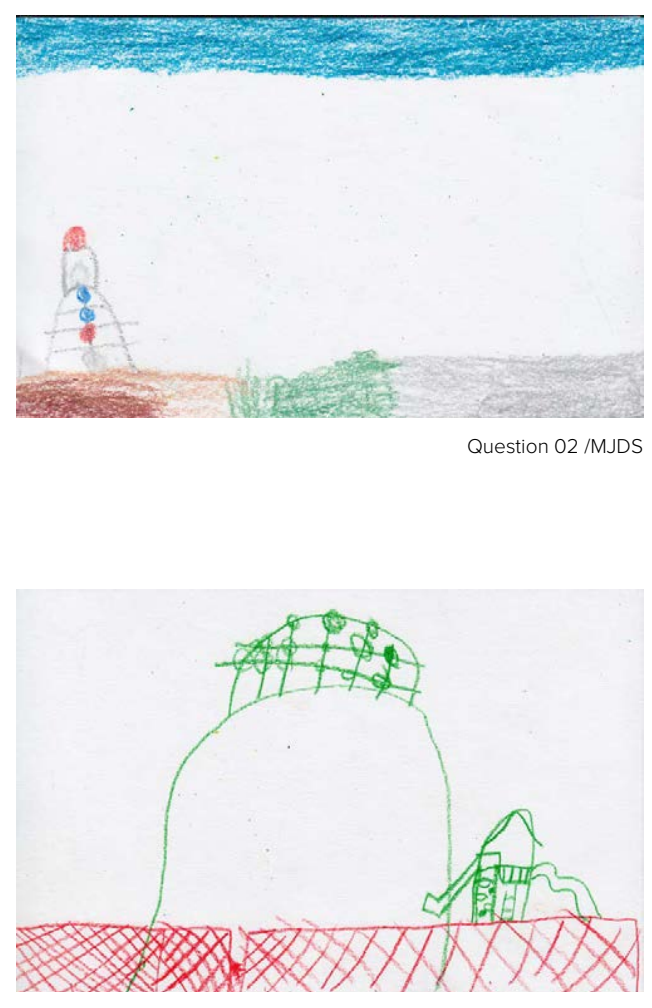

Question 02 /MJDS

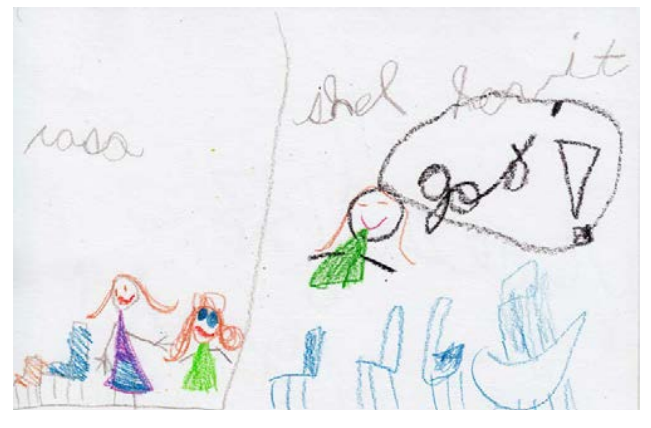

Question 02 /MJDS
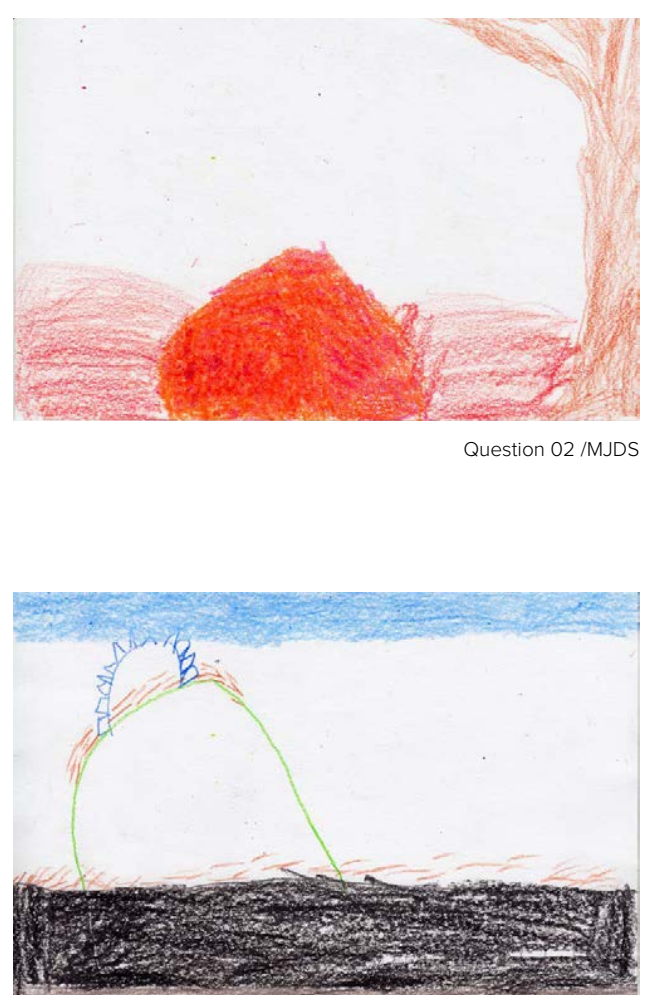

Question 02 /MJDS 


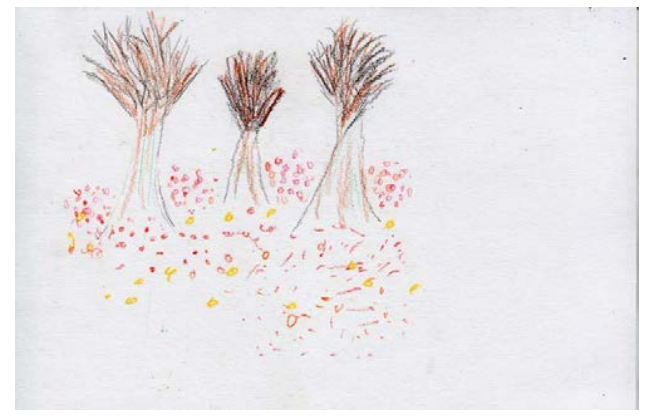

Question 02 /MJDS
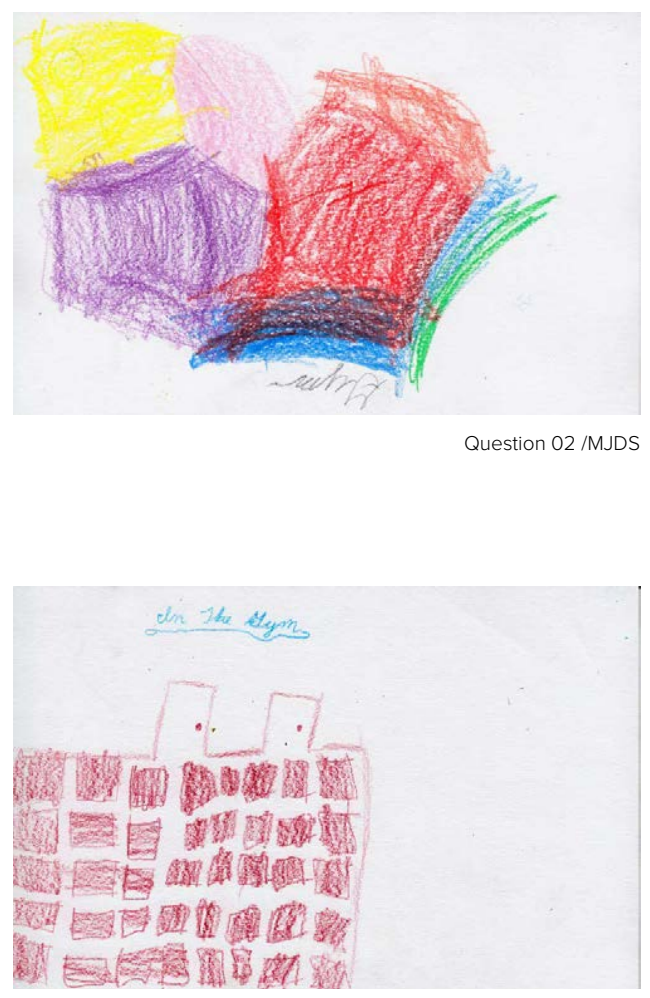

Question 02 /MJDS

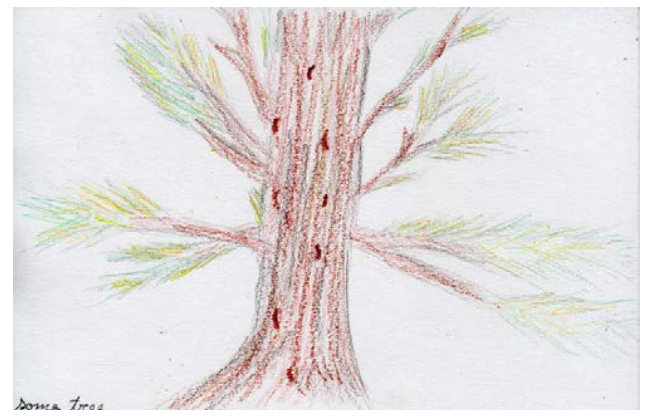

Question 02 /MJDS
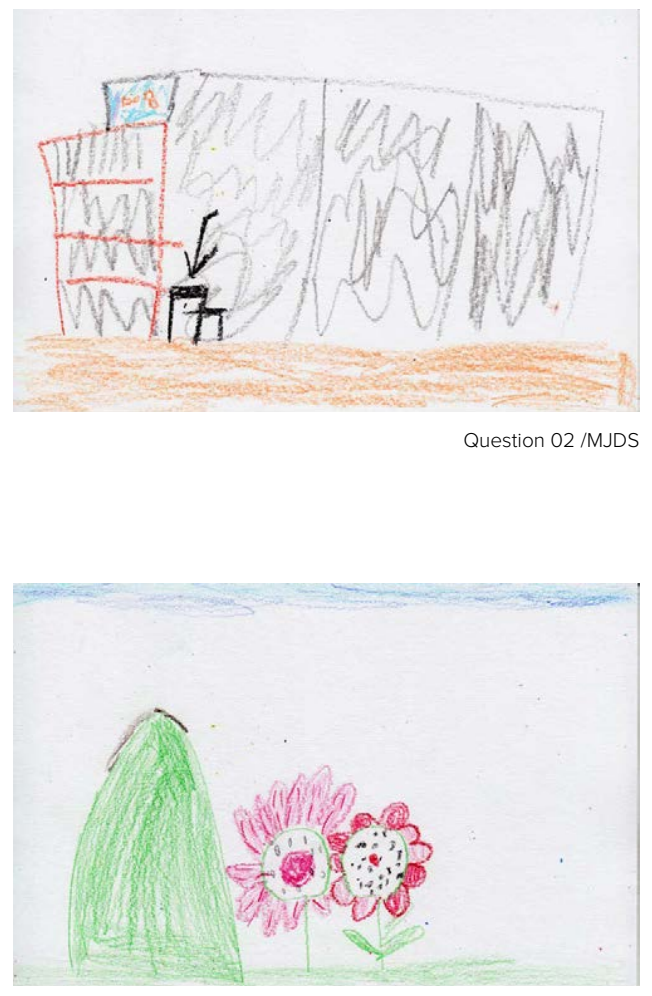

Question 02 /MJDS 


\section{Workshop/ Children's Drawings}

Question 03 - Draw Your Favourite Material In or Around the School
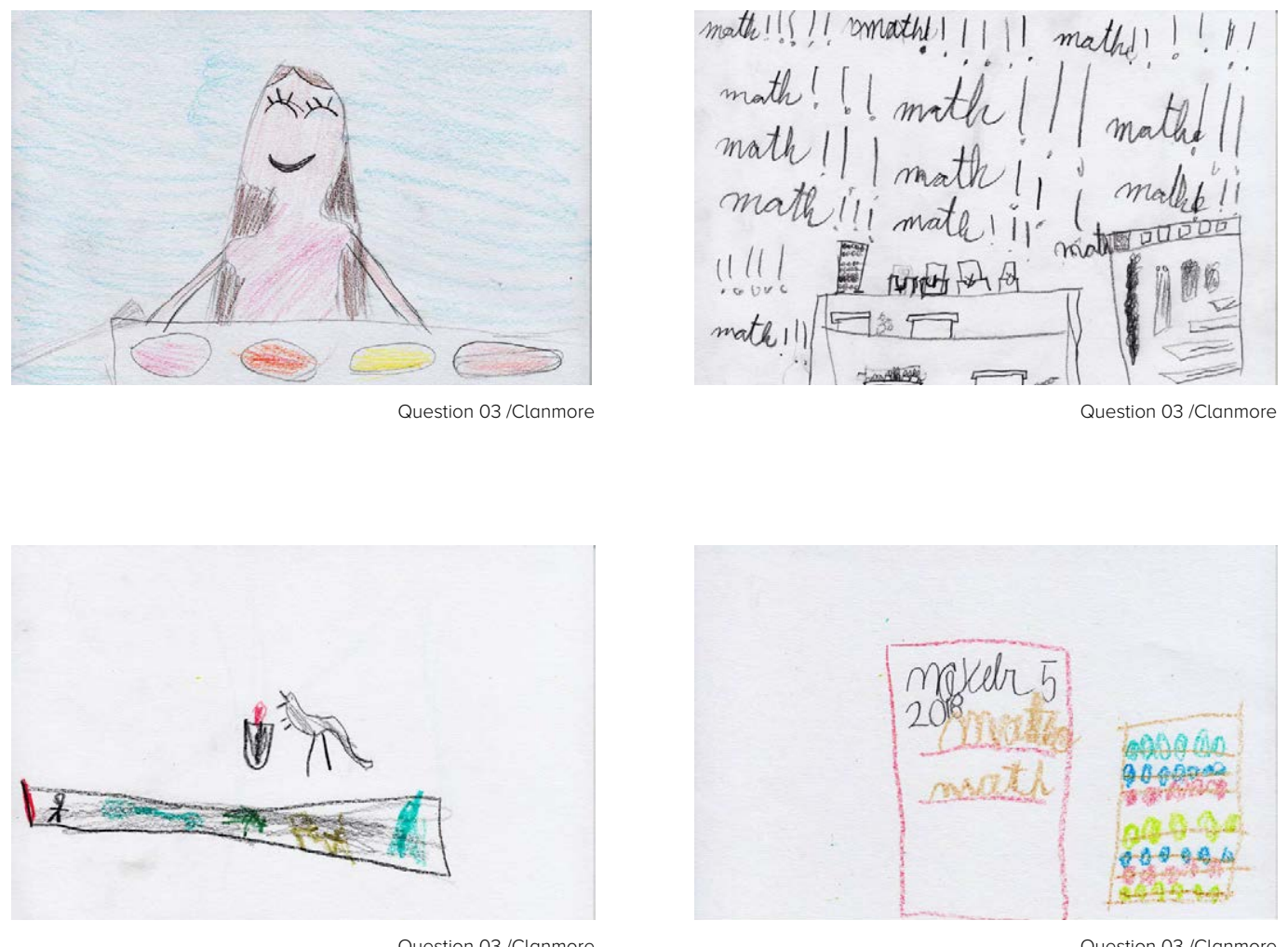

Question 03 /Clanmore
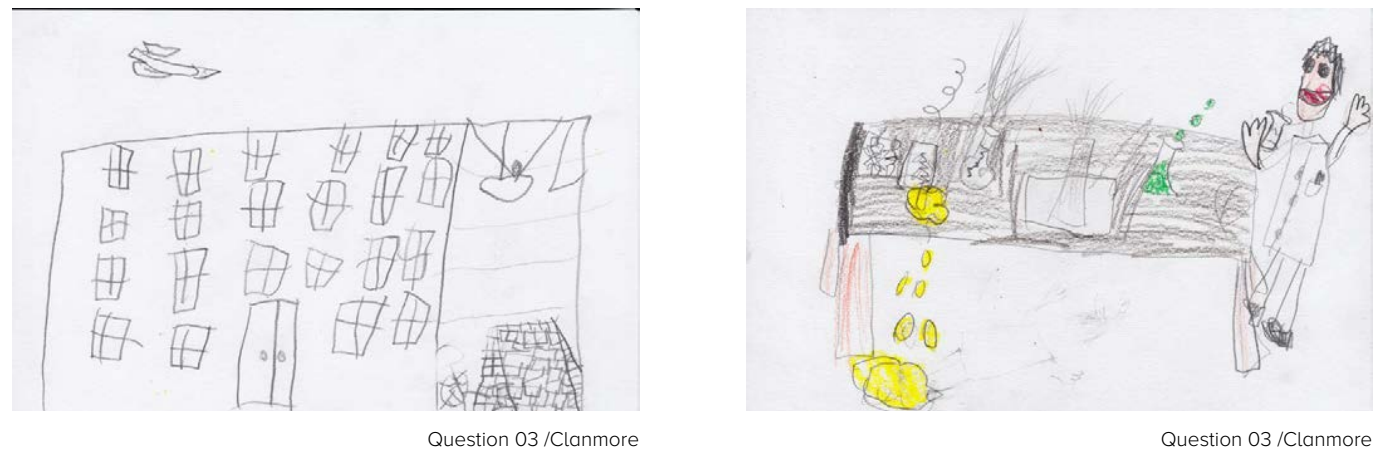

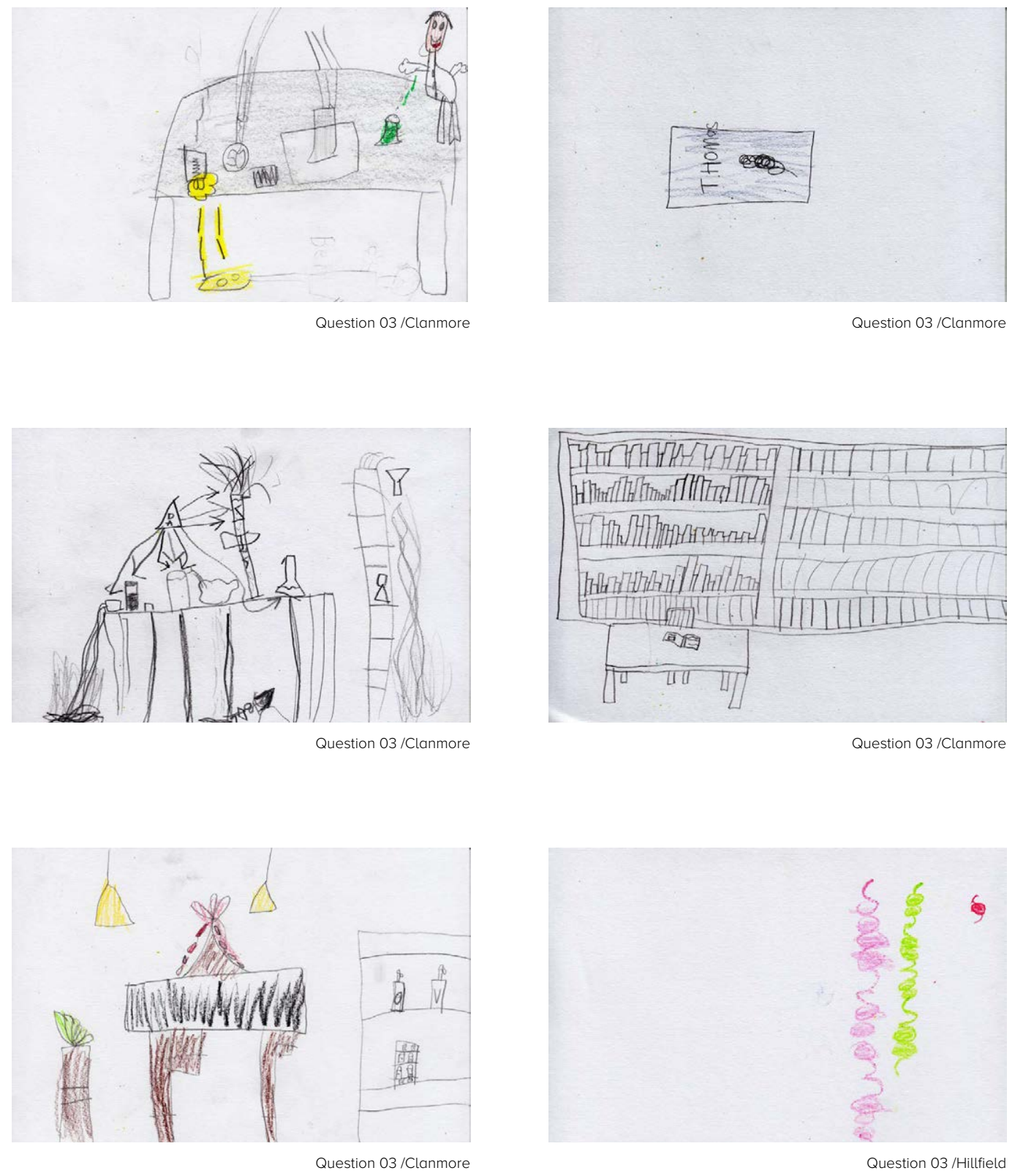

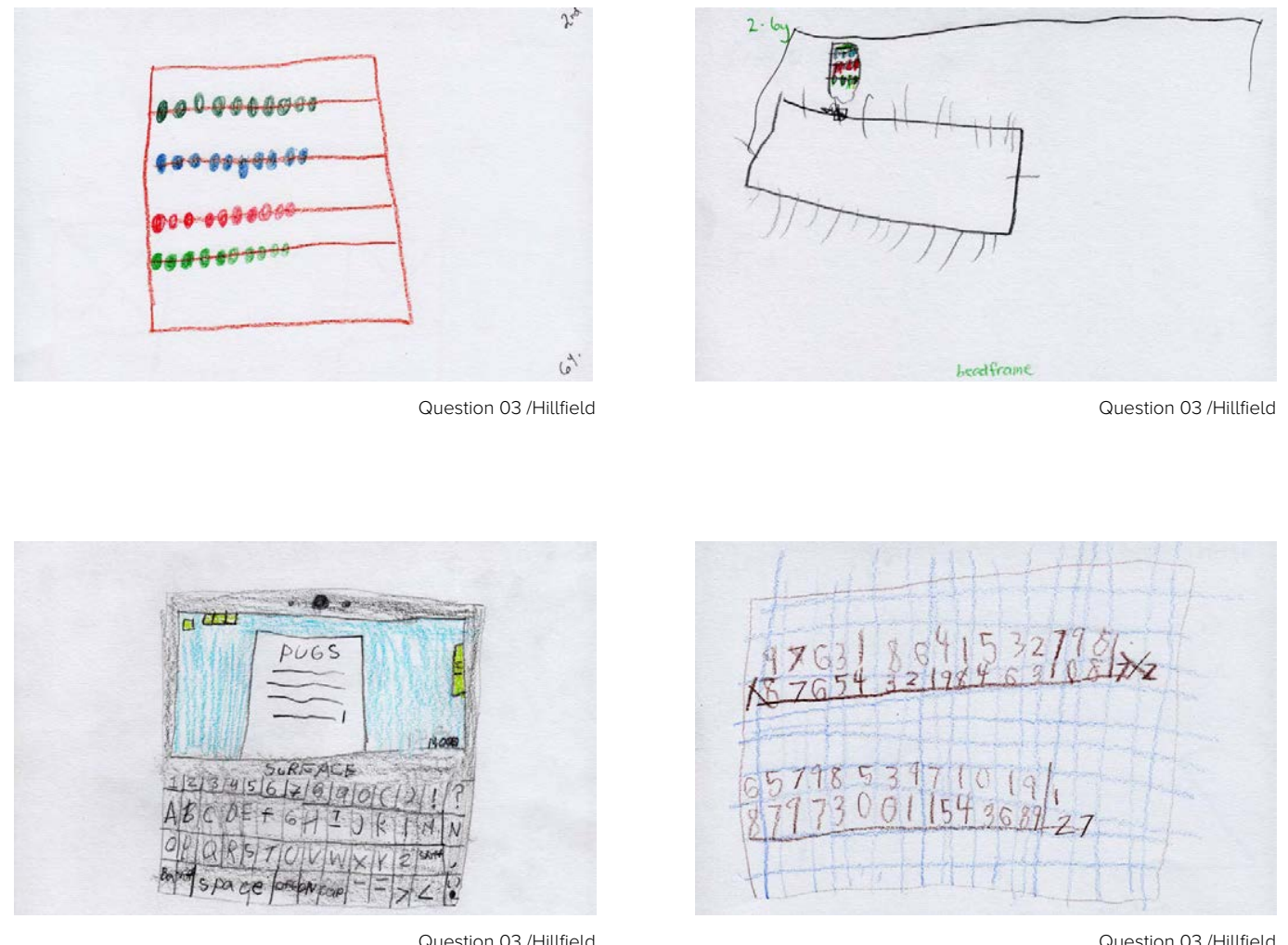

Question 03 /Hillfield

Question 03 /Hillfield
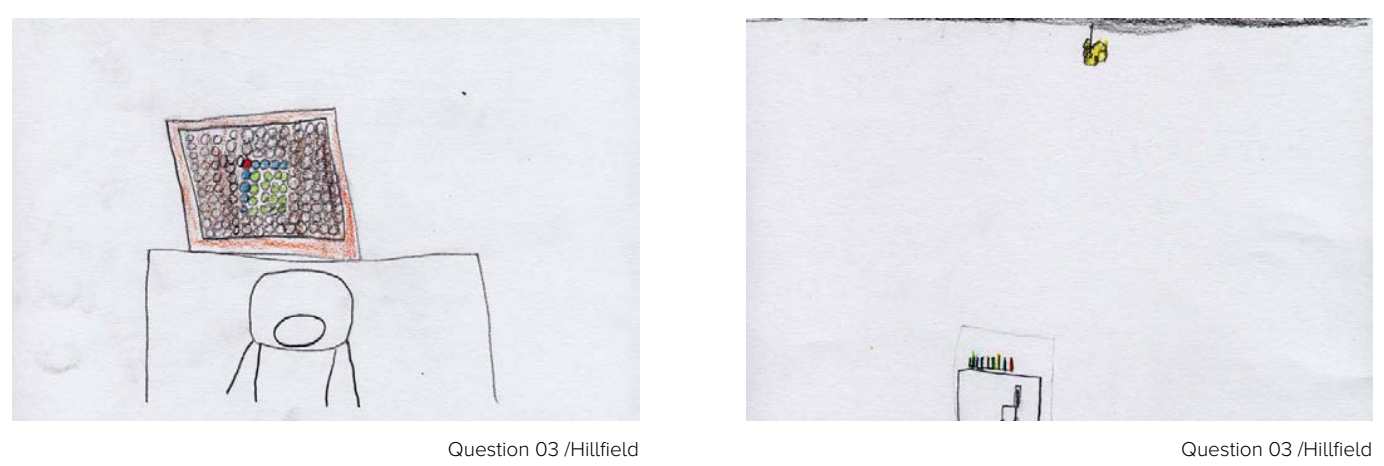

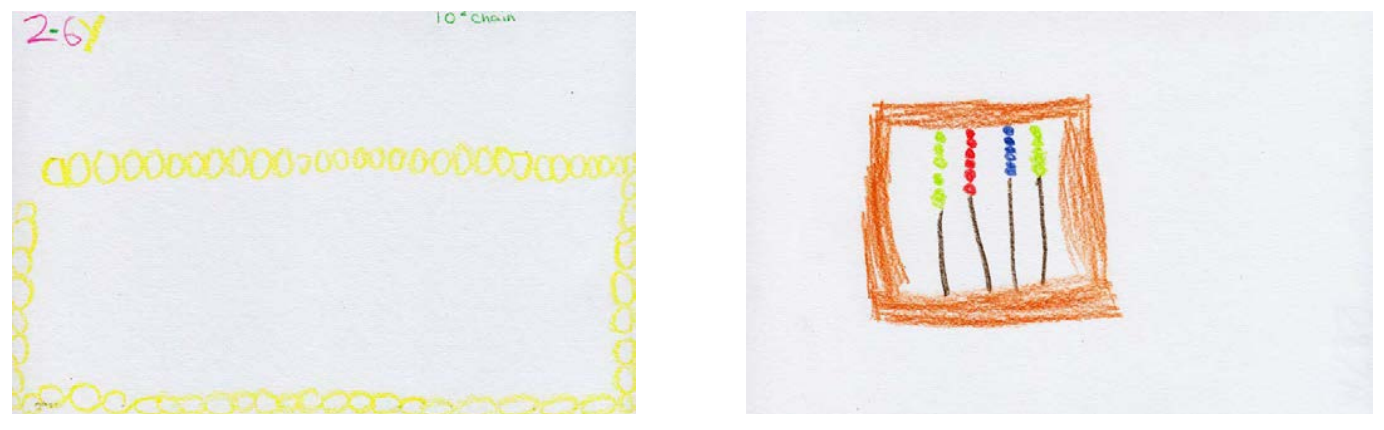

Question 03 /Hillfield

Question 03 /Hillfield
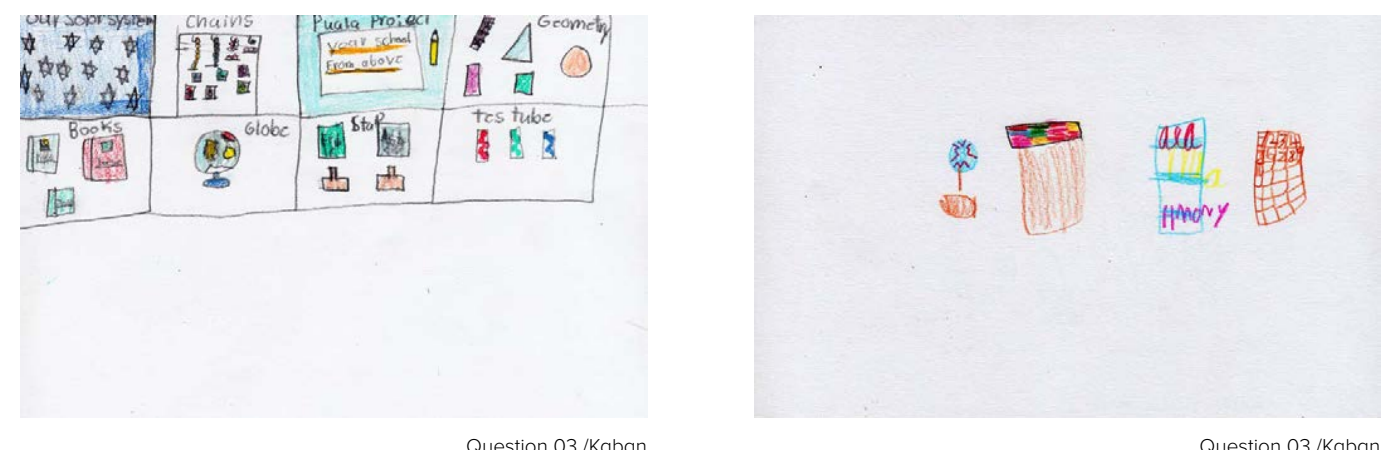

Question 03 /Kaban
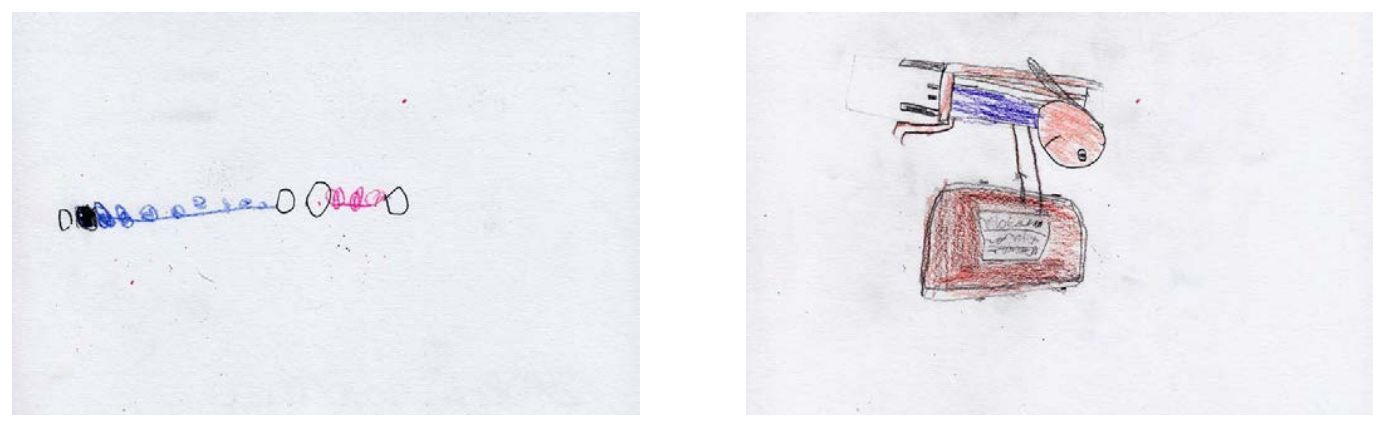

Question 03 /Kaban

Question 03 /Kaban 

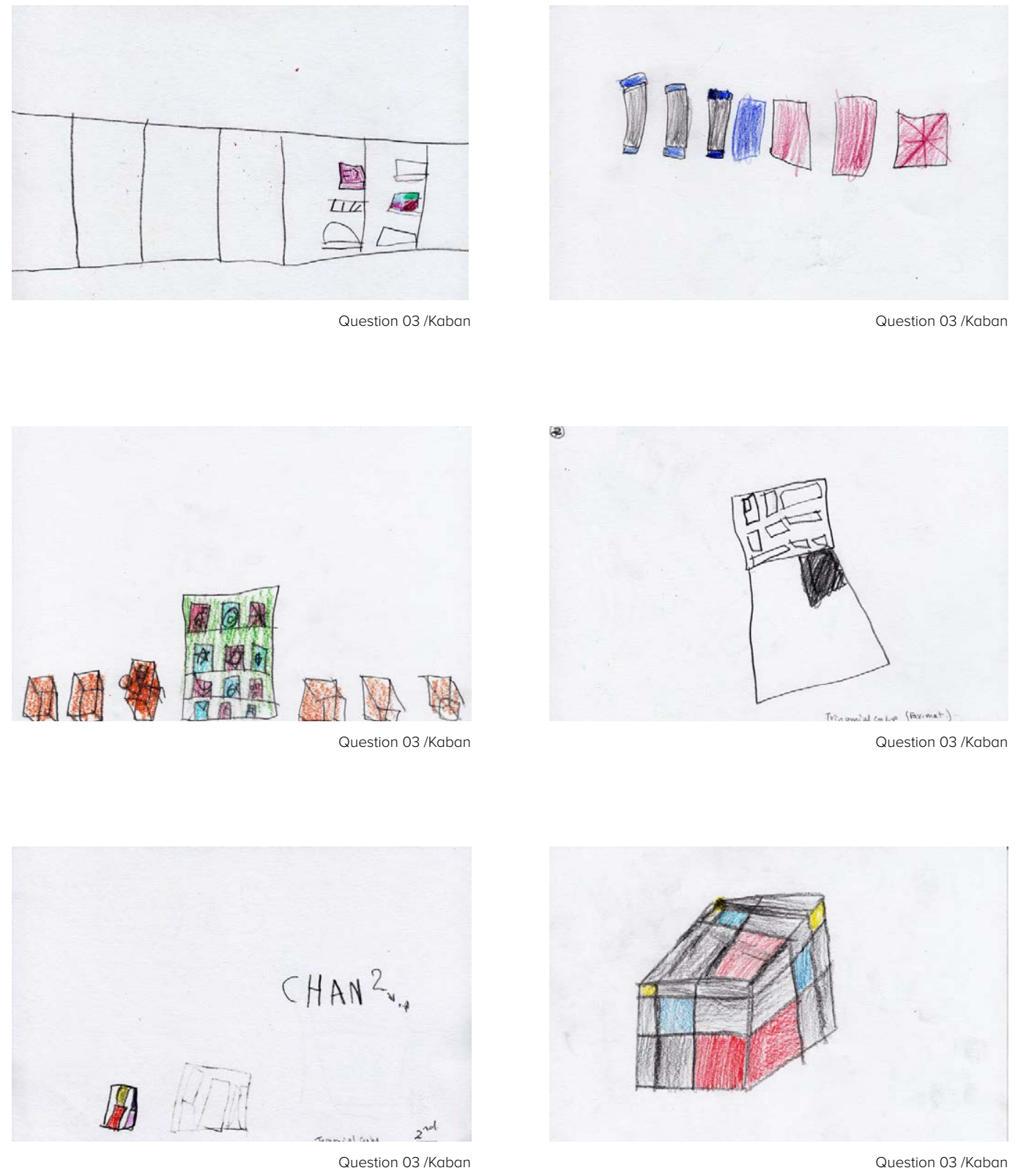

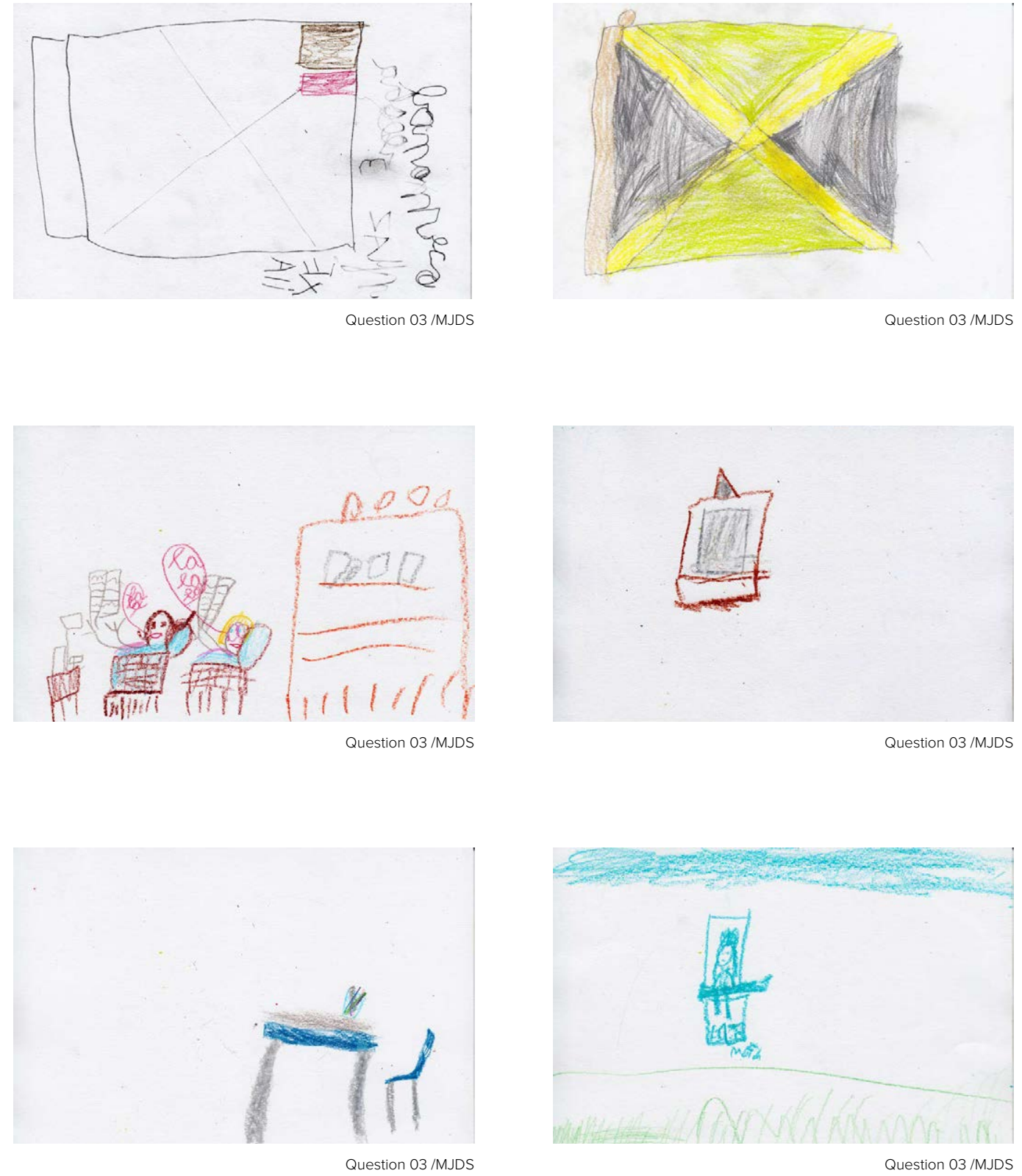


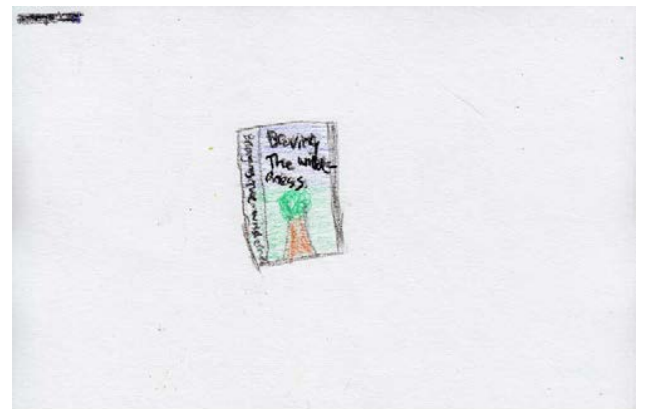

Question 03 /MJDS
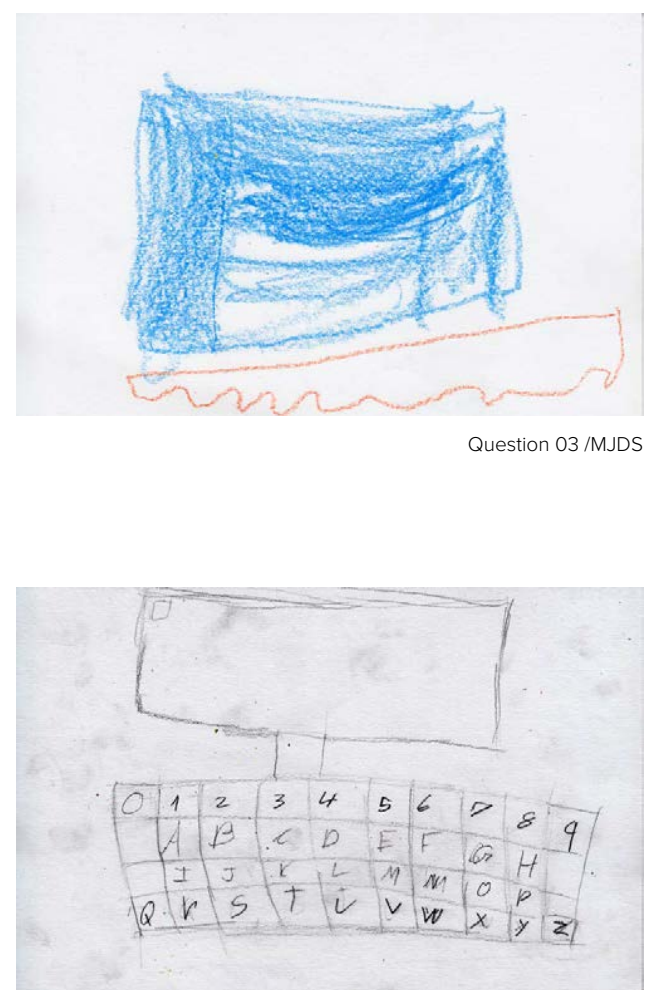

Question 03 /MJDS

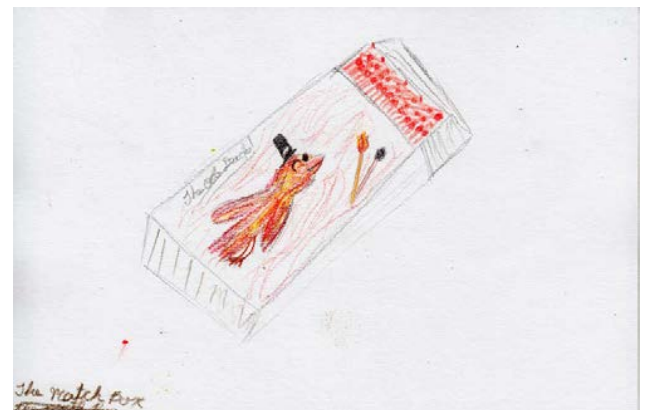

Question 03 /MJDS
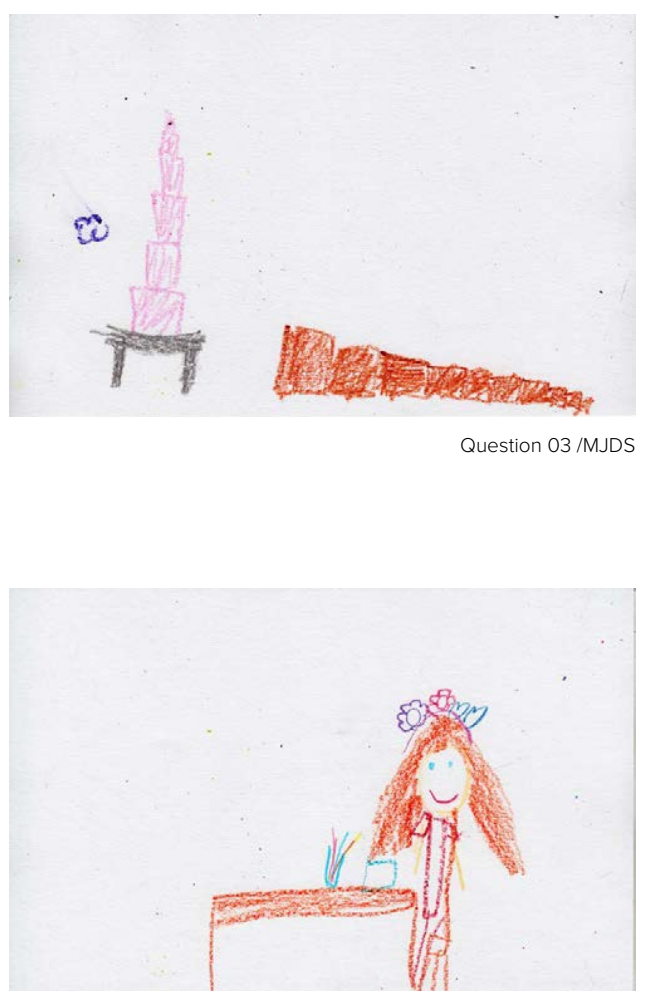

Question 03 /MJDS 


\section{Workshop/ Children's Drawings}

Question 04 - Draw Something New to Add In or Around the School

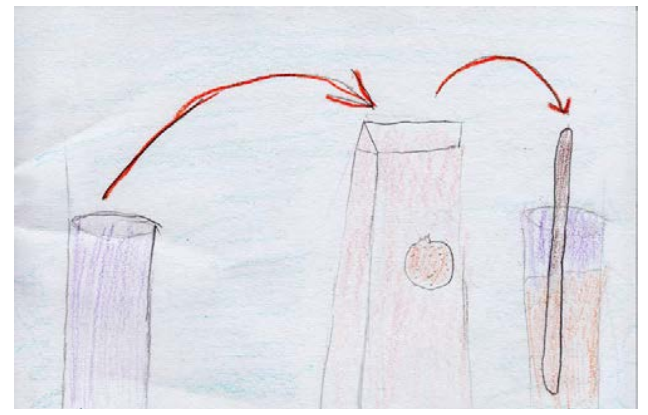

Question 04 /Clanmore
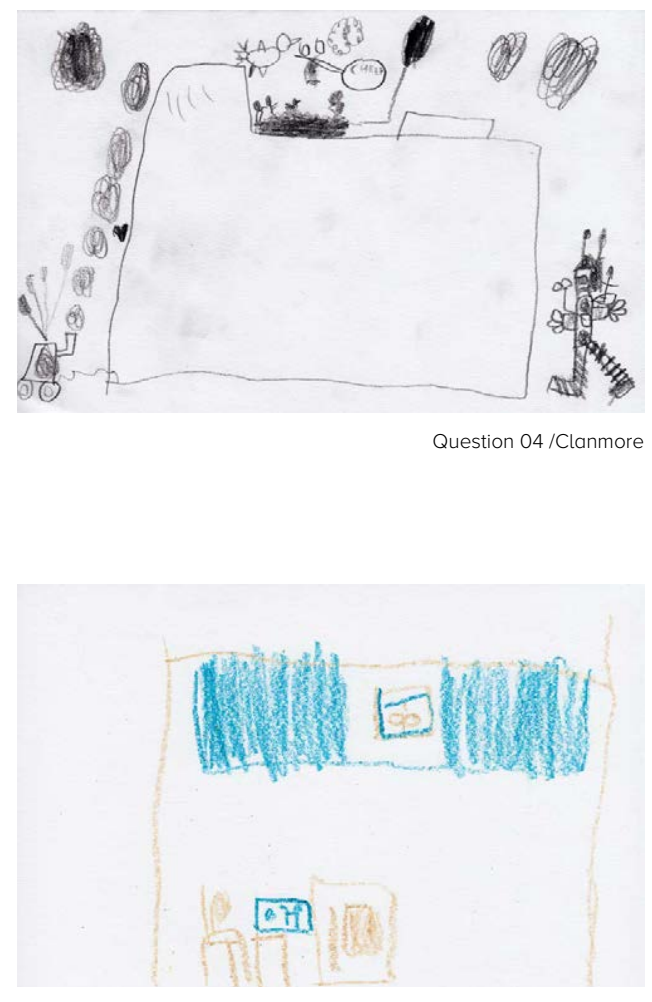

Question 04 /Clanmore

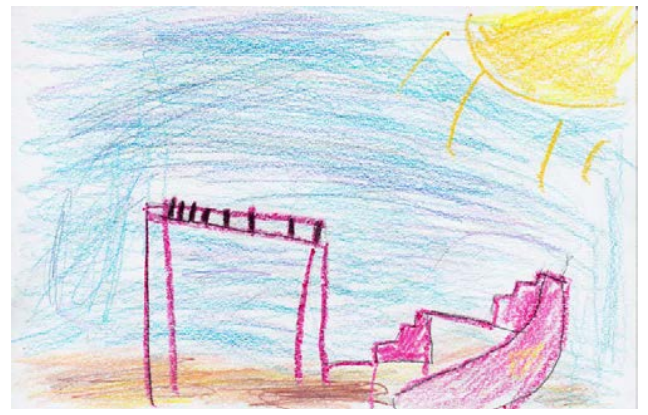

Question 04 /Clanmore
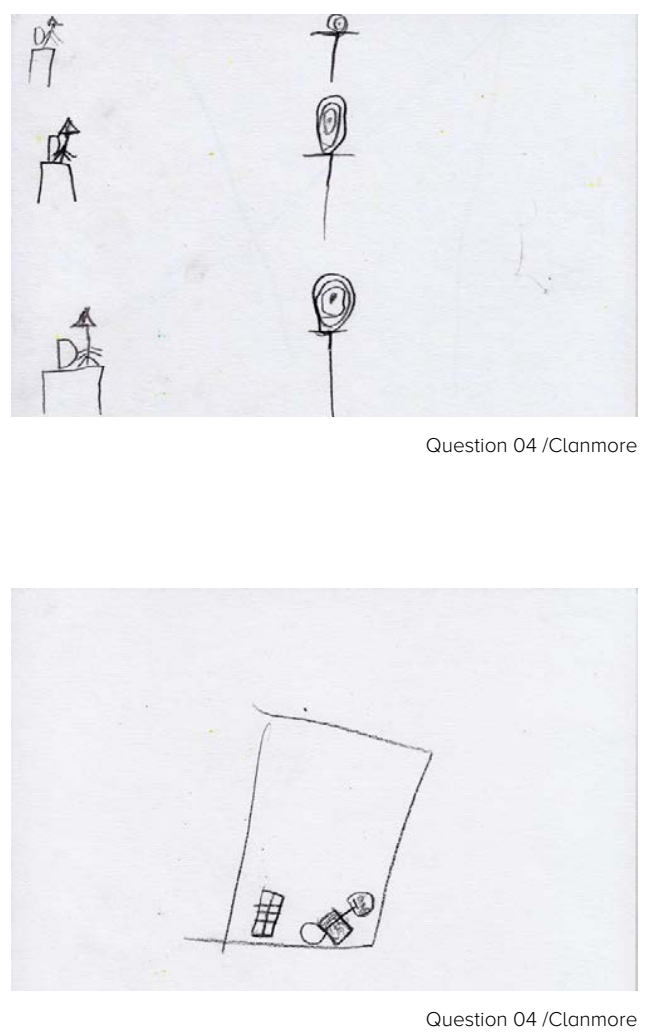

Appendix C - Workshop/ Children's Drawings 


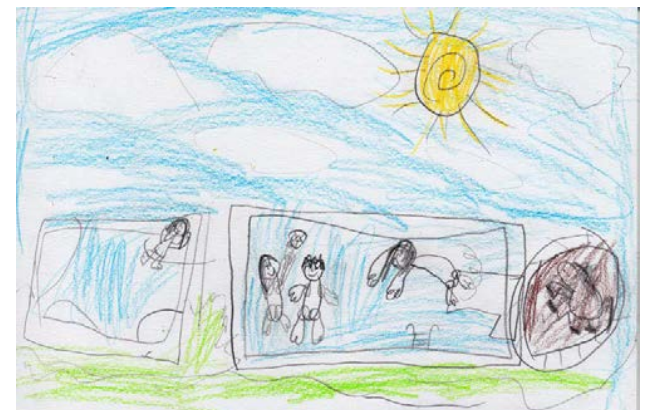

Question 04 /Clanmore
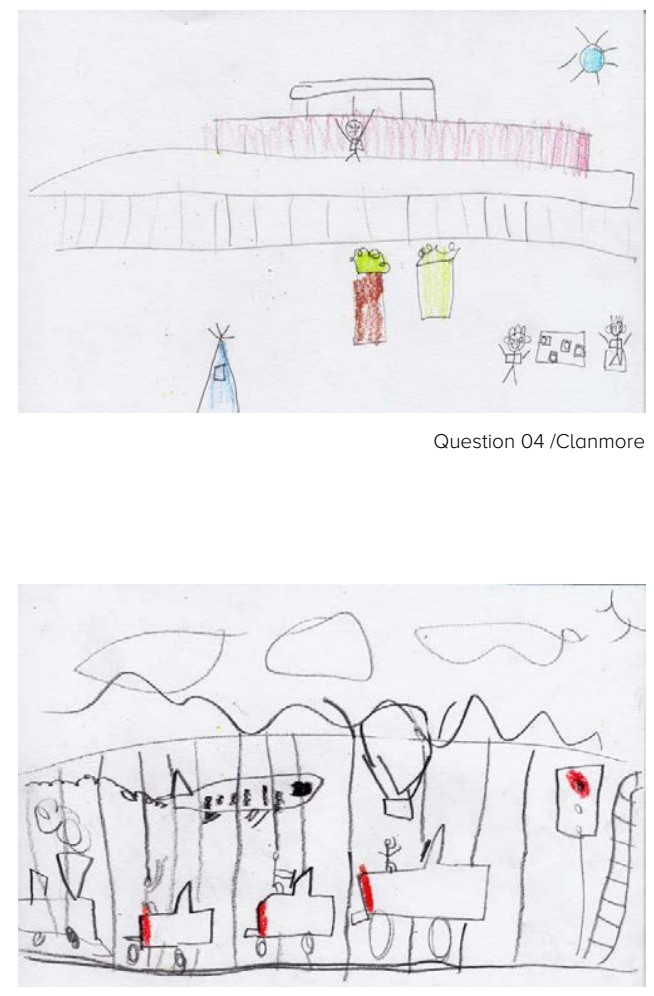

Question 04 /Clanmore
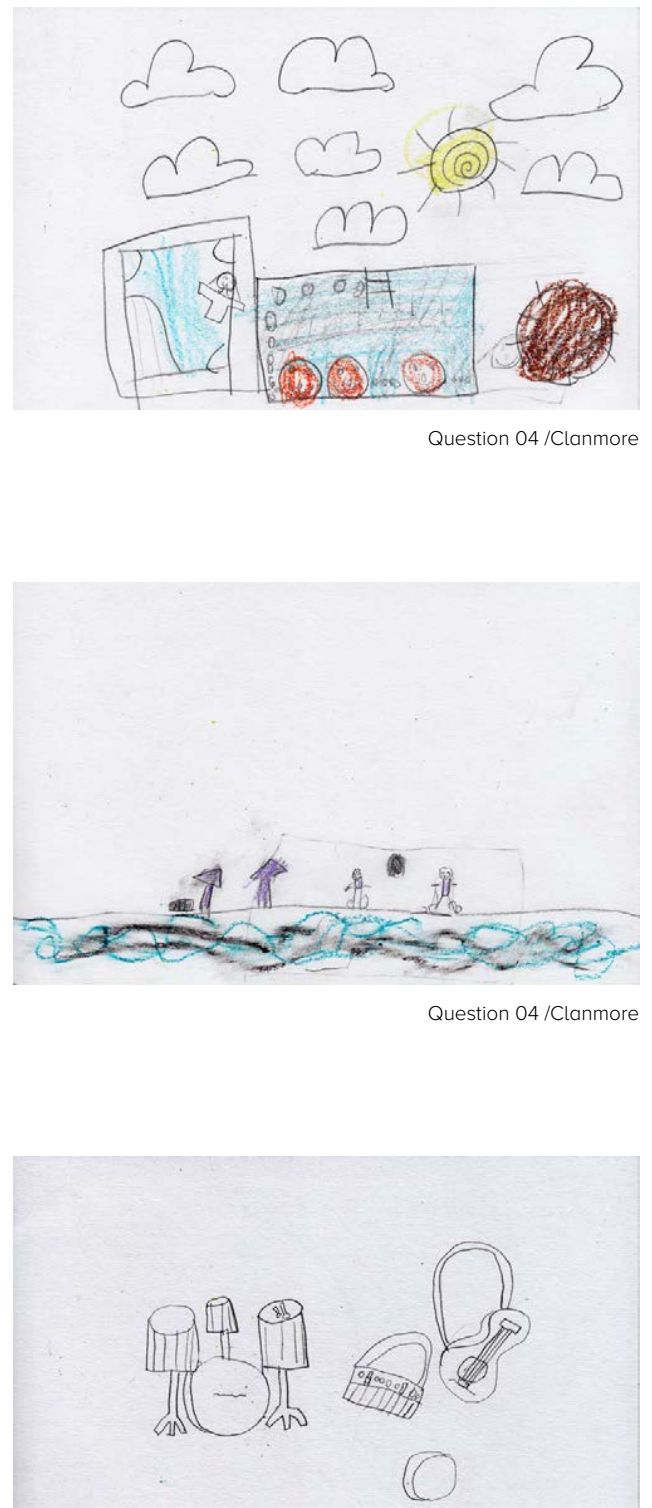

Question 04 /Clanmore 


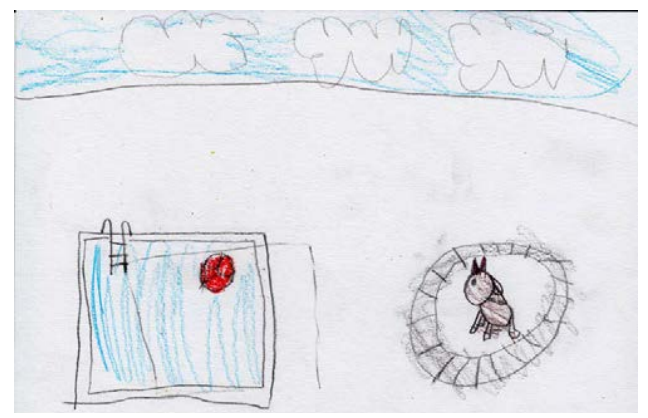

Question 04 /Clanmore

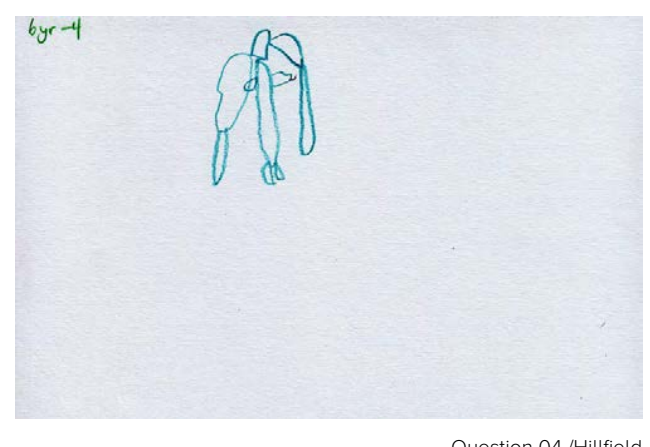

Question 04 /Hillfield

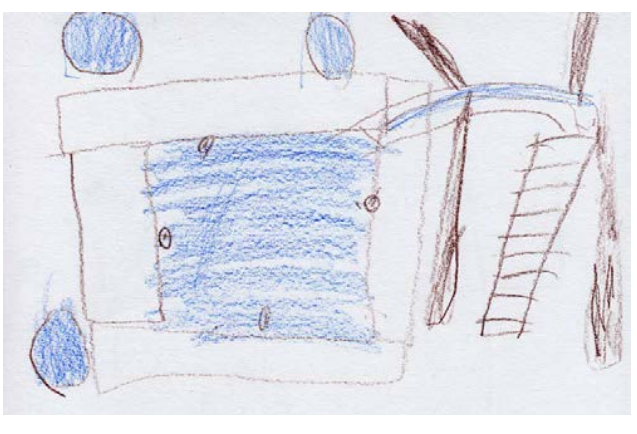

Question 04 /Hillfield

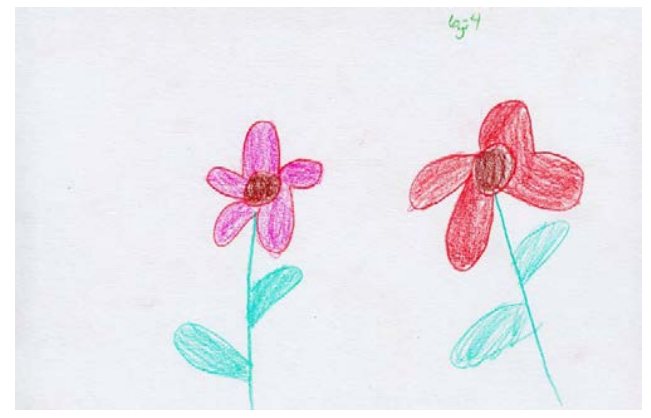

Question 04/Hillfield
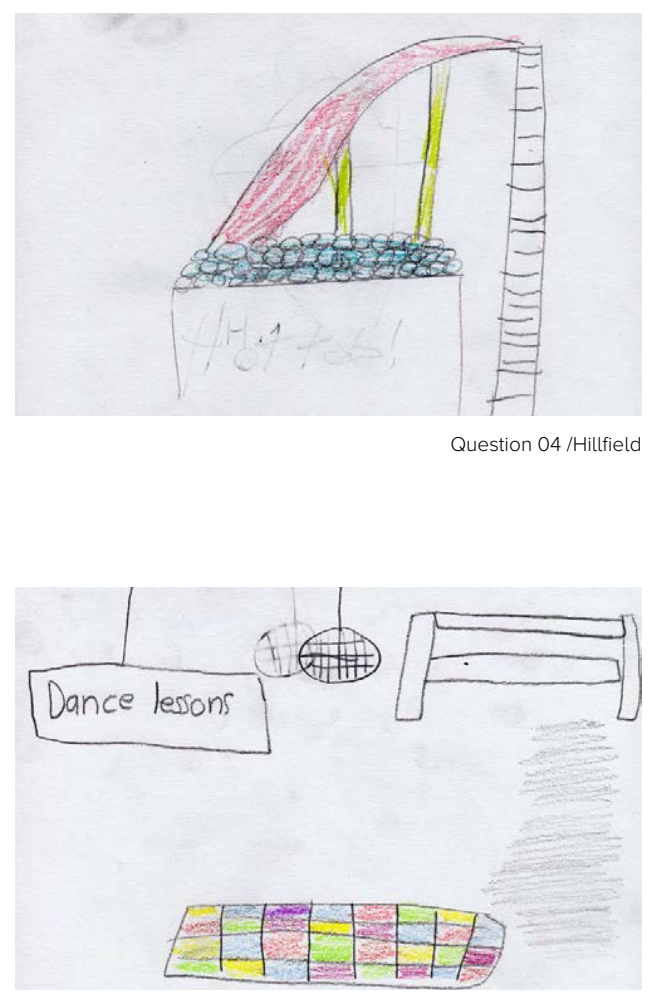

Question 04 /Hillfield 

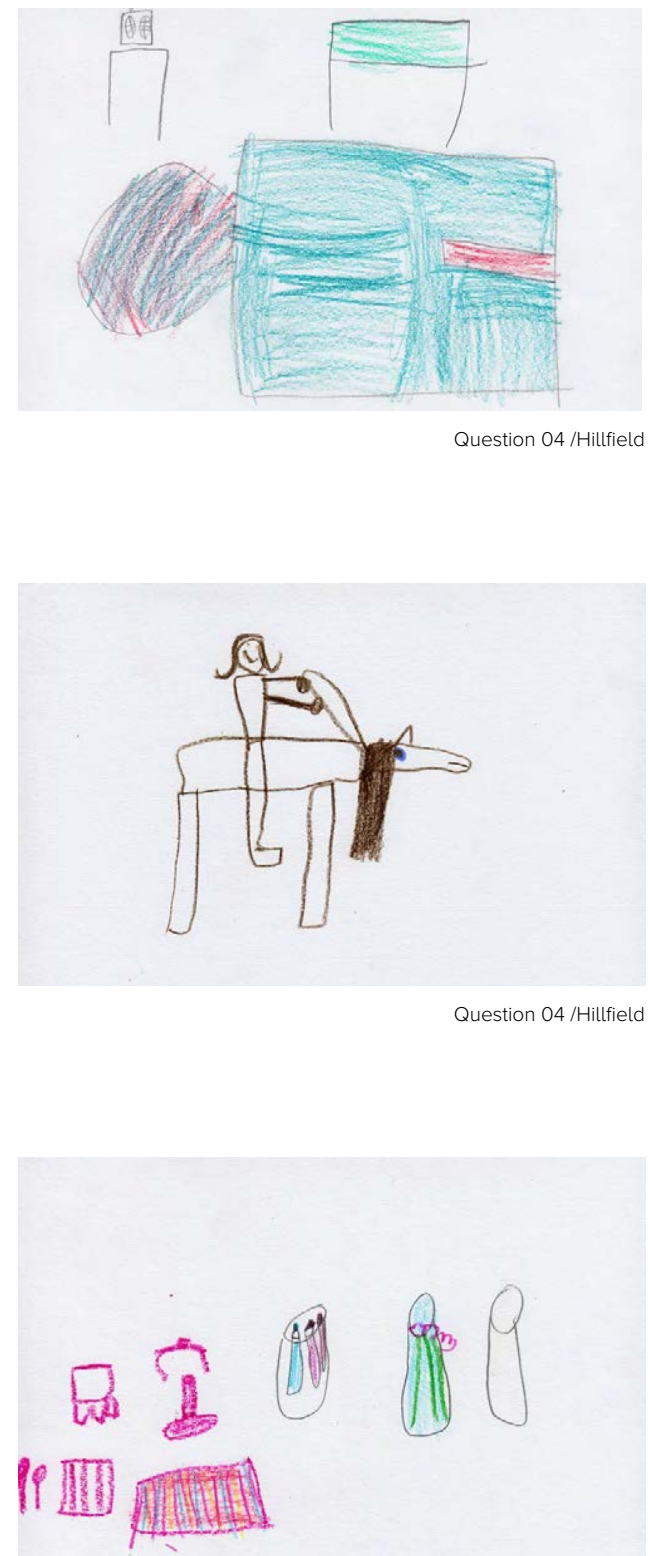

Question 04 /Kaban

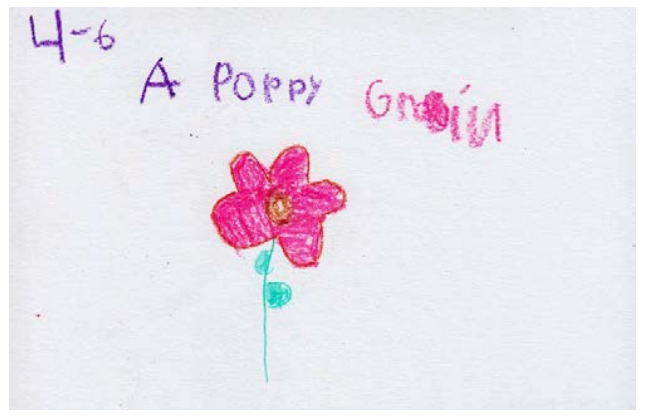

Question 04 /Hillfield
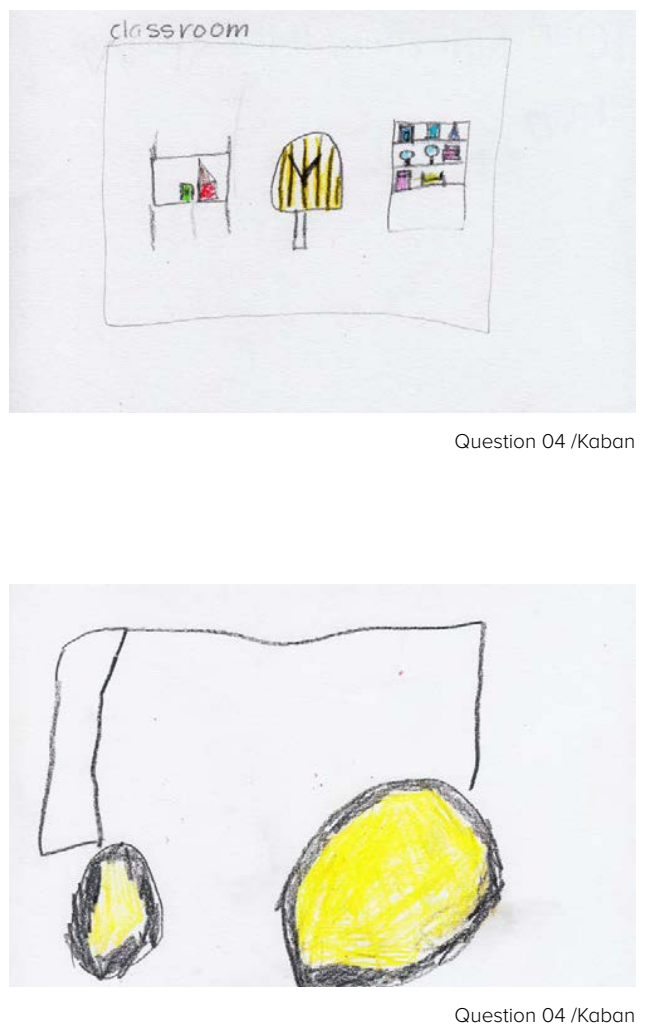

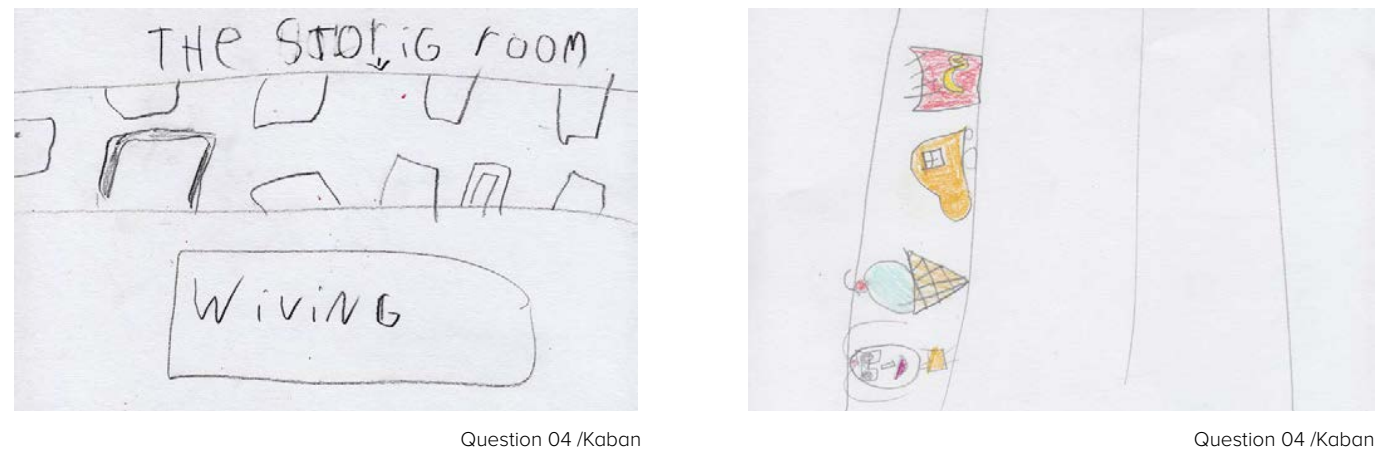

Question 04 /Kaban
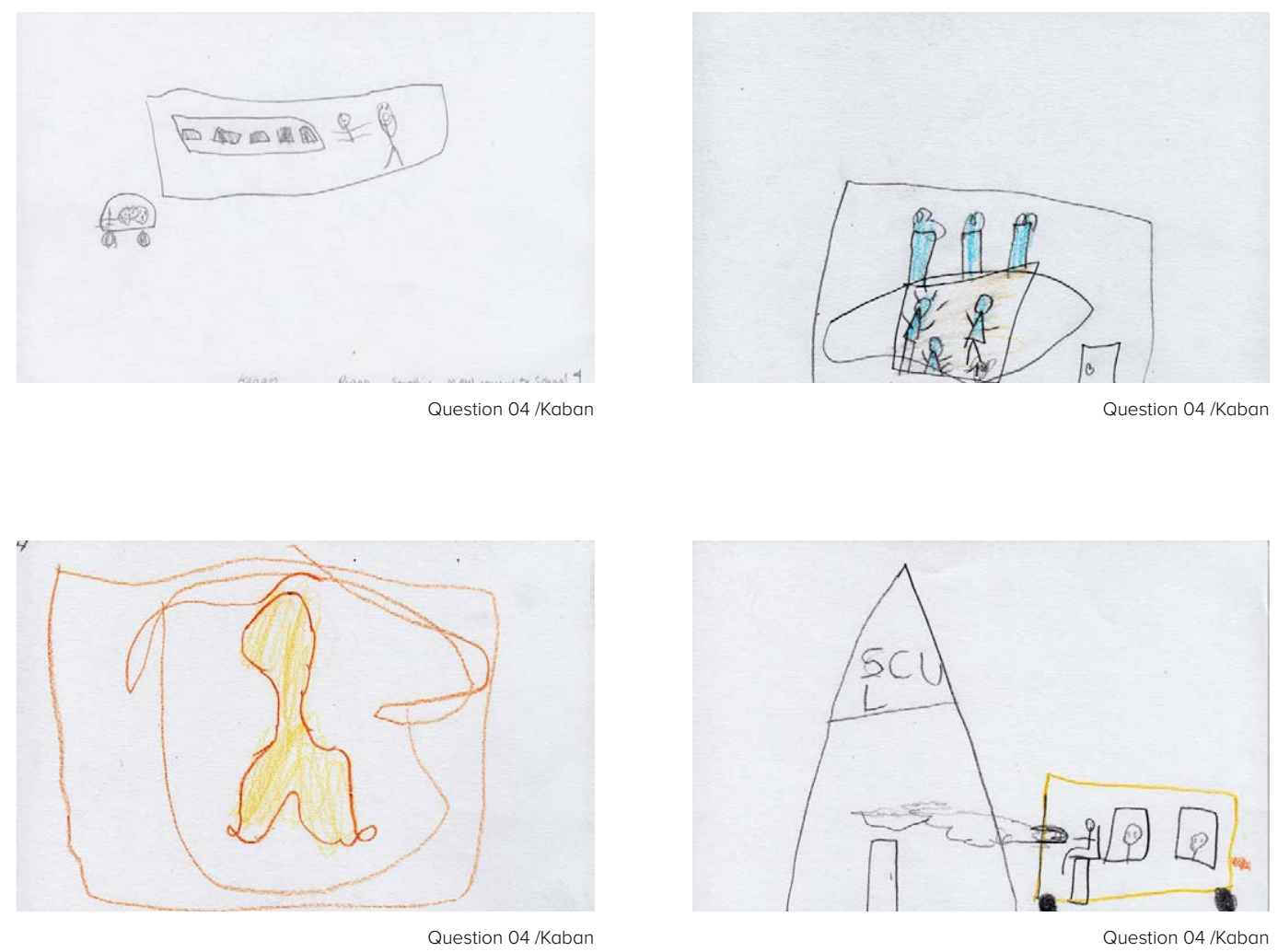

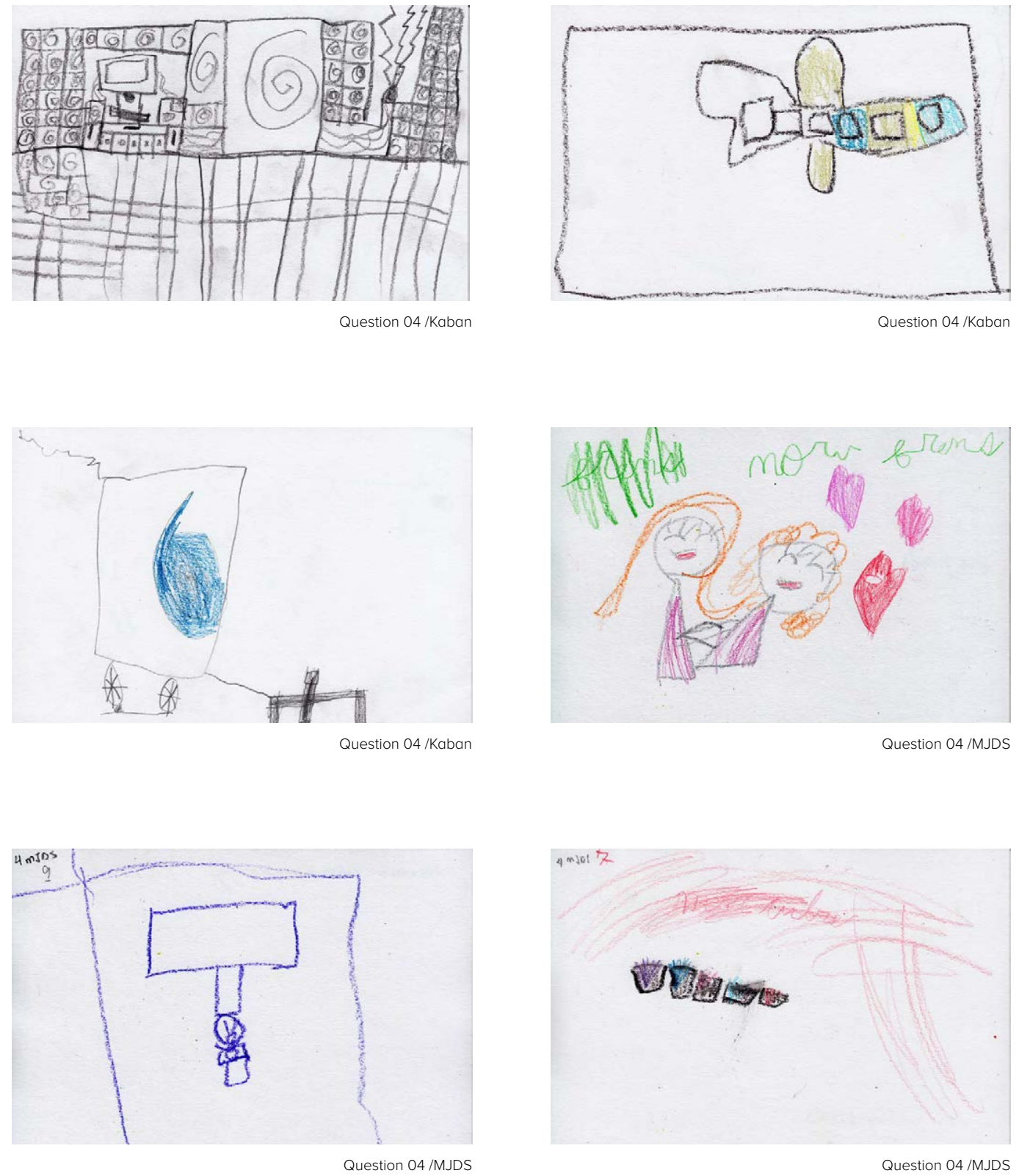


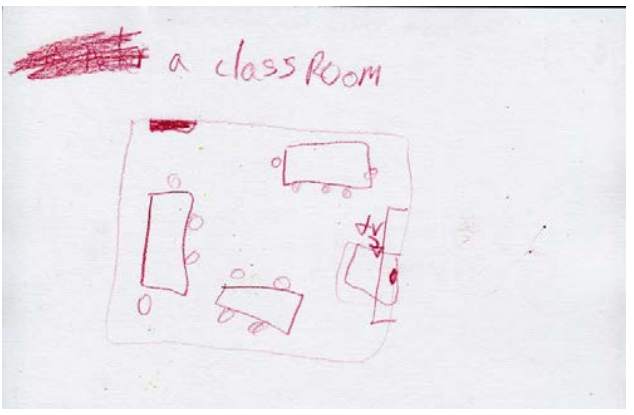

Question 04/MJDS
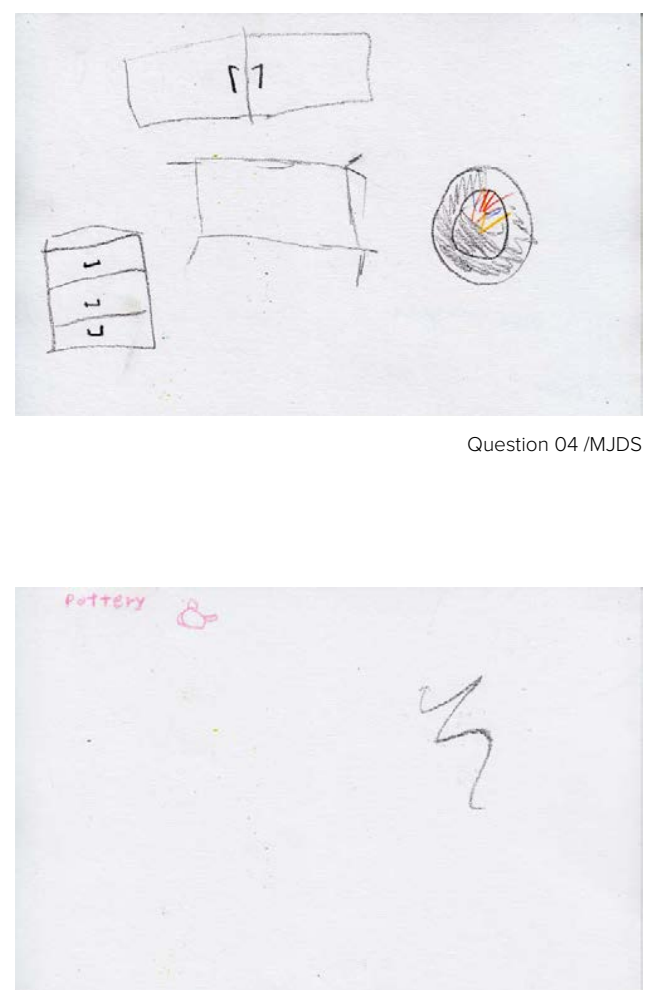

Question 04/MJDS

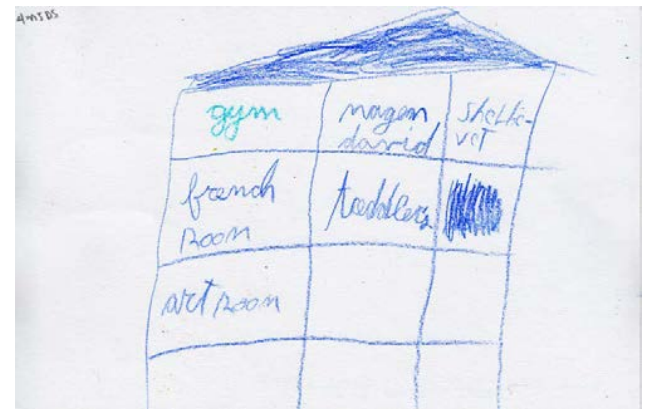

Question 04 /MJDS
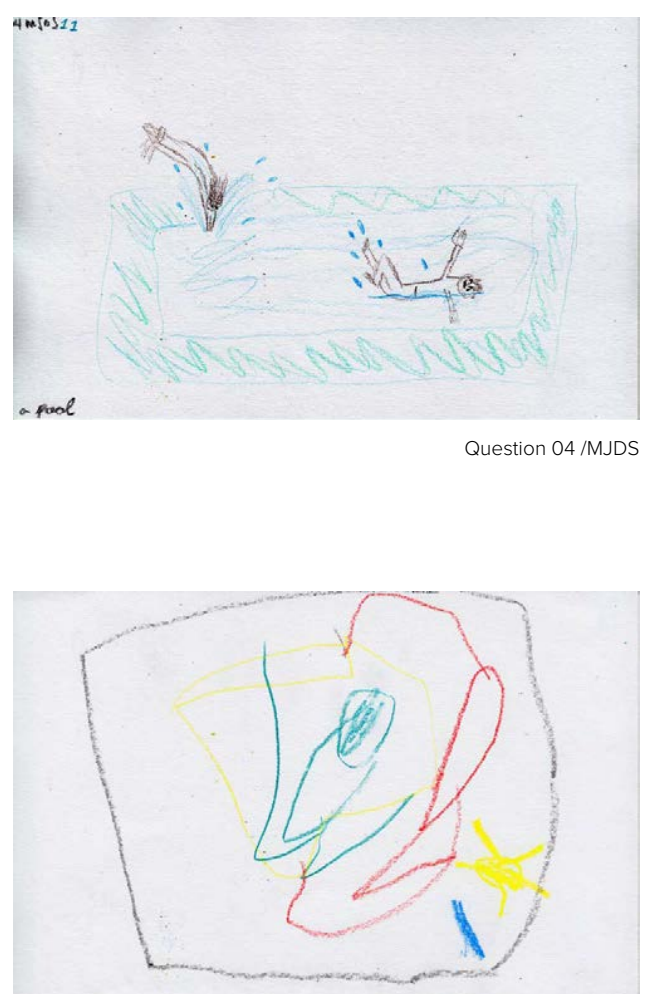

Question 04 /MJDS 

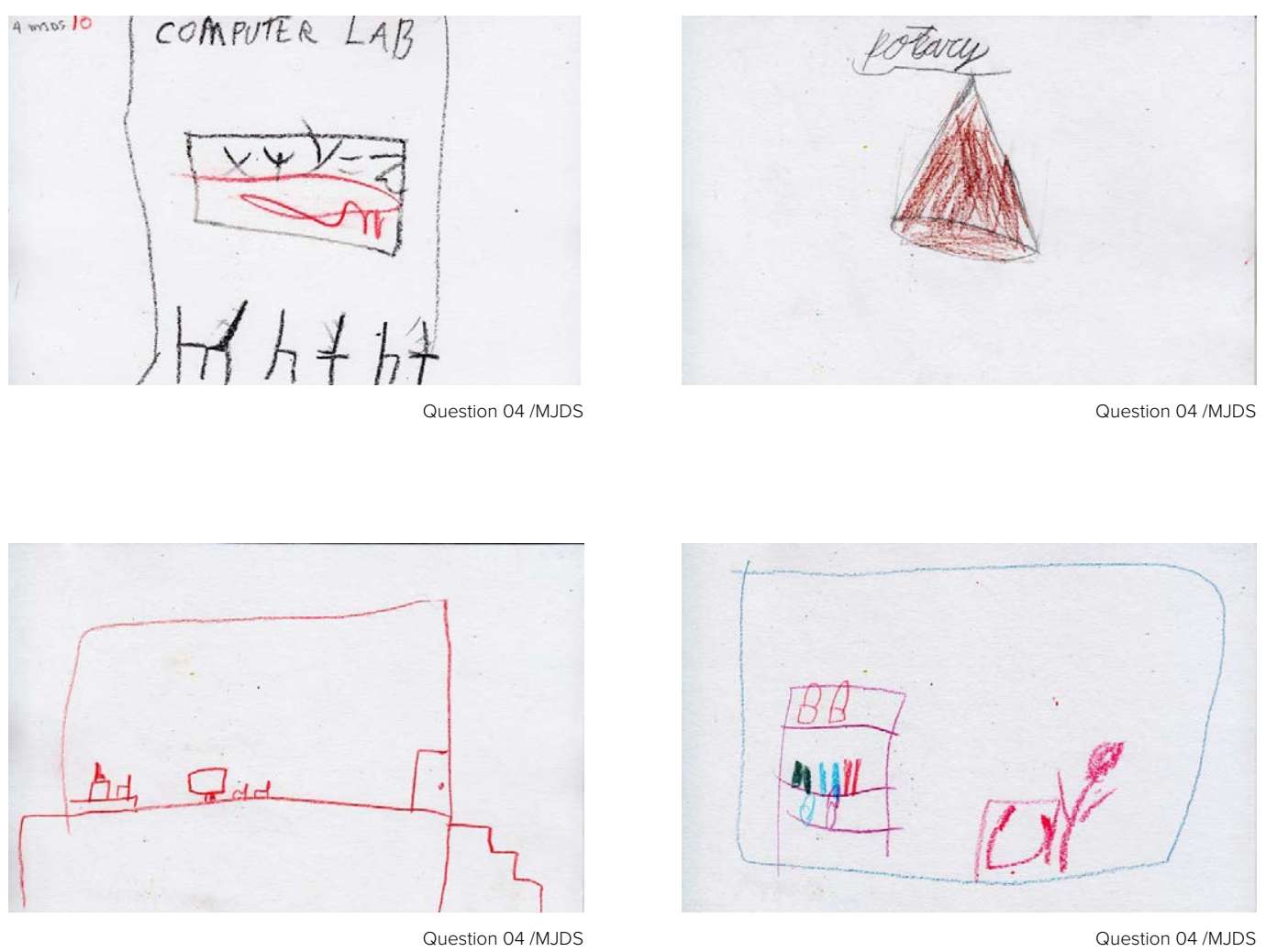

Appendix C - Workshop/ Children's Drawings

217 


\section{Appendix_D}

\section{Workshop/ Teacher Interview Notes}

Kaban Montessori School - Teacher question

- Wants to do the Black line Montessori material (which needs a lot of space $(30 \mathrm{~m})$

- There is not enough space for this activity and outside it would get dirty

- No space for specialized activities/ over flow activities that require more space

- They use gym for now, but when children nap there, they cannot use it, or leave material there

- Specialized activities include computers, projections, different languages

- Want a bigger gym

- Currently the gym has bad acoustics

- Bigger elementary classroom

Montessori Jewish Day School - Teacher question

- Would like a courtyard, for independent use.

- A space where children can go independently to learn / lessons on their own

- Would like larger spaces in classrooms, specifically for a nook where more bodily movement can occur (for children 3-6) 


\section{Appendix _ E}

Process Drawings

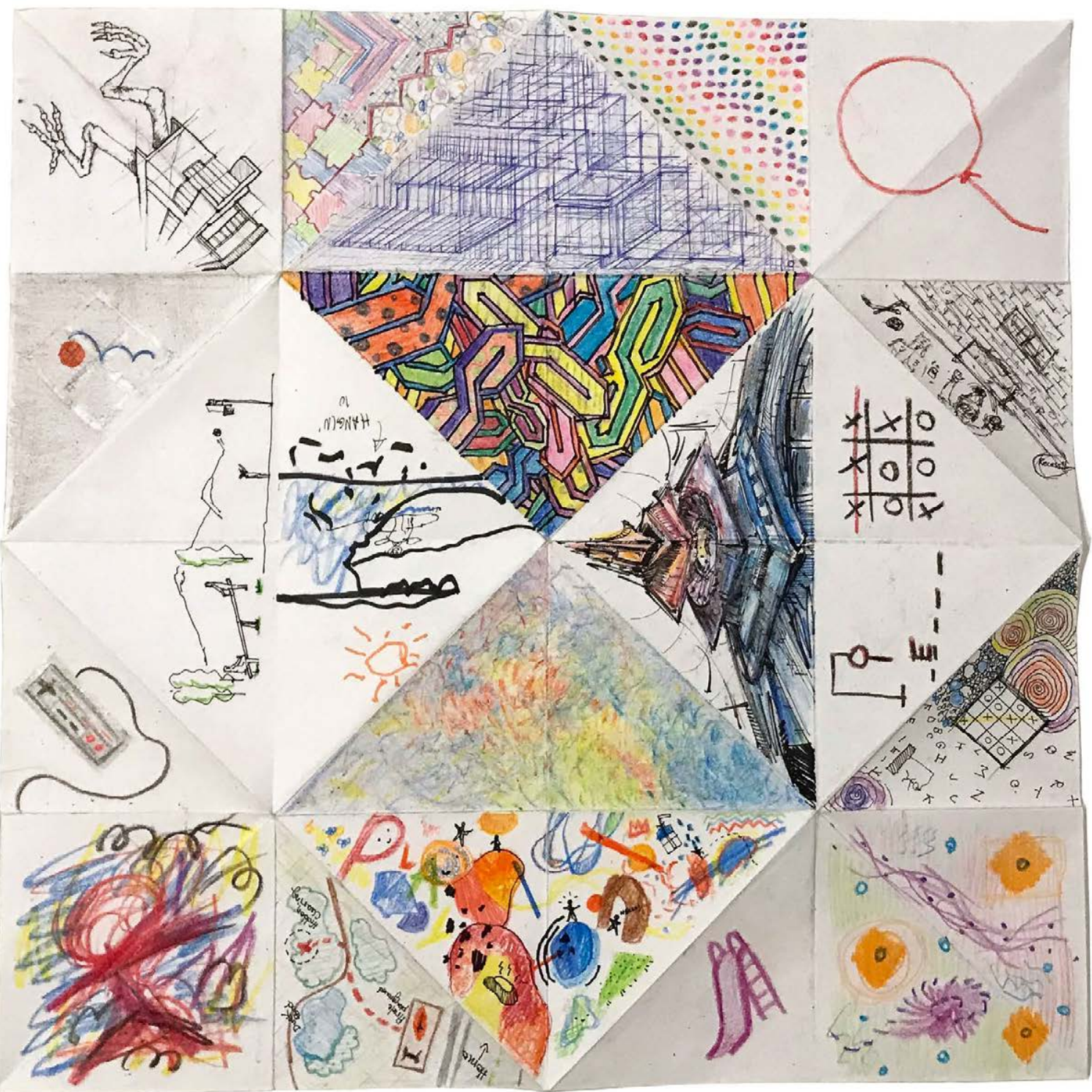




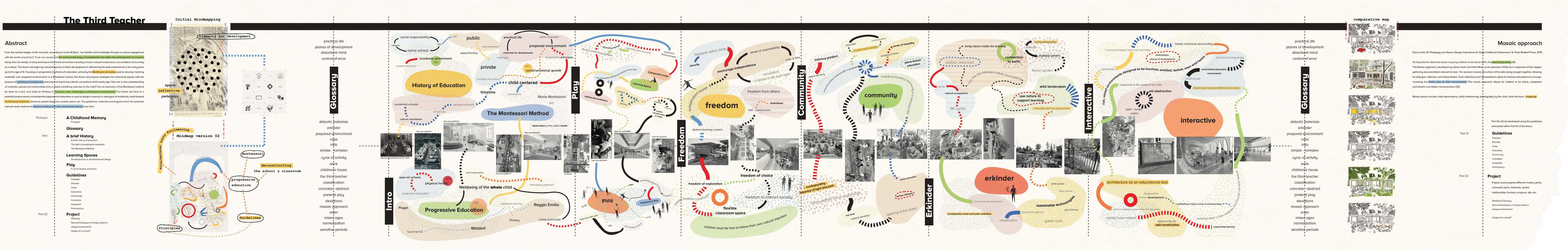

